This report was prepared as an account of work sponsored by an agency of the United States Government. Neither the United States Government nor any agency thereof, nor any of their employees, makes any warranty, express or implied, or assumes any legal liability or responsibility for the accuracy, completeness, or usefulness of any information, apparatus, product, or process disclosed, or represents that its use would not infringe privately owned rights. Reference herein to any specific commercial product, process, or service by trade name, trademark, manufacturer, or otherwise does not necessarily constitute or imply its endorsement, recommendation, or favoring by the United States Government or any agency thereof. The views and opinions of authors expressed herein do not necessarily state or reflect those of the United States Government or any agency thereof.

\title{
Characterization of Greater-Than-Class C Sealed Sources Volume 1: Sealed Sources Held by Specific Licensees
}

\author{
Gerald Harris
}

September 1994

\section{Idaho National Engineering Laboratory Idaho Falls, Idaho 83415}

Prepared for the

U.S. Department of Energy

Assistant Secretary for Environmental Management

Under DOE Idaho Operations Office

Contract DE-AC07-76ID01570 



\section{DISCLAIMER}

Portions of this document may be illegible in electronic image products. Images are produced from the best available original document. 


\begin{abstract}
Sealed sources are small, relatively high-activity radioactive sources typically encapsulated in a metallic container. The activities can range from less than $1 \mathrm{mCi}$ to over $1,000 \mathrm{Ci}$. They are used in a variety of industries and are commonly available. Many of the sources will be classified as Greater-Than-Class C low-level radioactive waste (GTCC LLW) for the purpose of waste disposal. The U.S. Department of Energy is responsible for disposing of this class of low-level radioactive waste.

To better understand the scope of the GTCC LLW situation regarding sealed sources and to provide data to a model that projects future quantities of GTCC material, data from a comprehensive 1991 U.S. Nuclear Regulatory Commission (NRC) survey and a related 1992 survey of Agreement States were analyzed to estimate the number, volume, and activity of Potential GTCC sealed sources currently available from specific licensees. Potential GTCC sealed sources are sources that exceed the limits stated in 10 CFR 61 when isotope concentrations are averaged over the volume of the capsule. Based on the surveys, the estimated number of existing Potential GTCC sealed sources held by specific licensees is 89,000 , with an unpackaged volume of $0.93 \mathrm{~m}^{3}$ and an activity of $2,300,000 \mathrm{Ci}$. However, current disposal practices allow concentration averaging over the disposal container, substantially reducing the number of sealed sources which will actually be classified as GTCC LLW.
\end{abstract}




\section{SUMMARY}

This report, the first of three volumes investigating sealed sources that are or may be Greater-Than-Class C (GTCC) low-level radioactive waste (LLW), presents the results of two surveys that estimate the number, volume, and activity of sealed sources held by specific licensees, and for which the U.S. Department of Energy (DOE) may have responsibility.

By enacting the Low-Level Radioactive Waste Policy Amendments Act of 1985, the U.S. congress made DOE responsible for ensuring the safe disposal of GTCC LLW. To help identify the amount of GTCC LLW that may require disposal, DOE desires refined estimates of how much GTCC material is in sealed source form. In 1991 and 1992, government agencies conducted two surveys of organizations holding specific licenses for radioactive materials to better quantify the number of sealed sources currently in existence that are potential GTCC LLW. One of the surveys was conducted by the U.S. Nuclear Regulatory Commission (NRC) in 1991. This survey was administered to NRC specific licensees possessing by-product material. In 1992, DOE conducted the second survey, which was administered to a random sample of Agreement State specific licensees. This report presents the results of the two surveys to better estimate the number of Potential GTCC sealed sources.

Two types of radioactive materials licenses exist: general licenses and specific licenses, as discussed in 10 CFR 30. General licenses are "in effect" upon purchase of a device containing a sealed source. Typically, no physical license is exchanged-rather, these licenses are for devices (described in $10 \mathrm{CFR}$ 31) that are essentially exempted from the more strict regulatory control that governs devices covered by specific licenses. Each source or device is registered through a regulatory agency; as part of the registration process, it is determined whether the source or device requires a general or specific license. A specific licensee may possess devices containing sealed sources that are covered under a general license. This report deals with both general-and specific-licensed sealed sources handled by specific licensees.

A potential GTCC (PGTCC) source is a sealed source that exceeds the Class $\mathrm{C}$ concentration limit when the activity of the source is concentration averaged over the source's capsule volume or weight. Current LLW disposal practices typically allow concentration averaging over the disposal container volume for non-transuranics (TRUs), and over the mass for TRUs. As such, the assumption from LLW disposal practices without concentration averaging results in a conservative number of GTCC sources. Most of the PGTCC sources will not become GTCC LLW.

For the most likely (base case) scenario, results show that, in 1992, there were 89,000 PGTCC sealed sources having a total unpackaged volume of $0.92 \mathrm{~m}^{3}$ and a total undecayed activity of $2,300,000 \mathrm{Ci}$. These values include both general and specific licensed sources, but only those held by specific licensees. The PGTCC values represent the most basic estimates, and can be used as a foundation on which to apply any assumptions regarding packaging or concentration averaging. The impacts of packaging volumes and concentration averaging practices on these estimates are explored in other studies.

Section 1, Introduction, presents historical background information relating to regulatory control of GTCC sealed sources, describes past estimates of numbers of GTCC sealed sources, and presents the purpose of this report.

Sealed sources are typically small, relatively high-activity radioactive sources encapsulated in a closed metallic container. Source activities can range from less than $1 \mathrm{mCi}$ to over $1,000 \mathrm{Ci}$. However, most sources have activities less than $100 \mathrm{mCi}$. The source is often placed in a device intended for a specific purpose, typically for performing some type of measurement. Sealed sources have a wide variety of uses in medicine, construction, manufacturing, research, and other fields. Examples of sealed sources include moisture/density gauges, level gauges, and well logging devices. In most cases, an organization must be licensed by a regulatory agency to own or operate a device containing a sealed source. 
DOE desires estimates of the volume and activities of GTCC material to determine options for disposing of the materials. A computer model has been generated to project the amount of GTCC material that will require disposal in the future. The information contained in this report will be input to that projection model to better estimate the amount of sealed source material requiring disposal.

Section 2, Survey Methodology and Databases, discusses how the two surveys (the NRC survey and the DOE Agreement States survey) were conducted. The two agencies had different strategies and different purposes for conducting the surveys.

The NRC was interested in determining the number, use, condition, and disposition of sealed sources to evaluate the effectiveness of NRC regulations. DOE was interested in determining the number and types of sealed sources that could become GTCC LLW to plan for their disposal. include:

A number of problems occurred in conducting the surveys. Two that warranted consideration

- The response rate was less than expected, particularly in the Agreement States survey

- The quality of the responses varied greatly between licensees.

The possible uncertainties in the results that are introduced by these problems are discussed in Appendix B.

There were 645 responses from the 1,125 surveys sent in the Agreement States survey, or $57 \%$. The NRC received 5,672 responses out of 7,373 forms mailed, or $77 \%$. It can be surmised that at least part (if not most) of the differences in response rates was because the Agreement States survey was sent through third-class mail.

Section 3, Analysis Methodology, reports on two stages of the analysis:

- Data summary

- GTCC determination.

The first stage, data summary, compiled the results of the two surveys without regard to the potential GTCC status of the source. The primary goal for this step was to determine the comparability of the two surveys and to get a general description of the sampled licensees.

The second stage determined which sealed sources were PGTCC by comparing the 10 CFR 61.55 Class $\mathrm{C}$ concentration limits to the sealed source activities reported in the combined NRC and Agreement States surveys. To allow comparison with the reported activities, the Class $\mathbf{C}$ concentration limits were multiplied by assumed volumes for the sources. The volume used was the capsule volume and no other packaging was considered.

Section 4, Results, reports on the third stage of the analysis, which took the results of the first two stages to extrapolate the results to the population of all specific licensees. The total number and activity of PGTCC sealed sources was deduced for three cases: low, base, and high.

Section 5, Discussion, provides a brief assessment of the affect of concentration averaging on the results.

Section 6, Conclusions, presents the results of this comprehensive survey and analysis of PGTCC sealed sources handled by specific licensees. 
The majority of these sources are in fixed and portable gauges, with well logging devices also accounting for a significant portion of the total volume. Cs-137 is the most frequently encountered isotope, found in over half of the total number of PGTCC sealed sources and accounting for most of the activity.

This report represents what the sealed source situation was in 1992. In this report, all sources were considered waste; in fact, only a portion of the sources may become waste during a given year.

\section{Extrapolations to All Licensees}

This report is the first of three volumes. This report and Volume 2 discuss sealed sources held by specific licensees, while Volume 3 concerns sealed sources held by general licensees. These reports give estimates of the total number of PGTCC sources (those whose activity is averaged over the source capsule) and the number of GTCC sources (assumed here to be those remaining after concentration averaging has been performed over the disposal container, as explained in Appendix D of Volume 1).

As mentioned earlier, this report estimates that, in 1992, the number of PGTCC sources held by specific licensees was 89,000 . The estimated 1992 number of GTCC sources is 28,400 (Appendix D). In Volume 2, it is estimated that 8,000 PGTCC sources are sold per year to specific licensees.

Volume 3 estimates that the general licensee population possesses roughly $36 \%$ of the total 1992 number of GTCC sealed sources. Together with the GTCC sources held by specific licensees, this yields about 44,000 total GTCC sources held by all licensees. The results presented in this report and in Volume 3 for GTCC sealed sources are summarized in Table ES-1.

Volume 3 estimates that the general licensee population possesses roughly $63 \%$ of the total 1992 number of PGTCC sealed sources. Together with the PGTCC sources held by specific licensees, this yields about 250,000 total PGTCC sources held by all licensees. The results presented in this report and in Volume 3 for PGTCC sealed sources are summarized in Table ES-2.

For general licensees, Volume 3 extrapolates the estimated annual number of GTCC sources sold to the number of PGTCC sources sold. When those results are added to the number of PGTCC sources sold to specific licensees (from Volume 2), the resulting estimate is 24,000 PGTCC sources sold to all licensees per year. This is shown in Table ES-3. 
Table ES-1. Base case estimates of the number of GTCC sources held by specific and general licensees. Numbers rounded to two significant digits.

\begin{tabular}{|c|c|c|c|c|c|c|c|c|}
\hline Device type & Am-241 & $\mathrm{Cm}-244$ & Cs-137 & $\mathrm{Pu}-238$ & $\mathrm{Pu}-239$ & $\mathrm{Pu}-241$ & $\mathrm{U}-238$ & Subtotal \\
\hline Calibration & 1,900 & 14 & 10 & 45 & 250 & 14 & - & 2,300 \\
\hline Medical & 93 & - & 10 & - & - & - & 24 & 130 \\
\hline Well logging & 3,700 & - & 一 & - & - & - & 一 & 3,700 \\
\hline Portable gauge & 14,000 & - & - & - & - & - & - & 14,000 \\
\hline Irradiation & 110 & - & 590 & - & - & - & - & 700 \\
\hline Fixed gauge & 16,000 & 3 & - & 45 & - & - & - & 16,000 \\
\hline General neutron applications & 1,300 & - & - & 110 & 460 & - & - & 1,900 \\
\hline$X R F$ & 1,300 & 1,300 & - & 180 & - & - & - & 2,800 \\
\hline Other & 550 & 21 & 10 & 1,500 & 480 & 21 & 28 & 2,600 \\
\hline Subtotal & 39,000 & 1,300 & 620 & 1,900 & 1,200 & 35 & 52 & 44,000 \\
\hline
\end{tabular}


Table ES-2. Base case estimates of the number of PGTCC sources held by specific and general licensees. Numbers rounded to two significant digits.

\begin{tabular}{|c|c|c|c|c|c|c|c|c|c|c|c|c|c|}
\hline Device type & $\mathrm{Am}-241$ & C-14 & $\mathrm{Cm}-244$ & Cs-137 & $\mathrm{Ni}-63$ & Np-237 & $\mathrm{Pu}-238$ & Pu-239 & $\mathrm{Pu}-241$ & Sr-90 & Tc-99 & $\mathrm{U}-238$ & Subtotal \\
\hline Calibration & 3,000 & 24 & 34 & 3,400 & 110 & 10 & 41 & 280 & 17 & 1,900 & 17 & 34 & 8,900 \\
\hline Medical & 340 & - & - & 1,200 & - & - & - & - & - & 24 & 3 & 28 & 1,600 \\
\hline Well logging & 4,300 & - & - & 2,200 & - & - & 170 & - & 3 & - & - & - & 6,700 \\
\hline Portable gauge & 15,000 & - & - & 110 & - & - & - & - & - & - & - & - & 15,000 \\
\hline Irradiation & 160 & - & - & 1,700 & - & - & - & - & - & 10 & - & - & 1,800 \\
\hline Fixed gauge & 17,000 & 30 & 17 & 170,000 & - & - & 3 & - & - & 270 & - & - & 190,000 \\
\hline $\begin{array}{l}\text { General neutron } \\
\text { applications }\end{array}$ & 1,500 & - & - & - & - & - & 110 & 530 & - & 一 & - & - & 2,100 \\
\hline XRF & 3,300 & - & 1,400 & 3 & - & - & 180 & - & - & - & - & - & 4,900 \\
\hline Other & 1,100 & 62 & 34 & 11,000 & 3,900 & 3 & 1,600 & 650 & 21 & 300 & 500 & 80 & 19,000 \\
\hline Subtotal & 46,000 & 120 & 1,500 & 190,000 & 4,000 & 13 & 2,100 & 1,500 & 41 & 2,500 & 520 & 140 & 250,000 \\
\hline
\end{tabular}


Table ES-3. Base case estimates of the number of PGTCC sealed sources sold annually to both specific and general licensees. The numbers are rounded to at most two significant digits.

\begin{tabular}{|c|c|c|c|c|c|c|c|c|c|c|c|c|c|}
\hline Device type & Am-241 & $C-14$ & $\mathrm{Cm}-244$ & Cs-137 & $\mathrm{Ni}-63$ & Np-237 & $\mathrm{Pu}-238$ & $\mathrm{Pu}-239$ & $\mathrm{Pu}-241$ & $\mathrm{Sr}-90$ & $\mathrm{Tc}-99$ & $\mathrm{U}-238$ & Total \\
\hline Calibration & 290 & 2 & 3 & 330 & 11 & 1 & 4 & 30 & 2 & 190 & 2 & 3 & 860 \\
\hline Medical & 30 & 0 & 0 & 110 & 0 & 0 & 0 & 0 & 0 & 2 & 0 & 3 & 150 \\
\hline Well logging & 130 & 0 & 0 & 60 & 0 & 0 & 5 & 0 & 0 & 0 & 0 & 0 & 190 \\
\hline Portable gauge & 1,500 & 0 & 0 & 11 & 0 & 0 & 0 & 0 & 0 & 0 & 0 & 0 & 1,500 \\
\hline Irradiation & 15 & 0 & 0 & 120 & 0 & 0 & 0 & 0 & 0 & 1 & 0 & 0 & 140 \\
\hline Fixed gauge & 1,700 & 3 & 2 & 17,000 & 0 & 0 & 0 & 0 & 0 & 27 & 0 & 0 & 19,000 \\
\hline $\begin{array}{l}\text { General neutron } \\
\text { applications }\end{array}$ & 140 & 0 & 0 & 0 & 0 & 0 & 11 & 50 & 0 & 0 & 0 & 0 & 210 \\
\hline $\mathrm{XRF}$ & 310 & 0 & 136 & 0 & 0 & 0 & 14 & 0 & 0 & 0 & 0 & 0 & 460 \\
\hline Other & 110 & 6 & 3 & 1,100 & 370 & 0 & 15 & 60 & 2 & 30 & 40 & 8 & 1,700 \\
\hline Total & 4,200 & 12 & 140 & 19,000 & 390 & 1 & 50 & 140 & 4 & 250 & 50 & 14 & 24,000 \\
\hline
\end{tabular}




\section{FOREWORD}

This report is the first of three volumes investigating sealed sources that are or may be Greater-Than-Class C (GTCC) low-level radioactive waste (LLW). It estimates the number, volume, and activity of such sealed sources held by specific licensees, and for which the U.S. Department of Energy may have responsibility. This report does not address sources that will be manufactured in the future. These data are currently being studied, and, along with a physical characterization of each type of sealed source, are documented in Volume 2. Volume 3 characterizes GTCC sealed sources held by general licensees. 


\section{ACKNOWLEDGEMENTS}

The author wishes to thank Karen Williams, Ed May, and Don Fischer for their help in making this report more readable and accurate. Chris Scott and Sonia Rogers were instrumental in taming the large databases generated by the surveys. In addition, Steven Baggett of the U.S. NRC provided much help and advice. Above all, the author thanks the many licensees who took part in the survey, making this report possible. 


\section{CONTENTS}

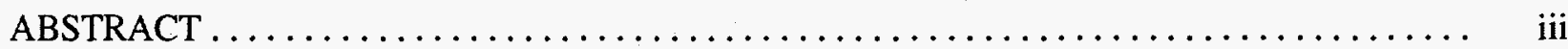

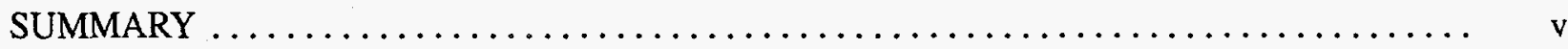

FOREWORD $\ldots \ldots \ldots \ldots \ldots \ldots \ldots \ldots \ldots \ldots \ldots \ldots \ldots \ldots \ldots \ldots \ldots \ldots \ldots \ldots \ldots \ldots \ldots \ldots$

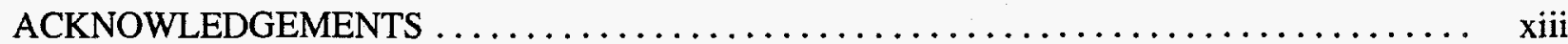

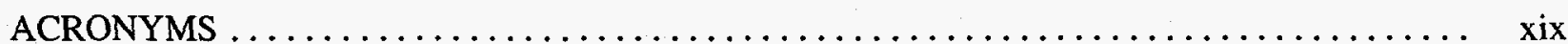

1. INTRODUCTION $\ldots \ldots \ldots \ldots \ldots \ldots \ldots \ldots \ldots \ldots \ldots \ldots \ldots \ldots \ldots \ldots \ldots \ldots \ldots \ldots \ldots \ldots \ldots$

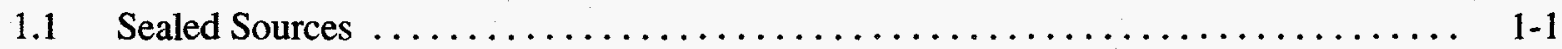

1.2 Estimates of GTCC Sealed Sources $\ldots \ldots \ldots \ldots \ldots \ldots \ldots \ldots \ldots \ldots \ldots \ldots \ldots \ldots$

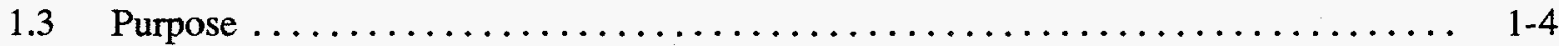

2. SURVEY METHODOLOGY AND DATABASES $\ldots \ldots \ldots \ldots \ldots \ldots \ldots \ldots \ldots \ldots \ldots \ldots \ldots$

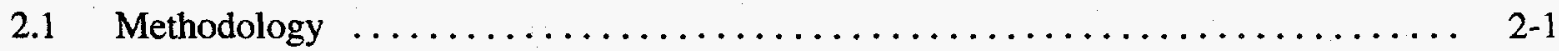

2.1.1 Nuclear Regulatory Commission Census $\ldots \ldots \ldots \ldots \ldots \ldots \ldots \ldots \ldots . \ldots \ldots$

2.1.2 Agreement State Sample ........................ 2-2

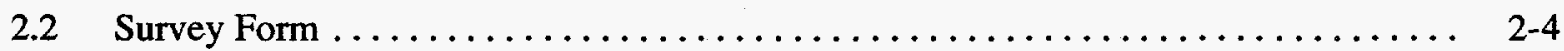

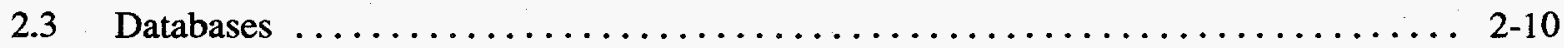

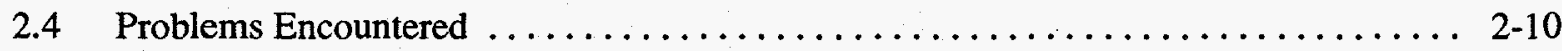

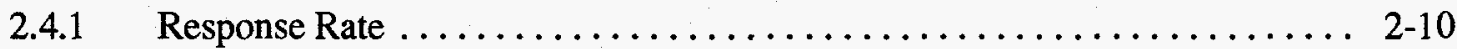

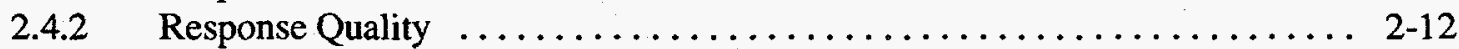

3. ANALYSIS METHODOLOGY $\ldots \ldots \ldots \ldots \ldots \ldots \ldots \ldots \ldots \ldots \ldots \ldots \ldots \ldots \ldots \ldots \ldots \ldots \ldots$

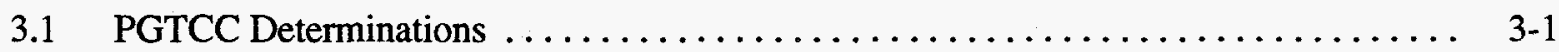

3.1.1 PGTCC Activity Limits for Calibration Sources $\ldots \ldots \ldots \ldots \ldots \ldots \ldots . \quad 3-4$

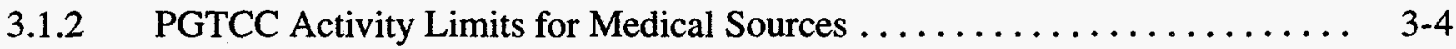

3.1.3 PGTCC Activity Limits for Well Logging Sources $\ldots \ldots \ldots \ldots \ldots \ldots \ldots$. $3-4$

3.1.4 PGTCC Activity Limits for Gas Chromatography Sources ........... 3-4

3.1.5 PGTCC Activity Limits for Portable Gauging Sources ............. 3-4

3.1.6 PGTCC Activity Limits for Irradiation Sources ................ 3-5

3.1.7 PGTCC Activity Limits for Fixed Gauging Sources $\ldots \ldots \ldots \ldots \ldots \ldots \ldots$. $\ldots \ldots$

3.1.8 PGTCC Activity Limits for General Neutron Applications Sources ....... 3-5

3.1.9 PGTCC Activity Limits for X-Ray Fluorescence Sources ........... 3-5

3.1.10 PGTCC Activity Limits for Other Sources ................ 3-6 


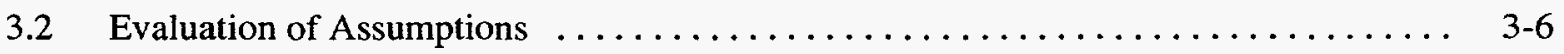

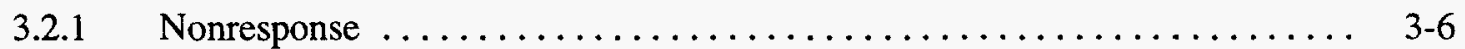

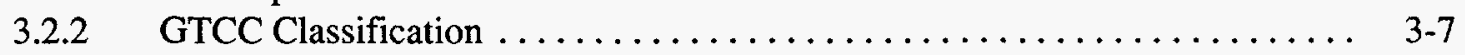

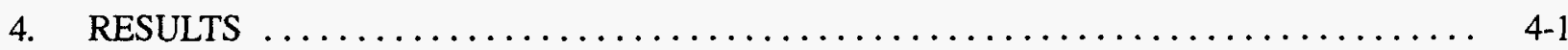

4.1 Survey Results Compilation $\ldots \ldots \ldots \ldots \ldots \ldots \ldots \ldots \ldots \ldots \ldots \ldots \ldots \ldots \ldots \ldots \ldots \ldots \ldots \ldots$

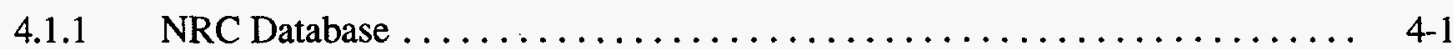

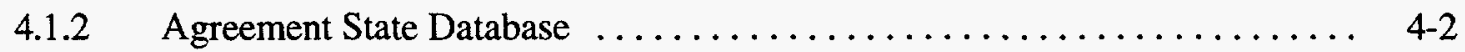

4.1.3 NRC Sealed Source and Device Registry ................... 4 .2

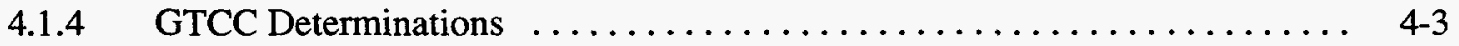

4.1.5 Results ................................ $4-3$

4.2 Extrapolations to Total Population $\ldots \ldots \ldots \ldots \ldots \ldots \ldots \ldots \ldots \ldots \ldots \ldots \ldots \ldots$

4.2.1 Extrapolated Number of PGTCC Sealed Sources Currently Available . . . . . 4-9

4.2.2 Extrapolated Unpackaged Volume of PGTCC Sealed Sources

Currently Available ........................... 4-9

4.2.3 Extrapolated Activity of PGTCC Sealed Sources Currently Available .... . 4-10

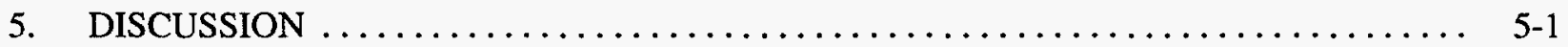

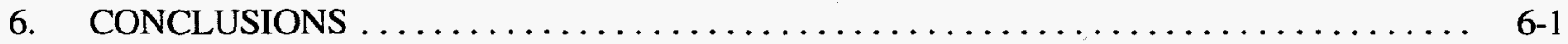

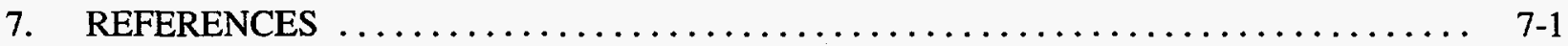

Appendix A-Agreement State Sampling Design $\ldots \ldots \ldots \ldots \ldots \ldots \ldots \ldots \ldots \ldots \ldots \ldots \ldots \ldots \ldots \ldots$

Appendix B-Uncertainty Analysis $\ldots \ldots \ldots \ldots \ldots \ldots \ldots \ldots \ldots \ldots \ldots \ldots \ldots \ldots \ldots \ldots \ldots \ldots \ldots$

Appendix C-Sealed Source Activity Distributions $\ldots \ldots \ldots \ldots \ldots \ldots \ldots \ldots \ldots \ldots \ldots \ldots \ldots \ldots \ldots$

Appendix D-Comparison to 1989 NRC Report Results $\ldots \ldots \ldots \ldots \ldots \ldots \ldots \ldots \ldots \ldots \ldots$ D-1

FIGURE

2-1. Survey form sent to Agreement State licensees $\ldots \ldots \ldots \ldots \ldots \ldots \ldots \ldots \ldots \ldots \ldots$

\section{TABLES}

ES-1. Base case estimates of the number of ACA GTCC sources held by specific and general licensees. Numbers rounded to two significant digits $\ldots \ldots \ldots \ldots \ldots \ldots \ldots$ viii

ES-2. Base case estimates of the number of PGTCC sources held by specific and general licensees. Numbers rounded to two significant digits

ES-3. Base case estimates of the number of PGTCC sealed sources sold annually to both specific and general licensees. The numbers are rounded to at most two significant digits 
1-1. Class $\mathrm{C}$ limits for low-level radioactive waste from $10 \mathrm{CFR} 61 \ldots \ldots \ldots \ldots \ldots \ldots$

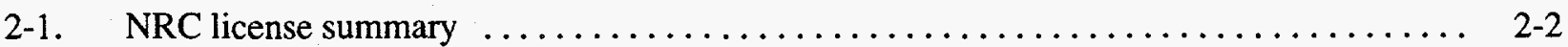

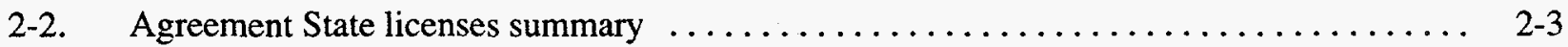

2-3. Description of fields in the source database $\ldots \ldots \ldots \ldots \ldots \ldots \ldots \ldots \ldots \ldots \ldots \ldots \ldots \ldots$

3-1. Source capsule volumes ( $\mathrm{cm} 3)$ and activity limits $(\mathrm{mCi})$ for sources classified

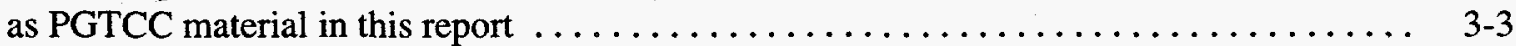

4-1. Summary of the number of responses $\ldots \ldots \ldots \ldots \ldots \ldots \ldots \ldots \ldots \ldots \ldots \ldots \ldots \ldots$

4-2. Number of active and inactive PGTCC sources $\ldots \ldots \ldots \ldots \ldots \ldots \ldots \ldots \ldots \ldots \ldots$

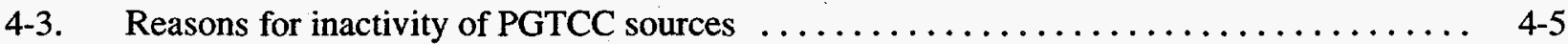

4-4. Plans for disposal of inactive PGTCC sources $\ldots \ldots \ldots \ldots \ldots \ldots \ldots \ldots \ldots \ldots$

4-5. Breakdown of the number of active and inactive sources by device type

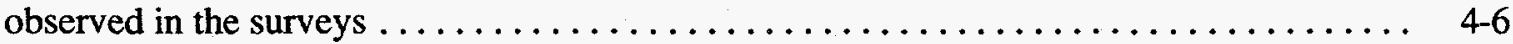

4-6. Breakdown of the number of active and inactive sources by isotope

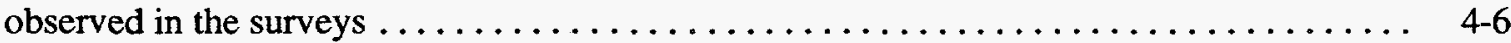

4-7. Number of PGTCC sources observed in the surveys $\ldots \ldots \ldots \ldots \ldots \ldots \ldots \ldots \ldots \ldots$

4-8. Extrapolated number of current PGTCC sources for the low case scenario $\ldots \ldots \ldots \ldots$ 4-11

4-9. Extrapolated number of current PGTCC sources for the base case scenario ......... 4-12

4-10. Extrapolated number of current PGTCC sources for the high case scenario ......... 4-13

4-11. Extrapolated unpackaged volume $(\mathrm{cm} 3)$ of current PGTCC sources for the

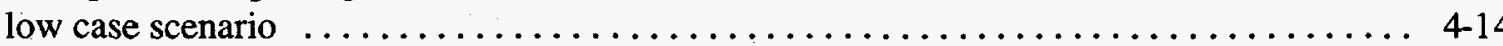

4-12. Extrapolated unpackaged volume $(\mathrm{cm} 3)$ of current PGTCC sources for the base case scenario ................................... 4-15

4-13. Extrapolated unpackaged volume $(\mathrm{cm} 3)$ of current PGTCC sources for the high case scenario

4-14. Extrapolated activity (Ci) of current PGTCC sources for the low case scenario

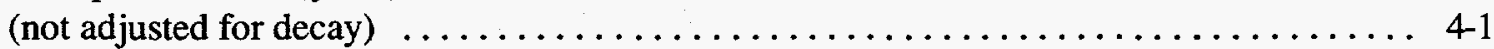

4-15. Extrapolated activity (Ci) of current PGTCC sources for the base case scenario (not adjusted for decay)

4-16. Extrapolated activity (Ci) of current PGTCC sources for the high case scenario (not adjusted for decay)

6-1. Estimated number, volume, and activity of current PGTCC sealed sources

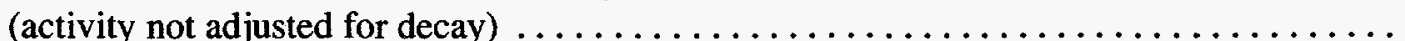




\section{ACRONYMS}

$\begin{array}{ll}\text { AS } & \text { Agreement State } \\ \text { CFR } & \text { Code of Federal Regulations } \\ \text { DOE } & \text { U.S. Department of Energy } \\ \text { GTCC } & \text { Greater-Than-Class C } \\ \text { LLW } & \text { low-level radioactive waste } \\ \text { NRC } & \text { U.S. Nuclear Regulatory Commission } \\ \text { PGTCC } & \text { Potential Greater-Than-Class-C } \\ \text { TRU } & \text { transuranic }\end{array}$

xix 


\section{Characterization of Greater-Than-Class C Sealed Sources Volume 1: Sealed Sources Held by Specific Licensees}

\section{INTRODUCTION}

By enacting the Low-Level Radioactive Waste Policy Amendments Act of 1985, the U.S. Congress made the U.S. Department of Energy (DOE) responsible for ensuring the safe disposal of Greater-ThanClass C (GTCC) low-level radioactive waste (LLW). To help identify the amount of GTCC LLW that may require disposal, DOE must refine the estimates of how much GTCC material is in sealed source form. In 1991 and 1992, government agencies conducted two surveys of organizations holding specific licenses for radioactive materials to better quantify the number of sealed sources currently in existence that are potential GTCC LLW. One of the surveys was conducted by the U.S. Nuclear Regulatory Commission (NRC) in 1991. This survey was administered to NRC specific licensees possessing by-product material. In 1992, DOE conducted the second survey, which was administered to a random sample of Agreement State specific licensees. This report presents the results of the two surveys.

The sealed sources considered in this report are Potential GTCC (PGTCC) sources, as opposed to after concentration averaged (ACA) GTCC sources.

- $\quad$ PGTCC sources exceed the Class C concentration limits when the concentration of radioactive isotopes is calculated over the source capsule volume.

- $\quad$ GTCC sources exceed the Class $\mathrm{C}$ concentration limits when current disposal practices are used. Current disposal practices allow concentration averaging to occur over the disposal container, with some restrictions. That is, of those PGTCC sources, concentration averaging removes the sources with the lowest activities and averages their radionuclide activity over the volume or mass of encapsulation media filling an entire waste container, thereby reducing the concentration to a level acceptable to a near-surface LLW disposal facility.

The PGTCC values represent the most basic estimates, and can be used as a foundation on which to apply any assumptions regarding packaging or concentration averaging. The impacts of packaging volumes and concentration averaging practices on these estimates are explored in other studies. This report deals almost exclusively with PGTCC sealed sources. Many, if not most of these sources will not actually need to be stored or disposed of by the DOE.

\subsection{Sealed Sources}

Sealed sources are typically small, relatively high-activity radioactive sources encapsulated in a closed metallic container. Source activities can range from less than $1 \mathrm{mCi}$ to over $1,000 \mathrm{Ci}$. However, most sources have activities less than $100 \mathrm{mCi}$. The source is often placed in a device intended for a specific purpose, typically for performing some type of measurement. Sealed sources and devices containing sealed sources have a wide variety of uses in medicine, construction, manufacturing, research, and other fields. Examples of devices that often have sealed sources include moisture/density gauges, level gauges, and well logging devices. In most cases, an organization must be licensed by a regulatory agency to own or operate a device containing a sealed source. A related study, documented in Volume 2, describes the physical characteristics of the various sealed sources discussed in this report. 
Two types of radioactive materials licenses exist, general licenses and specific licenses, as discussed in 10 CFR 30. General licenses are "in effect" upon purchase of a device containing a sealed source. However, no physical license is exchanged-rather, these licenses are for devices (described in 10 CFR 31) that are essentially exempted from the more strict regulatory control that governs devices covered by specific licenses. However, a specific licensee may possess devices containing sealed sources that are covered under a general license. This report deals with both general-and specific-licensed sealed sources that are handled by specific licensees.

A large number of sources are used under general licenses. Because companies holding general licenses are not tracked as closely as those with specific licenses, information on generally licensed sources is limited. An effort to obtain more information on the quantities of PGTCC sealed sources under general licenses is documented in Volume 3.

A prospective licensee must apply for a specific license from the appropriate nuclear regulatory agency. While the NRC has jurisdiction over nuclear materials licensing in some States, 28 States have opted to regulate such materials through their own regulatory agency. These States, known as Agreement States, have entered into agreements with the NRC to regulate certain by-product materials within their State.

Requirements for specific license holders vary depending upon the type and amount of radioactive material the license grants. Generally, the license requires the licensee to have a radiation safety officer to keep track of the device, control use and access, and perform leak tests. For licensees with larger amounts of material, additional requirements are necessary.

Sealed sources are the most widely available type of nuclear material. While the sources are small in volume, they often are highly radioactive. The widespread availability and the high activities combine to make management and disposal of sealed sources an ongoing concern.

LLW is categorized into three classes (A, B, and C), depending upon the isotopes and concentrations in the waste. These classes are defined in 10 CFR 61. LLW with concentrations above the highest limit (Class C) is categorized as GTCC LLW. The limits are shown in Table 1-1 for the radionuclides commonly used in sealed sources that can be GTCC LLW (many sources contain isotopes that have no Class C limits, such as cobalt-60 and radium-226, and hence, cannot be GTCC LLW). Because the ratio of activity to volume is relatively high, sealed sources that require disposal often fall into the GTCC LLW category. It is a purpose of this report to estimate how many sealed sources held by specific licensees are PGTCC material, which encompasses those sources which will be GTCC LLW.

When a licensee no longer needs a device containing a sealed source, the method of disposal depends upon the source concentration. Sources that qualify as Class A, B, or C LLW can be shipped to a LLW disposal facility. Sources that are GTCC material are generally stored by the licensee until disposal becomes available. In some cases, manufacturers accept GTCC sources for recycling at a fee to the licensee. Also, the regulatory agencies and DOE have accepted some GTCC sources for storage. Waste brokers typically do not accept GTCC sources. 
Table 1-1. Class $\mathrm{C}$ limits for low-level radioactive waste from 10 CFR 61.

\begin{tabular}{lc}
\multicolumn{1}{c}{ Radionuclide } & Concentration limit \\
\hline C-14 & $8.0 \mathrm{Ci} / \mathrm{m}^{3}$ \\
Tc-99 & $3.0 \mathrm{Ci} / \mathrm{m}^{3}$ \\
Ni-63 & $700 \mathrm{Ci} / \mathrm{m}^{3}$ \\
Sr-90 & $7,000 \mathrm{Ci} / \mathrm{m}^{3}$ \\
Cs-137 & $4,600 \mathrm{Ci} / \mathrm{m}^{3}$ \\
Pu-241 Alpha-emitting transuranic nuclides & $3,500 \mathrm{nCi} / \mathrm{g}$ \\
& $100 \mathrm{nCi} / \mathrm{g}$ \\
\hline
\end{tabular}

\subsection{Estimates of GTCC Sealed Sources}

DOE is responsible for ensuring the safe disposal of radioactive waste classified as GTCC LLW. To better understand the magnitude of this waste type, DOE issued a characterization report in 1991 (DOE/LLW-114). ${ }^{1}$ The report identified four types of GTCC LLW:

- Operations and decommissioning waste from nuclear power plants

- DOE-held waste

- $\quad$ Sealed sources

- Other GTCC waste.

The estimates for sealed sources in DOE/LLW-114 were based on a 1989 report by the NRC, Above Class C Source/Device Inventory Survey. ${ }^{2}$ The NRC estimated that in 1989 there were 27,156 sealed sources or devices that could become GTCC LLW. The DOE/LLW-114 report used this figure to conclude that the unpackaged and packaged GTCC waste volumes for sealed sources were $0.016 \mathrm{~m}^{3}$ and $6.08 \mathrm{~m}^{3}$, respectively, with a total activity of $3.03 \mathrm{E}+5 \mathrm{Ci}$.

The primary difference between this report and the 1989 NRC report on GTCC sealed sources is that this report uses a different concentration averaging scenario. The 1989 report assumes that a single source is packaged in a 55-gal drum filled with cement, and activities were averaged over the total drum volume to determine concentration. This report averages isotope activities only over the volume of the capsule containing the sealed source. This will allow the projection models discussed in DOE/LLW-114 more flexibility in applying packaging factors and concentration averaging. The results and projections contained in this report represent sources that have the potential for becoming GTCC LLW; many, if not most, of the sources discussed in this report will not be GTCC LLW after concentration averaging is applied.

DOE wanted to better estimate the number of PGTCC sealed sources through a survey of licensees; this report is a result. 


\subsection{Purpose}

The purpose of this report is to estimate the current total number of PGTCC sealed sources held by specific licensees, and the total volume and total activity of these sources. This report does not attempt to calculate volumes of devices or packaging, or to account for impacts of concentration averaging practices.

DOE requires estimates of the volume and activities of GTCC material to determine the options for disposing of the materials. The 1994 DOE/LLW-114 Revision 1 report $^{3}$ uses a computer model to project the amount of GTCC material that will require disposal in the future. The information contained in this report will be input to that model to better estimate the amount of sealed source material requiring disposal.

The sources analyzed in this report are currently not classified as waste, but will eventually become waste. While this report provides a snapshot of the current numbers of PGTCC sealed sources, more sources will be produced and these sources will also become waste. The projection of future manufacture and disposal of GTCC sealed sources is not considered in this report. 


\section{SURVEY METHODOLOGY AND DATABASES}

This section discusses how the two surveys (the NRC survey and the Agreement States survey) were conducted.

The need for more information on GTCC sealed sources required that a sample of radioactive materials licensees be questioned as to the type, number, and status of their sealed sources. Two agencies were involved in implementing the survey: the NRC and DOE. The NRC has authority over individuals and companies handling nuclear materials in 22 States. The remaining 28 States are Agreement States with their own nuclear materials regulatory agencies.

The NRC already had plans to conduct a survey of organizations holding specific NRC licenses that authorize the possession of sealed source materials. DOE decided to conduct a survey of specific licensees in the Agreement States. Although the two agencies were conducting the surveys for different reasons, the required information was much the same. Therefore, DOE used the same survey form that the NRC used.

While using the same form was primarily done for efficiency, it had the added benefit of allowing greater sharing of data between the two agencies. Using the same form also ensured comparability of the results. As discussed below, however, using a single form has caused some limitations in assessing the scope of GTCC sealed sources. This was because the NRC developed the survey for its own purposes independent of DOE.

\subsection{Methodology}

The two agencies had different strategies and different purposes for conducting the surveys. The NRC was interested in determining the number, use, condition, and disposition of sealed sources to evaluate the effectiveness of NRC regulations. The purpose was not to determine the number of GTCC sealed sources. DOE was interested in determining the number and types of sealed sources that could be GTCC material to plan for their disposal.

The results from the two surveys were combined to estimate GTCC sealed sources in the United States. Since some licensees are licensed through both the NRC and Agreement States, there was a small degree of overlap between the surveys. This is discussed further in Section 4.

Two general survey methods are typically used: the census and the sample. A census surveys all members of the population of interest. A statistical sample randomly selects a subpopulation of the population of interest and makes inferences on the population based on the results. The NRC conducted a census of its specific licensees possessing by-product material. This is in line with the NRC's need to assess the status of their licensees. DOE conducted a statistical sample of Agreement States licensees. This was more costeffective and was in line with DOE needs.

\subsubsection{Nuclear Regulatory Commission Census}

The census of NRC licensees was conducted by the Energy and Environmental Systems Division of the Oak Ridge Associated Universities for the NRC. The survey was sent to 7,373 NRC license holders. The breakdown of the number of licenses by State is shown in Table 2-1. 
Table 2-1. NRC license summary.

\begin{tabular}{|c|c|c|c|c|c|}
\hline State & $\begin{array}{c}\text { Number of } \\
\text { licenses }^{\mathrm{a}}\end{array}$ & State & $\begin{array}{c}\text { Number of } \\
\text { licenses }\end{array}$ & State & $\begin{array}{c}\text { Number of } \\
\text { licenses }\end{array}$ \\
\hline Alaska & 74 & Alabama & 24 & Arkansas & 11 \\
\hline American Samoa & 1 & Arizona & 21 & California & 57 \\
\hline Canada & 11 & Colorado & 38 & Connecticut & 259 \\
\hline Washington, D.C. & 67 & Delaware & 63 & Florida & 27 \\
\hline Georgia & 15 & Guam & 6 & Hawaii & 69 \\
\hline Iowa & 7 & Idaho & 10 & Illinois & 90 \\
\hline Indiana & 341 & Kansas & 22 & Kentucky & 18 \\
\hline Louisiana & 12 & Massachusetts & 493 & Maryland & 55 \\
\hline Maine & 98 & Michigan & 631 & Minnesota & 224 \\
\hline Missouri & 389 & Mississippi & 15 & Montana & 94 \\
\hline North Carolina & 22 & North Dakota & 4 & Nebraska & 5 \\
\hline New Hampshire & 7 & New Jersey & 614 & New Mexico & 21 \\
\hline Nevada & 6 & New York & 47 & Ohio & 727 \\
\hline Oklahoma & 278 & Oregon . & 14 & Pennsylvania & 922 \\
\hline Puerto Rico & 150 & Rhode Island & 3 & South Carolina & 8 \\
\hline South Dakota & 48 & Tennessee & 36 & Texas & 62 \\
\hline Utah & 12 & Virginia & 451 & Vermont & 40 \\
\hline U.S. Virgin Islands & 9 & Washington & 29 & Wisconsin & 314 \\
\hline \multirow[t]{2}{*}{ West Virginia } & 211 & Wyoming & 89 & Unspecified & 2 \\
\hline & & & & Total & 7,373 \\
\hline
\end{tabular}

a. The counts are the number of specific licenses administered by the NRC that have mailing addresses in the given State. Roughly $10 \%$ of the licensees hold multiple licenses.

The survey was sent in June 1991; responses were received and entered into a database by the winter of 1991-1992. Two potentially significant differences existed between the NRC and Agreement States surveys. First, the NRC survey listed the license number on the cover letter with the survey, while the Agreement States survey did not. (The license number may have helped the respondent identify the sources or devices of interest.) Second, the NRC survey was based on current licensee lists taken directly from NRC computers, while the Agreement States survey was not based on these lists.

\subsubsection{Agreement State Sample}

EG\&G Idaho sampled the Agreement States license holders for DOE. This survey was sent to 1,125 licensees. The breakdown of the number of licenses by State is shown in Table 2-2. 
Table 2-2. Agreement State licenses summary.

\begin{tabular}{|c|c|c|c|c|c|}
\hline State & $\begin{array}{l}\text { Number of } \\
\text { licensees }^{\mathrm{a}}\end{array}$ & $\begin{array}{l}\text { Number } \\
\text { surveyed }^{\mathrm{b}}\end{array}$ & State & $\begin{array}{l}\text { Number of } \\
\text { licensees }\end{array}$ & $\begin{array}{l}\text { Number } \\
\text { surveyed }\end{array}$ \\
\hline Alabama & 403 & 50 & Arizona & 310 & 29 \\
\hline Arkansas & 205 & 20 & California & 2,235 & 192 \\
\hline Colorado & 418 & 45 & Florida & 1,093 & 66 \\
\hline Georgia & 501 & 18 & Idaho $^{c}$ & 148 & 17 \\
\hline Illinois & 788 & 67 & Iowa & 225 & 18 \\
\hline Kansas & 335 & 40 & Kentucky & 393 & 21 \\
\hline Louisiana & 509 & 26 & Maryland & 521 & 33 \\
\hline Mississippi & 320 & 17 & Nebraska & 172 & 13 \\
\hline Nevada & 130 & 11 & New Hampshire & 110 & 5 \\
\hline New Mexico & 243 & 27 & New York & 1,269 & 93 \\
\hline North Carolina & 571 & 50 & North Dakota & 139 & 8 \\
\hline Oregon & 303 & 30 & Rhode Island & 75 & 5 \\
\hline South Carolina & 321 & 20 & Tennessee & 550 & 27 \\
\hline Texas & 1,724 & 140 & Utah & 170 & 25 \\
\hline Washington & 178 & 12 & Total & 14,359 & 1,125 \\
\hline
\end{tabular}

a. Number of licensees is the number of specific licensees administered by the State - it includes licensees whose mailing address may be outside of the State.

b. Number surveyed is the number of specific licensees located within the State who were sent a survey.

c. Idaho is no longer an Agreement State. At the time of the survey, it was.

DOE had two reasons for conducting a random sample:

- The purpose was to estimate the quantity of GTCC sealed sources that will require disposal. An exact number was not required and probably would be difficult if not impossible to determine, considering that a site for disposal will not be available in the near future.

- A sample is more cost-effective than a full census. 
To establish the population of Agreement States licensees, each Agreement States nuclear regulatory agency was asked to provide a listing of its licensees in the summer of 1991. As the lists were received, they were entered into a database.

The quality of the listings varied significantly across the States. Some States provided their full listings on a computer disk, while others provided partial listings in hardcopy form. Larger States, such as California and Texas, were asked to provide a subset of their complete list, focusing on license categories that were likely to indicate sealed source possession. (Some subjectivity exists in this subsetting process, but it is not likely to have much impact on the results.)

The determination to sample (send surveys to) 1,125 of 14,359 licensees was based on data quality objectives and is discussed more fully in Appendix A. It was calculated that this number of samples would give a desired $15 \%$ relative precision in estimating the percentage of sealed sources that may be GTCC. A minimum acceptable data quality objective was to receive at least 649 responses to achieve $20 \%$ relative precision. (An estimate with a $15 \%$ relative precision is a better, more precise, estimate than one with $20 \%$ relative precision. See the discussion on relative precision in Appendix A for more information.) Meeting the minimum data quality objective was considered sufficient for the success of the survey.

Once the Agreement States licensee lists were entered and the sample size was determined, the sample was randomly selected from the results database. The survey was mailed in March 1992. Responses were entered into the database if they possessed one of the isotopes listed in 10 CFR 61.55 with activities greater than $1 \mathrm{mCi}$. The $1 \mathrm{mCi}$ cutoff was used to obtain consistency in the data. The survey form requested information only on sources with $1 \mathrm{mCi}$ or more activity. However, some respondents did include information on sources with under $1 \mathrm{mCi}$ activity. Results were entered into the database in the spring of 1992.

\subsection{Survey Form}

The Agreement States survey form is shown in Figure 2-1. The 1991 NRC survey form is essentially the same; the only differences are with coding of the principal uses of the devices and the number of license codes and isotope types. The coding differed in that the original NRC form coded "radiography" and "selfluminous light source" as principal use types " $h$ " and " $k$," respectively. On the Agreement States form, these use types were coded as "l" (i.e., "other"). The NRC also listed a number of codes that are specific to NRC license identification in its table of isotopes. These codes were not included in the isotope table of the Agreement States form.

For the purposes of estimating total numbers of GTCC sealed sources, many isotopes that may be contained in sealed sources are not relevant (this is explained more fully in Section 3.1). Hence, some of the isotopes included in the table of isotopes (Table 1 of the survey form) shown in Figure 2-1 are not of concern for this study.

The NRC requested that respondents complete the form for only those isotopes with activities greater than $1 \mathrm{mCi}$. The purpose of this was to avoid compiling information on the vast number of check sources. Check sources are small sources typically used for assessing the performance of a radiation measuring device. They differ from true calibration sources in size and in the lack of standardization (i.e., they are not traceable to a standard).

While it may be reasonable to exclude these sources, the cutoff point excludes some sources that are PGTCC. That is, some small-volume sources would be PGTCC waste for some isotopes, particularly transuranic (TRU) isotopes, based solely on averaging the activity over the source capsule volume. However, the NRC considers the TRU activity limit for GTCC sources as $27 \mathrm{mCi}$, since they assume concentration 


\section{SEALED SOURCE/DEVICE SURVEY FORM INSTRUCTIONS PART A}

1.0 (a-b) A sealed source is any radioactive material that is encased in a capsule or a matrix designed to prevent the leakage or escape of the radioactive material. Check the appropriate box to indicate if you have any sealed sources containing radionuclides with activity equal to or greater than one millicurie (see Table 1). If YES is checked, complete this form for each sealed source and/or device type. See question 1.0 (c) if you have multiple sealed sources that have identical model numbers.

1.0 (c) If you have multiple sealed sources that have identical model numbers, indicate the total number of sources this form represents. Otherwise, fill out a separate form for each source and/or device.

2.1 (a) Give the element and mass number for the radionuclide. For example, Cs 137.

2.2 (a-d) Give the activity of the radionuclide in either curies, millicuries, becquerels, or grams.

2.3 If available, give the date the activity was measured or assayed (Month/Day/Year).

3.1, 3.2, 3.3 If available, give the manufacturer, model number, and serial number for the source. Please spell out the manufacturer's name.

4.1, 4.2, 4.3 If available, give the manufacturer, model number, and serial number for the device (unit containing the source). Please spell out the manufacturer's name.

5.0 Check the one box that is most appropriate for the principal use of the radioactive material. If multiple primary uses exist, use multiple forms.

6.0 (a-b) Indicate the source/device status by checking the appropriate box. If the form represents multiple sources, enter the quantity (number) for those actively used (at least once in the past year) and the quantity for those inactive. If all are actively used, enter the quantity (number) in box (a) and proceed to PART $B$ on the reverse side of this form.

$6.1(a-c) \quad$ For an inactive source, mark the appropriate category. For multiple, identical sources enter the total number in each status.

7.0 (a-f) What are your plans for the inactive source(s)? Enter the quantity (number) for each choice in the appropriate categories.

8.0 Use this area or additional sheets for comments or explanations you may have for PART A of the report.

\section{PART B}

$1.0(a-b) \quad$ Check the appropriate box indicating whether you have lost a sealed source with activity equal to or greater than one millicurie (see Table 1) during 1990. A form is required for each unique sealed source or device type. If no, go to 6.0 .

1.0 (c) If you checked YES [1.0 (b)], give the quantity (number) of sealed sources lost only if they have identical model numbers. If they are different, use a separate form for each source lost.

2.1 (a-b) Give the element and mass number for the radionuclide. For example, Cs 137.

2.2 (a-d) Give the activity of the radionuclide in either curies, millicuries, becquerels, or grams.

2.3 If available, give the date the activity was measured or assayed (Month/Day/Year).

3.1, 3.2, 3.3 If available, give the manufacturer, model number, and serial number for the source. Please spell out manufacturer's name.

4.1, 4.2, 4.3 If available, give the manufacturer, model number, and serial number for the device (unit containing the source). Please spell out manufacturer's name.

5.0 Use this area or additional sheets for comments or explanations you may have for PART B of the survey.

$6.0(\mathrm{a}-\mathrm{c}) \quad$ Legibly print your name and date. Return the entire package in the pre-addressed envelope. Thank you for your cooperation.

Figure 2-1. Survey form sent to Agreement State licensees. 
TABLE 1

\begin{tabular}{|c|c|c|c|c|c|c|c|c|}
\hline $\mathrm{AC}$ & & ACTINIUM & $\mathrm{CM}$ & 244 & CURIUM & I & 133 & IODINE \\
\hline $\mathrm{AC}$ & 227 & ACTINIUM & $\mathrm{CM}$ & 245 & CURIUM & I & 135 & IODINE \\
\hline $\mathrm{AC}$ & 228 & ACTINIUM & $\mathrm{CM}$ & 246 & CURIUM & IN & 113 & INDIUM \\
\hline$A G$ & 110 & SILVER & $\mathrm{CM}$ & 247 & CURIUM & IN & $113 \mathrm{M}$ & INDIUM \\
\hline $\mathrm{AG}$ & $110 \mathrm{M}$ & SILVER & $\mathrm{CM}$ & 248 & CURIUM & IN & 114 & INDIUM \\
\hline $\mathrm{AG}$ & 111 & SILVER & $\mathrm{CM}$ & 249 & CURIUM & IN & $114 \mathrm{M}$ & INDIUM \\
\hline $\mathrm{AM}$ & & AMERICIUM & $\mathrm{CM}$ & 250 & CURIUM & IR & $191 \mathrm{M}$ & IRIDIUM \\
\hline $\mathrm{AM}$ & 241 & AMERICIUM & $\mathrm{CO}$ & & COBALT & IR & 192 & IRIDIUM \\
\hline $\mathrm{AM}$ & 242 & AMERICIUM & $\mathrm{CO}$ & 57 & COBALT & IR & 193 & IRIDIUM \\
\hline $\mathrm{AM}$ & $242 \mathrm{M}$ & AMERICIUM & $\mathrm{CO}$ & 58 & COBALT & IR & 194 & IRIDIUM \\
\hline AM & 243 & AMERICIUM & $\mathrm{CO}$ & 60 & COBALT & $\mathbf{K}$ & 40 & POTASSIUM \\
\hline AM & 244 & AMERICIUM & $\mathrm{CO}$ & 61 & COBALT & $\mathbf{K}$ & 42 & POTASSIUM \\
\hline $\mathrm{AM}$ & 246 & AMERICIUM & $\mathrm{CO}$ & 62 & COBALT & $\mathrm{KR}$ & 79 & KRYPTON \\
\hline $\mathrm{AR}$ & 37 & ARGON & $\mathrm{CO}$ & 63 & COBALT & $\mathrm{KR}$ & 81 & KRYPTON \\
\hline $\mathrm{AR}$ & 41 & ARGON & $\mathrm{CO}$ & 64 & COBALT & $\mathrm{KR}$ & $83 \mathrm{M}$ & KRYPTON \\
\hline AS & 72 & ARSENIC & $\mathrm{CR}$ & & CHROMIUM & $\mathrm{KR}$ & 84 & KRYPTON \\
\hline AS & 73 & ARSENIC & $\mathrm{CR}$ & 51 & CHROMIUM & $\mathrm{KR}$ & 85 & KRYPTON \\
\hline AS & 74 & ARSENIC & $\mathrm{CR}$ & 52 & CHROMIUM & LA & 140 & LANTHANUM \\
\hline AS & 76 & ARSENIC & $\mathrm{CS}$ & & CESIUM & $\mathrm{LU}$ & 172 & LUTECIUM \\
\hline AS & 77 & ARSENIC & $\mathrm{CS}$ & 134 & CESIUM & LU & 177 & LUTECIUM \\
\hline $\mathrm{BA}$ & 131 & BARIUM & $\mathrm{CS}$ & 137 & CESIUM & MG & 28 & MAGNESIUM \\
\hline BA & 133 & BARIUM & $\mathrm{CS}$ & 139 & CESIUM & $\mathrm{MN}$ & 54 & MANGANESE \\
\hline BA & $137 \mathrm{M}$ & BARIUM & $\mathrm{CU}$ & 64 & COPPER & MN & 56 & MANGANESE \\
\hline $\mathrm{BA}$ & 140 & BARIUM & $\mathrm{CU}$ & 67 & COPPER & NA & 22 & SODIUM \\
\hline BI & 207 & BISMUTH & DY & 159 & DYSPROISUM & NA & 24 & SODIUM \\
\hline BI & 210 & BISMUTH & DY & 165 & DYSPROISUM & NB & $92 \mathrm{M}$ & NIOBIUM \\
\hline BK & 247 & BERKELIUM & ER & 169 & ERBIUM & NB & 94 & NIOBIUM \\
\hline BK & 249 & BERKELIUM & $\mathrm{EU}$ & 152 & EUROPIUM & NB & 95 & NIOBIUM \\
\hline BK & 250 & BERKELIUM & $\mathrm{EU}$ & $152 \mathrm{M}$ & EUROPIUM & ND & & NEODYMIUM \\
\hline BR & 76 & BROMINE & EU & 154 & EUROPIUM & NI & 59 & NICKEL \\
\hline $\mathrm{BR}$ & 77 & BROMINE & EU & 155 & EUROPIUM & NI & 63 & NICKEL \\
\hline BR & 80 & BROMINE & $\mathbf{F}$ & 18 & FLOURINE & NP & 234 & NEPTUNIUM \\
\hline BR & 82 & BROMINE & $\mathbf{F E}$ & 55 & IRON & NP & 235 & NEPTUNIUM \\
\hline $\mathrm{C}$ & 14 & CARBON & $\mathrm{FE}$ & 59 & IRON & NP & 237 & NEPTUNIUM \\
\hline $\mathrm{CA}$ & & CALCIUM & GA & 67 & GALLIUM & NP & 239 & NEPTUNIUM \\
\hline $\mathrm{CA}$ & 45 & CALCIUM & GA & 70 & GALLIUM & os & 185 & OSMIUM \\
\hline $\mathrm{CA}$ & 47 & CALCIUM & GA & 72 & GALLIUM & OS & 191 & OSMIUM \\
\hline $\mathrm{CD}$ & 109 & CADMIUM & GD & 151 & GADOLINIUM & $\mathrm{P}$ & & PHOSPHORUS \\
\hline $\mathrm{CD}$ & 113 & CADMIUM & GD & 153 & GADOLINIUM & $P$ & 31 & PHOSPHORUS \\
\hline $\mathrm{CD}$ & $113 \mathrm{M}$ & CADMIUM & GD & 159 & GADOLINIUM & $\mathrm{P}$ & 32 & PHOSPHORUS \\
\hline $\mathrm{CD}$ & 115 & CADMIUM & GD & 162 & GADOLINIUM & $\mathbf{P}$ & 33 & PHOSPHORUS \\
\hline $\mathrm{CD}$ & $115 \mathrm{M}$ & CADMIUM & GE & 68 & GERMANIUM & PA & 231 & PROTACTINIUM \\
\hline $\mathrm{CE}$ & 137 & CERIUM & $G E$ & 77 & GERMANIUM & PA & 233 & PROTACTINIUM \\
\hline $\mathrm{CE}$ & 139 & CERIUM & $\mathbf{H}$ & 3 & HYDROGEN & PA & 234 & PROTACTINIUM \\
\hline CE & 141 & CERIUM & $\mathrm{HF}$ & 172 & HAFNIUM & PB & 210 & LEAD \\
\hline $\mathrm{CE}$ & 143 & CERIUM & HF & $180 \mathrm{M}$ & HAFNIUM & PD & 109 & PALLADIUM \\
\hline $\mathrm{CE}$ & 144 & CERIUM & $\mathrm{HF}$ & 181 & HAFNIUM & PM & 145 & PROMETHIUM \\
\hline CF & & CALIFORNIUM & HG & 195 & MERCURY & PM & 147 & PROMETHIUM \\
\hline $\mathrm{CF}$ & 241 & CALIFORNIUM & HG & 197 & MERCURY & PM & 148 & PROMETHIUM \\
\hline CF & 249 & CALIFORNIUM & HG & 203 & MERCURY & PO & & POLONIUM \\
\hline CF & 250 & CALIFORNIUM & HO & 166 & HOLMIUM & PO & 208 & POLONIUM \\
\hline $\mathrm{CF}$ & 252 & CALIFORNIUM & HO & $166 \mathrm{M}$ & HOLMIUM & PO & 209 & POLONIUM \\
\hline $\mathrm{CF}$ & 253 & CALIFORNIUM & $\mathrm{I}$ & & IODINE & PO & 210 & POLONIUM \\
\hline $\mathrm{CL}$ & 35 & CHLORINE & $\mathrm{I}$ & 125 & IODINE & PO & 218 & POLONIUM \\
\hline $\mathrm{CL}$ & 36 & CHLORINE & $\mathrm{I}$ & 126 & IODINE & PR & 143 & PRASEODYMIUM \\
\hline $\mathrm{CL}$ & 38 & CHLORINE & 1 & 128 & IODINE & $\mathrm{PT}$ & 183 & PLATINUM \\
\hline $\mathrm{CM}$ & & CURIUM & $\mathbf{I}$ & 129 & IODINE & PT & 193 & PLATINUM \\
\hline $\mathrm{CM}$ & 242 & CURIUM & I & 131 & IODINE & PT & $195 \mathrm{M}$ & PLATINUM \\
\hline $\mathrm{CM}$ & 243 & CURIUM & I & 132 & IODINE & PT & 197 & PLATINUM \\
\hline
\end{tabular}

Figure 2-1. (continued). 


\begin{tabular}{|c|c|c|c|c|c|c|c|c|}
\hline PU & & PLUTONIUM & $\mathrm{SN}$ & $121 \mathrm{M}$ & TIN & $\mathrm{TM}$ & 171 & THULIUM \\
\hline $\mathrm{PU}$ & 236 & PLUTONIUM & $\mathrm{SN}$ & 125 & TIN & $\mathrm{TM}$ & 172 & THULIUM \\
\hline PU & 237 & PLUTONIUM & SR & & STRONTIUM & $\mathrm{U}$ & & URANIUM \\
\hline PU & 238 & PLUTONIUM & SR & 85 & STRONTIUM & $\mathrm{U}$ & 232 & URANIUM \\
\hline PU & 239 & PLUTONIUM & SR & 87 & STRONTIUM & $\mathbf{U}$ & 233 & URANIUM \\
\hline $\mathrm{PU}$ & 240 & PLUTONIUM & SR & 89 & STRONTIUM & $\mathbf{U}$ & 234 & URANIUM \\
\hline PU & 241 & PLUTONIUM & SR & 90 & STRONTIUM & $\mathbf{U}$ & 235 & URANIUM \\
\hline PU & 242 & PLUTONIUM & $\mathrm{TA}$ & 182 & TANTALUM & $\mathbf{U}$ & 236 & URANIUM \\
\hline PU & 244 & PLUTONIUM & $\mathrm{TA}$ & 183 & TANTALUM & $\mathbf{U}$ & 237 & URANIUM \\
\hline RA & 226 & RADIUM & TB & 160 & TERBIUM & $\mathbf{U}$ & 238 & URANIUM \\
\hline RB & & RUBIDIUM & TB & 161 & TERBIUM & $\mathbf{U}$ & 239 & URANIUM \\
\hline RB & 86 & RUBIDIUM & TC & & TECHNETIUM & V & 48 & VANADIUM \\
\hline RE & 186 & RHENIUM & $\mathrm{TC}$ & 96 & TECHNETIUM & $\mathrm{V}$ & 49 & VANADIUM \\
\hline RE & 188 & RHENIUM & TC & 99 & TECHNETIUM & w & & TUNGSTEN \\
\hline RU & 97 & RUTHENIUM & $\mathrm{TC}$ & $99 \mathrm{M}$ & TECHNETIUM & W & 181 & TUNGSTEN \\
\hline RU & 103 & RUTHENIUM & TE & 123 & TELLURIUM & W & 185 & TUNGSTEN \\
\hline RU & 105 & RUTHENIUM & $\mathrm{TE}$ & $123 \mathrm{M}$ & TELLURIUM & w & 187 & TUNGSTEN \\
\hline RU & 106 & RUTHENIUM & $\mathrm{TE}$ & 125 & TELLURIUM & w & 188 & TUNGSTEN \\
\hline $\mathbf{S}$ & 34 & SULFUR & TE & $125 \mathrm{M}$ & TELLURIUM & $\mathrm{XE}$ & & XENON \\
\hline $\mathbf{S}$ & 35 & SULFUR & $\mathrm{TE}$ & 129 & TELLURIUM & $\mathrm{XE}$ & 127 & XENON \\
\hline SB & & ANTIMONY & $\mathrm{TE}$ & 132 & TELLURIUM & $\mathrm{XE}$ & $131 \mathrm{M}$ & XENON \\
\hline SB & 122 & ANTIMONY & TH & & THORIUM & $\mathrm{XE}$ & 133 & XENON \\
\hline SB & 124 & ANTIMONY & TH & 225 & THORIUM & $\mathrm{XE}$ & 135 & XENON \\
\hline SB & 125 & ANTIMONY & TH & 227 & THORIUM & $\mathbf{Y}$ & 88 & YTTRIUM \\
\hline SC & 46 & SCANDIUM & TH & 228 & THORIUM & $\mathrm{Y}$ & 90 & YTTRIUM \\
\hline SC & 47 & SCANDIUM & TH & 229 & THORIUM & $\mathbf{Y}$ & 91 & YTTRIUM \\
\hline SE & 75 & SELENIUM & TH & 230 & THORIUM & $\mathbf{Y B}$ & 169 & YTTERBIUM \\
\hline SI & 31 & SILICON & TH & 231 & THORIUM & YB & 175 & YTTERBIUM \\
\hline SM & 145 & SAMARIUM & TH & 232 & THORIUM & YB & 177 & YTTERBIUM \\
\hline SM & 151 & SAMARIUM & TH & 233 & THORIUM & $\mathrm{ZN}$ & 63 & ZINC \\
\hline SM & 153 & SAMARIUM & TI & 44 & TITANIUM & $\mathrm{ZN}$ & 65 & ZINC \\
\hline SN & 113 & TIN & TL & 201 & THALLIUM & $\mathrm{ZN}$ & 69 & ZINC \\
\hline SN & 119 & TIN & $\mathrm{TL}$ & 204 & THALLIUM & $\mathbf{Z N}$ & $69 \mathrm{M}$ & ZINC \\
\hline SN & $119 \mathrm{M}$ & TIN & TM & 166 & THULIUM & $\mathbf{Z R}$ & 95 & ZIRCONIUM \\
\hline SN & 121 & TIN & TM & 170 & THULIUM & & & \\
\hline
\end{tabular}

Figure 2-1. (continued). 


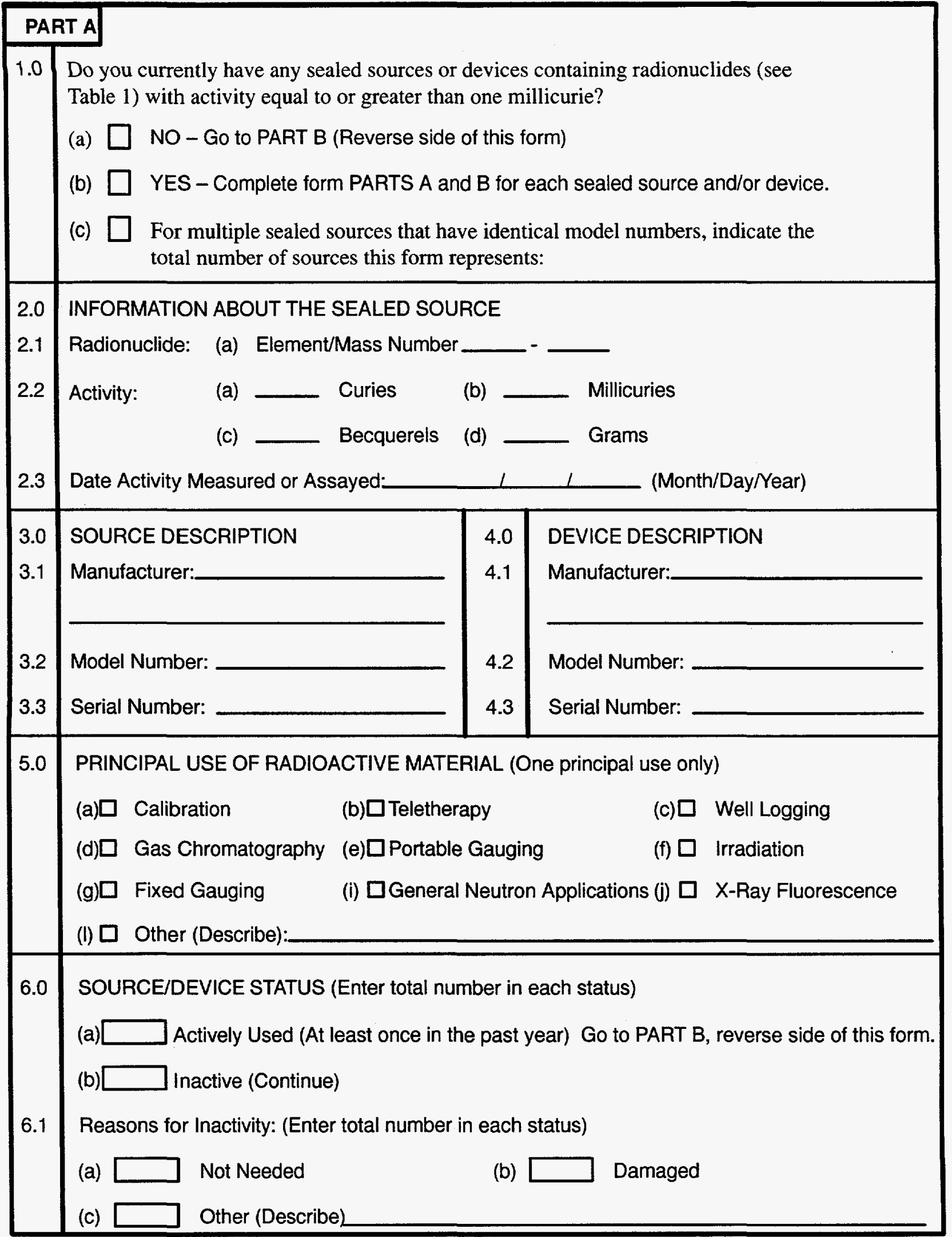

Figure 2-1. (continued). 


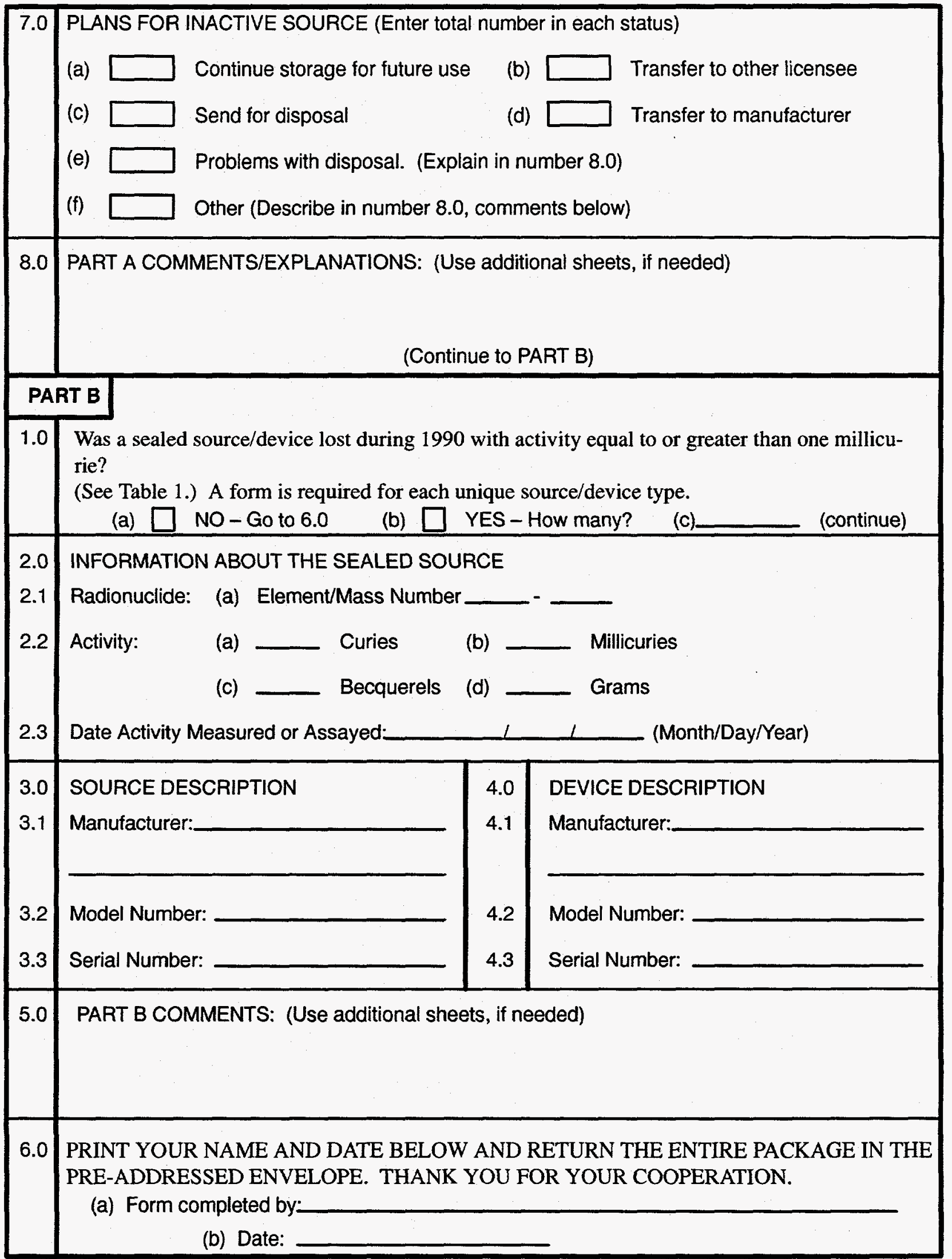

Figure 2-1. (continued). 
averaging of the source activity over a 55-gal drum. When they are packaged for disposal, sources with activities under $1 \mathrm{mCi}$ are highly unlikely to become GTCC material because activity is averaged over the larger packaged volume.

Further, the NRC form did not ask for information on the volume or mass. This is because the NRC can use the model number to look up specifications in their Sealed Source and Device Registry. The activity and volume information is needed to determine if the source has GTCC LLW potential. The Class C limits are in units of concentration. Without the volume information, it is not possible to directly assess the potential for the source to be GTCC material. As is discussed later, volumes were assigned by device type based on past information since the hardcopies of the NRC Registry that contain information on source volumes are not readily available. More precise estimates are possible by matching the source or device model numbers to manufacturer information on the source volumes.

Nonetheless, using the same form for both surveys was useful. It maintained the comparability of the data so that the databases could be combined. It also saved time and money by not having DOE "reinvent the wheel" and by not requiring Office of Management and Budget clearance of a different survey.

\subsection{Databases}

The sealed source survey database is composed of two databases. The first database contains the licensee information, including addresses, contact names, and phone numbers. The second database is linked hierarchically to the licensee database and contains information on each sealed source model the licensee possesses. This database is essentially a computerized version of the survey form. Its structure is shown in Table 2-3.

\subsection{Problems Encountered}

A number of problems occurred in conducting the Agreement States survey. Two that warranted consideration include:

- The response rate was less than expected

- The quality of the responses varied greatly between licensees.

The possible uncertainties in the results that are introduced by these problems are discussed in Appendix B.

\subsubsection{Response Rate}

There were 645 responses from the 1,125 surveys sent in the Agreement States survey, or $57 \%$. The NRC received 5,672 responses out of 7,373 forms mailed, or 77\%. It can be surmised that at least part (if not most) of the differences in response rates was because the Agreement States survey was sent through thirdclass mail.

To save money, the Agreement States surveys were sent bulk-rate. However, it was later learned that bulk-rate mail is not forwarded nor returned to the sender when the addressee has moved. Also, mail room personnel at large companies are sometimes advised to essentially ignore bulk-rate mail unless it is addressed to a specific employee. 
Table 2-3. Description of fields in the source database.

\begin{tabular}{|c|c|c|}
\hline Field & Field name & Description \\
\hline 1 & UID & Unique identification number \\
\hline 2 & PROG_CODE & Program code \\
\hline 3 & LICNO & License number \\
\hline 4 & OWN_SOURCE & T/F: Does licensee own the source? \\
\hline 5 & NUM_SOU & Number of sources represented \\
\hline 6 & ELEMENT & Element (e.g., cesium, americium) \\
\hline 7 & MASS_NO & Mass number of associated element \\
\hline 8 & NEUTRON_SO & Neutron source for the device \\
\hline 9 & CURIES & Activity in curies \\
\hline 10 & MILLICURIE & Activity in millicuries \\
\hline 11 & BECQUERELS & Activity in becquerels \\
\hline 12 & GRAMS & Grams of radioactive material \\
\hline 13 & TOTAL_ACT & $\mathrm{T} / \mathrm{F}:$ Is activity a sum of the represented sources? \\
\hline 14 & SO_MANUFAC & Source manufacturer name \\
\hline 15 & SO_MOD_NO & Source model number \\
\hline 16 & SO_SER_NO & Source serial number \\
\hline 17 & DEV_MANUFA & Device manufacturer name \\
\hline 18 & DEV_MOD_NO & Device model number \\
\hline 19 & DEV_SER_NO & Device serial number \\
\hline 20 & DATE_ASSAY & Date source last assayed (to get activity) \\
\hline 21 & PRIN_USE & Principal use \\
\hline 22 & OTHER_USE & Description of other use, if not in principal use \\
\hline 23 & ACT_USED & Number of sources actively used (in the last year) \\
\hline 24 & INACTIVE & Number of sources not actively used \\
\hline 25 & DAMAGE & Number of damaged inactive sources \\
\hline 26 & NOT_NEEDED & Number of inactive sources no longer needed \\
\hline 27 & OTHER_INAC & Number of sources with another reason for inactivity \\
\hline 28 & REASON & Description of other reason for inactivity \\
\hline 29 & STORED & Number of inactive sources being stored \\
\hline 30 & TRANS_LIC & Number of inactive sources being transferred to a licensee \\
\hline 31 & SENT_DISP & Number of inactive sources being sent for disposal \\
\hline 32 & TRANS_MANU & Number of inactive sources being transferred to the manufacturer \\
\hline 33 & PROBLEMS & Number of inactive sources having problems with disposal \\
\hline 34 & OTHER_DISP & Number of inactive sources being disposed with other methods \\
\hline 35 & TCOMMENTS & Comments \\
\hline 36 & NAME_COMP & Name of person completing the form \\
\hline 37 & DATE_COMP & Date form completed \\
\hline
\end{tabular}


Since undeliverable forms were not returned to EG\&G Idaho, there was no way to assess how much of the nonresponse was caused by this. However, the listings were current, and it is expected that most forms were received by the addressed company.

However, many of the Agreement States licensee lists provided to EG\&G Idaho did not include the name of a radiation safety officer or other contact name. Hence, these surveys were mailed in care of a generic radiation safety officer of the company. It is believed that in many cases, these forms were thrown to the trash in the mail room because they were third class and did not include a specific employee name. The degree to which this occurred cannot be estimated.

Another possible reason for the low response is that the NRC respondents recognize the NRC as the administrator of their license and thus, may be more likely to respond, whereas DOE does not have any authority over the Agreement States licensees.

The minimum data quality requirement was to receive 649 responses to achieve $20 \%$ relative precision in estimating the proportion of inactive GTCC sealed sources. This number (649) was based on an assumed proportion of inactive GTCC sealed sources of $15 \%$. The results of the survey show the proportion is $17.6 \%$; with 630 responses, this results in a relative precision of $17.2 \%$. Hence, the data quality objective for a relative precision of (at most) $20 \%$ was met, since a relative precision of $17 \%$ is better, i.e., more precise, than one of $20 \%$. See Appendix A for a discussion of relative precision requirements and definitions.

\subsubsection{Response Quality}

The actual quality of the responses varied from licensee to licensee. Some licensees keep close track of all their sealed sources, and thus were able to clearly and accurately respond to the questionnaire. For others, apparently a great deal of effort was required to fill out the forms. In a few cases, the licensees did not understand the questions asked and required help in filling out the forms. Finally, errors were noted in some responses; for example, the total number of sources did not equal the number of active sources plus the number of inactive sources, as listed on the respondent's form.

The respondents had particular problems identifying the principal use of the device. This required extensive work in the database to correct. Basically, the NRC's Sealed Source and Device Registry was used to correct the principal use codes. This is explained in detail in Section 4.

The data were checked after being entered into the database. When anomalies were found, the original survey form was retrieved and the data were verified. When errors existed in the input to the database, the database was corrected. However, a number of unresolved problems still remained. Those responses exhibiting real anomalies were generally not included in the analyses of the data if the anomaly would affect the results. 


\section{ANALYSIS METHODOLOGY}

The analysis generally proceeded in three stages:

- Data summary

- $\quad$ PGTCC determination

- $\quad$ PGTCC extrapolations for three scenarios.

The first stage, data summary, compiled the results without regard to the PGTCC status of the source. The primary goal for this step was to determine the comparability of the two surveys and to get a general description of the sampled licensees.

The second stage involved determining which sealed sources were PGTCC by applying the PGTCC activity limits to the combined NRC and Agreement States survey results. The determination of whether a sealed source is PGTCC is discussed in detail in Section 3.1.

The third stage took the results of the first two stages to extrapolate the results to the population of all specific licensees. The total number of PGTCC sealed sources was deduced for three scenarios: low, base, and high. The low and high case scenarios are respectively defined as the lower and upper $95 \%$ confidence limits on the base case estimate.

In each stage, the results were initially determined for each isotope within the principal use (e.g., calibration, teletherapy, well logging). These results (device type by isotope) were then summed across all isotopes to get the totals by principal use, and the results were summed across all principal uses to get the total by isotope.

The extrapolation to all licensees was performed by multiplying the estimated number of sources per licensee (from the sample) by the total number of licensees. This is explained in more detail in Section 4.

\subsection{PGTCC Determinations}

To determine whether a particular sealed source is PGTCC material, the radionuclide activity of the source given in the survey is compared to the regulatory limit. However, the regulatory limits (10 CFR 61.55) are stated as concentrations (units of $\mathrm{Ci} / \mathrm{m}^{3}$ for non-TRU waste and units of $\mathrm{nCi} / \mathrm{g}$ for TRU waste). To compare the survey source data to the regulatory limits, the regulatory limits are converted to units of activity, and each survey activity response is compared to the activity limit. A survey response activity larger than the regulatory-derived activity limit is concluded to be PGTCC material. Otherwise, it is not PGTCC material.

To convert the regulatory concentration limit to an activity, the concentration is multiplied by a source volume. Source volume information came from three references-the Amersham catalog ${ }^{4}$ (a major manufacturer of sealed sources), personal communications with NRC licensing personnel, and an NRC Policy Issue paper. ${ }^{5}$ As part of that paper, the NRC has the same purpose as this section - determine the activity at which a source is PGTCC material. Additionally, the Amersham catalog ${ }^{4}$ provides dimensions of their sources, which were used to get a range of reasonable source volumes for each principal use code. The source volumes are of the encapsulated source.

The volumes are assigned by principal use; therefore, the regulatory-derived activity limit changes between principal uses. Within a given principal use, the source volumes are relatively homogeneous. By 
assigning volumes to each principal use, the results are more precise than using a single generic volume for all sources. The volume is chosen to reflect the typical source volume, as seen in the references $(1,3,4)$.

Three scenarios are considered to derive upper and lower limits on the number of PGTCC sources requiring disposal, as well as a "base" case, which is the current best estimate. The "low" and "high" case scenarios are defined by the lower and upper $95 \%$ confidence limits on the base case estimates. The determination of the confidence limits is documented in Appendix B.

Because the regulatory limits for alpha-emitting TRU nuclides are low relative to the activity and volume of sources containing TRU material, this study considers all alpha-emitting TRU radionuclides with half-lives greater than five years, and Pu-241 (a beta-emitter) to be PGTCC material (if the source activity is greater than $1 \mathrm{mCi}$ ). This includes Am-241, Cm-244, $\mathrm{Np}-237, \mathrm{Pu}-238$, and $\mathrm{Pu}-239$, each with a regulatory limit of $100 \mathrm{nCi} / \mathrm{g}$ for these TRU nuclides, and 3,500 nCi/g for Pu-241. Few Pu-241 sources exist, so assuming that all Pu-241 sources are PGTCC does not have a major impact on the results.

For each principal use category, sealed sources containing Ni-63, Sr-90, Cs-137, C-14, or Tc-99 are considered individually, based on the expected unit volume of the source for the category. As an example cal-

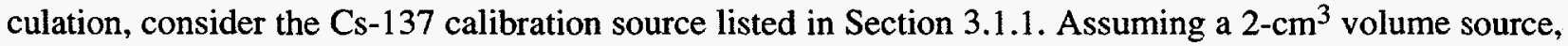
the activity needed to qualify as PGTCC material is $2 \mathrm{~cm}^{3} \times 4,600 \mu \mathrm{Ci} / \mathrm{cm}^{3} \times 0.001 \mathrm{mCi} / \mu \mathrm{Ci}=9.2 \mathrm{mCi}$ $\left(4,600 \mu \mathrm{Ci} / \mathrm{cm}^{3}\right.$ is equivalent to the Class $\mathrm{C}$ limit of $4,600 \mathrm{Ci} / \mathrm{m}^{3}$ from $\left.10 \mathrm{CFR} 61.55\right)$. Consequently, a Cs-137 calibration source with an activity greater than $9.2 \mathrm{mCi}$ would be considered PGTCC material; one with an activity less than $9.2 \mathrm{mCi}$ would not be PGTCC material.

As discussed in Section 2.2, the survey was only to be completed for sources with activities greater than $1 \mathrm{mCi}$. If the calculated PGTCC activity limit is less than $1 \mathrm{mCi}$ for a given radionuclide in a given principal use category, then all sources containing that radionuclide in the given category are considered to be PGTCC material, since the survey was designed to collect information on sealed sources with activities greater than $1 \mathrm{mCi}$. These cases are explicitly noted in Table 3-1, which lists the source volumes and PGTCC activity limits by principal use. Uncertainty introduced by this assumption is qualitatively assessed in Appendix B.

If a particular survey response for a sealed source does not state an activity, then it is conservatively assumed to represent a PGTCC source.

No adjustment for decay is made. This is because a large number of respondents did not give a date when the source was measured. For those that did give a date, it was generally either the date that the source or device was purchased or the date within the last year that it was leak tested. Not adjusting for decay will make the calculations conservative. As discussed in Appendix B, the estimated number of PGTCC sources is not significantly affected by decay, but their estimated activities are. 
Table 3-1. Source capsule volumes $\left(\mathrm{cm}^{3}\right)$ and activity limits $(\mathrm{mCi})$ for sources classified as PGTCC material in this report.

\begin{tabular}{|c|c|c|c|c|c|c|c|c|c|c|c|c|c|}
\hline \multirow[b]{2}{*}{ Device Type } & \multirow[b]{2}{*}{ Volume } & \multicolumn{12}{|c|}{ PGTCC Activity Limits } \\
\hline & & Am-241 & $C-14$ & $\mathrm{Cm}-244$ & Cs-137 & $\mathrm{Ni}-63$ & Np-237 & $\mathrm{Pu}-238$ & $\mathrm{Pu}-239$ & $\mathrm{Pu}-241$ & $\mathrm{Sr}-90$ & $\mathrm{Tc}-99$ & $\mathrm{U}-238$ \\
\hline Calibration & 2.0 & 1.0 & $<1.0^{\mathrm{a}}$ & 1.0 & 9.2 & $1: 4$ & 1.0 & 1.0 & 1.0 & 1.0 & 14.0 & $<1.0^{\mathrm{a}}$ & 1.0 \\
\hline Medical & 20.0 & 1.0 & - & - & 92.0 & - & - & - & - & - & 140.0 & $<1.0^{\mathrm{a}}$ & 1.0 \\
\hline Well logging & 25.0 & 1.0 & - & - & 115.0 & - & - & 1.0 & - & 1.0 & - & - & - \\
\hline Portable gauge & 20.0 & 1.0 & - & - & 92.0 & - & - & - & - & - & - & - & - \\
\hline Irradiation & 40.0 & 1.0 & - & - & 184.0 & - & - & - & - & - & 280.0 & - & - \\
\hline Fixed gauge & 3.0 & 1.0 & $<1.0^{\mathrm{a}}$ & 1.0 & 13.8 & - & - & 1.0 & - & - & 21.0 & - & - \\
\hline $\begin{array}{l}\text { General neutron } \\
\text { applications }\end{array}$ & 20.0 & 1.0 & - & - & - & - & - & 1.0 & 1.0 & - & - & - & - \\
\hline $\mathrm{X}$-ray fluorescence & 0.5 & 1.0 & - & 1.0 & 2.3 & - & - & 1.0 & - & - & - & - & - \\
\hline Other & 10.0 & 1.0 & 1.0 & 1.0 & 1.0 & 1.0 & 1.0 & 1.0 & 1.0 & 1.0 & 1.0 & 1.0 & 1.0 \\
\hline
\end{tabular}

a. Since these activity limits are less than $1 \mathrm{mCi}$, and since all sources reported in the survey are assumed to have activities above these limits, all these sources are PGTCC. 


\subsubsection{PGTCC Activity Limits for Calibration Sources}

Calibration devices contain sources of known activity that are used to determine the variation in accuracy of a measuring instrument and to ascertain necessary correction factors. These sources vary widely in their activities and radionuclides. The radionuclides observed in calibration sources in the survey responses include Am-241, C-14, Cm-244, Cs-137, Ni-63, Np-237, Pu-238, Pu-239, Pu-241, Sr-90, Tc-99, and U-238. Calibration sources containing Am-241, Cm-244, Np-237, Pu-238, Pu-239, Pu-241, or U-238 will be considered PGTCC material, as they are TRU. For the remaining isotopes, the regulatory-derived activity limits are calculated assuming a $2-\mathrm{cm}^{3}$ capsule volume. The isotopes and minimum activities qualifying as PGTCC material are shown in Table 3-1.

\subsubsection{PGTCC Activity Limits for Medical Sources}

Sealed sources have a wide variety of medical uses in the diagnosis and treatment of disease. The source activities can vary greatly depending upon the specific application. The applications include teletherapy, radiography, therapeutic seeds, and ophthalmic applicators. The radionuclides observed in medical sources in the survey responses include Am-241, Cs-137, Sr-90, Tc-99, and U-238 with Cs-137 being the most frequently observed. Medical sources containing Am-241 and U-238 will be considered PGTCC material, as they are TRU. For the remaining sources, the regulatory-derived activity limits are calculated assuming a $20-\mathrm{cm}^{3}$ capsule volume. The isotopes and regulatory-derived activity limits are as shown in Table 3-1.

\subsubsection{PGTCC Activity Limits for Well Logging Sources}

Well logging devices are primarily used by oil companies to determine geophysical characteristics of the well. The survey responses show that radionuclides in well logging sources include Am-241, $\mathrm{Cs}-137, \mathrm{Pu}-238$, and $\mathrm{Pu}-241$. They have a wide range of activities, with maximum activities of up to 20 Ci. Well logging sources containing Am-241, Pu-238, and Pu-241 will be considered PGTCC material, as they are TRU. For the Cs-137 sources, the regulatory-derived activity limits are calculated assuming a $25-\mathrm{cm}^{3}$ capsule volume (see Table $3-1$ ).

\subsubsection{PGTCC Activity Limiț for Gas Chromatography Sources}

Gas chromatography devices use electron capture detectors to quantify the concentrations of chemicals in samples. The radionuclides observed in gas chromatography sources in the survey responses include $\mathrm{Ni}-63$. The activity is typically around $15 \mathrm{mCi}$. The NRC Policy Issue paper (Reference 4), states that gas chromatography sources have $0.015 \mathrm{~cm}^{3}$ volumes. The minimum activity limits are then all less than $1 \mathrm{mCi}$ for $\mathrm{Ni}-63$. While using the strict calculation of average activity per source volume makes these sources all PGTCC material, these devices are commonly disposed of at near-surface disposal facilities. ${ }^{a}$ Therefore, these devices will not be considered PGTCC material.

\subsubsection{PGTCC Activity Limits for Portable Gauging Sources}

Portable gauging devices have a variety of uses, primarily in construction and agriculture. They are commonly referred to as moisture-density gauges since they measure moisture content (e.g., soil) and compute material densities (e.g., asphalt). The radionuclides observed in portable gauge sources in the survey responses include Am-241 and Cs-137. The typical gauge has a $20-\mathrm{cm}^{3}$ volume source ${ }^{\mathrm{a}}$.

a. Steve L. Baggett (NRC) letter to Roger Scott (EG\&G Idaho), December 30, 1992. 
Portable gauges often have two sources, one with Cs-137 and the other with Am-241 or Am-241/Be. The activity of the source(s) is typically less than $50 \mathrm{mCi}$. Portable gauge sources containing Am-241 will be considered PGTCC material, as they are TRU. For the Cs-137 sources, the regulatory-derived activity limits are calculated assuming a $20-\mathrm{cm}^{3}$ capsule volume. This leads to the $92 \mathrm{mCi}$ limit presented in Table 3-1 for the minimum activity of a PGTCC source.

\subsubsection{PGTCC Activity Limits for Irradiation Sources}

Irradiation devices have a variety of uses in the food, medical, and research industries. The survey shows that radionuclides observed in irradiation devices include Am-241, Cs-137, and Sr-90. The activities can get quite high, up to $12,000 \mathrm{Ci}$. All irradiation sources containing Am-241 will be considered PGTCC material, as they are TRU. The regulatory-derived activity limits are calculated assuming a $40-\mathrm{cm}^{3}$ capsule volume. Category II through IV gamma irradiators have source volumes up to 2,000 $\mathrm{cm}^{3}$ (made from multiple sources). It is assumed that the sources are of the Category I type. This assumption is conservative in that the Category I irradiation sources have the smallest volumes, in general, and will lead to lower regulatory-derived limits than the Category II through Category IV irradiators. The uncertainty introduced by this assumption is negligible: Category II irradiators have sources comparable to Category I irradiators, while Category III and IV irradiators most commonly use Co-60 sources; Co-60 can at most be Class B under 10 CFR 61.

\subsubsection{PGTCC Activity Limits for Fixed Gauging Sources}

Fixed gauges are commonly used in the mining and manufacturing industries to control production lines; for example, checking the level of a coal stream. The radionuclides observed in fixed gauging sources in the survey responses are Am-241, C-14, Cm-244, Cs-137, Pu-238, and Sr-90. Sources containing Am-241, Cm-244, or Pu-238 will be considered PGTCC material, as they are TRU. The source isotopes and activities can vary widely. The source volumes typically range between 1 and $5 \mathrm{~cm}^{3}$. The regulatory-derived activity limits for the C-14 and Cs-137 sources are calculated assuming a $3-\mathrm{cm}^{3}$ capsule volume (see Table 3-1).

\subsubsection{PGTCC Activity Limits for General Neutron Applications Sources}

General neutron applications include all applications, except reactor startup and well logging, that use a neutron source. The survey shows that radionuclides in general neutron applications sources are Am-241, Pu-238, and Pu-239. Since these are all TRU, all general neutron applications sources will be considered PGTCC material.

\subsubsection{PGTCC Activity Limits for X-Ray Fluorescence Sources}

$\mathrm{X}$-ray fluorescence devices use radioactive material to excite the atoms of samples that in turn emit characteristic $x$-rays and thereby, provide a means for sample analysis. The survey shows that radionuclides observed in X-ray fluorescence devices include Am-241, Cm-244, Cs-137, and Pu-238. All x-ray fluorescence sources containing Am-241, Cm-244, or Pu-238 will be considered PGTCC material as these are TRU. Assuming a source capsule volume of $0.5 \mathrm{~cm}^{3}$, the regulatory-derived activity limit for the Cs-137 sources is presented in Table 3-1. 


\subsubsection{PGTCC Activity Limits for Other Sources}

A large number of sources have principal uses outside the above categories. Some of the miscellaneous uses include ion generation (nonchromatography), thermal generators, gas sources, and light sources. The radionuclides observed in the "Other" category in the survey include Am-241, C-14, Cm-244, Cs-137, Ni-63, Np-237, Pu-238, Pu-239, Pu-241, Sr-90, Tc-99, and U-238. Because of the wide range of uses, the volumes cannot be characterized as in Sections 3.1.1 to 3.1.9; so, the regulatoryderived activity limits are impossible to pin down. Therefore, all TRU radionuclides with a principal use of "Other" (Am-241, Cm-244, Np-237, Pu-238, Pu-239, Pu-241, and U-238) will be considered PGTCC material (see Table 3-1). For the non-TRU radionuclides, they will conservatively be considered PGTCC material.

\subsection{Evaluation of Assumptions}

The analysis methodology worked with little difficulty. Nonetheless, concerns exist regarding the assumptions of the analyses, especially the following:

- Assumption that surveyed licensees who did not respond to the survey are similar to those who did respond

- Assumption of what the volumes of the sources are for the PGTCC classification.

These two assumptions are discussed below. The possible uncertainties introduced are qualitatively assessed in Appendix B.

\subsubsection{Nonresponse}

Nonresponse is always a problem in conducting a survey; the reason or reasons why licensees do not respond to the survey may affect the results.

Companies that have many sources and do not track them very closely might be less likely to fill out a survey of their sources. For example, it was previously noted that some companies keep close track of their sources and are likely to be responsible in their use and disposal. For these people, the survey would be easy to complete-it would take little effort and they probably do not feel that they have anything to hide. Some companies do not track their sources very closely. If they do not have many sources, they may feel that it is not too much effort to fill out the survey. However, if they have many sources, they are less likely to respond to the survey because of the effort required. In this example, the nonrespondents would be distinctly different from the respondents in that they would have more sources, on the average.

The real reasons for not responding may not have had anything to do with the results. For example, about 15 of the nonrespondents were called two months after the surveys had been mailed. This nonrandom assessment found that roughly $90 \%$ of these licensees had not received the survey, a result of sending the survey as third-class mail. The remaining contacted nonrespondents had various reasons for not responding: forgetting or losing the survey, cynicism about surveys, and no time available to fill out the survey.

While it is currently impossible to validate the assumption that the nonrespondents are similar to the respondents, evidence indicates that the major reason for not responding is that many did not receive the survey. Assuming that whether a person received the survey or not is independent of how many sources that person controls; this would indicate that nonrespondents are similar to the respondents. 


\subsubsection{GTCC Classification}

As discussed in Section 3.1, source volumes were assigned to each principal use. These volumes are based on typical sources of the given device type. Since the Class $\mathrm{C}$ regulatory limits are given in units of activity per volume, the derived PGTCC source activity limits depend heavily upon the assumed capsule volume. However, capsule volumes may vary considerably in a given principal use, and hence a single volume may not adequately represent the available sources.

Once again, it must be emphasized that most of the PGTCC sources will not become GTCC material. An extremely conservative concentration averaging scenario is used to determine the PGTCC source activity limits - averaging only over the capsule volume. This is done to allow the greatest flexibility in projection modeling. With the understanding that most of the small activity sources will be disposed of at an LLW facility, the implication is that the actual assumed capsule volume used to compute the regulatory-derived PGTCC source activity limits is not particularly relevant as long as that volume is not significantly larger than the true capsule volumes.

Two problems may affect the results. The first is the misclassification of the device or isotope. A perusal of the results indicates that some respondents apparently misidentified the device type or isotope in their response. The databases were updated to properly classify each device into a principal use code by using the device model number. However, not all sources had model numbers associated with them and some model numbers could not be verified as to the principal use. This is discussed in detail in Section 4. Based on correspondence with NRC personnel and information contained in the Sealed Source and Device Registry, problems with misclassification of the isotope and device have been alleviated.

The second related problem is concentration averaging. Averaging activities across the volume of the device results in smaller concentrations than averaging across the volume of the encapsulated source. To avoid this problem, a source volume is used rather than a device or containment volume. The impacts of packaging volumes and concentration averaging practices are explored in other studies. ${ }^{3}$ 


\section{RESULTS}

This section presents the results of the analyses, including the compiled results of the surveys and the PGTCC determinations. The combined results are used to estimate the number of PGTCC sealed sources in the entire population of radioactive materials specific licensees.

In the following discussion, the term "viable source" is used to indicate a source that contains an isotope that may be PGTCC material (see Table 1-1) and has an activity greater than or equal to $1 \mathrm{mCi}$. A PGTCC source is a viable source that also exceeds the regulatory-derived activity limits shown in Table 3-1. The focus of this chapter is to determine which of the viable sources in the database are PGTCC sources, and then to extrapolate the number of PGTCC sources to the population of specific licensees.

\subsection{Survey Results Compilation}

Initially, the results from the two surveys were handled separately. This allowed comparison of results to determine whether any differences existed between the NRC licensees and Agreement States (AS) licensees regarding sealed sources.

\subsubsection{NRC Database}

In May 1992, EG\&G Idaho received the databases containing the results of the NRC survey. In the initial phase of the analysis, the survey results were compiled and the data were quality checked.

The NRC Sealed Source Database (SSD) contained response data from all companies licensed by the NRC to have sealed sources. Since the focus of this study is GTCC material, only a subset (70\%) of the NRC SSD survey database was used. Records excluded from the analysis represented sources that were not viable GTCC material. (A record represents one or more instances of a given source or device model held by a licensee; a licensee with multiple models is represented by multiple records in the database.)

Several assumptions were made when using the NRC SSD data to obtain the potential GTCC source counts. The original NRC SSD survey contained 16,647 records of licensee responses. The only responses used were those that represented viable sources, thus reducing the number of records to 12,096 . These included three records that had been entered with the ELEMENT field as "CS" and with the MASS_NO field left blank. For these records, the MASS_NO field was changed to 137 , thus remaining in the GTCC NRC subset database.

Internal consistency checks were performed on some of the fields in the GTCC NRC subset database for which comparisons could be made. The ACT_USE and INACTIVE fields were tallied and compared to the NUM_SOU field. Based on the NUM_SOU field, a total of 53,501 viable sources were addressed in the database. However, the tally on the ACT_USE and INACTIVE fields resulted in 53,444 viable sources. The difference in the two totals resulted from discrepancies in 10 of the total 12,096 records. These records were adjusted to resolve the discrepancy.

Similar count discrepancies were found when the number of inactive sources from the INACTIVE field was compared to the number of inactive sources based on the sum of the fields containing reasons for inactivity (NOT_NEEDED, DAMAGE, and OTHER_INAC). The total number of inactive sources from the three fields was 14,520 , compared to 14,201 from the INACTIVE field, and resulted in the editing of 85 of the total 12,096 records.

When tallying the number of inactive sources based on the plans for the inactive sources (STORED, TRANS_LIC, SENT_DISP, TRANS_MANU, PROBLEMS, and OTHER_DISP), the total of inactive sources was 14,791 . This discrepancy resulted in the editing of 155 total records. 
Finally, as discussed in Section 3.1 on GTCC determinations, the following changes were made to the GTCC subset database: (a) all records for Ra-226 were deleted since they are not considered viable, and (b) since the survey was to be completed only for sources with at least $1 \mathrm{mCi}$ activity, all records with activity values of less than $1 \mathrm{mCi}$ were deleted. Note that records were retained in the database if the activity field was left blank, since the true activity could not be determined.

\subsubsection{Agreement State Database}

The Agreement States database contained response data from the companies sampled in the Agreement States survey. The database was restricted to include only viable sources.

Of the 645 responses received, 444 had viable sources. However, in some cases, source activities were not included in the respondent's form (presumably the respondent did not know the activity or it was too much effort to determine) and were entered into the database as having an activity of zero. All of these sources were included in the database to be conservative. Those sources with activities of zero were not included in the calculation of total activity.

As with the NRC database, internal consistency checks were performed on some of the fields in the database for which comparisons could be made, as described in Section 4.1.1. In most cases, when discrepancies were found, they were easily corrected by returning to the original survey form. Nonetheless, some discrepancies still exist. The most common was to have a response that the form represents more than one source, yet the sum of the ACT_USE and INACTIVE fields was 1 or 0 (no response). In the case where the sum was 1 , it was changed to reflect the number of sources represented by the form. When the sum was 0 , no action was taken. Similar problems occurred when summing across the "Reasons For Inactivity" and "Plans For Inactive Sources" questions. These adjustments did not affect the extrapolations because the extrapolations do not depend on whether a device is actively used.

Only one survey respondent with viable sources was deleted entirely from the Agreement States database. This licensee was not able to provide information on the devices located at their site in a reasonable amount of time. Hence, the most accurate data they provided was the number of sources they possessed. More detailed data were necessary for inclusion in the database.

\subsubsection{NRC Sealed Source and Device Registry}

Validation of the NRC and Agreement States databases revealed substantial problems in the assignment of principal use codes. For example, Hewlett-Packard gas chromatographs were sometimes found listed under the fixed gauge category. The problem was serious enough to warrant using the NRC Sealed Source \& Device Registry to assign principal use codes rather than simply using the survey response.

The NRC Sealed Source and Device Registry contains descriptions of all sources and devices manufactured in the United States. Part of the Registry is available in a dBase III database format for sources and devices licensed after the late 1960 s. The database includes information on the principal use of the device or source.

Since the Registry is an authoritative source of information, it was used to better categorize the principal use codes assigned to the responses from the Agreement States and NRC surveys. Since the principal use codes in the Registry differ slightly from those in the surveys, the Registry codes were matched to the corresponding survey code.

Actually implementing these changes was a fairly laborious process involving several steps: 
1. The Agreement States and NRC survey databases were combined.

2. Two new fields were added to the database to track the device manufacturer and source/device model number.

3. Manufacturer names and model numbers were made consistent throughout.

4. Each manufacturer name and model number were assigned an NRC Registry Number, which became a unique identifier for that model.

5. The survey response database and the Registry database were then linked by the Registry Number.

6. A new code, PUCODE, was assigned to survey responses to identify the principal use of each device or source. If the model was linked to a Registry Number, PUCODE was assigned the corresponding principal use designation from the Registry; otherwise, PUCODE was assigned the survey respondent's code.

The resulting survey response database, ALLSO.DBF, was examined for responses that were repeated in both the NRC and Agreement States survey. Since some licensees hold licenses from multiple sources, there was some overlap between the surveys. Specifically, eight licensees responded to both the NRC and Agreement States surveys. Of these eight, only four had sources that contained isotopes of interest to this study. This resulted in six records accounting for 15 sources being removed from ALLSO.DBF.

\subsubsection{GTCC Determinations}

The determination of whether a source is considered PGTCC material, as discussed in Section 3.1, is based on isotope and volume assumptions assigned to each category of possible principal use of the source. The principal use of each source was identified from the PUCODE field of the database.

Records in ALLSO.DBF that did not represent a PGTCC source were deleted from the database. This left a database of 15,519 records representing 44,423 sources held by 3,427 licensees. Of these, 11,524 records represented 37,421 sources held by $2,984 \mathrm{NRC}$ licensees, and 3,995 records represented 7,002 sources held by 443 Agreement States licensees.

\subsubsection{Results}

The results are shown in Tables 4-1 to 4-7. Tables 4-1 through 4-4 extrapolate to the total population of PGTCC sealed sources. Tables 4-5 through 4-7 represent only data observed in the surveys.

The results in Table 4-1 are calculated as follows. The total number of licensees is the sum of the total number of NRC licensees $(7,373)$ and Agreement States licensees $(14,359)$, as shown in Tables 2-1 and 2-2, respectively. The number of responses for the NRC and Agreement States is the number of responses to the survey. 
Table 4-1. Summary of the number of responses.

\begin{tabular}{lccc}
\hline & NRC survey & $\begin{array}{c}\text { Agreement } \\
\text { States survey }\end{array}$ & $\begin{array}{c}\text { Extrapolated } \\
\text { total }\end{array}$ \\
\hline $\begin{array}{l}\text { Number of licensees } \\
\text { Number of responses }\end{array}$ & 7,373 & 14,359 & 21,732 \\
Number of licensees with PGTCC sources & 5,672 & 644 & 6,316 \\
Number of PGTCC sources & 2,297 & 377 & $9,201^{\mathrm{a}}$ \\
Number of PGTCC sources per licensee & 20,579 & 5,281 & $88,979^{\mathrm{a}}$ \\
Number of PGTCC sources per licensee with & 3.63 & 8.20 & $4.09^{\mathrm{a}}$ \\
PGTCC source(s) & 8.96 & 14.01 & $9.67^{\mathrm{a}}$ \\
\hline a. Total is an extrapolation to all specific licensees as described in report text, Section 4.1 .5$. & \\
\hline
\end{tabular}

Table 4-2. Number of active and inactive PGTCC sources.

\begin{tabular}{|c|c|c|c|c|c|c|}
\hline \multirow[b]{2}{*}{ Status } & \multicolumn{2}{|c|}{ NRC survey } & \multicolumn{2}{|c|}{$\begin{array}{c}\text { Agreement States } \\
\text { survey }\end{array}$} & \multicolumn{2}{|c|}{$\begin{array}{c}\text { Extrapolated } \\
\text { total }^{\mathrm{a}}\end{array}$} \\
\hline & Count & $\%$ & Count & $\%$ & Count & $\%$ \\
\hline Active & 14,860 & 72.21 & 4,170 & 78.96 & 65,478 & 73.59 \\
\hline Inactive & 5,719 & 27.79 & 1,111 & 21.04 & 23,501 & 26.41 \\
\hline Total & 20,579 & & 5,281 & & 88,979 & \\
\hline
\end{tabular}


Table 4-3. Reasons for inactivity of PGTCC sources.

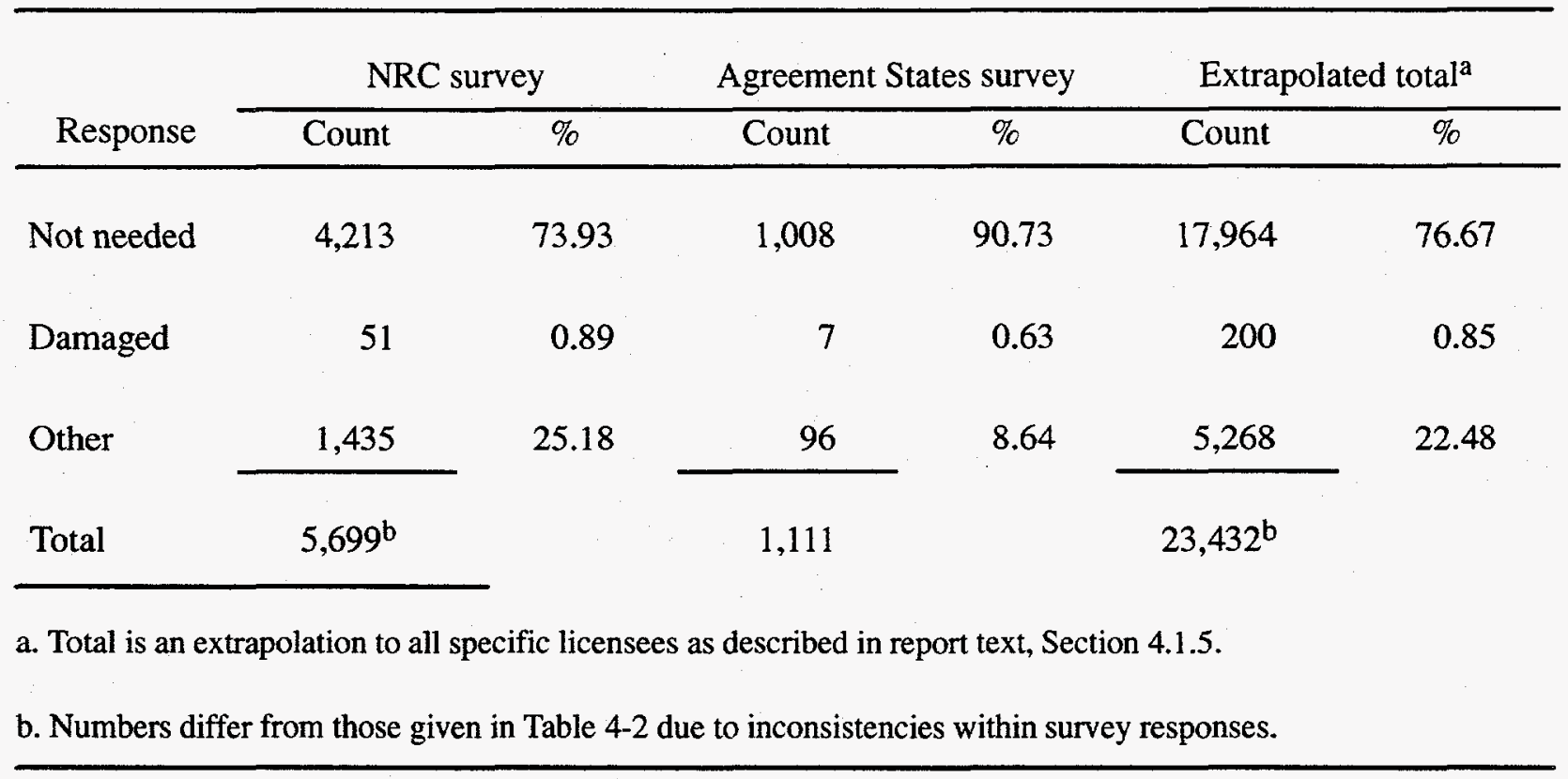

Table 4-4. Plans for disposal of inactive PGTCC sources.

\begin{tabular}{|c|c|c|c|c|c|c|}
\hline \multirow[b]{2}{*}{ Response } & \multicolumn{2}{|c|}{ NRC survey } & \multicolumn{2}{|c|}{$\begin{array}{l}\text { Agreement } \\
\text { States survey }\end{array}$} & \multicolumn{2}{|c|}{$\begin{array}{c}\text { Extrapolated } \\
\text { total }^{\mathrm{a}}\end{array}$} \\
\hline & Count & $\%$ & Count & $\%$ & Count & $\%$ \\
\hline Storage & 3,955 & 70.22 & 364 & 32.76 & 14,861 & 64.05 \\
\hline Transfer to another licensee & 72 & 1.28 & 13 & 1.17 & 292 & 1.26 \\
\hline Send for disposal & 524 & 9.30 & 161 & 14.49 & 2,357 & 10.16 \\
\hline Transfer to manufacturer & 252 & 4.47 & 7 & 0.63 & 891 & 3.84 \\
\hline Problems & 238 & 4.23 & 541 & 48.69 & 2,680 & 11.55 \\
\hline Other & 591 & 10.49 & 25 & 2.25 & 2,120 & 9.14 \\
\hline Total & $5,632^{b}$ & & 1,111 & & $23,201^{b}$ & \\
\hline a. Total is an extrapolation to a & ensees & scribed & ort text & ion 4.1 & & \\
\hline
\end{tabular}


Table 4-5. Breakdown of the number of active and inactive sources by device type observed in the surveys.

\begin{tabular}{lrrrrrr}
\hline & \multicolumn{2}{c}{ Active } & \multicolumn{2}{c}{ Inactive } & \multicolumn{2}{c}{ Total } \\
\cline { 2 - 7 } \multicolumn{1}{c}{ Device type } & \multicolumn{1}{c}{ Count } & Row \% & Count & Row \% & Count & Column \% \\
\hline & & & & & & \\
Calibration & 1,964 & 75.71 & 630 & 24.29 & 2,594 & 10.03 \\
Medical & 380 & 82.61 & 80 & 17.39 & 460 & 1.78 \\
Well logging & 1,060 & 54.92 & 870 & 45.08 & 1,930 & 7.46 \\
Portable gauge & 4,229 & 94.44 & 249 & 5.56 & 4,478 & 17.32 \\
Irradiation & 412 & 78.03 & 116 & 21.97 & 528 & 2.04 \\
Fixed gauge & 7,825 & 83.89 & 1,503 & 16.11 & 9,328 & 36.07 \\
General neutron applications & 516 & 83.77 & 100 & 16.23 & 616 & 2.38 \\
X-ray fluorescence & 226 & 69.75 & 98 & 30.25 & 324 & 1.25 \\
Other & 2,418 & 43.16 & 3,184 & 56.84 & 5,602 & 21.66 \\
\hline & & & & & & \\
Total & 19,030 & 73.59 & 6,830 & 26.41 & 25,860 & 100.00 \\
& & & & & & \\
\hline
\end{tabular}

Table 4-6. Breakdown of the number of active and inactive sources by isotope observed in the surveys.

\begin{tabular}{lrrrrrr}
\hline & \multicolumn{2}{c}{ Active } & \multicolumn{2}{c}{ Inactive } & \multicolumn{2}{c}{ Total } \\
\cline { 2 - 7 } \multicolumn{1}{c}{ Isotope } & \multicolumn{1}{c}{ Count } & Row \% & Count & Row \% & Count & Column \% \\
\hline Am-241 & & & & & & \\
C-14 & 6,906 & 82.87 & 1,428 & 17.13 & 8,334 & 32.23 \\
Cm-244 & 22 & 62.86 & 13 & 37.14 & 35 & 0.14 \\
Cs-137 & 87 & 91.58 & 8 & 8.42 & 95 & 0.37 \\
Ni-63 & 10,796 & 75.38 & 3,527 & 24.62 & 14,323 & 55.39 \\
Np-237 & 337 & 29.10 & 821 & 70.90 & 1,158 & 4.48 \\
Pu-238 & 3 & 75.00 & 1 & 25.00 & 4 & 0.02 \\
Pu-239 & 162 & 26.69 & 445 & 73.31 & 607 & 2.35 \\
Pu-241 & 208 & 49.17 & 215 & 50.83 & 423 & 1.64 \\
Sr-90 & 4 & 33.33 & 8 & 66.67 & 12 & 0.05 \\
Tc-99 & 388 & 56.23 & 302 & 43.77 & 690 & 2.67 \\
U-238 & 85 & 61.59 & 53 & 38.41 & 138 & 0.53 \\
& 32 & 78.05 & 9 & 21.95 & 41 & 0.16 \\
Total & & & & & & \\
& 19,030 & 73.59 & 6,830 & 26.41 & 25,860 & 100.00 \\
& & & & & & \\
\hline
\end{tabular}


Table 4-7. Number of PGTCC sources observed in the surveys.

\begin{tabular}{|c|c|c|c|c|c|c|c|c|c|c|c|c|c|}
\hline Device & Am-241 & C-14 & $\mathrm{Cm}-244$ & Cs-137 & $\mathrm{Ni}-63$ & Np-237 & $\mathrm{Pu}-238$ & $\mathrm{Pu}-239$ & $\mathrm{Pu}-241$ & Sr-90 & Tc-99 & $\mathrm{U}-238$ & Total \\
\hline Calibration & 872 & 7 & 10 & 997 & 33 & 3 & 12 & 80 & 5 & 560 & 5 & 10 & 2,594 \\
\hline Medical & 100 & 0 & 0 & 344 & 0 & 0 & 0 & 0 & 0 & 7 & 1 & 8 & 460 \\
\hline Well logging & 1,253 & 0 & 0 & 626 & 0 & 0 & 50 & 0 & 1 & 0 & 0 & 0 & 1,930 \\
\hline Portable gauge & 4,445 & 0 & 0 & 33 & 0 & 0 & 0 & 0 & 0 & 0 & 0 & 0 & 4,478 \\
\hline Irradiation & 45 & 0 & 0 & 480 & 0 & 0 & 0 & 0 & 0 & 3 & 0 & 0 & 528 \\
\hline Fixed gauge & 662 & 10 & 5 & 8,617 & 0 & 0 & 1 & 0 & 0 & 33 & 0 & 0 & 9,328 \\
\hline $\begin{array}{l}\text { General neutron } \\
\text { applications }\end{array}$ & 430 & 0 & 0 & 0 & 0 & 0 & 33 & 153 & 0 & 0 & 0 & 0 & 616 \\
\hline$X$-ray fluorescence & 200 & 0 & 70 & 1 & 0 & 0 & 53 & 0 & 0 & 0 & 0 & 0 & 324 \\
\hline Other & 327 & 18 & 10 & 3,225 & 1,125 & 1 & 458 & 190 & 6 & 87 & 132 & 23 & 5,602 \\
\hline Total & 8,334 & 35 & 95 & 14,323 & 1,158 & 4 & 607 & 423 & 12 & 690 & 138 & 41 & 25,860 \\
\hline
\end{tabular}


Since there were 6,316 respondents to the survey, the extrapolated totals found in Tables 4-1 through 4-4 are computed by the following steps.

1. Add the NRC and AS results to get the total from both surveys.

2. Divide the total by 6,316 (total number of responses to survey) to get the average number per licensee.

3. Multiply the average by 21,732 (total number of specific licensees) to get the total extrapolated to all specific licensees.

In equation form this can be written as

Extrapolated total $=\frac{N R C+A S}{6,316} 21,732$.

For example, from Table 4-1, there are 2,297 NRC licensees and 377 AS licensees responding to the survey that have PGTCC sources. Then the extrapolated number of licensees with PGTCC sources is

Extrapolated total $=\frac{2,297+377}{6,316} 21,732=9,201$ licensees.

The percentage columns in Tables 4-2 through 4-4 are calculated by dividing the count by the total for the column. For example, the percent of NRC PGTCC sources actively used is $(14,860 \div 20,579) \times 100 \%=$ $72.21 \%$.

Tables 4-5 and 4-6 are breakdowns of the number of active and inactive sources by device type and isotope, respectively. The row percentages are found by dividing the count by the total for the row. For example, in Table 4-5, the row percentage of active calibration sources is $(1,965 \div 2,594) \times 100 \%=75.71 \%$. The column percentages corresponding to the totals are found by dividing the count by the column total. For example, the total percentage of calibration sources is $(2,594 \div 25,860) \times 100 \%=10.03 \%$.

The breakdowns are fairly consistent between the NRC and Agreement States responses. Notable differences between the two include the following:

- From Table 4-3, about $75 \%$ of NRC inactive sources were not needed, as compared to nearly $90 \%$ in the Agreement States results

- From Table 4-4, plans for inactive sources, about 50\% of the inactive sources in the Agreement States survey were a disposal problem as opposed to only $4 \%$ in the NRC survey

- About $70 \%$ of the NRC inactive sources are in storage, with only $30 \%$ in storage in the Agreement States results.

The differences between the status of inactive sources in the two surveys can partially be explained by the full cost recovery policy of the NRC. Under the policy, the licensing costs to the licensee will potentially be higher than Agreement States licensing agencies that do not use full cost recovery. The NRC licensees are motivated to better use their sources. However, it is not clear why the Agreement State licensees are having so much more difficulty in disposing of their sources. One possible explanation is that some Agreement States do not have the resources to help the licensees find solutions to disposal problems. 
Table 4-7 summarizes the number of PGTCC sources observed in the surveys, broken down by device type and isotope. The most common device types with PGTCC sources are fixed and portable gauging devices, composing approximately $53 \%$ of the responses. The most common isotopes are Cs-137 (55\%) and Am-241 (32\%).

\subsection{Extrapolations to Total Population}

The results from Section 4.1 were used to extrapolate the total number of PGTCC sealed sources to the entire population. Although Tables 4-2 through 4-6 break the results out into active and inactive status, all the PGTCC sources will eventually become inactive. That is, the lifetime of the device is not infiniteeventually it will break or be replaced by better equipment. Hence the extrapolations do not distinguish between active and inactive sources.

\subsubsection{Extrapolated Number of PGTCC Sealed Sources Currently Available}

The results of extrapolating the data in Table 4-7 to all specific licensees and then calculating lower and upper confidence limits on the results (i.e. the low and high case scenarios) are shown in Tables 4-8 through 4-10. These tables show the extrapolated number of PGTCC sealed sources currently held by specific licensees for the low, base, and high cases, respectively.

The extrapolated number of base use PGTCC sources is calculated as follows. From the survey of 6,316 licensees, let $y_{j k}$ be the number of PGTCC sources with isotope $\mathrm{j}$ and principal use $\mathrm{k}$, as shown in Table 4-7. Then the base case extrapolated number of PGTCC sources with isotope $\mathrm{j}$ and principal use $\mathrm{k}, \hat{Y}_{j k}$, is calculated as

$\hat{Y}_{j k}=21,732 \frac{y_{j k}}{6,316}$,

where 21,732 is the total number of specific licensees. For example, from Table 4-7, there were $872 \mathrm{Am}-241$ calibration devices; so $y_{j k}=872$, where $\mathrm{j}=\mathrm{Am}-241$ and $\mathrm{k}=$ calibration, then the extrapolated number of PGTCC Am-241 calibration devices shown in Table 4-9 is

$\hat{Y}_{j k}=21,732 \frac{872}{6,316}=3,000$.

The low and high case scenarios are determined from the upper and lower limits of the $95 \%$ confidence interval on the base case estimates. The confidence interval calculations are discussed in Appendix B.

For the low case, the total extrapolated number of GTCC sealed sources is 51,000 . For the base case, it is 89,000 , and for the high case it is 128,000 . The uncertainties associated with these results are discussed in Appendix B.

\subsubsection{Extrapolated Unpackaged Volume of PGTCC Sealed Sources Currently Available}

Based on the results in Section 4.2.1 and the assumed volumes given in Section 3.1, estimates of the unpackaged volume of PGTCC sealed sources can be made for the low, base, and high cases. The volume calculations are performed by multiplying the number of PGTCC sealed sources for a device type by the assumed volume of the source for that device. The total volume is then the sum of the volumes across device types. The results are shown in Tables 4-11 through 4-13 for the low, base, and high case scenarios, respectively. 
These numbers result in unpackaged volumes of $0.5,0.93$, and $1.37 \mathrm{~m}^{3}$ for the low, base, and high cases, respectively. The largest volumes are generated by portable gauges, accounting for about $30 \%$ of the total unpackaged volumes.

\subsubsection{Extrapolated Activity of PGTCC Sealed Sources Currently Available}

The extrapolated radionuclide activities are displayed in Tables 4-14 through 4-16 for the low, base, and high case scenarios, respectively. No adjustment for decay was made. Calculations of mean activities are given in Appendix B. Source activity distributions are shown in Appendix C.

The base case activities are found by multiplying the mean activity for the given isotope and principal use combination by the corresponding base case extrapolated number of PGTCC sources. As with the low and high cases for the extrapolated number of PGTCC sources, the low and high cases for the extrapolated activity are calculated as the lower and upper limits of the $95 \%$ confidence interval on the base case activities. The calculations are described in Appendix B.

The estimated total activities for the low, base, and high cases are 1,600,000,2,300,000, and 3,000,000 $\mathrm{Ci}$, respectively. Virtually all the activity is from Cs-137 in irradiation devices. Calibration sources with Cs-137 and well logging sources with Am-241 are the most significant contributors to the remaining activity. The uncertainties associated with these results are discussed in Appendix B. 
Table 4-8. Extrapolated number of current PGTCC sources for the low case scenario. ${ }^{\text {a }}$

\begin{tabular}{|c|c|c|c|c|c|c|c|c|c|c|c|c|c|}
\hline Device type & Am-241 & C-14 & $\mathrm{Cm}-244$ & Cs- 137 & $\mathrm{Ni}-63$ & Np-237 & Pu-238 & Pu-239 & $\mathrm{Pu}-241$ & Sr-90 & Tc-99 & $\mathrm{U}-238$ & Total \\
\hline Calibration & 1,300 & 7 & 13 & 2,400 & 10 & 0 & 12 & 110 & 0 & 0 & 2 & 2 & 4,000 \\
\hline Medical & 180 & 0 & 0 & 500 & 0 & 0 & 0 & 0 & 0 & 9 & 0 & 10 & 700 \\
\hline Well logging & 1,100 & 0 & 0 & 400 & 0 & 0 & 0 & 0 & 0 & 0 & 0 & 0 & 1,500 \\
\hline Portable gauge & 12,800 & 0 & 0 & 60 & 0 & 0 & 0 & 0 & 0 & 0 & 0 & 0 & 12,800 \\
\hline Irradiation & 0 & 0 & 0 & 1,300 & 0 & 0 & 0 & 0 & 0 & 0 & 0 & 0 & 1,300 \\
\hline Fixed gauge & 1,700 & 0 & 0 & 25,000 & 0 & 0 & 0 & 0 & 0 & 60 & 0 & 0 & 27,000 \\
\hline $\begin{array}{l}\text { General neutron } \\
\text { applications }\end{array}$ & 1,000 & 0 & 0 & 0 & 0 & 0 & 40 & 330 & 0 & 0 & 0 & 0 & 1,400 \\
\hline $\mathrm{X}$-ray fluorescence & 410 & 0 & 50 & 0 & 0 & 0 & 30 & 0 & 0 & 0 & 0 & 0 & 500 \\
\hline Other & 790 & 26 & 10 & 1,000 & 10 & 0 & 0 & 370 & 1 & 160 & 0 & 40 & 2,000 \\
\hline Total & 19,200 & 30 & 70 & 30,000 & 20 & 0 & 80 & 810 & 1 & 200 & 2 & 50 & 51,000 \\
\hline
\end{tabular}


Table 4-9. Extrapolated number of current PGTCC sources for the base case scenario. ${ }^{\text {a }}$

\begin{tabular}{|c|c|c|c|c|c|c|c|c|c|c|c|c|c|}
\hline Device type & Am-241 & $\mathrm{C}-14$ & $\mathrm{Cm}-244$ & Cs-137 & Ni-63 & Np-237 & $\mathrm{Pu}-238$ & $\mathrm{Pu}-239$ & $\mathrm{Pu}-241$ & Sr-90 & Tc-99 & $\mathrm{U}-238$ & Total \\
\hline Calibration & 3,000 & 24 & 34 & 3,400 & 110 & 10 & 41 & 280 & 17 & 1,900 & 17 & 34 & 8,900 \\
\hline Medical & 340 & 0 & 0 & 1,200 & 0 & 0 & 0 & 0 & 0 & 24 & 3 & 28 & 1,600 \\
\hline Well logging & 4,300 & 0 & 0 & 2,200 & 0 & 0 & 170 & 0 & 3 & 0 & 0 & 0 & 6,600 \\
\hline Portable gauge & 15,300 & 0 & 0 & 110 & 0 & 0 & 0 & 0 & 0 & 0 & 0 & 0 & 15,400 \\
\hline Irradiation & 160 & 0 & 0 & 1,700 & 0 & 0 & 0 & 0 & 0 & 10 & 0 & 0 & 1,800 \\
\hline Fixed gauge & 2,300 & 30 & 17 & 30,000 & 0 & 0 & 3 & 0 & 0 & 110 & 0 & 0 & 32,000 \\
\hline $\begin{array}{l}\text { General neutron } \\
\text { applications }\end{array}$ & 1,500 & 0 & 0 & 0 & 0 & 0 & 110 & 530 & 0 & 0 & 0 & 0 & 2,100 \\
\hline $\mathrm{X}$-ray fluorescence & 690 & 0 & 240 & 3 & 0 & 0 & 180 & 0 & 0 & 0 & 0 & 0 & 1,110 \\
\hline Other & 1,130 & 62 & 34 & 11,000 & 3,900 & 3 & 1,600 & 650 & 21 & 300 & 500 & 80 & 19,000 \\
\hline Total & 28,700 & 120 & 330 & 49,000 & 4,000 & 13 & 2,100 & 1,460 & 41 & 2,400 & 500 & 140 & 89,000 \\
\hline
\end{tabular}


Table 4-10. Extrapolated number of current PGTCC sources for the high case scenario. ${ }^{a}$

\begin{tabular}{|c|c|c|c|c|c|c|c|c|c|c|c|c|c|}
\hline Device type & Am-241 & C-14 & $\mathrm{Cm}-244$ & Cs- 137 & $\mathrm{Ni}-63$ & Np-237 & $\mathrm{Pu}-238$ & Pu-239 & $\mathrm{Pu}-241$ & Sr-90 & Tc-99 & $\mathrm{U}-238$ & Total \\
\hline Calibration & 4,700 & 41 & 56 & 4,400 & 220 & 27 & 70 & 440 & 46 & 4,100 & 32 & 67 & 14,200 \\
\hline Medical & 510 & 0 & 0 & 1,900 & 0 & 0 & 0 & 0 & 0 & 39 & 9 & 45 & 2,500 \\
\hline Well logging & 7,500 & 0 & 0 & 3,900 & 0 & 0 & 460 & 0 & 9 & 0 & 0 & 0 & 11,900 \\
\hline Portable gauge & 17,800 & 0 & 0 & 170 & 0 & 0 & 0 & 0 & 0 & 0 & 0 & 0 & 18,000 \\
\hline Irradiation & 310 & 0 & 0 & 2,100 & 0 & 0 & 0 & 0 & 0 & 20 & 0 & 0 & 2,400 \\
\hline Fixed gauge & 2,900 & 90 & 34 & 34,000 & 0 & 0 & 9 & 0 & 0 & 160 & 0 & 0 & 38,000 \\
\hline $\begin{array}{l}\text { General neutron } \\
\text { applications }\end{array}$ & 1,900 & 0 & 0 & 0 & 0 & 0 & 190 & 720 & 0 & 0 & 0 & 0 & 2,800 \\
\hline $\mathrm{X}$-ray fluorescence & 960 & 0 & 430 & 9 & 0 & 0 & 330 & 0 & 0 & 0 & 0 & 0 & 1,740 \\
\hline Other & 1,470 & 98 & 59 & 21,000 & 7,700 & 9 & 3,700 & 940 & 40 & 440 & 1,100 & 120 & 37,000 \\
\hline Total & 38,100 & 230 & 580 & 68,000 & 7,900 & 36 & 4,800 & 2,100 & 96 & 4,800 & 1,100 & 230 & 128,000 \\
\hline
\end{tabular}


Table 4-11. Extrapolated unpackaged volume $\left(\mathrm{cm}^{3}\right)$ of current PGTCC sources for the low case scenario. ${ }^{\mathrm{a}}$

\begin{tabular}{|c|c|c|c|c|c|c|c|c|c|c|c|c|c|}
\hline Device type & Am-241 & $C-14$ & $\mathrm{Cm}-244$ & Cs-137 & $\mathrm{Ni}-63$ & Np-237 & $\mathrm{Pu}-238$ & $\mathrm{Pu}-239$ & Pu-241 & Sr-90 & Tc-99 & $\mathrm{U}-238$ & Total \\
\hline Calibration & 2,600 & 14 & 30 & 4,900 & 20 & 0 & 20 & 210 & 0 & 0 & 4 & 4 & 8,000 \\
\hline Medical & 3,600 & 0 & 0 & 10,000 & 0 & 0 & 0 & 0 & 0 & 180 & 0 & 200 & 14,000 \\
\hline Well logging & 30,000 & 0 & 0 & 10,000 & 0 & 0 & 0 & 0 & 0 & 0 & 0 & 0 & 40,000 \\
\hline Portable gauge & 260,000 & 0 & 0 & 1,100 & 0 & 0 & 0 & 0 & 0 & 0 & 0 & 0 & 260,000 \\
\hline Irradiation & 0 & 0 & 0 & 50,000 & 0 & 0 & 0 & 0 & 0 & 0 & 0 & 0 & 50,000 \\
\hline Fixed gauge & 5,000 & 0 & 0 & 75,000 & 0 & 0 & 0 & 0 & 0 & 190 & 0 & 0 & 80,000 \\
\hline $\begin{array}{l}\text { General neutron } \\
\text { applications }\end{array}$ & 21,000 & 0 & 0 & 0 & 0 & 0 & 700 & 6,600 & 0 & 0 & 0 & 0 & 28,000 \\
\hline $\mathrm{X}$-ray fluorescence & 210 & 0 & 30 & 0 & 0 & 0 & 20 & 0 & 0 & 0 & 0 & 0 & 250 \\
\hline Other & 7,900 & 260 & 100 & 8,000 & 100 & 0 & 0 & 3,700 & 10 & 1,600 & 0 & 400 & 20,000 \\
\hline Total & 320,000 & 270 & 150 & 160,000 & 200 & 0 & 800 & 10,600 & 10 & 2,000 & 4 & 600 & 500,000 \\
\hline
\end{tabular}


Table 4-12. Extrapolated unpackaged volume $\left(\mathrm{cm}^{3}\right)$ of current PGTCC sources for the base case scenario. ${ }^{\mathrm{a}}$

\begin{tabular}{|c|c|c|c|c|c|c|c|c|c|c|c|c|c|}
\hline Device type & Am-241 & C-14 & $\mathrm{Cm}-244$ & Cs-137 & $\mathrm{Ni}-63$ & Np-237 & $\mathrm{Pu}-238$ & Pu-239 & $\mathrm{Pu}-241$ & Sr-90 & Tc-99 & U-238 & Total \\
\hline Calibration & 6,000 & 48 & 70 & 6,900 & 230 & 20 & 80 & 550 & 30 & 4,000 & 34 & 70 & 18,000 \\
\hline Medical & 6,900 & 0 & 0 & 24,000 & 0 & 0 & 0 & 0 & 0 & 480 & 60 & 560 & 32,000 \\
\hline Well logging & 110,000 & 0 & 0 & 50,000 & 0 & 0 & 4,000 & 0 & 80 & 0 & 0 & 0 & 170,000 \\
\hline Portable gauge & 310,000 & 0 & 0 & 2,300 & 0 & 0 & 0 & 0 & 0 & 0 & 0 & 0 & 310,000 \\
\hline Irradiation & 6,000 & 0 & 0 & 66,000 & 0 & 0 & 0 & 0 & 0 & 400 & 0 & 0 & 73,000 \\
\hline Fixed gauge & 6,800 & 100 & 50 & 89,000 & 0 & 0 & 9 & 0 & 0 & 340 & 0 & 0 & 96,000 \\
\hline $\begin{array}{l}\text { General neutron } \\
\text { applications }\end{array}$ & 30,000 & 0 & 0 & 0 & 0 & 0 & 2,300 & 10,500 & 0 & 0 & 0 & 0 & 42,000 \\
\hline $\mathrm{X}$-ray fluorescence & 340 & 0 & 120 & 2 & 0 & 0 & 90 & 0 & 0 & 0 & 0 & 0 & 560 \\
\hline Other & 11,300 & 620 & 340 & 110,000 & 39,000 & 30 & 16,000 & 6,500 & 210 & 3,000 & 5,000 & 800 & 190,000 \\
\hline Total & 480,000 & 770 & 580 & 350,000 & 39,000 & 50 & 23,000 & 17,600 & 300 & 8,000 & 5,000 & 1,400 & 930,000 \\
\hline
\end{tabular}

a. Individual values are rounded to the number of significant digits consistent with the standard error of the estimated number. Hence, summing across rows or columns will not produce the same values given in the "Total" column or row. 
onTable 4-13. Extrapolated unpackaged volume $\left(\mathrm{cm}^{3}\right)$ of current PGTCC sources for the high case scenario.a

\begin{tabular}{|c|c|c|c|c|c|c|c|c|c|c|c|c|c|}
\hline Device type & Am-241 & C-14 & $\mathrm{Cm}-244$ & Cs-137 & $\mathrm{Ni}-63$ & Np-237 & $\mathrm{Pu}-238$ & Pu-239 & $\mathrm{Pu}-241$ & Sr-90 & Tc-99 & $\mathrm{U}-238$ & Total \\
\hline Calibration & 9,400 & 82 & 110 & 8,900 & 430 & 54 & 140 & 890 & 90 & 8,000 & 64 & 130 & 28,000 \\
\hline Medical & 10,200 & 0 & 0 & 38,000 & 0 & 0 & 0 & 0 & 0 & 780 & 180 & 900 & 50,000 \\
\hline Well logging & 190,000 & 0 & 0 & 100,000 & 0 & 0 & 11,000 & 0 & 230 & 0 & 0 & 0 & 300,000 \\
\hline Portable gauge & 360,000 & 0 & 0 & 3,400 & 0 & 0 & 0 & 0 & 0 & 0 & 0 & 0 & 360,000 \\
\hline Irradiation & 12,000 & 0 & 0 & 82,000 & 0 & 0 & 0 & 0 & 0 & 800 & 0 & 0 & 95,000 \\
\hline Fixed gauge & 8,700 & 270 & 100 & 103,000 & 0 & 0 & 27 & 0 & 0 & 490 & 0 & 0 & 113,000 \\
\hline $\begin{array}{l}\text { General neutron } \\
\text { applications }\end{array}$ & 38,000 & 0 & 0 & 0 & 0 & 0 & 3,800 & 14,400 & 0 & 0 & 0 & 0 & 57,000 \\
\hline $\mathrm{X}$-ray fluorescence & 480 & 0 & 220 & 5 & 0 & 0 & 170 & 0 & 0 & 0 & 0 & 0 & 870 \\
\hline Other & 14,700 & 980 & 590 & 210,000 & 77,000 & 90 & 37,000 & 9,400 & 400 & 4,400 & 11,000 & 1,200 & 370,000 \\
\hline Total & 640,000 & 1,340 & 1,020 & 550,000 & 78,000 & 140 & 53,000 & 24,700 & 720 & 15,000 & 11,000 & 2,200 & $1,370,000$ \\
\hline
\end{tabular}

a. Individual values are rounded to the number of significant digits consistent with the standard error of the estimated number. Hence, summing across rows or columns will not produce the same values given in the "Total" column or row. 
Table 4-14. Extrapolated activity (Ci) of current PGTCC sources for the low case scenario (not adjusted for decay). ${ }^{\mathrm{a}}$

\begin{tabular}{|c|c|c|c|c|c|c|c|c|c|c|c|c|c|}
\hline Device type & Am-241 & C-14 & $\mathrm{Cm}-244$ & Cs-137 & $\mathrm{Ni}-63$ & Np-237 & $\mathrm{Pu}-238$ & $\mathrm{Pu}-239$ & $\mathrm{Pu}-241$ & Sr-90 & Tc-99 & U-238 & Total \\
\hline Calibration & 600 & $<1$ & $<1$ & 50,000 & $<1$ & 0 & 6 & $<1$ & 0 & 0 & $<1$ & $<1$ & 50,000 \\
\hline Medical & 5 & 0 & 0 & 300 & 0 & 0 & 0 & 0 & 0 & 1 & 0 & $<1$ & 300 \\
\hline Well logging & 8,000 & 0 & 0 & 600 & 0 & 0 & 0 & 0 & 0 & 0 & 0 & 0 & 9,000 \\
\hline Portable gauge & 570 & 0 & 0 & 15 & 0 & 0 & 0 & 0 & 0 & 0 & 0 & 0 & 590 \\
\hline Irradiation & 0 & 0 & 0 & $1,500,000$ & 0 & 0 & 0 & 0 & 0 & 0 & 0 & 0 & $1,500,000$ \\
\hline Fixed gauge & 1,400 & 0 & 0 & 8,400 & 0 & 0 & 0 & 0 & 0 & 8 & 0 & 0 & 9,800 \\
\hline $\begin{array}{l}\text { General neutron } \\
\text { applications }\end{array}$ & 300 & 0 & 0 & 0 & 0 & 0 & 400 & 540 & 0 & 0 & 0 & 0 & 1,200 \\
\hline X-ray fluorescence & 28 & 0 & 4 & 0 & 0 & 0 & 1 & 0 & 0 & 0 & 0 & 0 & 33 \\
\hline Other & 290 & $<1$ & $<1$ & 200 & $<1$ & 0 & 0 & 600 & $<1$ & $<1$ & 0 & $<1$ & 1,000 \\
\hline Total & 11,000 & $<1$ & 4 & $1,500,000$ & $<1$ & 0 & 400 & 1,000 & $<1$ & 9 & $<1$ & $<1$ & $1,600,000$ \\
\hline
\end{tabular}


Table 4-15. Extrapolated activity (Ci) of current PGTCC sources for the base case scenario (not adjusted for decay). ${ }^{\mathrm{a}}$

\begin{tabular}{|c|c|c|c|c|c|c|c|c|c|c|c|c|c|}
\hline Device type & Am-241 & C-14 & $\mathrm{Cm}-244$ & Cs-137 & $\mathrm{Ni}-63$ & Np-237 & $\mathrm{Pu}-238$ & $\mathrm{Pu}-239$ & $\mathrm{Pu}-241$ & $\mathrm{Sr}-90$ & Tc-99 & U-238 & Total \\
\hline Calibration & 1,600 & $<1$ & 3 & 120,000 & 4 & $<1$ & 20 & 7,000 & $<1$ & 330 & $<1$ & $<1$ & 120,000 \\
\hline Medical & 10 & 0 & 0 & 800 & 0 & 0 & 0 & 0 & 0 & 5 & 3 & 6 & 900 \\
\hline Well logging & 33,000 & 0 & 0 & 3,100 & 0 & 0 & 1,800 & 0 & 130 & 0 & 0 & 0 & 38,000 \\
\hline Portable gauge & 690 & 0 & 0 & 40 & 0 & 0 & 0 & 0 & 0 & 0 & 0 & 0 & 730 \\
\hline Irradiation & 100 & 0 & 0 & $2,100,000$ & 0 & 0 & 0 & 0 & 0 & 60 & 0 & 0 & $2,100,000$ \\
\hline Fixed gauge & 2,100 & $<1$ & $<1$ & 10,100 & 0 & 0 & 2 & 0 & 0 & 25 & 0 & 0 & 12,200 \\
\hline $\begin{array}{l}\text { General neutron } \\
\text { applications }\end{array}$ & 800 & 0 & 0 & 0 & 0 & 0 & 1,600 & 920 & 0 & 0 & 0 & 0 & 3,400 \\
\hline $\mathrm{X}$-ray fluorescence & 61 & 0 & 22 & $<1$ & 0 & 0 & 8 & 0 & 0 & 0 & 0 & 0 & 91 \\
\hline Other & 620 & 1 & 5 & 2,600 & 60 & $<1$ & 8,000 & 1,100 & 34 & 400 & 1,200 & 5 & 14,000 \\
\hline Total & 39,000 & 1 & 30 & $2,200,000$ & 60 & $<1$ & 11,000 & 9,000 & 160 & 800 & 1,200 & 11 & $2,300,000$ \\
\hline
\end{tabular}


Table 4-16. Extrapolated activity (Ci) of current PGTCC sources for the high case scenario (not adjusted for decay). ${ }^{\mathrm{a}}$

\begin{tabular}{|c|c|c|c|c|c|c|c|c|c|c|c|c|c|}
\hline Device type & Am-241 & C-14 & $\mathrm{Cm}-244$ & Cs-137 & $\mathrm{Ni}-63$ & Np-237 & $\mathrm{Pu}-238$ & Pu-239 & $\mathrm{Pu}-241$ & Sr-90 & Tc-99 & U-238 & Total \\
\hline Calibration & 2,600 & 1 & 7 & 180,000 & 8 & $<1$ & 34 & 16,000 & $<1$ & 700 & $<1$ & $<1$ & 200,000 \\
\hline Medical & 16 & 0 & 0 & 1,300 & 0 & 0 & 0 & 0 & 0 & 9 & 9 & 16 & 1,400 \\
\hline Well logging & 58,000 & 0 & 0 & 5,600 & 0 & 0 & 4,800 & 0 & 380 & 0 & 0 & 0 & 69,000 \\
\hline Portable gauge & 810 & 0 & 0 & 65 & 0 & 0 & 0 & 0 & 0 & 0 & 0 & 0 & 870 \\
\hline Irradiation & 210 & 0 & 0 & $2,600,000$ & 0 & 0 & 0 & 0 & 0 & 170 & 0 & 0 & $2,600,000$ \\
\hline Fixed gauge & 2,900 & $<1$ & 1 & 11,700 & 0 & 0 & 4 & 0 & 0 & 41 & 0 & 0 & 14,600 \\
\hline $\begin{array}{l}\text { General neutron } \\
\text { applications }\end{array}$ & 1,400 & 0 & 0 & 0 & 0 & 0 & 2,900 & 1,300 & 0 & 0 & 0 & 0 & 5,600 \\
\hline $\mathrm{X}$-ray fluorescence & 94 & 0 & 40 & $<1$ & 0 & 0 & 15 & 0 & 0 & 0 & 0 & 0 & 149 \\
\hline Other & 950 & 3 & 13 & 4,900 & 120 & $<1$ & 18,000 & 1,700 & 67 & 900 & 2,700 & 12 & 29,000 \\
\hline Total & 67,000 & 4 & 61 & $2,900,000$ & 130 & $<1$ & 26,000 & 19,000 & 440 & 1,800 & 2,700 & 28 & $3,000,000$ \\
\hline
\end{tabular}




\section{DISCUSSION}

In this Volume, the number, volume, and activity of PGTCC sources currently held by specific licensees are estimated. Planning for storage and disposal of PGTCC sources must also be based on material held by general licensees and future production rates. Future production of sealed sources and sources held by general licensees are discussed in Volumes 2 and 3, respectively.

Because of uncertainty in establishing what will constitute a GTCC source in the future, this document uses a conservative approach by just concentration averaging over the capsule volume. In fact, many, if not most, of the PGTCC sources are unlikely to need storage or disposal at a GTCC LLW facility.

To show the effect of concentration averaging in establishing the true number of GTCC sources, Appendix D applies the NRC's 1989 definition of a GTCC source to determine how many PGTCC sources would become GTCC material. Additionally, that Appendix compares the results with the 1989 NRC survey results. Using the NRC definition of a GTCC source (which allows concentration averaging over a 55-gal drum), only about one-third, or 28,000 , of the 89,000 PGTCC sources are GTCC material.

Recently, the NRC released a draft technical position on concentration averaging that is slightly less restrictive than the method used in their 1989 report. In the 1989 report, for example, alpha-emitting TRU sources up to $27 \mathrm{mCi}$ could be disposed of at an LLW facility; the NRC technical position allows up to 50 mCi alpha-emitting TRU sources to be disposed of at a LLW facility. This could have significant consequences to $\mathrm{DOE}$ in that the $50 \mathrm{mCi}$ limit eliminates the approximately 15,000 portable gauge sources, which use $40 \mathrm{mCi} \mathrm{Am-241} \mathrm{sources,} \mathrm{from} \mathrm{GTCC} \mathrm{disposal} \mathrm{consideration.}$

The estimated number and activity of PGTCC sources estimated in this report are based on a large amount of generally good quality data. The unpackaged volume estimates are expected to be of only reasonable quality. This is because the assumed source volumes were based on limited information.

The volumes were selected to be representative of the sources in a given principal use. Initially, the volumes were used to establish reasonable PGTCC source activity limits. As discussed in Section 3.2.2, if the assumed volumes are not significantly larger than the true source capsule volumes, the assumed volume selection is somewhat irrelevant for establishing PGTCC activity limits, and hence determining numbers and activities of PGTCC sources.

However, selection of assumed source volumes is a critical factor in accurately estimating unpackaged volumes of PGTCC sources. Since the licensee typically will not know the source volume (and is not licensed to remove the source from a device to measure it), the survey did not ask for this information. Furthermore, it would be virtually impossible to assign source volumes to each source observed in the survey.

As such, the use of assumed source volumes that are representative of the true volumes within a given principal use code was implemented. In turn, these should provide representative estimates for the base case unpackaged volumes; the low and high cases should adequately span the volumes that can be reasonably

expected. If, however, estimates with a high degree of precision (say less than a cubic meter for the total volume) are needed for planning of storage facilities, then the unpackaged volume estimates given here should be used with caution. Under this situation, it would be better to consider alternative methods of volume estimation. 


\section{CONCLUSIONS}

This report presents the results of a comprehensive survey and analysis of PGTCC sealed sources handled by specific licensees. The numerical results for the number of PGTCC sealed sources, their volume, and their activity are summarized in Table 6-1. The most likely scenario shows that there are 89,000 PGTCC sealed sources having a total unpackaged volume of $0.93 \mathrm{~m}^{3}$ and a total activity of 2,300,000 $\mathrm{Ci}$. These values include both general and specific licensed sources, but only those held by specific licensees.

The majority of these sources are in fixed and portable gauges, with well logging devices also accounting for a significant portion of the total volume. Cs-137 is the most frequently encountered isotope, accounting for over half of the total number of PGTCC sealed sources and most of the activity.

The PGTCC values presented in Section 4 of this report represent estimates that can be used as a foundation on which to apply any assumptions regarding packaging or concentration averaging. The possible impact of packaging volumes and concentration averaging practices are explored in the projection models described in DOE/LLW-114 Revision 1.3 These models apply packaging factors and concentration averaging to estimate the number of GTCC LLW sources that DOE will need to dispose of safely.

Comparison of this report's results to the 1989 NRC report indicates general agreement when the 1989 NRC assumptions are applied to these data. However, there is some disagreement on activities of isotopes, the breakdown of sources in storage or needing imminent disposal or transfer, and the relative numbers of irradiation sources and x-ray fluorescence sources. This comparison is shown in Appendix D.

Finally, this report represents what the sealed source situation was in 1992. In this report, all sources were considered waste; in fact, only a portion of the sources may become waste during a given year. The report does not address what sources will be manufactured in the future. These data are currently being studied in separate efforts.

Table 6-1. Estimated number, volume, and activity of 1992 PGTCC sealed sources (activity not adjusted for decay).

\begin{tabular}{lccc}
\hline \multicolumn{1}{c}{ Scenario } & Number & $\begin{array}{c}\text { Unpackaged } \\
\text { volume } \\
\left(\mathrm{m}^{3}\right)\end{array}$ & $\begin{array}{c}\text { Activity } \\
(\mathrm{Ci})\end{array}$ \\
\hline Low case & 51,000 & 0.50 & $1,600,000$ \\
Base case & 89,000 & 0.93 & $2,300,000$ \\
High case & 128,000 & 1.37 & $3,000,000$ \\
\hline
\end{tabular}




\section{REFERENCES}

1. R. A. Hulse, Greater-Than-Class C Low-Level Radioactive Waste Characterization: Estimated Volumes, Radionuclide Activities, and Other Characteristics, DOE/LLW-114, National Low-Level Waste Management Program, EG\&G Idaho, Inc., August 1991.

2. Above Class C Source/Device Inventory Survey, U.S. Nuclear Regulatory Commission, 1989.

3. Greater-Than-Class C Low-Level Radioactive Waste Characterization: Estimated Volumes, Radionuclide Activities, and Other Characteristics, DOE/LLW-114 Revision 1, Greater-Than-Class C LowLevel Radioactive Waste Management Program, EG\&G Idaho, Inc., September 1994.

4. Amersham Corporation, Radiation Sources for Industrial Gauging and Analytical Instrumentation, Amersham Corporation, Arlingtion Heights, IL, (no date given).

5. U.S. Nuclear Regulatory Commission, "Partial Response to Staff Requirements-Briefing on DOE Acceptance of Greater than Class C Waste," Commission Paper SECY-89-169, March 15, 1989. 
Appendix A

Agreement State Sampling Design

A-1 
A-2 


\section{Appendix A}

\section{Agreement State Sampling Design}

\section{INTRODUCTION}

This Engineering Design File discusses the assessment of sample size for the Greater-Than-Class C Low Level Radioactive Waste (GTCC LLW) Sealed Source survey. It is essentially broken into two parts. The first part discusses the 1989 U. S. Nuclear Regulatory Commission (NRC) sealed source survey. The results of this survey are then used in the second part to motivate the calculation of sample size for our survey.

A primary purpose of our survey is to assess the quantity and activity of sealed sources that will need to be disposed. However, the NRC sealed source survey database does not include volume information. Therefore the strategy taken was to determine the total number of GTCC sealed sources that are no longer actively used by licensees. Throughout this document, the term "licensees" will refer to "specific licensees". General licensees are not considered.

\section{NRC Sealed Source Survey}

In 1989, the NRC administered a survey to both NRC licensees and Agreement State licensees. This survey was used to better define the scope of the problem of surplus sources. The following is a summary of the methods and findings of that survey as reported in the NRC report "Above Class C Source/Device Inventory Survey" by Steven Baggett and Thomas Rich. The data used in the NRC report is a subset of the data used for this current report in that some states were not included in the NRC analysis.

Purpose. The NRC has become concerned about the disposal and transfer of radioactive material that is classified as GTCC. The NRC does not currently have jurisdiction over the disposal of this material, but licenses organizations that have a need to dispose of such material. A survey was conducted to a) better define the scope of the problem of surplus sources, and b) obtain data on numbers of GTCC sources that licensees currently possess, and the numbers which are in excess of their needs.

Survey Design. The NRC surveyed licensees who were renewing their licenses. The survey was administered by NRC Regional personnel to NRC licensees. Agreement State licensees were also surveyed. The NRC sent the survey to Agreement State licensing personnel and requested them to send the questionnaire to applicable licensees in their states.
While the survey was not administered in a random fashion, the results are expected to still result in a representative sample of all licensees. However, the Agreement States used various methods of surveying their licensees, not always random.

Summary of NRC Findings. Based on a sample of 2,202 licensees, the NRC made the following conclusions about GTCC sealed sources.

1. There are 4,928 licensees having GTCC sources.

2. There are $27,156 \mathrm{GTCC}$ sources or devices.

3. There will be $1,784 \mathrm{GTCC}$ sources that will need to be disposed of or transferred and 2,645 in storage.

4. The volume of the GTCC sources needing to be disposed will range between 1,076 to $1,595 \mathrm{~cm}^{3}$.

1989 Survey Form. The 1989 survey form has two parts. The first part asks for general information about the licensee's sealed sources, including the number of GTCC sources and disposal methods. The second part asks for specific information about each source or device that is GTCC. A copy of the survey is included in Attachment 1.

\section{Compacts}

For some of the analyses in this report, the results are broken down by LLW Regional Compacts. As a result of the Low-Level Radioactive Waste Policy Act, states were motivated to form regional groupings, called compacts, for controlling the disposal of LLW material within the compact. The classification of states into compacts is based on the status in 1985 . Some states have been reclassified since then.

There are 10 compacts. Table A-1 shows the states belonging to each compact. Note that Ohio, Delaware, and Maryland are members of more than one compact. To avoid duplication in the analyses in this report, Ohio licensees were tabulated in the Appalachian Compact, Delaware licensees in the Northeast Compact, and Maryland licensees in the Northeast Compact.

There are 7 states that are unaffiliated with any compact. These states were grouped together for the analyses as Independents. 
Table A-1. Breakdown of the states by their membership in LLW Regional Compacts.

\begin{tabular}{ll}
\multicolumn{1}{c}{ Compact Name } & \multicolumn{1}{c}{ States } \\
\hline Appalachian & DE, MD, OH, PA, WV \\
Central & AR, KS, LA, NE, OK \\
Central Midwest & IL, KY \\
Dakotas & ND, SD \\
Midwest & IA, IN, MI, MN, MO, OH, WI \\
Northeast & CT, DE, MD, NJ \\
Northwest & AK, HI, ID, MT, OR, UT, WA \\
Rocky Mountain & CO, NM, NV, WY \\
Southeast & AL, FL, GA, MS, NC, SC, TN, \\
& VA \\
Western & AZ, CA \\
Independent $^{\mathrm{a}}$ & MA, ME, NH, NY, RI, TX, VT \\
& \\
\hline
\end{tabular}

a. These states are unaffiliated with any compact.

\section{ANALYSIS OF NRC SEALED SOURCE SURVEY DATA}

In July 1991, EG\&G Idaho, Inc. received a database from the NRC that included all the survey responses from the 1989 survey. This data is used to assess the data quality and quantity requirements for the currently proposed survey. In this section, a description of the database and the results of the descriptive analyses are given.

\section{NRC Database}

The NRC database contained responses from 1,692 licensees with 8,584GTCC sources or devices. Apparently, only survey respondents that had GTCC sources or devices are included in the database.

Database Structure. The database is broken into two dBase IV files. The first file, GTCCVEN.DBF, includes demographic information about the licensee and their method for disposing of sources. Table A-2 shows the field names and descriptions for this file.

The second file, GTCCGAGE.DBF, is linked to the first file by license number. This database contains specific information about each GTCC source or device, including isotope and whether the source or device is still in use. Table A-3 shows the field names and descriptions for this file.

There is a third database that the NRC included on the disc. This database, MODEL.DBF, is just a table of all
GTCC sources or devices identified by manufacturer and model number. This database was not used for this report.

Differences Between the 1989 NRC Database and the Current Database. The major difference between the database used in the NRC report and the database used in this analysis is the addition of the results from a number of Agreement States. In 1989, the database contained 1,332 licensees who had 7,340 GTCC sources or devices. The current database has 1,692 licensees with 8,584 GTCC sources or devices.

Also, the current database had a number of typographical errors that were corrected when possible. The number of errors was fairly small and should not seriously impact the results of this analysis.

Finally, since the current database includes licensees who had GTCC sources or devices, we do not have information on the total number of survey respondents that the NRC had when they wrote their report. This makes it difficult to project results to the population, if not impossible. However, projection of results to the population is not a major objective of this report.

\section{Descriptive Statistics}

Initially, the NRC database was analyzed for descriptive statistics. These are used to examine the gross structure to the data. The focus of these analyses is on the status of the device (active vs. inactive) and if inactive, what the licensee intends to do with the device. Also the activity levels of the sources are considered.

Status of Sources/Devices. Of the 8,584 GTCC sources in the database, $1,390(16 \%)$ are no longer actively used on a routine basis. Of these sources, $790(57 \%)$ are surplus, $502(36 \%)$ are going to be transferred or disposed, $11(0.8 \%)$ are damaged, $11(0.8 \%)$ are damaged and are going to be transferred or disposed, $4(0.3 \%)$ are lost, and $72(5 \%)$ have other plans for inactive sources. These results are depicted in Figure A-1.

Table A-4 shows the number of sources that are active and inactive by the type of source (e.g. well logging device, portable gauge). Note that while the portable gauges make up the majority of the GTCC devices, it is the well logging devices that are most commonly inactive and need to be disposed or transferred.

Table A-5 shows the number of active and inactive sources by region. The region is based on LLW compacts. Most of the GTCC sources identified in the survey are in independent states (not a member of a compact). These independent states also have the largest number of inactive devices and devices needing to be disposed or transferred. The Dakotas have the largest proportion of inactive devices and the largest proportion of devices needing to be disposed or transferred. 
Table A-2. Description of the contents of the GTCCVEN.DBF database. See also the survey form in Attachment 1.

Field Name

LICENSE

LICNAME

CONNAME

TITLE

DEPT

STREET

CITY

STATE

ZIP

PHONE

EXT

MANUFACT

TRANSFEROR

NODISP

OTHER

DISMEMO

AUTHUSE

DIFF

ADDCOMM

\section{Field Description}

License number

Name on license

Name of contact person

Title of contact person

Department of contact person

Street address of licensee or contact person

City address of licensee or contact person

State address of licensee or contact person

$Z$ ip code of licensee or contact person

Phone number of contact person

Phone number extension of contact person

Does licensee give source to manufacturer for disposal?

Does licensee transfer the source to another licensee for disposal?

Licensee has not had to dispose of sources

Does licensee use another method for disposal?

Description of other disposal methods

Can licensee find an authorized recipient to handle devices that are no longer needed?

Are there any difficulties in using this authorized recipient?

Additional comments.

Table A-3. Description of the contents of the GTCCGAGE.DBF database. See also the survey form in Attachment 1.

Field Name

LICENSE

MANNAME

MODEL

DSTYPE

ISOTOPE

ACT

UNIT

TYPUSE

ACTIVE

INACTIVE

COMMENTS
Field Description

License number

Name of source or device manufacturer

NRC approved model number of the source or device

Specifies whether the model is a device or source

Source isotope

Source activity

Units associated with source activity

Type of use of the source (e.g. well logging, irradiator)

Is the source currently used on a routine basis?

Status of inactive sources (i.e. sources not currently used routinely)

Comments/explanations 
Source Activities. The activities of the sources ranged from $0.04 \mathrm{mCi}$ in an $\mathrm{Am} 241$ source to $60,000 \mathrm{Ci}$ in a Cs 137 source. The overall average activity is $35,280 \mathrm{Ci}$ with standard deviation 350,200 . The median is $50 \mathrm{Ci}$. This large standard deviation relative to the mean is caused by skewness in the data. Specifically, there are some extremely large source activities relative to the average source activity.

The distribution of the activities are plotted by isotope in Figure A-2. This Figure is a boxplot. The boxes enclose $50 \%$ of the activities for the isotope, bounded by the 25 th and 75 th percentiles. The line inside the box is the median activity. Individually plotted points represent outliers. The horizontal width of the box is proportional to the number of sources with that isotope.

Figure A-2 shows that the Cs137 sources have the highest activities. The most common source isotope is Am241.
The distribution of activities by type of device are shown in Figure A-3. The irradiation devices have the highest activities, though the median activity of a well logging device and waste broker are comparable to that of irradiation devices. The teletherapy devices have the largest median activity, but there are only 4 of these devices identified from the survey.

Disposal Methods. The licensees were asked a series of questions relating to their disposal practices. The results are shown in Table A-6.

The preferred method for disposing of sources is to return them to the manufacturer. However, $42 \%$ of the licensees do not attempt to dispose of some sources. Only $5 \%$ of the licensees have difficulty finding a recipient of excess sources. $4 \%$ have difficulties using their authorized recipients.

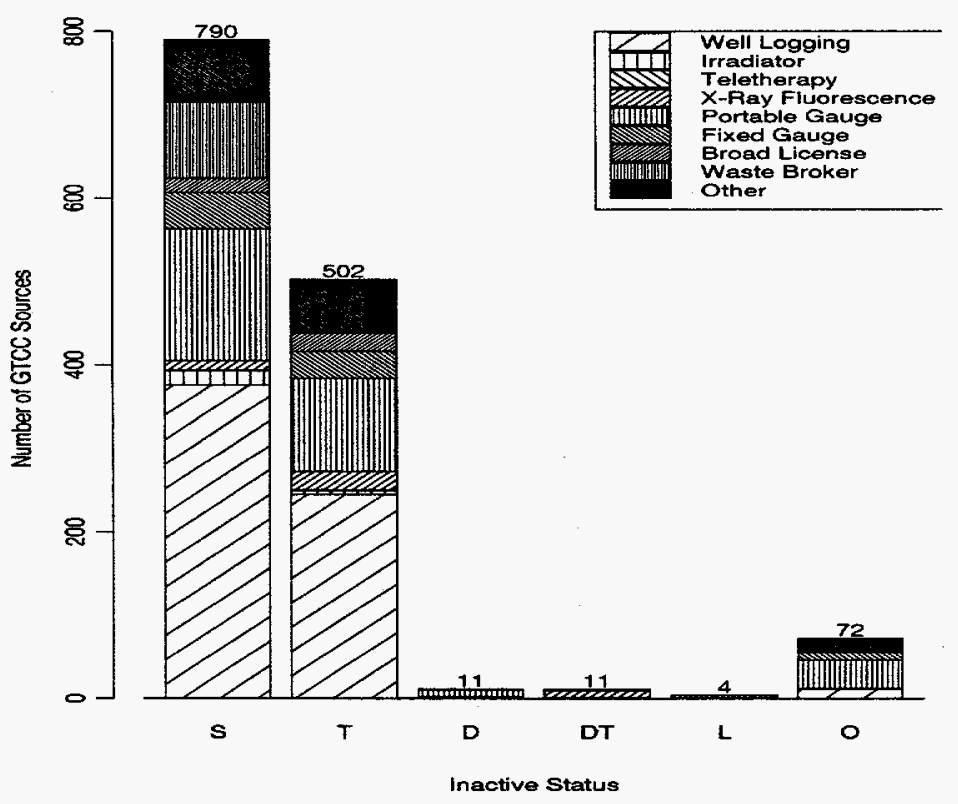

Figure A-1. Plot of number of GTCC sources included in the survey classified by inactivity status and type of device. Inactivity status: $S=$ Surplus, $T=$ Needs to transfer or dispose, $\mathrm{D}=$ Damaged, $\mathrm{DT}=$ Damaged and wants to transfer or dispose, $\mathrm{L}=\mathrm{Lost}$, and $\mathrm{O}=$ Other. 
Table A-4. Breakdown of the GTCC sources by operational status and source/device type. Source/Device type codes: $\mathrm{WL}=$ Well Logging, $\mathrm{IR}=\mathrm{Irradiator}, \mathrm{TL}=$ Teletherapy, $\mathrm{XR}=\mathrm{X}$-Ray Fluorescence, $\mathrm{PG}=$ Portable Gauge, $\mathrm{FG}=$ Fixed Gauge, $\mathrm{BL}=\mathrm{Broad}$ License, $\mathrm{PM}=$ Pacemaker, $\mathrm{WB}=$ Waste $\mathrm{Broker}$, and $\mathrm{OT}=$ Other. Inactive status codes: $\mathrm{S}=$ Surplus, $\mathrm{T}=$ Wants to dispose or transfer, $\mathrm{D}=$ Damaged, $\mathrm{DT}=$ Damaged and wants to dispose or transfer, $\mathrm{L}=\mathrm{Lost}$, and $\mathrm{O}=\mathrm{Other}$.

Source/Device Type

\begin{tabular}{|c|c|c|c|c|c|c|c|c|c|c|c|}
\hline \multirow{2}{*}{$\begin{array}{l}\text { Operational } \\
\text { Status }\end{array}$} & & & & & & & & & & & \multirow[b]{2}{*}{ Total } \\
\hline & WL & IR & TL & $\mathbf{X R}$ & PG & FG & BL & $\mathbf{P M}$ & WB & OT & \\
\hline Active & 1,179 & 132 & 2 & 100 & 4,559 & 544 & 98 & 29 & 0 & 551 & 7,194 \\
\hline Inactive & 635 & 22 & 2 & 42 & 315 & 88 & 41 & 0 & 92 & 153 & 1,390 \\
\hline $\bar{S}$ & 376 & 17 & 1 & 11 & 158 & 44 & 17 & 0 & 92 & 74 & 790 \\
\hline $\mathbf{T}$ & 245 & 4 & 1 & 22 & 112 & 32 & 22 & 0 & 0 & 64 & 502 \\
\hline D & 2 & 0 & 0 & 0 & 8 & 1 & 0 & 0 & 0 & 0 & 11 \\
\hline DT & 0 & 1 & 0 & 8 & 0 & 2 & 0 & 0 & 0 & 0 & 11 \\
\hline $\mathbf{L}$ & 1 & 0 & 0 & 0 & 3 & 0 & 0 & 0 & 0 & 0 & 4 \\
\hline $\mathbf{o}$ & 11 & 0 & 0 & 1 & 34 & 9 & 2 & 0 & 0 & 15 & 72 \\
\hline Total & 1,814 & 154 & 4 & 142 & 4,874 & 632 & 139 & 29 & 92 & 704 & 8,584 \\
\hline
\end{tabular}

Table A-5. Breakdown of the GTCC sources by operational status within each LLW regional compact. LLW regional compact codes: $\mathrm{AP}=$ Appalachian, $\mathrm{CE}=$ Central, $\mathrm{CM}=$ Central Midwest, $\mathrm{DK}=$ Dakota, $\mathrm{IN}=$ Independent, $\mathrm{MW}=\mathrm{Mid}-$ west, $\mathrm{NE}=$ Northeast, $\mathrm{NW}=$ Northwest, $\mathrm{RM}=$ Rocky Mountain, $\mathrm{SE}=$ Southeast, $\mathrm{WE}=$ West. Inactive status codes: $\mathrm{S}=$ Surplus, $\mathrm{T}=$ Wants to dispose or transfer, $\mathrm{D}=$ Damaged, $\mathrm{DT}=$ Damaged and wants to dispose or transfer, $\mathrm{L}=$ Lost, and $\mathrm{O}=\mathrm{O}$ ther.

LLW Regional Compact

\begin{tabular}{|c|c|c|c|c|c|c|c|c|c|c|c|}
\hline \multirow{2}{*}{$\begin{array}{l}\text { Operational } \\
\text { Status }\end{array}$} & \\
\hline & $\mathbf{A P}$ & $\mathbf{C E}$ & $\mathbf{C M}$ & DK & $\mathbf{I N}$ & MW & NE & NW & $\mathbf{R M}$ & SE & WE \\
\hline Active & 226 & 287 & 520 & 52 & 2,683 & 335 & 110 & 641 & 373 & 1,747 & 220 \\
\hline Inactive & 35 & 17 & 68 & 23 & 877 & 20 & 25 & 55 & 58 & 189 & 23 \\
\hline$\overline{\mathbf{S}}$ & 15 & 7 & 39 & 4 & 557 & 4 & 11 & 28 & 18 & 97 & 10 \\
\hline $\mathbf{T}$ & 8 & 10 & 21 & 17 & 299 & 11 & 12 & 25 & 31 & 60 & 8 \\
\hline D & 0 & 0 & 0 & 1 & 2 & 0 & 0 & 0 & 1 & 4 & 3 \\
\hline DT & 2 & 0 & 0 & 0 & 8 & 0 & 1 & 0 & 0 & 0 & 0 \\
\hline $\mathbf{L}$ & 0 & 0 & 0 & 1 & 2 & 0 & 0 & 0 & 0 & 1 & 0 \\
\hline o & 10 & 0 & 8 & 0 & 9 & 5 & 1 & 2 & 8 & 27 & 2 \\
\hline \# of Sources & 261 & 304 & 588 & 75 & 3,560 & 355 & 135 & 696 & 431 & 1,936 & 243 \\
\hline
\end{tabular}




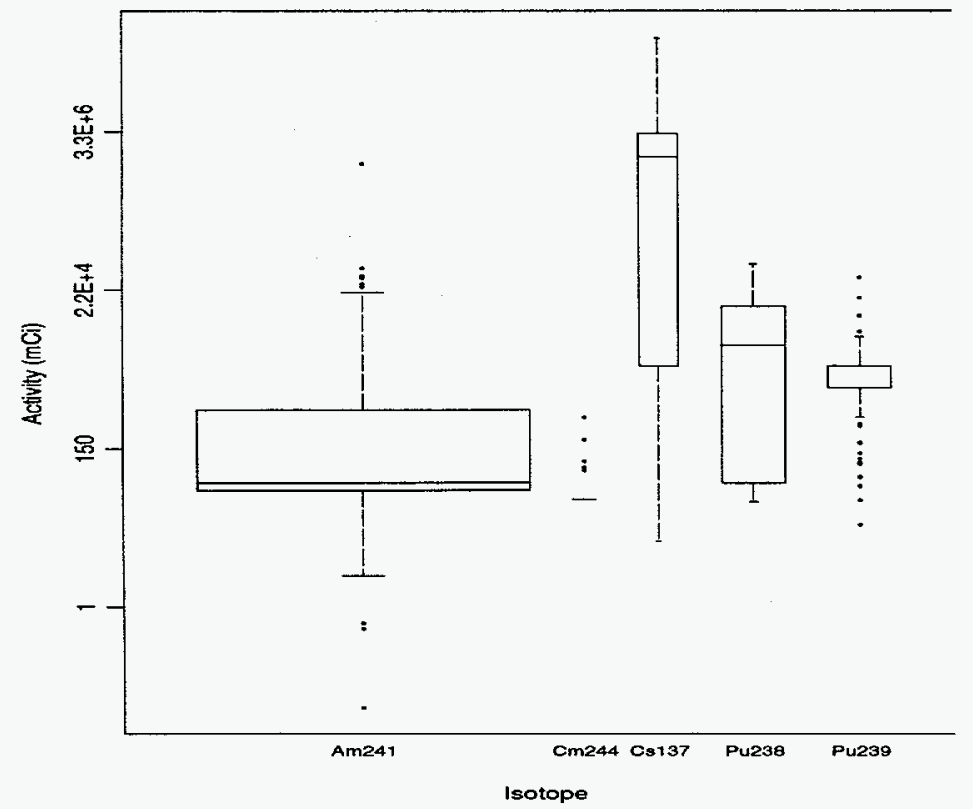

Figure A-2. Boxplots showing distribution of activity by isotope. See text for explanation. Width of box is proportional to the number of devices containing the isotope.

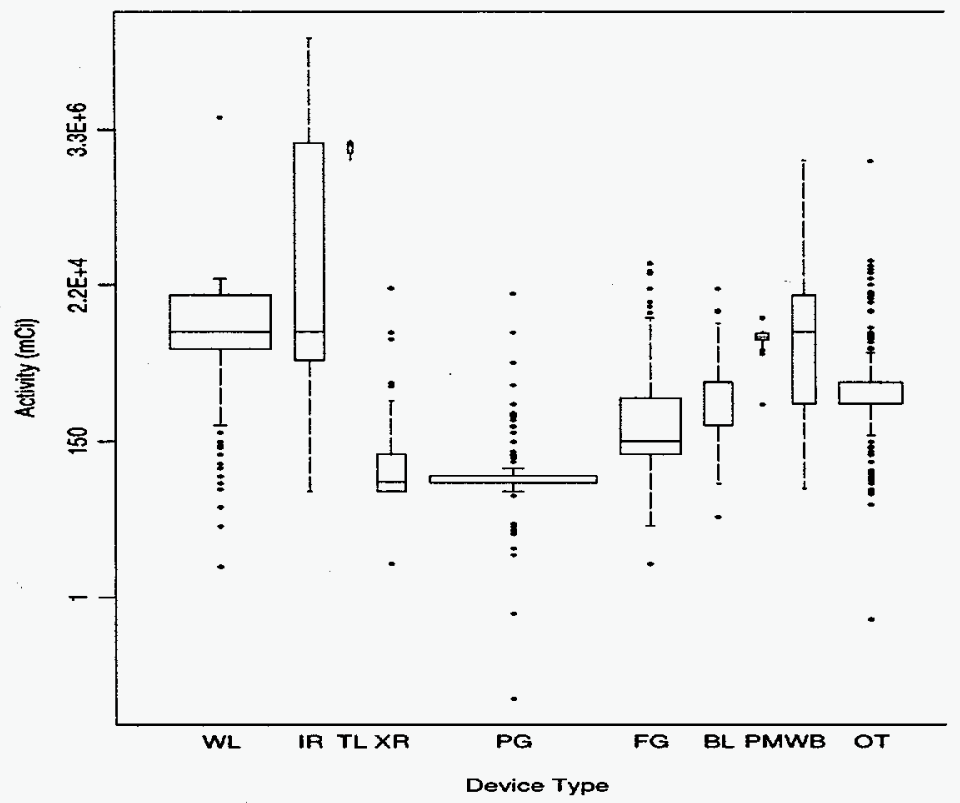

Figure A-3. Boxplots showing distribution of activity by source type. See text for explanation. Width of box is proportional to the number of devices of the given type. 
Table A-6. Summary of responses to disposal questions, based on a sample of 1,692 licensees who have GTCC sources.

\begin{tabular}{l|cc}
\multicolumn{1}{c|}{ Question } & Yes (\%) & No (\%) \\
\hline Do you dispose of sources through the manufacturer? & 48.8 & 51.2 \\
Do you dispose of sources by transferring to another licensee? & 12.0 & 88.0 \\
Do you not dispose of sources? & 42.4 & 57.6 \\
Do you dispose of sources by other means? & 6.6 & 93.4 \\
Are you able to find an authorized recipient to handle sources you no longer want? & 94.7 & 5.3 \\
Are there any difficulties in using this authorized recipient? & 4.1 & 95.9 \\
\hline
\end{tabular}

\section{SAMPLE SIZE ESTIMATION}

The calculation of sample size was made to meet a given level of precision. The sample size calculations are rather involved and are discussed in Attachment 2. The sample sizes were computed for a simple random sample, and for samples stratified on LLW compact and device type.

The simple random sample involves selecting the given sample size from all Agreement State licensees. The stratified sample must be broken down so that a specified number of samples is randomly selected from each compact.

Precision expresses the degree of closeness of the estimated mean to the true mean. The relative precision is given as the percent difference from the true mean that the estimated mean can be at $95 \%$ confidence. For example, if the true proportion of inactive GTCC sources is 0.15 , then a $5 \%$ relative precision would mean that one can be $95 \%$ confident that the estimated proportion will fall between 0.1425 and 0.1575 since $5 \%$ of 0.15 is 0.0075 .

\section{Results}

The calculated sample sizes for a simple random sample and the stratified samples are plotted against relative precision in Figure A-4. Table A-7 shows a subset of these calculations.

As can be seen from Figure A-4, the gain in precision by stratifying on compact is not great, but is fairly significant for stratification by device type. Stratifying by compact increases the precision by only about $2.5 \%$ for a given sample size, as compared to a simple random sample.

The results also show that increasing the required relative precision from 15 to $10 \%$ more than doubles the required sample size, and increasing the required relative precision from 10 to $5 \%$ more than triples the required sample size.
Table A-7. Subset of the sample size calculations displayed in Figure A-4.

\begin{tabular}{cccc}
\hline $\begin{array}{c}\text { Relative } \\
\text { Precision } \\
(\%)\end{array}$ & SRS & $\begin{array}{c}\text { Stratified } \\
\text { Device } \\
\text { Type }\end{array}$ & $\begin{array}{c}\text { Stratified } \\
\text { Compact }\end{array}$ \\
\hline 5 & 7,029 & 5,645 & 6,643 \\
10 & 2,369 & 1,833 & 2,227 \\
15 & 1,125 & 862 & 1,056 \\
20 & 649 & 495 & 609 \\
25 & 420 & 320 & 394 \\
\hline
\end{tabular}

\section{DISCUSSION}

The sample size results indicate that stratification by device type would significantly improve the precision. However, the Agreement State licensee lists do not all include enough information to stratify the licensees by the type of devices they use. In fact some states may not even have this information readily available due to a lack of current database technology in some Agreement State licensing agencies. Therefore, the cost savings in sending out fewer surveys stratified by device type may be offset by the increased cost of implementing the stratification.

The stratification by compact would result in only a minimal increase in precision, if any. Therefore, it may be easiest to implement a simple random sample. This method could be supplanted by a check to ensure that the selected sample will be representative or cover the population.

Through discussions with the Low Level Waste Program personnel, it has been decided that a simple random sample of the agreement states will meet their needs It has been agreed that a $15 \%$ relative precision is sufficient, so 1,125 surveys will be sent. A $20 \%$ relative precision will be acceptable, so 649 responses must be received. 


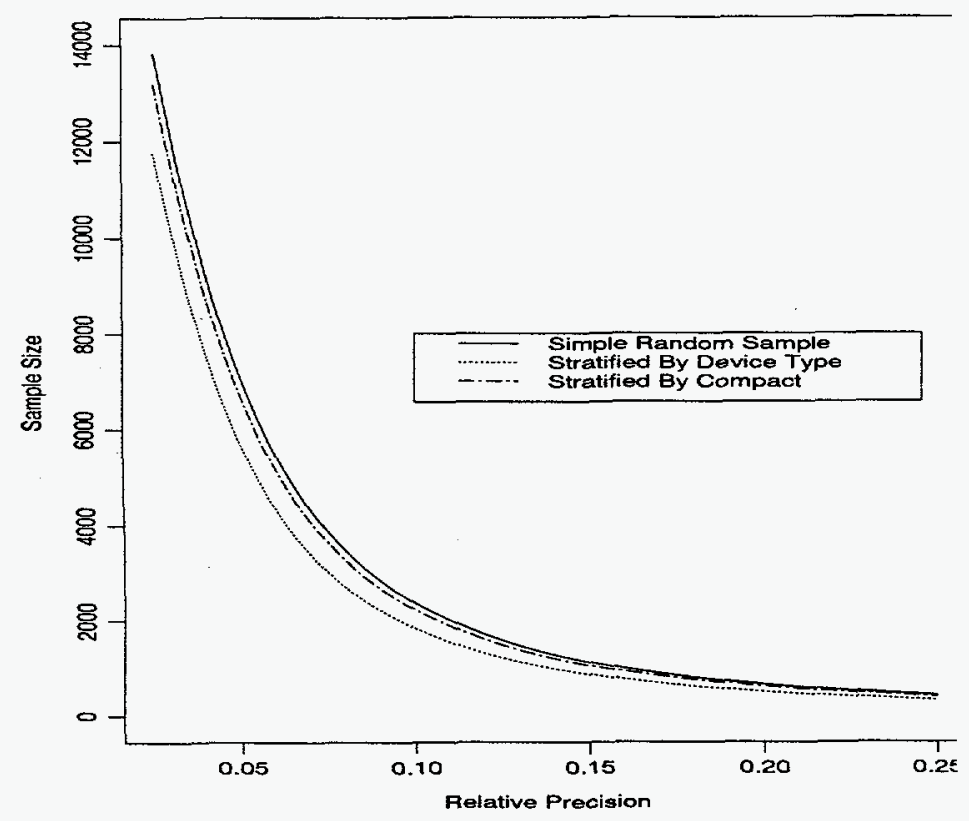

Figure A-4. Plot of expected precision in estimating the proportion of GTCC sources that are no longer actively used for a given sample size. The sample sizes refer to the number of licensees needing to be surveyed. The stratified sample is stratified by LLW Regional Compact. 
Attachment 1

1989 NRC Sealed Source

Survey Form 


$$
\text { A-12 }
$$




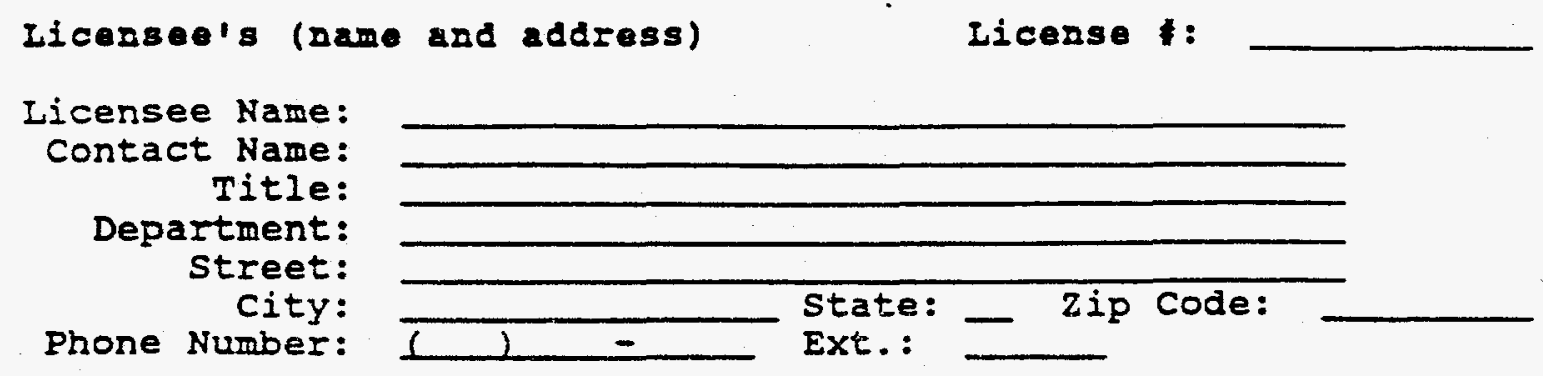

Provide accurate and complete responses to each question below:

1) How many sealed sources and/or devices do you have that are above Class $C$ (i.e. Am-241>27 mCi, Pu-238 or $-239>27 \mathrm{mCi}$, $\mathrm{Cm}-244>27 \mathrm{mCi}, \mathrm{Cs}-137>910 \mathrm{Ci}$, or any other transuranic > 27 mCi with a half-life greater than five years)? Identify each source or device on the attached inventory sheet.

2) How do you dispose of your sources and/or devices? (check appropriate box)

Manufacturer:

Transfer to another licensee:

Other:

If other, please elaborate:

3)a. Are you able to find and use an authorized recipient to purchase, dispose, or store any sources and/or devices that you no longer want? (check one) Yes No If no, please elaborate:

b. Are there any diffculties in using this authorized recipient? (check one) Yes No If yes, please elaborate:

4) Additional comments - check here and use back of this sheet.

Surveyor:

Date:

Note: Activity levels described in question 1 were derived from limits established in $10 \mathrm{CFR} 61$ section 61.55. The levels were based on typical size sources. 


\section{BURVEYOR'S INFORYATION SEEET}

License * This number must be placed on all survey sheets. The license number will be used as the unique identifier for computer tracking purposes.

Manufacturer - This will denote the vendor of the source or device (source housing), i.e. Ohmart, kay-Ray, Amersham, Gulf Nuclear, DOE, etc.

Hodel - The vendor's NRC approved model number for the source or source and device combination. Care should be exercised not to include system numbers.

Type - Denotes if the model is a source by placing a "S" in the box or a device by placing a "D" in the box.

Active - only check this box if the source or device is used on a routine basis by the licensee and not considered inactive as defined below.

Inactive - If the source or device is not used on a routine basis by the licensee, the codes on the survey sheet are to be used to indicate the status of the source.

The codes are self explanatory. However, for the purposes of this paper the following codes are defined.

Damaged - This code denotes that the source or device has been damaged in any way. This also includes any leaking sources. If you use this code then provide a brief explanation of the damage. You may also need to bring this to the attention of your supervisor to determine the need for follow-up action.

Surplus - Those sources or devices that are being held as a spare for later use by the licensee.

Iogistics - Please print legibly.

- Make a copy of the survey sheet, retain a copy for the license file and forward the original to our office for analysis.

- Thank you for your cooperation. 
License \#:

ABOVE CLASS C SOURCE/DEVICE INVENTORY SHEET

\begin{tabular}{|c|c|c|c|c|c|c|c|}
\hline Manufacturer & Modol * & 1sotope & $\mid \begin{array}{c}\text { Activity } \\
\text { mGI_or CA }\end{array}$ & Use & Active & Inactive & Explanation \\
\hline & & & & & & & \\
\hline & & & & & & & \\
\hline & & & & & & & \\
\hline & & & & & & & \\
\hline & & & & & & & \\
\hline & & & & & & & \\
\hline & & & & & & & \\
\hline & & & & & & & \\
\hline & & & & & & & \\
\hline & & & & & & & \\
\hline & & & & & & & \\
\hline & & & & & & & \\
\hline & & & & & & & \\
\hline & & & & & & & \\
\hline
\end{tabular}

NOTE: List each source/device separately. If inactive or use ls other, please explain.

CODES:

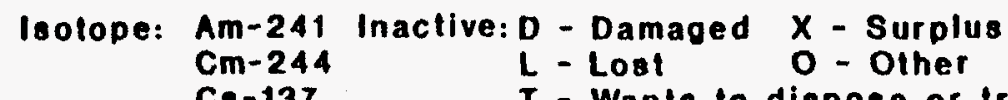

Uae: A - Well logoing

Cm-244

Cs -137

B - Irradiator

F - Fixed gauges

Pu-238

DT - Damaged and wants to

C - Teletherapy

G - Broad licenses

Pu-239 diapose or transfer

D - X-ray fluoreacenco 1 - Wate broker

E-Portable gauges O-Other 


\section{. \\ (}

A- 16 
Attachment 2

Sample Size Estimation 
A-1 8 


\section{PURPOSE}

This attachment discusses the calculations made to assess the required number of licensee surveys for the GTCC sealed source survey. The ultimate goal of this survey will be to determine the total volume of GTCC sealed sources currently held by specific licensees that will need to be disposed.

The unit sampled is the licensee. The population of interest is composed of those GTCC sealed sources that are no longer actively used. The approach taken is to estimate the number of GTCC sealed sources that must be included in the survey to get a particle level of precision in estimating the number of GTCC sealed sources that are inactive. The overall strategy of the sample size calculations is shown in Figure A-5.

\section{METHOD OVERVIEW}

The data from the initial NRC sealed source survey did not include information about GTCC sealed source volumes. Therefore, for lack of information on expected average and variance of volumes, the design of the current survey can not be based on estimating the total volume of material needing to be disposed.

An alternative method is to estimate the number of GTCC sealed sources that need to be disposed. The implication is that the total number of sealed sources that need to be disposed is strongly related to the total volume needing to be disposed.

However, the surveys are sent to licensees who typically have multiple sources. Therefore, determining the number of licensees to survey to ensure that enough sealed sources are included in the sample involves assessing the average number of GTCC sealed sources per licensee.

To help optimize the sampling, a number of stratifications were considered. A stratified sample differs from a simple random sample in that the population of interest is divided into distinct subpopulations, and random sampling is performed on each subpopulation. The stratified sample results in better precision of estimates over the simple random sample, for a fixed sample size. The degree of improvement depends on the homogeneity of the units within each stratum and the heterogeneity of the strata. The more homogeneity within the strata and heterogeneity between the strata, the better the improvement in precision for stratified sampling as opposed to a simple random sample.

The stratification criteria considered were by device type (e.g. well logging device, portable gauge) and by LEW regional compact.
The device type stratification was initially considered because it was thought that this would be the best grouping for sealed source volumes. That is, like devices will have approximately the same volume of radionuclide. Of course, for certain devices, the source volumes will vary considerably.

The LLW regional compact stratification was considered since it was thought that it may indicate the ease with which a licensee could transfer a sealed source. That is, a licensee in a compact that is well organized may be more able to find a user for a surplus or excess source; whereas a licensee in a less well organized compact may have difficulty finding another licensee to transfer a source to.

\section{CALCULATIONS}

The results discussed in the body of this report form the input to the calculations of sample size. These calculations are now discussed and presented for each step identified in Figure A-5. First, we give the equations that form the basis of the sample size calculations.

\section{Sample Size Equations}

The following equations were used to determine sample size. They are taken from Cochran (1977).

Simple Random Sample. The sample size for a simple random sample, $\mathrm{n}_{\mathrm{srs}}$, is determined by

$n_{s r s}=\frac{n_{0}}{1+\frac{\left(n_{0}-1\right)}{N}}$

where $\mathrm{N}$ is the total number of units in the population and

$$
n_{0}=\frac{t^{2}(1-p)}{p r^{2}}
$$

where $t$ is the normal deviate for the given confidence level, $r$ is the required relative precision, and $p$ is the expected population proportion.

Stratified Sample. The sample size for a stratified random sample, $\mathrm{n}_{\mathrm{st}}$, is given by

$$
n_{s t}=\frac{n_{1}}{1+\frac{1}{N} \sum_{h} W_{h} p_{h}\left(1-p_{h}\right)}
$$

where $\mathrm{p}_{\mathrm{h}}$ is the expected proportion in stratum $\mathrm{h}, \mathrm{W}_{\mathrm{h}}$ is the proportion of the population belonging to strata $h$,

$$
n_{1}=\frac{\left(\sum_{h} W_{h} \sqrt{p_{h}\left(1-p_{h}\right)}\right)^{2}}{V}
$$

and

$$
V=\left(\frac{p r}{t}\right)^{2},
$$

where $\mathrm{p}, \mathrm{r}, \mathrm{t}$ are as before. 
Simple Random Sample

Estimate proportion of GTCC sealed sources that are inactive

\section{Stratified Sample}

Estimate proportion of GTCC sealed sources that are inactive in each stratum. Estimate the proportion of GTCC sealed sources in each stratum.

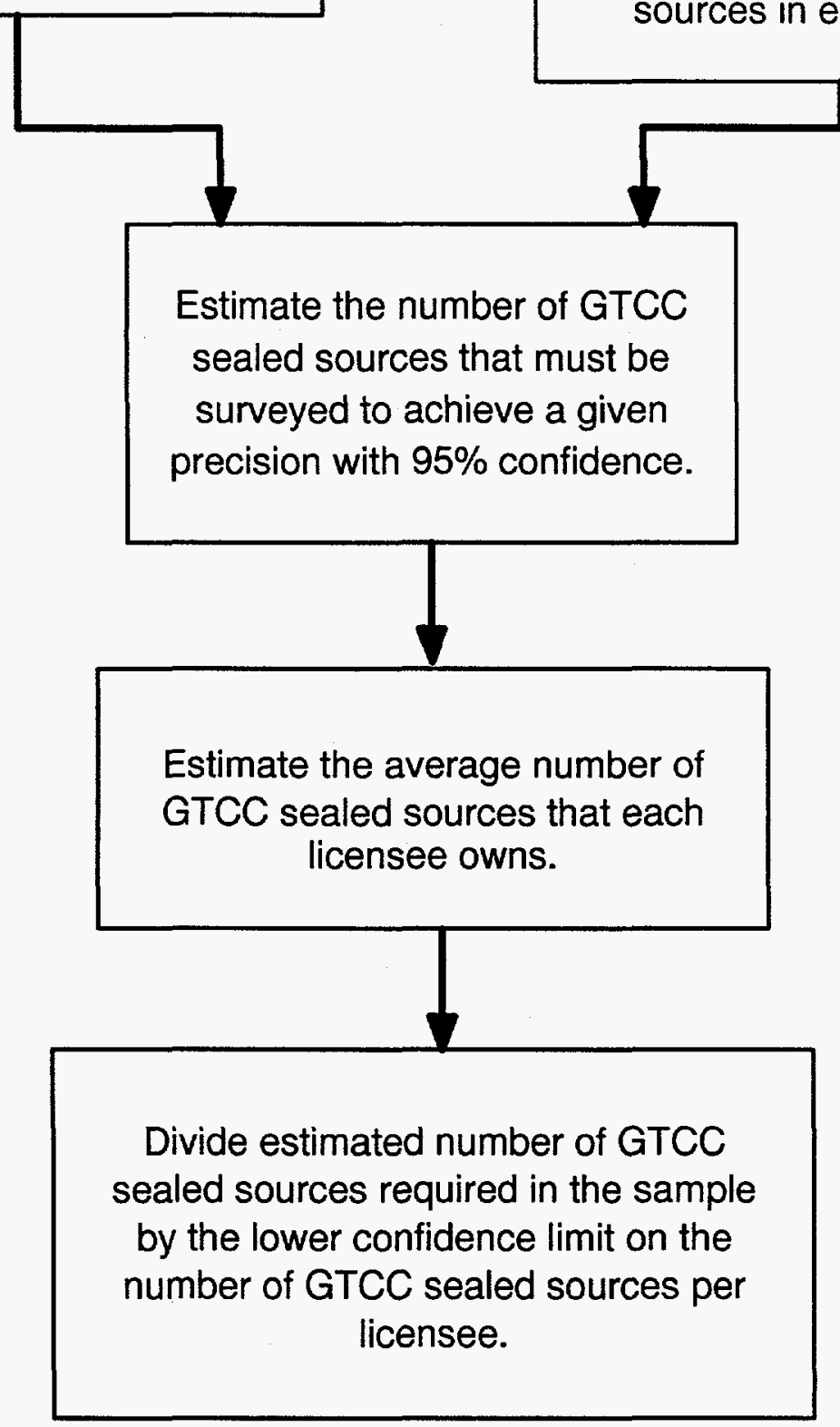

Figure A-5. Summary of the steps involved in estimating the required sample size. 


\section{Proportion of Inactive GTCC Sealed Sources}

Initially we need estimates of the proportion of GTCC sealed sources that are inactive. This value corresponds to $\mathrm{p}$ in Equation (A-1) and $\mathrm{ph}$ in Equation (A-2).

Simple Random Sample. From the NRC sealed source survey database, of the 8,584 GTCC sealed sources in the database, 1,390 were classified as inactive. This corresponds to an overall proportion of 0.162 .

Stratified Random Sample. The estimates of the strata proportions are derived from the NRC sealed source survey database.

Stratification By Device Type. From Table A-4 of this report, the proportions of inactive GTCC sealed sources in each device type are shown in Table A-8.

Table A-8. Proportion of inactive GTCC sealed sources by device type.

\begin{tabular}{c|ccccc}
\hline Type & WL & IR & TL & XR & PG \\
\hline Ph & 0.3501 & 0.1429 & 0.5000 & 0.2958 & 0.0646 \\
Type & FG & BL & PM & WB & OT \\
\hline ph & 0.1392 & 0.2950 & 0.0000 & 1.0000 & 0.2173 \\
\hline
\end{tabular}

The values of $W_{h}$ for each device type are shown in Table A-9, and are based on the results from the NRC sealed source database.

Table A-9. Proportion of the total GTCC sealed sources that belong to each device type.

\begin{tabular}{c|ccccc}
\hline Type & WL & IR & TL & XR & PG \\
\hline $\mathbf{W}_{\mathbf{h}}$ & 0.2113 & 0.0179 & 0.0005 & 0.0165 & 0.5678 \\
Type & FG & BL & PM & WB & OT \\
\hline $\mathbf{W}_{\mathbf{h}}$ & 0.0736 & 0.0162 & 0.0034 & 0.0107 & 0.0820 \\
\hline
\end{tabular}

Stratification By LLW Regional Compact. From Table A-5 of this report, the proportions of inactive GTCC sealed sources in each Regional Compact are shown in Table A-10.
Table A-10. Proportion of inactive GTCC sealed sources by LLW Regional Compact (R.C.).

\begin{tabular}{c|ccccc}
\hline R.C. & AP & CE & CM & DK & IN \\
\hline ph & 0.1341 & 0.0559 & 0.1156 & 0.3067 & 0.2463 \\
R.C. & MW & NE & NW & RM & SE \\
\hline ph & 0.0563 & 0.1852 & 0.0790 & 0.1346 & 0.0976 \\
R.C. & WE & & & & \\
\hline ph & 0.0947 & & & & \\
\hline
\end{tabular}

The values of $W_{h}$ for each LLW Regional Compact are shown in Table A-11. Because the states of Nebraska, New Mexico, and Rhode Island did not respond, the values of $W_{h}$ for the Central, Rocky Mountain, and Independent compacts have been adjusted upward by adding the average number of licensees per state to the values derived in Table A-5.

Table A-11. Proportion of the total GTCC sealed sources that belong to each Regional Compact (R.C.).

\begin{tabular}{c|ccccc}
\hline R.C. & AP & CE & CM & DK & IN \\
\hline $\mathbf{W}_{\mathbf{h}}$ & 0.0278 & 0.0404 & 0.0626 & 0.0080 & 0.4419 \\
R.C. & $\mathbf{M W}$ & $\mathbf{N E}$ & $\mathbf{N W}$ & $\mathbf{R M}$ & SE \\
\hline $\mathbf{W}_{\mathbf{h}}$ & 0.0378 & 0.0144 & 0.0741 & 0.0612 & 0.2060 \\
R.C. & $\mathbf{W E}$ & & & & \\
\hline $\mathbf{W}_{\mathbf{h}}$ & 0.0259 & & & & \\
\hline
\end{tabular}

\section{Number of GTCC Sealed Sources To Sample}

By using Equations (A-1) and (A-2) we can estimate the number of GTCC sealed sources that must be sampled in order to achieve a given precision level with $95 \%$ confidence. The precision is given relative to the proportion of inactive sources. For example, a relative precision of 0.1 for a simple random sample means that the precision is $10 \%$ of the true proportion.

The results of the sample size calculations are shown in Figure A- 6 for the simple random sample and stratified samples. A subset of the values are tabulated in Table A-12. From these results, it can be seen that stratification by device type would result in a moderate reduction in sample size over the other two sample designs. 
Table A-12. Subset of the sample size calculations displayed in Figure A-6.

\begin{tabular}{cccc}
\hline $\begin{array}{c}\text { Relative } \\
\text { Precision } \\
(\%)\end{array}$ & SRS & $\begin{array}{c}\text { Stratified } \\
\text { Device } \\
\text { Type }\end{array}$ & $\begin{array}{c}\text { Stratified } \\
\text { Compact }\end{array}$ \\
\hline 5 & 5,430 & 4,361 & 5,132 \\
10 & 1,830 & 1,416 & 1,720 \\
15 & 870 & 666 & 816 \\
20 & 501 & 383 & 470 \\
25 & 325 & 248 & 305 \\
\hline
\end{tabular}

\section{Average Number of GTCC Sources per Licensee}

To determine the number of licensees to survey, we will take the results of the number of GTCC sealed sources to survey and divide that by an estimate of the average number of GTCC sealed sources per licensee. This average is calculated using both the NRC sealed source database and the conclusions made by the NRC in the report "Above Class C Source/Device Inventory Survey."

The NRC database does not include any licensees that do not have GTCC sealed sources. However, the estimate of the average number of GTCC sealed sources per licensee must take into account all licensees, including those that do not handle GTCC sealed sources. Therefore, the estimates from the NRC report are used to determine the proportion of licensees that do not have any GTCC sealed sources.

From that report, there are approximately 23,000 specific licensees, of which 4,928 have GTCC sources. Thus, about $79 \%$ of the licensees have no GTCC sources.

The distribution of the number of GTCC sealed sources per licensee with GTCC sources is estimated from the NRC database. This showed that $10 \%$ of all licensees have 1 GTCC sealed source, $4 \%$ have $2,2 \%$ have $3,1 \%$ have $4,1 \%$ have 5 , and the remaining $3 \%$ of licensees have more than 5 .

The largest number of GTCC sources held by a single licensee is 1,090 . The second largest is 334 . This indicates that there is skewness in the data. A plot of the $\log _{\mathrm{e}}$-transformed data indicates that the number of GTCC sources per licensee is roughly log-normally distributed. However, the value of 0 sources is not valid in a log-normal distribution. Further, the large number of 1 's in the distribution also indicated a departure from log-normality.

Therefore, a mixed distribution was used to estimate the average number of GTCC sources per licensee. The mix- ture is composed of $78.57 \% 0 \mathrm{~s}, 10.21 \% \mathrm{~s}$, and a lognormal distribution with mean 5.949 and variance 39.017 . Then the overall mean is 0.7725 GTCC sources per licensee.

\section{Number of Licensees to Survey}

The results for the number of GTCC sources required to be surveyed, as shown in Figure A-6 and Table A-12, now need only be divided by the average number of GTCC sealed sources per licensee, 0.7725 . These results are shown in Figure A-7 and subsetted in Table A-13.

Table A-13. Subset of the sample size calculations displayed in Figure A-7.

\begin{tabular}{cccc}
\hline $\begin{array}{c}\text { Relative } \\
\text { Difference } \\
(\%)\end{array}$ & SRS & $\begin{array}{c}\text { Stratified } \\
\text { Device } \\
\text { Type }\end{array}$ & $\begin{array}{c}\text { Stratified } \\
\text { Compact }\end{array}$ \\
\hline 5 & 7,029 & 5,645 & 6,643 \\
10 & 2,369 & 1,833 & 2,227 \\
15 & 1,125 & 862 & 1,056 \\
20 & 649 & 495 & 609 \\
25 & 420 & 320 & 394 \\
\hline
\end{tabular}

\section{CONCLUSION}

The stratification by device type results in the most precise estimate of the proportion of GTCC sealed sources needing to be disposed. However, the cost to implement this stratification may exceed the cost of sending out more surveys under a simple random sample to get the same precision. This is because not all the Agreement State licensee lists that we received included information on the device types used by the licensee. To obtain this information would require a fairly significant effort, with no promise that all Agreement States can provide the information.

Stratification by compact does reduce the required sample size over the simple random sample, but not by much. Further, certain compacts are mostly composed of Agreement States, and others are composed mostly of NonAgreement States. Thus our sample would disproportionately sample certain compacts or states.

Implementing a simple random sample may be a reasonable approach. It is easy to implement and can be modified if the selected sample does not appear to be sufficiently representative. The fact that it does not result in as much precision as the stratified samples may not be a problem as the precision of the estimation might not be as important a factor as other considerations. 


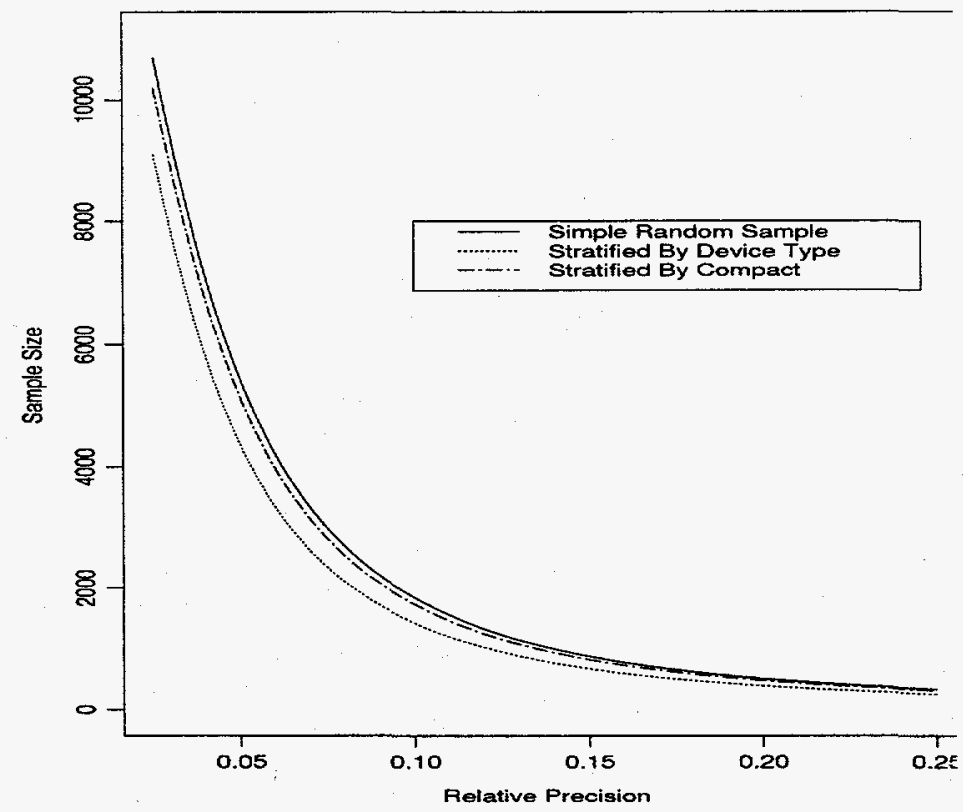

Figure A-6. Plot of the expected precision in estimating the proportion of GTCC sources that are no longer active for given sample sizes. The sample sizes refer to the number of GTCC sources that need to be covered in the sample.

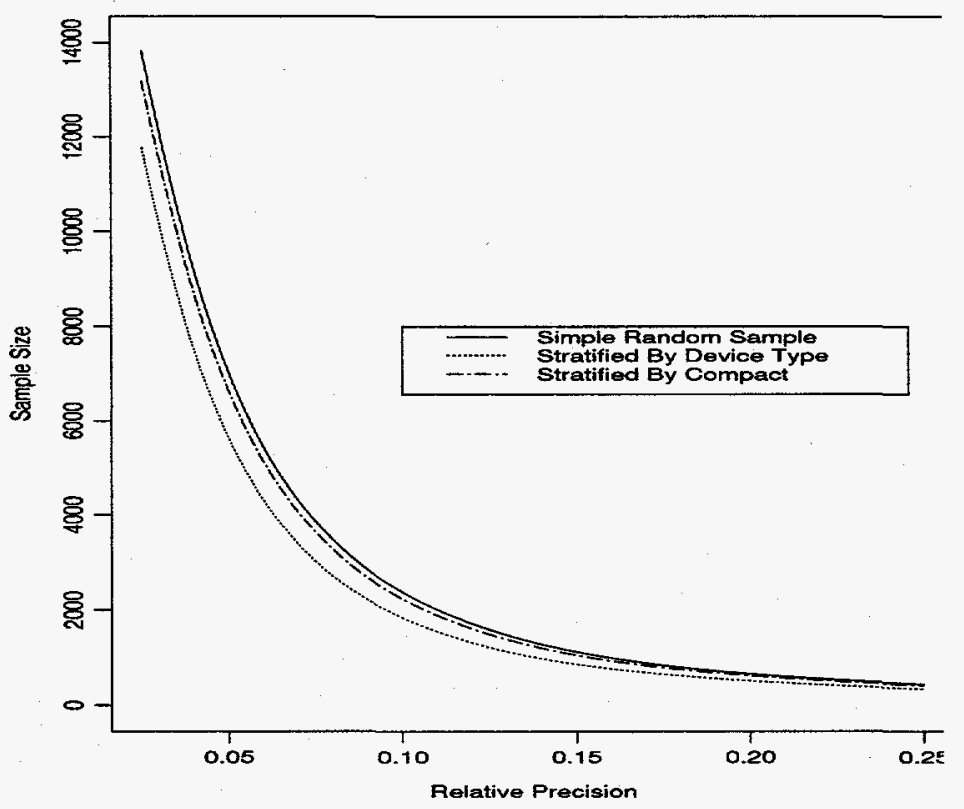

Figure A-7. Plot of the expected precision in estimating the proportion of GTCC sources that are no longer active for given sample sizes. The sample sizes refer to the number of specific licensees that need to be covered in the sample.

\section{References}

Cochran, William G. (1977), Sampling Techniques, John Wiley \& Sons, N.Y. 


\section{Appendix B}

Uncertainty Analysis of Results

\section{B-1 Quantitative Uncertainty Assessment B-2 Qualitative Uncertainty Assessment}


B-2 


\section{Appendix B}

\section{Uncertainty Analysis of Results}

\section{B-1. QUANTITATIVE UNCERTAINTY ASSESSMENT \\ B-1.1 Number of PGTCC Sources}

The assessment of uncertainty in the number of PGTCC sources held by specific licensees makes use of 95\% confidence intervals. The interpretation of the confidence interval is that the interval contains the true number of PGTCC sources with $95 \%$ confidence. The lower and upper confidence limits are used as the low and high case scenario estimates. In the first part of this section, the methodology for computing the confidence interval is presented. The results are presented in the second part.

\section{B-1.1.1 Confidence Intervals for the Number of PGTCC Sources-Methodology}

The methodology for computing confidence intervals from a simple random sample follows Cochran (1977). Let

$$
\begin{aligned}
& y_{i j k}=\begin{array}{r}
\text { number of PGTCC sources with isotope } \mathrm{j} \text { and principal use } \mathrm{k} \text { held } \\
\text { by the } \mathrm{i} \text { 'th survey respondent, }
\end{array} \\
& N=\text { number of NRC and AS specific licensees, } 21,732, \\
& n=\text { number of NRC and AS survey responses, } 6,317 .
\end{aligned}
$$

Then the total number of PGTCC sources with isotope $\mathrm{j}$ and principal use $\mathrm{k}, Y_{j k}$ is estimated as $\hat{Y}_{j k}=N \bar{y}_{j k}$,

where

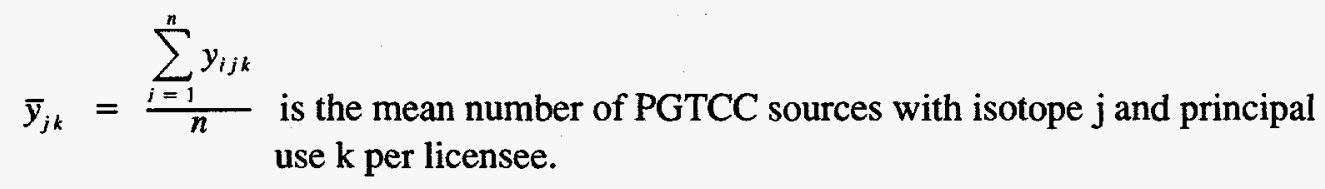

The standard error of the estimate of the total number of PGTCC sources with isotope $\mathrm{j}$ and principal use $\mathrm{k}, s_{\hat{r}_{j k}}$, is calculated as

$$
s_{\hat{r}_{j k}}=\frac{N s_{j k}}{\sqrt{n}} \sqrt{1-\frac{n}{N}}
$$

where

$$
s_{j k}=\sqrt{\frac{\sum_{i=1}^{n}\left(y_{i j k}-\bar{y}_{j k}\right)^{2}}{n-1}} \text { is the standard deviation of the number of PGTCC }
$$

Then the confidence limits for the total number of PGTCC sources with isotope $\mathrm{j}$ and principal use $\mathrm{k}$ are calculated from

$\hat{Y}_{j k} \pm z s_{\hat{Y}_{j k}}$,

where

$$
z=1.96 \text {, for a } 95 \% \text { confidence level. }
$$


The construction of confidence intervals, as implemented here, assumes a normal distribution. For some combinations, however, the assumption may not be entirely valid. These combinations typically had few licensees, of which one or two had a large number of sources. While different distributional assumptions and transformations to make these data more normal were attempted, there was no clear improvement in the results. Hence the normal assumption is retained. It should be emphasized that this assumption only affects the confidence intervals; the calculated total number of PGTCC sources is not affected.

For example, from Table B-1, consider the Pu-238 sources of the "Other" principal use. There were 31 licensees in the survey who had these types of sources. Of these licensees, one had 374 sources, and the remaining had 6 or less sources, with 16 licensees having only 1 such source each. This inflates the estimate of the standard error and causes the large width of the confidence interval.

Calculation of confidence limits on the total number of PGTCC sources for a given isotope (across all principal uses) or a given principal use (across all isotopes) or for all isotopes and principal uses (i.e. the grand total) uses essentially the same methodology as that given above. The exception is that the summations in the calculations of the mean and standard deviations differ, as does the subscript notation. For example, to calculate the confidence interval on the total number of PGTCC sources for a principal use, $k$, first calculate the total as

$\hat{Y}_{k}=N \bar{y}_{k}$,

where

$$
\bar{y}_{k}=\frac{\sum_{i=1}^{n} \sum_{j=1}^{J_{k}} y_{i j k}}{n} \text { is the mean number of PGTCC sources with principal use } \mathrm{k} \text { per }
$$

Then the standard error of the estimate of the total number of PGTCC sources with principal use $k, s_{\hat{\gamma}_{j k}}$, is calculated as

$s_{\hat{r}_{k}}=\frac{N s_{k}}{\sqrt{n}} \sqrt{1-\frac{n}{N}}$,

where

$$
s_{k}=\sqrt{\frac{\sum_{i=1}^{n} \sum_{j=1}^{j_{k}}\left(y_{i j k}-\bar{y}_{k}\right)^{2}}{n-1}} \text { is the standard deviation of the number of PGTCC }
$$

sources for principal use $\mathrm{k}$ per licensee.

Then the confidence limits for the total number of PGTCC sources with principal use $\mathrm{k}$ are calculated from $\hat{Y}_{k} \pm z s_{\hat{Y}_{k}}$.

\section{B-1.1.2 Confidence Intervals for the Number of PGTCC Sources-Results}

Table B-1 shows the 95\% confidence intervals on the number of PGTCC sources. When the lower confidence limit is less than zero, it is set to zero since there cannot be a negative number of PGTCC sources. A lower confidence limit less than zero can also be considered an indicator that the normal distribution assumption does not hold for that combination of isotope and principal use. 
Table B-1. Summary statistics for the projection of the number of PGTCC sources.

\begin{tabular}{|c|c|c|c|c|c|}
\hline \multirow{2}{*}{ Device Type } & \multirow{2}{*}{ Isotope } & \multirow{2}{*}{$\begin{array}{l}\text { Total Number } \\
\text { of Sources }^{\mathrm{a}}\end{array}$} & \multirow{2}{*}{$\begin{array}{c}\text { Standard } \\
\text { Error of Total }\end{array}$} & \multicolumn{2}{|c|}{$95 \%$ Confidence Interval } \\
\hline & & & & Lower ${ }^{b}$ & Upper \\
\hline Calibration & Am-241 & 3,000 & 858 & 1,319 & 4,682 \\
\hline Calibration & C-14 & 24 & 9 & 7 & 41 \\
\hline Calibration & $\mathrm{Cm}-244$ & 34 & 11 & 13 & 56 \\
\hline Calibration & Cs-137 & 3,430 & 508 & 2,434 & 4,427 \\
\hline Calibration & $\mathrm{Ni}-63$ & 114 & 52 & 12 & 215 \\
\hline Calibration & $\mathrm{Np}-237$ & 10 & 9 & 0 & 27 \\
\hline Calibration & $\mathrm{Pu}-238$ & 41 & 15 & 12 & 70 \\
\hline Calibration & $\mathrm{Pu}-239$ & 275 & 86 & 106 & 444 \\
\hline Calibration & $\mathrm{Pu}-241$ & 17 & 14 & 0 & 46 \\
\hline Calibration & Sr-90 & 1,927 & 1,118 & 0 & 4,118 \\
\hline Calibration & Tc-99 & 17 & 8 & 2 & 32 \\
\hline Calibration & U-238 & 34 & 16 & 2 & 67 \\
\hline Medical & Am-241 & 344 & 84 & 179 & 509 \\
\hline Medical & Cs-137 & 1,184 & 355 & 489 & 1,879 \\
\hline Medical & Sr-90 & 24 & 8 & 9 & 39 \\
\hline Medical & Tc-99 & 3 & 3 & 0 & 9 \\
\hline Medical & $\mathrm{U}-238$ & 28 & 9 & 10 & 45 \\
\hline Well logging & Am-241 & 4,311 & 1,652 & 1,073 & 7,549 \\
\hline Well logging & Cs- 137 & 2,154 & 886 & 417 & 3,891 \\
\hline Well logging & $\mathrm{Pu}-238$ & 172 & 145 & 0 & 456 \\
\hline Well logging & $\mathrm{Pu}-241$ & 3 & 3 & 0 & 9 \\
\hline Portable gauge & Am-241 & 15,294 & 1,288 & 12,770 & 17,819 \\
\hline Portable gauge & Cs-137 & 114 & 29 & 56 & 171 \\
\hline Irradiation & Am-241 & 155 & 79 & 0 & 310 \\
\hline Irradiation & Cs-137 & 1,652 & 204 & 1,252 & 2,051 \\
\hline Irradiation & Sr-90 & 10 & 5 & 0 & 20 \\
\hline Fixed gauge & Am-241 & 2,278 & 319 & 1,654 & 2,902 \\
\hline Fixed gauge & C-14 & 34 & 29 & 0 & 91 \\
\hline Fixed gauge & $\mathrm{Cm}-244$ & 17 & 9 & 0 & 34 \\
\hline Fixed gauge & Cs-137 & 29,649 & 2,392 & 24,961 & 34,338 \\
\hline Fixed gauge & $\mathrm{Pu}-238$ & 3 & 3 & 0 & 9 \\
\hline Fixed gauge & Sr-90 & 114 & 26 & 63 & 164 \\
\hline General neutron applications & Am-241 & 1,480 & 226 & 1,037 & 1,922 \\
\hline General neutron applications & $\mathrm{Pu}-238$ & 114 & 39 & 37 & 190 \\
\hline
\end{tabular}


Table B-1. (continued).

\begin{tabular}{|c|c|c|c|c|c|}
\hline \multirow[b]{2}{*}{ Device Type } & \multirow[b]{2}{*}{ Isotope } & \multirow{2}{*}{$\begin{array}{l}\text { Total Number } \\
\text { of Sources }\end{array}$} & \multirow{2}{*}{$\begin{array}{c}\text { Standard } \\
\text { Error of Total }\end{array}$} & \multicolumn{2}{|c|}{$95 \%$ Confidence Interval } \\
\hline & & & & Lower ${ }^{b}$ & Upper \\
\hline General neutron applications & $\mathrm{Pu}-239$ & 526 & 99 & 332 & 721 \\
\hline $\mathrm{X}$-ray fluorescence & Am-241 & 688 & 141 & 413 & 964 \\
\hline $\mathrm{X}$-ray fluorescence & $\mathrm{Cm}-244$ & 241 & 97 & 51 & 431 \\
\hline $\mathrm{X}$-ray fluorescence & Cs-137 & 3 & 3 & 0 & 9 \\
\hline $\mathrm{X}$-ray fluorescence & $\mathrm{Pu}-238$ & 182 & 77 & 31 & 334 \\
\hline Other & Am-241 & 1,125 & 173 & 786 & 1,465 \\
\hline Other & $C-14$ & 62 & 18 & 26 & 98 \\
\hline Other & $\mathrm{Cm}-244$ & 34 & 12 & 10 & 59 \\
\hline Other & Cs-137 & 11,097 & 5,261 & 786 & 21,408 \\
\hline Other & Ni-63 & 3,871 & 1,968 & 13 & 7,729 \\
\hline Other & Np-237 & 3 & 3 & 0 & 9 \\
\hline Other & $\mathrm{Pu}-238$ & 1,576 & 1,085 & 0 & 3,703 \\
\hline Other & $\mathrm{Pu}-239$ & 654 & 144 & 372 & 935 \\
\hline Other & $\mathrm{Pu}-241$ & 21 & 10 & 1 & 40 \\
\hline Other & Sr-90 & 299 & 73 & 156 & 442 \\
\hline Other & Tc-99 & 454 & 308 & 0 & 1,058 \\
\hline Other & $\mathrm{U}-238$ & 79 & 21 & 39 & 120 \\
\hline Calibration & Total $^{\mathrm{d}}$ & 8,925 & 1,630 & 5,730 & 12,121 \\
\hline Medical & Total $^{d}$ & 1,583 & 365 & 867 & 2,298 \\
\hline Well logging & Total $^{d}$ & 6,641 & 2,440 & 1,859 & 11,423 \\
\hline Portable gauge & Total $^{d}$ & 15,408 & 1,289 & 12,882 & 17,934 \\
\hline Irradiation & Total $^{\mathrm{d}}$ & 1,817 & 220 & 1,385 & 2,249 \\
\hline Fixed gauge & Total $^{d}$ & 32,096 & 2,455 & 27,283 & 36,908 \\
\hline General neutron applications & Total $^{\mathrm{d}}$ & 2,120 & 251 & 1,628 & 2,611 \\
\hline $\mathrm{X}$-ray fluorescence & Total $^{\mathrm{d}}$ & 1,115 & 204 & 715 & 1,515 \\
\hline Other & Total $^{d}$ & 19,275 & 5,853 & 7,804 & 30,746 \\
\hline Total $^{\mathrm{d}}$ & $A m-241$ & 28,676 & 2,846 & 23,097 & 34,254 \\
\hline Total $^{\mathrm{d}}$ & C-14 & 120 & 37 & 49 & 192 \\
\hline Total $^{d}$ & $\mathrm{Cm}-244$ & 327 & 99 & 134 & 520 \\
\hline Total $^{\mathrm{d}}$ & Cs-137 & 49,282 & 6,216 & 37,100 & 61,465 \\
\hline Total $^{\mathrm{d}}$ & $\mathrm{Ni}-63$ & 3,984 & 1,969 & 125 & 7,844 \\
\hline Total $^{\mathrm{d}}$ & Np-237 & 14 & 9 & 0 & 32 \\
\hline
\end{tabular}


Table B-1. (continued).

\begin{tabular}{|c|c|c|c|c|c|}
\hline \multirow[b]{2}{*}{ Device Type } & \multirow[b]{2}{*}{ Isotope } & \multirow{2}{*}{$\begin{array}{l}\text { Total Number } \\
\text { of Sources }\end{array}$} & \multirow{2}{*}{$\begin{array}{c}\text { Standard } \\
\text { Error of Total }\end{array}$} & \multicolumn{2}{|c|}{$95 \%$ Confidence Interval } \\
\hline & & & & Lower ${ }^{b}$ & Upper ${ }^{c}$ \\
\hline Total $^{\mathrm{d}}$ & $\mathrm{Pu}-238$ & 2,089 & 1,101 & 0 & 4,247 \\
\hline Total $^{\mathrm{d}}$ & Pu-239 & 1,455 & 202 & 1,060 & 1,851 \\
\hline Total $^{\mathbf{d}}$ & $\mathrm{Pu}-241$ & 41 & 18 & 6 & 76 \\
\hline Total $^{d}$ & Sr-90 & 2,374 & 1,121 & 177 & 4,571 \\
\hline Total $^{d}$ & Tc-99 & 475 & 308 & 0 & 1,079 \\
\hline Total $^{d}$ & U-238 & 141 & 29 & 84 & 198 \\
\hline Total $^{\mathrm{d}}$ & Total & 88,979 & 7,742 & 73,805 & 104,153 \\
\hline \multicolumn{6}{|c|}{ a. The total number of sources correspond to the base case scenario estimates. } \\
\hline \multicolumn{6}{|c|}{ b. The lower confidence limit corresponds to the low case scenario estimates. } \\
\hline \multicolumn{6}{|c|}{ c. The upper confidence limit corresponds to the high case scenario estimates. } \\
\hline \multicolumn{6}{|c|}{$\begin{array}{l}\text { d. The confidence limit calculations for the totals are based on pooling all data. This differs from the method used to } \\
\text { calculate marginal totals in tables } 4-8 \text { and } 4-10 \text {. }\end{array}$} \\
\hline
\end{tabular}

\section{B-1.2 Total Unpackaged Volume of PGTCC Sources}

The assessment of uncertainty in the total unpackaged volume of PGTCC sources held by specific licensees makes use of $95 \%$ confidence intervals. The methodology for calculating the intervals is given in Section B-1.2.1. The results are given in Section B-1.2.2.

\section{B-1.2.1 Confidence Intervals for the Unpackaged Volume of PGTCC Sources: Methodology}

The calculation of the confidence intervals for the total unpackaged volume of PGTCC sources is based on estimating the distribution of the product of the number of PGTCC sources with the source capsule volume. The capsule volumes are shown in Table 3-1. The number of PGTCC sources is discussed in Section B-1.1.

Source capsule volumes given in Table 3-1 are assumed to be representative of the capsules within a given principal use. As such, and because there was not sufficient data to determine a distribution of capsule volumes, the capsule volume for a principal use is treated as a constant in the calculations of confidence intervals.

The variance of a product of a constant, $V$, and a random variable, $Y$, is given by

$\operatorname{var}[V Y]=V^{2} \operatorname{var}[Y]$

If $V$ is taken as the capsule volume and $Y$ as the number of PGTCC sources, then var[VY] is the variance of the total unpackaged volume. The square root of this variance is the standard error used in the calculation of the confidence interval as discussed in Section B-1.1.1. 
As in Section B-1.1.1, let $\hat{Y}_{j k}$ be the estimated number of PGTCC sources with isotope $\mathbf{j}$ and principal use $\mathrm{k}$. Also let $v_{k}$ be the source capsule volume for principal use $\mathrm{k}$. Then the unpackaged volume of PGTCC sources with isotope $\mathrm{j}$ and principal use $\mathrm{k}, V_{j k}$, is estimated as

$\hat{V}_{j k}=v_{k} \hat{Y}_{j k}$

The standard error of the estimate of the unpackaged volume of PGTCC sources with isotope $j$ and principal use $\mathrm{k}, s_{\hat{v}_{j k}}$, is calculated as

$s_{\hat{v}_{j k}}=v_{k} s_{\hat{r}_{j k}}$

where $s_{\hat{\gamma}_{j k}}$ is defined in Section B-1.1.1. Then the confidence limits for the unpackaged volume of PGTCC sources with isotope $\mathrm{j}$ and principal use $\mathrm{k}$ are calculated from

$\hat{Y}_{j k} \pm z s_{\hat{r}_{j k}}$,

where

$z=1.96$, for a $95 \%$ confidence level.

Calculations of confidence intervals on totals across isotopes or principal uses are essentially calculated as discussed in Section B-1.1.1, except that volumes rather than numbers of sources are used.

\section{B-1.2.1 Confidence Intervals for the Unpackaged Volume of PGTCC Sources: Results}

Table B- 2 shows the $95 \%$ confidence intervals on the unpackaged volume of PGTCC sources. When the lower confidence limit is less than zero, it is set to zero since there cannot be a negative volume of PGTCC sources. 
Table B-2. Summary statistics for the projection of the total unpackaged volume $\left(\mathrm{cm}^{3}\right)$ of PGTCC sources.

\begin{tabular}{|c|c|c|c|c|c|}
\hline \multirow[b]{2}{*}{ Device Type } & \multirow[b]{2}{*}{ Isotope } & \multirow{2}{*}{$\begin{array}{c}\text { Total } \\
\text { Volume }^{\mathrm{a}}\end{array}$} & \multirow{2}{*}{$\begin{array}{c}\text { Standard } \\
\text { Error of Total }\end{array}$} & \multicolumn{2}{|c|}{$95 \%$ Confidence Interval } \\
\hline & & & & Lower ${ }^{b}$ & Upper \\
\hline Calibration & Am-241 & 6,000 & 1,716 & 2,638 & 9,364 \\
\hline Calibration & $C-14$ & 48 & 18 & 14 & 82 \\
\hline Calibration & $\mathrm{Cm}-244$ & 68 & 22 & 26 & 112 \\
\hline Calibration & Cs-137 & 6,860 & 1,016 & 4,868 & 8,854 \\
\hline Calibration & $\mathrm{Ni}-63$ & 228 & 104 & 24 & 430 \\
\hline Calibration & $\mathrm{Np}-237$ & 20 & 18 & 0 & 54 \\
\hline Calibration & Pu-238 & 82 & 30 & 24 & 140 \\
\hline Calibration & $\mathrm{Pu}-239$ & 550 & 172 & 212 & 888 \\
\hline Calibration & $\mathrm{Pu}-241$ & 34 & 28 & 0 & 92 \\
\hline Calibration & Sr-90 & 3,854 & 2,236 & 0 & 8,236 \\
\hline Calibration & Tc-99 & 34 & 16 & 4 & 64 \\
\hline Calibration & U-238 & 68 & 32 & 4 & 134 \\
\hline Medical & Am-241 & 6,880 & 1,680 & 3,580 & 10,180 \\
\hline Medical & Cs-137 & 23,680 & 7,100 & 9,780 & 37,580 \\
\hline Medical & Sr-90 & 480 & 160 & 180 & 780 \\
\hline Medical & Tc-99 & 60 & 60 & 0 & 180 \\
\hline Medical & $\mathrm{U}-238$ & 560 & 180 & 200 & 900 \\
\hline Well logging & Am-241 & 107,775 & 41,300 & 26,825 & 188,725 \\
\hline Well logging & Cs-137 & 53,850 & 22,150 & 10,425 & 97,275 \\
\hline Well logging & $\mathrm{Pu}-238$ & 4,300 & 3,625 & 0 & 11,400 \\
\hline Well logging & $\mathrm{Pu}-241$ & 75 & 75 & 0 & 225 \\
\hline Portable gauge & Am-241 & 305,880 & 25,760 & 255,400 & 356,380 \\
\hline Portable gauge & Cs-137 & 2,280 & 580 & 1,120 & 3,420 \\
\hline Irradiation & Am-241 & 6,200 & 3,160 & 0 & 12,400 \\
\hline Irradiation & Cs-137 & 66,080 & 8,160 & 50,080 & 82,040 \\
\hline Irradiation & Sr-90 & 400 & 200 & 0 & 800 \\
\hline Fixed gauge & Am-241 & 6,834 & 957 & 4,962 & 8,706 \\
\hline Fixed gauge & $C-14$ & 102 & 87 & 0 & 273 \\
\hline Fixed gauge & $\mathrm{Cm}-244$ & 51 & 27 & 0 & 102 \\
\hline Fixed gauge & Cs-137 & 88,947 & 7,176 & 74,883 & 103,014 \\
\hline Fixed gauge & $\mathrm{Pu}-238$ & 9 & 9 & 0 & 27 \\
\hline Fixed gauge & Sr-90 & 342 & 78 & 189 & 492 \\
\hline General neutron applications & Am-241 & 29,600 & 4,520 & 20,740 & 38,440 \\
\hline General neutron applications & $\mathrm{Pu}-238$ & 2,280 & 780 & 740 & 3,800 \\
\hline
\end{tabular}


Table B-2. (continued).

\begin{tabular}{|c|c|c|c|c|c|}
\hline \multirow[b]{2}{*}{ Device Type } & \multirow[b]{2}{*}{ Isotope } & \multirow{2}{*}{$\begin{array}{c}\text { Total } \\
\text { Volume }^{\mathrm{a}}\end{array}$} & \multirow{2}{*}{$\begin{array}{c}\text { Standard } \\
\text { Error of Total }\end{array}$} & \multicolumn{2}{|c|}{ 95\% Confidence Interval } \\
\hline & & & & Lower ${ }^{b}$ & Upper $^{c}$ \\
\hline General neutron applications & $\mathrm{Pu}-239$ & 10,520 & 1,980 & 6,640 & 14,420 \\
\hline $\mathrm{X}$-ray fluorescence & Am-241 & 344 & 71 & 207 & 482 \\
\hline $\mathrm{X}$-ray fluorescence & $\mathrm{Cm}-244$ & 121 & 49 & 26 & 216 \\
\hline $\mathrm{X}$-ray fluorescence & Cs-137 & 2 & 2 & 0 & 5 \\
\hline $\mathrm{X}$-ray fluorescence & $\mathrm{Pu}-238$ & 91 & 39 & 16 & 167 \\
\hline Other & Am-241 & 11,250 & 1,730 & 7,860 & 14,650 \\
\hline Other & $\mathrm{C}-14$ & 620 & 180 & 260 & 980 \\
\hline Other & $\mathrm{Cm}-244$ & 340 & 120 & 100 & 590 \\
\hline Other & Cs-137 & 110,970 & 52,610 & 7,860 & 214,080 \\
\hline Other & $\mathrm{Ni}-63$ & 38,710 & 19,680 & 130 & 77,290 \\
\hline Other & Np-237 & 30 & 30 & 0 & 90 \\
\hline Other & Pu-238 & 15,760 & 10,850 & 0 & 37,030 \\
\hline Other & $\mathrm{Pu}-239$ & 6,540 & 1,440 & 3,720 & 9,350 \\
\hline Other & $\mathrm{Pu}-241$ & 210 & 100 & 10 & 400 \\
\hline Other & Sr-90 & 2,990 & 730 & 1,560 & 4,420 \\
\hline Other & Tc-99 & 4,540 & 3,080 & 0 & 10,580 \\
\hline Other & $\mathrm{U}-238$ & 790 & 210 & 390 & 1,200 \\
\hline Calibration & Total $^{\mathrm{d}}$ & 17,846 & 2,236 & 7,814 & 28,450 \\
\hline Medical & Total $^{\mathrm{d}}$ & 31,660 & 7,100 & 13,740 & 49,620 \\
\hline Well logging & Total $^{\mathrm{d}}$ & 166,000 & 41,300 & 37,250 & 297,625 \\
\hline Portable gauge & Total $^{\mathrm{d}}$ & 308,160 & 25,760 & 256,520 & 359,800 \\
\hline Irradiation & Total $^{\mathrm{d}}$ & 72,680 & 8,160 & 50,080 & 95,240 \\
\hline Fixed gauge & Total $^{\mathrm{d}}$ & 96,285 & 7,176 & 80,034 & 112,614 \\
\hline General neutron applications & Total $^{\mathrm{d}}$ & 42,400 & 4,520 & 28,120 & 56,660 \\
\hline $\mathrm{X}$-ray fluorescence & Total $^{\mathrm{d}}$ & 557 & 71 & 248 & 869 \\
\hline Other & Total $^{\mathrm{d}}$ & 192,750 & 52,610 & 21,890 & 370,660 \\
\hline Total $^{\mathrm{d}}$ & Am-241 & 480,763 & 41,300 & 322,212 & 639,327 \\
\hline Total $^{\mathrm{d}}$ & C-14 & 770 & 180 & 274 & 1,335 \\
\hline Total $^{d}$ & $\mathrm{Cm}-244$ & 580 & 120 & 152 & 1,020 \\
\hline Total $^{d}$ & Cs-137 & 352,669 & 52,610 & 159,016 & 546,268 \\
\hline Total $^{\mathrm{d}}$ & $\mathrm{Ni}-63$ & 38,938 & 19,680 & 154 & 77,720 \\
\hline Total $^{\mathrm{d}}$ & Np-237 & 50 & 30 & 0 & 144 \\
\hline Total $^{\mathrm{d}}$ & $\mathrm{Pu}-238$ & 22,522 & 10,850 & 780 & 52,564 \\
\hline Total $^{\mathrm{d}}$ & Pu-239 & 17,610 & 1,980 & 10,572 & 24,658 \\
\hline
\end{tabular}


Table B-2. (continued).

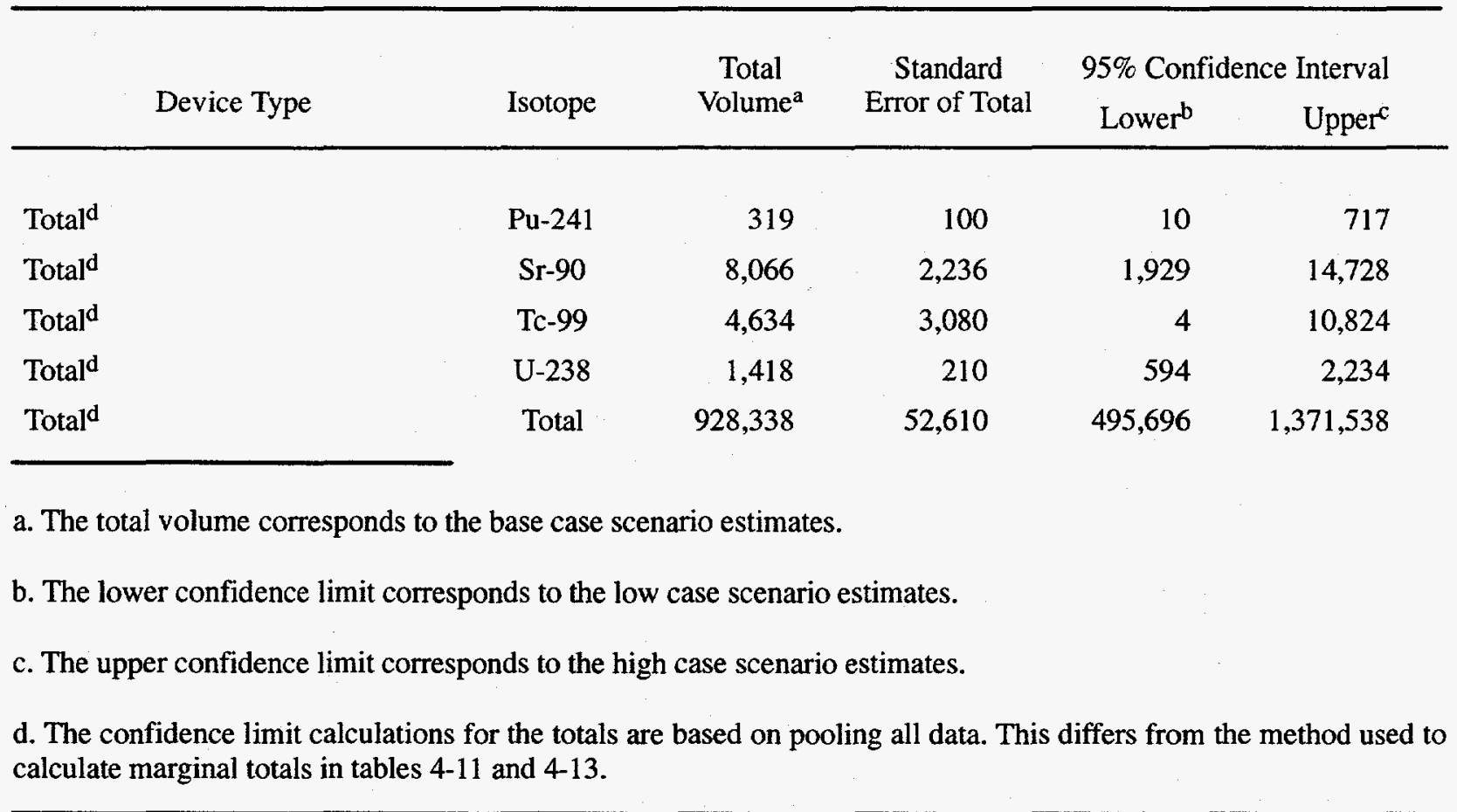




\section{B-1.3 Total Activity of PGTCC Sources}

To estimate the total number of PGTCC sources held by all specific licensees, the average number of sources per licensee responding to the survey was calculated and then multiplied by the total number of specific licensees. Since the surveys also asked for information about the activity of the sources, one would expect to be able to apply this same, relatively simple, sequence of calculations to get the total activity. However, due to the quality of the activity data, this methodology gave entirely unrealistic results.

The primary problem were sources with unreasonably large activities. These sources were extreme outliers and biased the results high. For example, consider irradiation sources with Sr-90. There were 3 of these sources observed in the survey. Two of these were well below $20 \mathrm{Ci}$, the maximum value for Sr-90 irradiation sources in the NRC Sealed Source and Device Registry. However, the other source is listed as having $125 \mathrm{Ci}$. The average activity of the three observed sources is over $45 \mathrm{Ci}$, which is above the maximum possible value. Removal of this outlier results in an average activity of $5.7 \mathrm{Ci}$, which is much more representative of Sr-90 irradiation source activities.

Some of the other problems were due to either invalid responses or mistakes during input of the results to the database. One consistent problem that could not always be resolved occurred when the quantity of the isotope in the original survey response was given as a weight, grams. Given the weight of the radioactive material, an activity can be calculated using the specific activity of the radionuclide (the activity per unit weight). However, in some cases, the weight given was not the weight of the radioactive material, but was a "gram Radium equivalent," though it was not indicated as such on the form. In other cases, the weight was probably not the weight of the pure radionuclide - rather it included the weight of the substrate containing the radionuclide (e.g. Cs-137 in a ceramic) or was the weight of the chemical containing the radionuclide (e.g. $\mathrm{PuO}_{2}$ ). While much effort went into correcting these and other problems in the database, perfection was impossible to achieve without an extreme expenditure of resources.

The assessment of uncertainty in the total activity of PGTCC sources held by specific licensees makes use of $95 \%$ confidence intervals. The methods used to determine average source activity is discussed in Section B-1.3.1. The methodology for calculating the confidence intervals is given in Section B-1.3.2. The results are given in Section B-1.3.3.

\section{B-1.3.1 Calculation of Average Activity}

To account for the problems in the survey responses for source activities, it would have been best to look at the responses in each combination of device type and isotope to determine which responses were invalid. To some extent this was already done with the quality check of the database. However, it would have been highly resource intensive to implement a case by case check of the data. Therefore, a simpler method was implemented which essentially removes highly suspect responses through the use of trimmed means.

B-1.3.1.1 Trimmed Means. The primary problem in estimating total activity was unreasonably large activities in some of the responses. The selected fix to this problem, which could be easily implemented, was to calculate modified trimmed means. A trimmed mean is typically calculated by not including an equal number of the largest and smallest values in the computation. For example, say there are 100 sorted observations, a trimmed mean would be a mean calculated using only the middle 90 observations - the five smallest observations and the five largest observations are not used in the calculation.

This general procedure was modified in that only selected large observations were excluded. The observations excluded had activities higher than the maximum activity observed in the NRC Sealed Source and Device Registry for the given isotope and device type. An activity that was identified as exceeding the maximum possible activity was initially verified and, if verified, was inspected to see if the problem could be resolved (if not verified, the input error was fixed). 
Hence, the procedure for calculating the mean given here essentially amounts to using the typical equations but excluding data that is highly suspect. This resulted in the exclusion of 70 records accounting for 128 sources. Table B-3 provides summary information about the excluded sources.

Table B-3. Breakdown and summary of the sources excluded from the calculation of the mean activity because the observed activity exceeded the maximum activity of registered sources.

\begin{tabular}{lccccc}
\hline \multicolumn{1}{c}{ Device } & Isotope & $\begin{array}{c}\text { Maximum } \\
\text { Registry } \\
\text { Activity (Ci) }\end{array}$ & $\begin{array}{c}\text { Maximum } \\
\text { Observed } \\
\text { Activity (Ci) }\end{array}$ & $\begin{array}{c}\text { Number of } \\
\text { Records } \\
\text { Excluded }\end{array}$ & $\begin{array}{c}\text { Number of } \\
\text { Sources } \\
\text { Excluded }\end{array}$ \\
\hline Calibration & Am-241 & 0.7 & 12 & 50 & 98 \\
Calibration & Pu-238 & 0.7 & 8,321 & 7 & 11 \\
Irradiation & Am-241 & 3.6 & 7.0 & 4 & 7 \\
Irradiation & Cs-137 & 22,500 & 213,000 & 4 & 4 \\
Irradiation & Sr-90 & 20 & 125 & 1 & 1 \\
X-ray fluorescence & Am-241 & 5.75 & 13.73 & 3 & 6 \\
Other & Pu-238 & 33 & 175 & 1 & 1 \\
\cline { 3 - 5 } & & & & 70 & 128 \\
\hline
\end{tabular}

It is not expected that exclusion of these sources from the calculations adds any significant bias to the results. More importantly, inclusion of these sources in the calculations would likely result in a significant bias since these source activities are invalid and much larger than the remaining source activities. There is, however, a possibility that some of these sources are custom sources, which would mean the response is valid and exclusion of the data causes a bias. Again, without an unwarranted expenditure of resources, it is impossible to determine which, if any, of these sources are valid custom sources.

It should be emphasized that the activity distributions are for PGTCC sources. The actual activity distributions for true GTCC sources will have a higher mean activity since the smaller activity PGTCC sources will probably be disposed of at LLW facilities. It is expected that a companion report to this report will provide a better characterization of GTCC sources, including activities.

B-1.3.1.2 Distributional Assumptions and Calculations. After the data had been trimmed, the remaining activities were examined to see if they more closely followed a normal or lognormal distribution. This was assessed through the use of QQ plots. These graphs plot the quantiles from the assumed distribution against the observed quantiles. If the data follow the assumed distribution, then the points in the graph will fall on a straight line. The distributional assessment was only made if there were at least 10 data points in the combination of device type and isotope. Combinations with less than 10 observations were assumed to be normally distributed.

If the data were normally distributed, then the trimmed mean for each combination of device type and isotope is calculated as follows. Let $y_{i j k}$ be the i'th activity observed in the combination of isotope $j$ and device type $\mathrm{k}$. Let $n^{\prime}{ }_{j k}$ be the trimmed number of sources observed with isotope $\mathrm{j}$ and device type $\mathrm{k}$. Then the trimmed mean activity, $\bar{y}_{j k}$, is calculated as 
$\bar{y}_{j k}=\frac{\sum_{i=1}^{n_{j k}^{\prime}} y_{i j k}}{n_{j k}^{\prime}}$.

If the data are assumed to be lognormally distributed, the data is initially transformed as $x_{i j k}=\ln \left(y_{i j k}\right)$. Then the mean, $\bar{x}_{j k}$, and variance, $s_{x_{j k}}^{2}$, are calculated as

$\bar{x}_{j k}=\frac{\sum_{i=1}^{n_{j k}^{\prime}} x_{i j k}}{n_{j k}^{\prime}}$ and $s_{x_{j k}^{2}}^{2}=\frac{\sum_{i=1}^{n_{j k}^{\prime}}\left(x_{i j k}-\bar{x}_{j k}\right)^{2}}{n_{j k}^{\prime}-1}$.

Then the trimmed mean activity is calculated as

$\bar{y}_{j k}=\left[\exp \left(\bar{x}_{j k}\right)\right] \Psi_{n_{j k}^{\prime}}\left(\frac{s_{x_{j k}}^{2}}{2}\right)$,

where

$$
\begin{aligned}
\Psi_{n_{j k}(t)} & =1+\frac{\left(n_{j k}^{\prime}-1\right) t}{n_{j k}^{\prime}}+\frac{\left(n_{j k}^{\prime}-1\right)^{3} t^{2}}{2 ! n_{j k}^{\prime 2}\left(n_{j k}^{\prime}+1\right)}+\frac{\left(n_{j k}^{\prime}-1\right)^{5} t^{3}}{3 ! n_{j k}^{\prime}\left(n_{j k}^{\prime}+1\right)\left(n_{j k}^{\prime}+3\right)} \\
& +\frac{\left(n_{j k}^{\prime}-1\right)^{7} t^{4}}{4 ! n_{j k}^{\prime}{ }^{4}\left(n_{j k}^{\prime}+1\right)\left(n_{j k}^{\prime}+3\right)\left(n_{j k}^{\prime}+5\right)}+\cdots \cdot
\end{aligned}
$$

The calculated means are shown in Table B-4. Both normal and lognormal distributions were found, and trimmed mean activities were used in the quantitative uncertainty analysis. Activity distributions broken down by isotope and principal use are shown in Appendix C.

\section{B-1.3.2 Confidence Intervals for the Total Activity of PGTCC Sources: Methodology}

The calculation of the confidence intervals for the total activity of PGTCC sources is based on estimating the distribution of the product of the number of PGTCC sources with the average activity per source. As discussed in Section B-1.3.1, the survey results for activity had extreme outliers, so a simple extrapolation from the survey results to the total population (as was done for estimating the total number of sources) was not possible since it gave highly unrealistic results. Instead the average activity of sources in a given principal use and isotope combination was estimated using a trimmed mean. The average activity is then multiplied by the number of PGTCC sources for the given combination of principal use and isotope to get the total activity.

The variance of a product of two independent random variables, $X$ and $Y$, is given by

$$
\operatorname{var}[X Y]=\mu_{Y}^{2} \operatorname{var}[X]+\mu_{X}^{2} \operatorname{var}[Y]+\operatorname{var}[X] \operatorname{var}[Y]
$$

where $\mu_{X}$ and $\mu_{Y}$ are the means of the $X$ and $Y$ variables, respectively. If $X$ is taken as the average activity per PGTCC source and $Y$ as the number of PGTCC sources, then $\operatorname{var}[X Y]$ is the variance of the total activity. The square root of the variance is the standard error used in the calculation of the confidence interval as discussed in Section B-1.1.1. 
Table B-1 gives the standard errors on the total number of sources. Squaring these values gives the variance of the total number, $\operatorname{var}[Y]$. The calculation of the variance of the average activity depends upon whether the distribution of source activities are assumed normal or lognormal. For combinations of principal use and isotope that had at least 10 observations, the source activities were analyzed to see if they were better fit by a normal or lognormal distribution. This was a graphical assessment using QQ-plots. When fewer than 10 sources were observed, the activity distribution was assumed normal.

Let $x_{i}$ be the activity of the $i$ 'th source observed in a given combination of principal use and isotope. Let $\bar{x}$ be the trimmed mean activity of the given combination; and $n$ ' be the number of sources used in calculating the trimmed mean. Then the variance of the mean of the normally distributed activities is given by

$\operatorname{var}[\bar{x}]=\frac{\sum_{i=1}^{n^{\prime}}\left(x_{i}-\bar{x}\right)^{2}}{n^{\prime}\left(n^{\prime}-1\right)}$.

The variance for the lognormally distributed activities is found by first transforming the activities as $w=\ln x$ and then calculating the mean, $\bar{w}$, and variance, $s_{w}^{2}$, of the transformed data, where

$$
s_{w}^{2}=\frac{\sum_{i=1}^{n^{\prime}}\left(w_{i}-\bar{w}\right)^{2}}{n^{\prime}-1} .
$$

Then the variance of the lognormal mean activity is

$$
\operatorname{var}[\bar{x}]=\exp (2 \bar{w})\left\{\left[\Psi_{n^{\prime}}\left(\frac{s_{w}^{2}}{2}\right)\right]^{2}-\Psi_{n^{\prime}}\left[\frac{s_{w}^{2}\left(n^{\prime}-2\right)}{n^{\prime}-1}\right]\right\},
$$

where $\Psi_{n^{\prime}}(t)$ is defined as in B-1.3.1. The values of the mean activity, $\bar{x}$, and the standard error of the estimate of the mean activity are shown in Table B-4.

Now let the product of the mean activity and the total number of sources be denoted by $\hat{Z}$. That is, using the previous notation, $\hat{Z}=\bar{x} \hat{Y}$. Then the variance of $\hat{Z}$ is estimated by

$s_{\hat{Z}}^{2}=\operatorname{var}[\hat{Z}]=\operatorname{var}[\hat{x} \hat{Y}]=\hat{Y}^{2} \operatorname{var}[\bar{x}]+\bar{x}^{2} s_{\hat{Y}}^{2}+\operatorname{var}[\bar{x}] s_{\hat{Y}}^{2}$,

where the calculation of $\hat{Y}$ and $s_{\hat{Y}}^{2}$ is discussed in Section B-1.1.1 and the calculation of $\bar{x}$ is discussed in Section B-1.3.1. The above calculations are performed on each combination of isotope and principal use. That is, for isotope $\mathrm{j}$ and principal use $\mathrm{k}$, the total activity, $\hat{Z}_{j k}$, and variance, $s_{\hat{\mathrm{z}}_{j k}}^{2}$, is calculated. Then the approximate $95 \%$ confidence interval on the total activity for isotope $\mathrm{j}$ and principal use $\mathrm{k}$ is calculated from

$\hat{Z}_{j k} \pm 1.96 s_{\hat{z}_{j k}}$.

As with the number of PGTCC sources, the lower and upper limits of the $95 \%$ confidence interval are used in the low and high case scenarios, respectively.

Calculating the confidence intervals for the marginal totals (e.g. total activity due to Cs-137 across all principal use codes) uses the relation that the variance of the sum of independent variables is equal to the sum of their variances. The marginal total activity, say for isotope $j$, is calculated as

$$
\hat{Z}_{j}=\sum_{k=1}^{K_{j}} \hat{Z}_{j k}
$$


where $K_{j}$ is the number of principal uses that have isotope $\mathrm{j}$ sources. The variance of $\hat{Z}_{j}$ is calculated as $s_{\hat{z}_{j}}^{2}=\sum_{k=1}^{K_{j}} s_{\hat{z}_{j k}}^{2}$.

Then the confidence interval is $\hat{Z}_{j} \pm 1.96 s_{\hat{z}_{j}}$. A similar set of calculations is made for the marginal totals for each principal use. Likewise for the grand total activity (across all isotopes and principal uses), except that summing is across both isotopes and principal uses. 
Table B-4. The mean and standard error of the activity of PGTCC sources by isotope and device type (not adjusted for decay).

\begin{tabular}{|c|c|c|c|c|c|}
\hline Device type & Isotope & $\begin{array}{l}\text { Number } \\
\text { of sources }\end{array}$ & Distribution $^{\mathbf{b}}$ & $\begin{array}{c}\text { Mean } \\
\text { activity (mCi) }\end{array}$ & $\begin{array}{c}\text { Standard } \\
\text { error }(\mathrm{mCi})\end{array}$ \\
\hline Calibration & Am-241 & 774 & $\mathrm{~L}$ & 536 & 78 \\
\hline Calibration & $C-14$ & 7 & $\mathrm{~N}$ & 20 & 7 \\
\hline Calibration & $\mathrm{Cm}-244$ & 10 & $\mathrm{~N}$ & 93 & 50 \\
\hline Calibration & Cs-137 & 992 & $\mathrm{~L}$ & 33,777 & 8,842 \\
\hline Calibration & $\mathrm{Ni}-63$ & 33 & $\mathrm{~N}$ & 34 & 7 \\
\hline Calibration & Np-237 & 3 & $\mathrm{~N}$ & 7 & $\mathrm{NA}^{\mathrm{c}}$ \\
\hline Calibration & $\mathrm{Pu}-238$ & 1 & $\mathbf{N}$ & 482 & NA \\
\hline Calibration & Pu-239 & 80 & $\mathrm{~L}$ & 25,186 & 14,627 \\
\hline Calibration & $\mathrm{Pu}-241$ & 1 & $\mathrm{~N}$ & 8 & NA \\
\hline Calibration & Sr-90 & 558 & $\mathrm{~N}$ & 170 & 4 \\
\hline Calibration & Tc-99 & 5 & $\mathrm{~N}$ & 4 & 2 \\
\hline Calibration & $\mathrm{U}-238$ & 8 & $\mathrm{~N}$ & 5 & 1 \\
\hline Medical & Am-241 & 100 & $\mathbf{L}$ & 30 & 3 \\
\hline Medical & Cs-137 & 344 & $\mathbf{L}$ & 699 & 44 \\
\hline Medical & Sr-90 & 7 & $\mathrm{~N}$ & 197 & 51 \\
\hline Medical & Tc-99 & 1 & $\mathrm{~N}$ & 1,000 & NA \\
\hline Medical & U-238 & 8 & $\mathrm{~N}$ & 212 & 154 \\
\hline Well logging & Am-241 & 1,252 & $\mathrm{~N}$ & 7,690 & 193 \\
\hline Well logging & Cs-137 & 625 & $\mathbf{N}$ & 1,447 & 20 \\
\hline Well logging & $\mathrm{Pu}-238$ & 50 & $\mathbf{N}$ & 10,454 & 882 \\
\hline Well logging & $\mathrm{Pu}-241$ & 1 & $\mathrm{~N}$ & 42,500 & NA \\
\hline Portable gauge & $\mathrm{Am}-241$ & 4,439 & $\mathrm{~N}$ & 45 & 1 \\
\hline Portable gauge & Cs-137 & 29 & $\mathrm{~L}$ & 351 & 62 \\
\hline Irradiation & Am-241 & 38 & $\mathrm{~N}$ & 656 & 104 \\
\hline Irradiation & Cs-137 & 476 & $\mathrm{~N}$ & $1,252,145$ & 90,280 \\
\hline Irradiation & Sr-90 & 2 & $\mathbf{N}$ & 5,680 & 4,320 \\
\hline Fixed gauge & $A m-241$ & 662 & $\mathrm{~L}$ & 932 & 99 \\
\hline Fixed gauge & $C-14$ & 10 & $\mathrm{~N}$ & 5 & NA \\
\hline Fixed gauge & $\mathrm{Cm}-244$ & 5 & $\mathrm{~N}$ & 20 & 5 \\
\hline Fixed gauge & Cs-137 & 8,612 & L & 339 & 7 \\
\hline Fixed gauge & $\mathrm{Pu}-238$ & 1 & $\mathrm{~N}$ & 500 & NA \\
\hline Fixed gauge & Sr-90 & 33 & $\mathrm{~L}$ & 216 & 53 \\
\hline General neutron applications & Am-241 & 430 & $\mathrm{~N}$ & 557 & 174 \\
\hline General neutron applications & $\mathrm{Pu}-238$ & 33 & $\mathbf{N}$ & 14,465 & 2,564 \\
\hline
\end{tabular}


Table B-4. (continued).

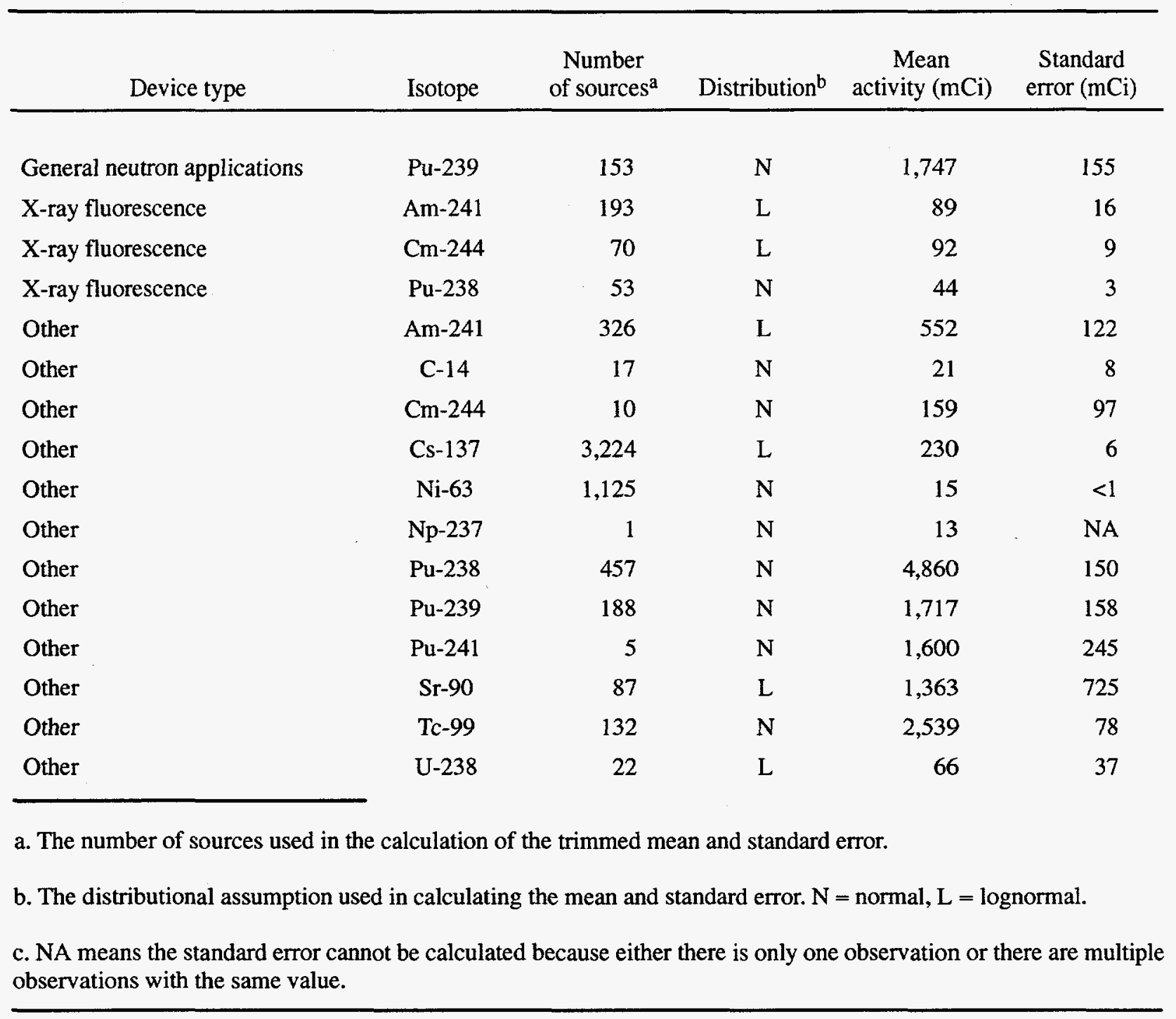

\section{B-1.3.2 Confidence Intervals for the Total Activity of PGTCC Sources - Results}

Table B-5 shows the upper and lower limits of the $95 \%$ confidence intervals on the total activity of PGTCC sources. Note that the vast majority of the total activity is due to irradiation devices with Cs-137 sources, accounting for over $95 \%$ of the total activity. Note also that the calculated activities are not adjusted for decay. Adjustment for decay is discussed further in Section B-2.7.

Many of the lower confidence limits are set to zero (the actual calculated values were less than zero). This is due to large variation in either the estimated mean activity or number of sources. Generally, this is not a problem for the most frequently occurring device types and isotopes. 
Table B-5. Summary statistics for the projection of the total activity (Ci) of PGTCC sources (not adjusted for decay).

\begin{tabular}{|c|c|c|c|c|c|}
\hline \multirow[b]{2}{*}{ Device Type } & \multirow[b]{2}{*}{ Isotope } & \multirow{2}{*}{$\begin{array}{c}\text { Total } \\
\text { Activity }^{\mathrm{a}}\end{array}$} & \multirow{2}{*}{$\begin{array}{c}\text { Standard } \\
\text { Error of Total }\end{array}$} & \multicolumn{2}{|c|}{$95 \%$ Confidence Interval } \\
\hline & & & & Lowerb & Upper \\
\hline Calibration & Am-241 & 1,608 & 520 & 588 & 2,628 \\
\hline Calibration & C-14 & $<1$ & $<1$ & 0 & 1 \\
\hline Calibration & $\mathrm{Cm}-244$ & 3 & 2 & 0 & 7 \\
\hline Calibration & Cs-137 & 115,855 & 35,134 & 46,993 & 184,717 \\
\hline Calibration & $\mathrm{Ni}-63$ & 4 & 2 & 0 & 8 \\
\hline Calibration & $\mathrm{Np}-237$ & $<1$ & $N A^{d}$ & NA & NA \\
\hline Calibration & $\mathrm{Pu}-238$ & 20 & 7 & 6 & 34 \\
\hline Calibration & Pu-239 & 6,926 & 4,739 & 0 & 16,214 \\
\hline Calibration & $\mathrm{Pu}-241$ & $<1$ & NA & NA & NA \\
\hline Calibration & Sr-90 & 328 & 190 & 0 & 701 \\
\hline Calibration & Tc-99 & $<1$ & $<1$ & 0 & $<1$ \\
\hline Calibration & $\mathrm{U}-238$ & $<1$ & $<1$ & 0 & $<1$ \\
\hline Medical & Am-241 & 10 & 3 & 5 & 16 \\
\hline Medical & Cs-137 & 828 & 254 & 330 & 1,326 \\
\hline Medical & Sr-90 & 5 & 2 & 1 & 9 \\
\hline Medical & Tc-99 & 3 & 3 & 0 & 9 \\
\hline Medical & U-238 & 6 & 5 & 0 & 16 \\
\hline Well logging & Am-241 & 33,152 & 12,735 & 8,191 & 58,112 \\
\hline Well logging & Cs-137 & 3,117 & 1,283 & 602 & 5,631 \\
\hline Well logging & $\mathrm{Pu}-238$ & 1,798 & 1,529 & 0 & 4,794 \\
\hline Well logging & $\mathrm{Pu}-241$ & 128 & 128 & 0 & 377 \\
\hline Portable gauge & Am-241 & 688 & 60 & 571 & 806 \\
\hline Portable gauge & Cs-137 & 40 & 13 & 15 & 65 \\
\hline Irradiation & Am-241 & 102 & 55 & 0 & 209 \\
\hline Irradiation & Cs-137 & $2,068,544$ & 296,363 & $1,487,672$ & $2,649,415$ \\
\hline Irradiation & $\mathrm{Sr}-90$ & 57 & 56 & 0 & 167 \\
\hline Fixed gauge & Am-241 & 2,123 & 374 & 1,389 & 2,857 \\
\hline Fixed gauge & C-14 & $<1$ & NA & NA & NA \\
\hline Fixed gauge & $\mathrm{Cm}-244$ & $<1$ & $<1$ & 0 & 1 \\
\hline Fixed gauge & Cs- 137 & 10,051 & 837 & 8,410 & 11,692 \\
\hline Fixed gauge & $\mathrm{Pu}-238$ & 2 & 2 & 0 & 4 \\
\hline Fixed gauge & Sr-90 & 25 & 8 & 8 & 41 \\
\hline
\end{tabular}


Table B-5. (continued).

\begin{tabular}{|c|c|c|c|c|c|}
\hline \multirow{2}{*}{ Device Type } & \multirow{2}{*}{ Isotope } & \multirow{2}{*}{$\begin{array}{c}\text { Total } \\
\text { Activitya }\end{array}$} & \multirow{2}{*}{$\begin{array}{c}\text { Standard } \\
\text { Error of Total }\end{array}$} & \multicolumn{2}{|c|}{$95 \%$ Confidence Interval } \\
\hline & & & & Lower ${ }^{b}$ & Upper \\
\hline General neutron applications & Am-241 & 824 & 289 & 257 & 1,391 \\
\hline General neutron applications & $\mathrm{Pu}-238$ & 1,649 & 643 & 388 & 2,910 \\
\hline General neutron applications & Pu-239 & 919 & 192 & 543 & 1,295 \\
\hline $\mathrm{X}$-ray fluorescence & Am-241 & 61 & 17 & 28 & 94 \\
\hline $\mathrm{X}$-ray fluorescence & $\mathrm{Cm}-244$ & 22 & 9 & 4 & 40 \\
\hline $\mathrm{X}$-ray fluorescence & Cs-137 & $<1$ & NA & NA & NA \\
\hline$X$-ray fluorescence & $\mathrm{Pu}-238$ & 8 & 3 & 1 & 15 \\
\hline Other & Am-241 & 621 & 169 & 291 & 951 \\
\hline Other & $\mathrm{C}-14$ & 1 & 1 & 0 & 3 \\
\hline Other & $\mathrm{Cm}-244$ & 5 & 4 & 0 & 13 \\
\hline Other & Cs-137 & 2,552 & 1,212 & 176 & 4,928 \\
\hline Other & Ni-63 & 58 & 30 & 0 & 117 \\
\hline Other & $\mathrm{Np}-237$ & $<1$ & NA & NA & NA \\
\hline Other & $\mathrm{Pu}-238$ & 7,659 & 5,281 & 0 & 18,010 \\
\hline Other & $\mathrm{Pu}-239$ & 1,123 & 269 & 596 & 1,650 \\
\hline Other & $\mathrm{Pu}-241$ & 34 & 17 & 0 & 67 \\
\hline Other & Sr-90 & 408 & 244 & 0 & 886 \\
\hline Other & Tc-99 & 1,153 & 783 & 0 & 2,688 \\
\hline Other & U-238 & 5 & 3 & 0 & 12 \\
\hline Calibration & Total $^{\mathrm{e}}$ & 124,744 & 35,456 & 55,249 & 194,239 \\
\hline Medical & Totale & 852 & 254 & 354 & 1,350 \\
\hline Well logging & Total $^{\mathrm{e}}$ & 38,195 & 12,891 & 12,928 & 63,462 \\
\hline Portable gauge & Total $^{\mathbf{e}}$ & 728 & 61 & 608 & 848 \\
\hline Irradiation & Total $^{e}$ & $2,068,703$ & 296,363 & $1,487,831$ & $2,649,575$ \\
\hline Fixed gauge & Total $^{e}$ & 12,201 & 917 & 10,404 & 13,998 \\
\hline General neutron applications & Total $^{\mathrm{e}}$ & 3,392 & 731 & 1,960 & 4,824 \\
\hline $\mathrm{X}$-ray fluorescence & Total $^{e}$ & 91 & 19 & 53 & 129 \\
\hline Other & Totale & 13,619 & 5,489 & 2,860 & 24,378 \\
\hline Total $^{\mathrm{e}}$ & Am-241 & 39,189 & 12,756 & 14,188 & 64,190 \\
\hline Totale & C-14 & 1 & 1 & 0 & 3 \\
\hline Totale & $\mathrm{Cm}-244$ & 30 & 10 & 10 & 50 \\
\hline Total ${ }^{e}$ & Cs-137 & $2,200,987$ & 298,445 & $1,616,035$ & $2,785,939$ \\
\hline Total $^{e}$ & $\mathrm{Ni}-63$ & 62 & 30 & 3 & 121 \\
\hline Totale & $\mathrm{Np}-237$ & $<1$ & NA & NA & NA \\
\hline
\end{tabular}


Table B-5. (continued).

\begin{tabular}{|c|c|c|c|c|c|}
\hline \multirow[b]{2}{*}{ Device Type } & \multirow[b]{2}{*}{ Isotope } & \multirow{2}{*}{$\begin{array}{l}\text { Total } \\
\text { Activity }\end{array}$} & \multirow{2}{*}{$\begin{array}{l}\text { Standard } \\
\text { Error of Total }\end{array}$} & \multicolumn{2}{|c|}{$95 \%$ Confidence Interval } \\
\hline & & & & Lower $^{b}$ & Upper \\
\hline Total $^{e}$ & $\mathrm{Pu}-238$ & 11,136 & 5,535 & 287 & 21,985 \\
\hline Total ${ }^{\mathrm{e}}$ & $\mathrm{Pu}-239$ & 8,968 & 4,751 & 0 & 18,279 \\
\hline Total $^{e}$ & $\mathrm{Pu}-241$ & 162 & 129 & 0 & 415 \\
\hline Totale & Sr-90 & 823 & 314 & 207 & 1,439 \\
\hline Total $^{\mathrm{e}}$ & Tc-99 & 1,156 & 783 & 0 & 2,691 \\
\hline Totale & $\mathrm{U}-238$ & 11 & 6 & 0 & 22 \\
\hline Totale & Total & $2,262,525$ & 298,808 & $1,676,862$ & $2,848,188$ \\
\hline \multicolumn{6}{|c|}{ a. The total activity corresponds to the base case scenario estimates. } \\
\hline \multicolumn{6}{|c|}{ b. The lower confidence limit corresponds to the low case scenario estimates. } \\
\hline \multicolumn{6}{|c|}{ c. The upper confidence limit corresponds to the high case scenario estimates. } \\
\hline \multicolumn{6}{|c|}{$\begin{array}{l}\text { d. NA means the values cannot be calculated because the variance of the mean activity is not available (due to too few } \\
\text { observations). }\end{array}$} \\
\hline
\end{tabular}




\section{B-2. QUALITATIVE UNCERTAINTY ASSESSMENT}

A number of the uncertainties and assumptions contained in the report cannot be subject to a strict quantitative analysis. In Section 1 of this Appendix, a quantitative assessment of the uncertainty in projecting results to all specific licensees is presented. In this section those assumptions and uncertainties that cannot be quantitatively analyzed are reviewed and their potential impacts on the results are assessed. Table B-6 gives an overview of these sources of uncertainty and their potential impact on the results.

The discussion focuses on how the uncertainties impact the number of PGTCC sources calculated in this report. It is assumed that their impact on the total activity and total volume is similar, unless noted otherwise.

\section{B-2.1 Concentration Averaging}

Because the regulatory definition of GTCC waste is in units of concentration, source activities given in the survey responses had to be converted to concentration to determine if the source is PGTCC material. An issue in determining the concentration is the selection of the volume to average the activity over. When they were open and operating, the low-level waste disposal sites in Beatty and Hanford, as well as the NRC, considered it acceptable to concentration average over the volume of the waste container. The container is typically a 55-gal drum filled with cement. However, Barnwell does not allow this.

Another alternative would be to average only over the volume of the radioactive material inside the source capsule. This alternative is not realistic. Removing the material from the capsule for disposal purposes is both hazardous and self-defeating. Source capsules are designed to meet strict standards to eliminate leakage of the material - the source capsule is itself a safe containment device.

Since it is not clear what concentration averaging scenario will be applied to radioactive waste in sealed source form in the future, this report averages activities over the volume of the source, including the capsule. This is the smallest reasonable volume to average over. The use of the smallest volume allows the greatest flexibility for assessing different packaging and concentration averaging scenarios that will later be applied to the results of this data as part of another study.

The impact of this method of averaging activities over source volumes is to grossly overestimate the number of sources that will likely need to be disposed. Hence, throughout this report, the author has emphasized that the sources are "Potential" GTCC material.

Non-TRU sources are particularly overestimated using this method. If concentration averaging over the volume of the waste container is allowed in the future, then, assuming the container is a 55-gal drum, the source activity limits would be 910 and $1,400 \mathrm{Ci}$ for $\mathrm{Cs}-137$ and $\mathrm{Sr}-90$, respectively. In this report, the source activity limits are generally under $100 \mathrm{mCi}$. Hence, most non-TRU sources will not be GTCC waste (and can be disposed of at LLW facilities) under this concentration averaging scenario.

For TRU sources, the concentration averaging scenario does not impact the results much. This is because the regulatory limit is $100 \mathrm{nCi} / \mathrm{g}$. If averaging over a 55 -gal drum filled with cement, the corresponding source activity limit would be $27 \mathrm{mCi}$. While some of the TRU sources counted as "Potential" GTCC material fall between 1 and $27 \mathrm{mCi}$, the most common devices using TRU sources (fixed and portable gauges) use activities typically from 40 to $100 \mathrm{mCi}$.

The effect of concentration averaging over a 55-gal drum is shown in Appendix D, "Comparison to 1989 NRC Report Results." Note that while the estimates given in the body of this report likely grossly overestimate the true number of GTCC sources, this was done purposefully to allow the modeling effort 
greater flexibility. The actual number of GTCC sources will be reported in the Fall 1994 revision of DOE/ LLW-114.

\section{B-2.2 Source Volumes}

As discussed in Section 2.1 of this Appendix, the number of PGTCC sources depends heavily on the volume that the activity is averaged over. While that section does discuss why source volumes were selected, it does not discuss how the source volumes were determined.

Source volume information was not included in the survey. This meant that individual source's GTCC potential could not be specifically assessed without assigning volumes on a source model basis. Assigning volumes in this manner would have been a huge task that would not necessarily result in great increases in precision. Many of the responses did not include model numbers, gave incorrect model numbers, or listed models that are essentially no longer manufactured and difficult to get information on.

Source volumes are related to both the total activity of the source and to the use of the source. There is a direct relationship between the activity and source volume: as the activity increases the volume typically will be larger. The principal use of the source also impacts its volume. For example, in well logging where sources are exposed to extreme stresses from heat and pressure, the sources are relatively large. Also, the principal use is a predictor of the required activity and hence a predictor of source volume.

Hence, source volumes were assigned by principal use. Basically, available literature was reviewed to determine the range of volumes of the sources. This literature included manufacturers' catalogs and NRC and DOE documents. The assumed volumes were selected to be representative of the sources used in a particular device type. Selection of the assumed volume will only have major impacts on the PGTCC activity limits if the volumes are too large than the true volumes. As for estimating total unpackaged volumes, the selection of the assumed volumes is also important; however, since the selected volumes are representative of the sources, the low and high cases are likely to encompass the true unpackaged volume.

\section{B-2.3 Response Rate}

Some nonresponse is to be expected in any survey, particularly one done through the mail. Nonresponse can affect both the precision and accuracy of the results of the survey. The precision is affected by the reduced number of observations. Accuracy is affected when the nonrespondents are not similar to the respondents with respect to the information of interest.

The AS survey achieved a $57 \%$ response rate and the NRC survey achieved a $77 \%$ response rate. Overall, there was $75 \%$ response. A series of followup phone calls was made as part of the AS survey. For reasons detailed in sections 2.4.1 and 3.2 of this report, it was concluded that nonreceipt of the survey by the licensee was the most common reason for nonresponse to the AS survey.

From discussions with Steve Baggett of the NRC, surveys of this type may result in a bias towards larger, more organized companies. These companies keep better records, are more aware of regulations and radioactive materials licensing issues, and have personnel dedicated to the oversight of radioactive materials. Smaller companies may not have sophisticated tracking systems or personnel dedicated to oversight of radioactive materials. In the past, the NRC has adjusted its estimates to account for this bias by comparing results to what the manufacturers have sold (the number of sources or devices that have been sold cannot be exceeded by what licensees possess). 
Table B-6. Summary of the qualitative uncertainties and their potential impact on the results.

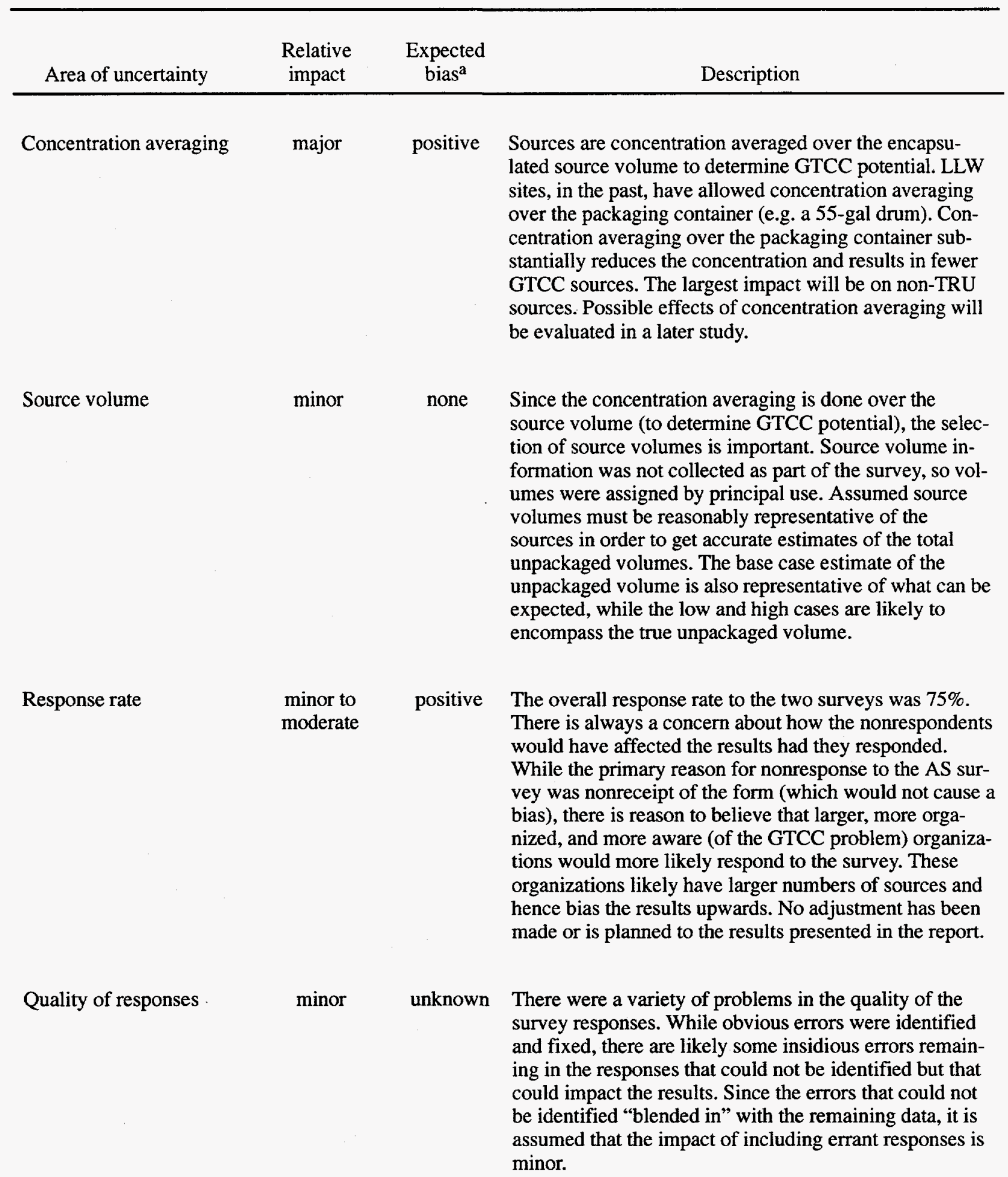


Table B-10. (continued).

\begin{tabular}{lccc}
\hline Relative & Expected \\
bias $^{\mathrm{a}}$ & Description \\
\hline
\end{tabular}

$1 \mathrm{mCi}$ Cutoff

micutoff

Differences between

NRC and AS licensees

Radionuclide decay moderate

negative
The survey was designed to get information on sources with activities greater than $1 \mathrm{mCi}$. The consensus is that sources with activities of less than $1 \mathrm{mCi}$ are currently disposed of at LLW sites. However, this assumes concentration averaging over a volume larger than the source volume; i.e., it differs from the assumption used in this report. Many (maybe even most) sources have activities under $1 \mathrm{mCi}$. When concentration averaging over the source volume, some of these would be considered PGTCC sources. Hence not including these sources in the survey creates an underestimate of the total number of PGTCC sources. However, the impact of using a 1 $\mathrm{mCi}$ cutoff on the overall goal of the project (to determine the amount of GTCC material) is probably trivial as there is no reason not to believe that these small activity sources cannot be disposed of at LLW sites in the future. No adjustment has been made or is planned to the results presented in this report.

minor none

The ratio of NRC survey responses to AS responses is about 9 to 1 ; yet the ratio of NRC licensees to AS licensees is about 1 to 2 . Hence, there is a heavy bias towards the NRC licensees. While there are some differences between the two populations of licensees, these differences should not substantially impact the results.

minor

positive

The source activities used in the report were not adjusted for decay. It is likely that for some sources that are classified as PGTCC in this report would not meet that classification if decay was taken into account. However, the overall impact is not expected to be very significant as some survey respondents did adjust their source activities for decay. More importantly, many of the radionuclides of interest have relatively long half-lives so that adjustment for decay would have little impact. It would have been impossible to adjust for decay because not all respondents provided dates of when the source was last measured, and some of those that did actually gave dates when the source was last leak tested, instead. The effect of adjusting for decay will, however, have a significant impact on the estimated activities.

a. The expected bias indicates whether the source of uncertainty causes a positive or negative bias in the results, as presented in this report. For example, a "positive" expected bias means that the results shown in the report likely overestimate the true values. 
Whether this bias is present in the current results is unclear. As a benchmark, it is known from manufacturers that there are at least 13,500 portable gauges. This report estimates approximately 15,500 gauges. While this may seem to be evidence of a positive bias in the results, when the uncertainty in the results is taken into account the $95 \%$ confidence limits safely enclose the 13,500 number.

As such, and since it is not clear how to adjust for such a bias if it does exist, no adjustment for nonresponse has been made to the results presented in this report.

\section{B-2.4 Quality of Responses}

The quality of the responses to the survey was the greatest problem encountered in the analysis of the survey data. Response quality is discussed in sections 2.4 and 4.1 in the main body of the report. The most common problems encountered were invalid responses to questions on the number of sources and source activities and mis-classification of the device type. Those sections discuss the actions taken to resolve the errors.

Virtually all the errors that were detected during data quality checks and during the analyses have been resolved. In a few cases (about 40 records out of 15,500) the problems were resolved through educated guesses. In no case where errors were subjectively resolved would the original error (had it been retained), nor the applied fix to the error, substantially impact the results.

However, there are certainly errors in the responses that were never identified. While the magnitude and impact of these errors is likely small, it is impossible to objectively assess these errors without resorting to resampling some of the survey respondents; such resampling is not justified or planned.

\section{B-2.5 $1 \mathrm{mCi}$ Cutoff}

The survey form sent to licensees asked them to report only sources with greater than $1 \mathrm{mCi}$ in activity. Had there been no activity cutoff point, the survey would have resulted in an overwhelming number of small sources. It would take licensees far more time to complete the survey and take the NRC and DOE far more time to compile the results; yet the information gained from including small sources would have little or no impact as these sources do not constitute a significant threat to the environment and public. In addition, these small activity sources are typically disposed at LLW facilities.

However, since this report concentration averages over the source, many of the small activity TRU sources are "Potential" GTCC material. The regulatory limit for TRUs for Class C LLW is $100 \mathrm{nCi} / \mathrm{g}$. If a source weighs about 1 pound $(454 \mathrm{~g})$, then the maximum activity of the source would be $45.4 \mu \mathrm{Ci}(0.0454$ $\mathrm{mCi})$. There are many calibration/check sources in the range of 0.05 to $1 \mathrm{mCi}$ with Am-241.

So the definition of "Potential" GTCC sources in essence was modified for this study to include the restriction that the source activity must be at least $1 \mathrm{mCi}$. It should be emphasized, however, that exclusion of these small activity sources will have no practical effect on the DOE's ability to assess the number of GTCC sources it must handle.

\section{B-2.6 NRC vs. AS Licensees}

The results from the NRC and AS surveys were combined without adjustment to extrapolate results to all specific licensees. The assumption is that the NRC and AS specific licensees are comparable. If this assumption is not true, it could significantly impact results.

Consider that the ratio of the number of responses to the NRC survey and the AS survey is 9 to 1 , yet the ratio of NRC specific licensees to AS specific licensees is 1 to 2. If the assumption of comparable populations is not met, the results are heavily biased towards the NRC results. 
To assess this assumption, a comparison between the two sets of results has been made. The first comparison which did show differences between the surveys was of the device type composition. These are shown in Table B-7. The primary differences in these results are the number of well logging devices and the "other" use category.

The well logging difference (4\% of the NRC sources, $23 \%$ of the AS sources) is due to Texas, an Agreement State, which is the home for most of the well logging companies. While these companies are typically licensed through both the NRC and Texas, the big companies (Schlumberger and Western Atlas Wireline, for example) responded to the AS survey but not to the NRC survey. Due to the downturn in the well logging industry, these companies have a large number of sources in storage. Hence, the AS survey reflects this. From discussions with manufacturers of well logging sources, there are about 4,000 to 5,000 Am-241 well logging sources. This report estimates there to be 4,300 well logging sources. So this difference in the surveys does not appear to impact the overall accuracy of the results.

Table B-7. Percentage of sources in each device type within the NRC and AS surveys.

\begin{tabular}{lrc}
\multicolumn{1}{c}{ Device type } & NRC survey & AS survey \\
\hline & & \\
Calibration & 9.99 & 10.19 \\
Medical & 1.66 & 2.25 \\
Well logging & 3.57 & 22.63 \\
Portable gauge & 17.55 & 16.40 \\
Irradiation & 2.07 & 1.93 \\
Fixed gauge & 35.93 & 36.62 \\
General neutron applications & 2.59 & 1.55 \\
X-ray fluorescence & 1.31 & 1.02 \\
Other & 25.32 & 7.04
\end{tabular}

The difference in the "other" use code ( $25 \%$ of the NRC and $7 \%$ of the AS) is more problematic to explain. While one would expect a higher proportion of non-well logging devices in the NRC states (to make up for the discrepancy in well logging devices), one would expect it to be evenly distributed among the other device types. However, it appears to all be in the "other" use type. All records were reviewed (as discussed in section 4.1) to more accurately determine the device type. Hence, this anomaly remains unexplained. While it certainly affects the estimated number of PGTCC sources in the other use category, it does not appear to impact the other device types.

One other notable difference between the two sets of survey results was observed. From Table 4-1 of the main body of this report, the average number of PGTCC sources per licensee with PGTCC sources is 14 for the AS respondents and 9 for the NRC respondents. This is in part due to the difference in well loggers, as discussed above.

Overall, then, while there are differences between the AS and NRC licensees, these differences are relatively minor and should have little impact on the results. 


\section{B-2.7 Radionuclide Decay}

The activity of a radioactive source is diminished over time through the process of decay. The amount of decay and reduction in activity, occurring over a given period of time, depends upon the half-life of the radionuclide; the longer the half-life, the less reduction in activity for a fixed period of time. Table B-8 shows the half-lives of the radionuclides considered PGTCC in this report.

Most of the sources and devices contained in the survey are likely to have been purchased since the early 1960 's. Hence, some of the sources are more than of 30 years old. From Table B-8, Cm-244, Cs-137, Ni-63, $\mathrm{Pu}-238, \mathrm{Pu}-241$, and $\mathrm{Sr}-90$ all have half-lives of roughly this order of magnitude. It would therefore seem reasonable to adjust the results to account for decay.

However, adjusting the relatively short-life TRUs ( $\mathrm{Cm}-244, \mathrm{Pu}-238$, and $\mathrm{Pu}-239)$ for decay would have little impact on the results in this report because the cutoff activity for these sources is $1 \mathrm{mCi}$ and virtually all these sources had activities greater than $2 \mathrm{mCi}$. Additionally, there were few $\mathrm{Ni}-63$ and $\mathrm{Sr}-90$ sources that were determined to be PGTCC; so adjusting for these isotopes would not have much impact either.

However, Cs-137 was the most frequent PGTCC source and its PGTCC activity limits, as given in Table 3-1 of the report, ranged from $1 \mathrm{mCi}$ to $184 \mathrm{mCi}$, depending upon the principal use. Adjusting the Cs- 137 results for decay would therefore impact the results. Adjustment for decay would have the largest impact on the fixed gauge sources.

The fixed gauge sources using Cs-137 range in activity from $10 \mathrm{mCi}$ to well over $1 \mathrm{Ci}$. Most of the PGTCC sources are around $100 \mathrm{mCi}$, with roughly $15 \%$ of the sources less than $30 \mathrm{mCi}$. The base case activity limit for $\mathrm{Cs}-137$ fixed gauge sources is $13.8 \mathrm{mCi}$. Assuming that $10 \%$ of the sources are about 30 years old, then about $1 \%(10 \%$ of $10 \%)$ would have decayed to below the limit. This amount of uncertainty is well within the limits established in section B-1.

While it would be desirable to adjust the results for decay, the survey does not provide sufficient information about the sources to do this reliably. The survey did ask the respondent to enter the date the source was last measured. About $50 \%$ of the respondents did not enter this information. Of the remaining $50 \%$, many of those, say $30 \%$, filled in the date the source was last leak tested. Hence, the survey data for the age of each individual source is unreliable. To implement an adjustment for decay in the analysis would have required more assumptions (and hence introduce more error) than the author thought justified considering the small effect such an adjustment would have. The above discussion indicates that decay causes at most a 2 to $3 \%$ overestimate of the number of PGTCC sources.

However, the activity estimates given in the report, which are not adjusted for decay, are significantly reduced when decay is taken into account. For example, assume that the activity of sources sold each year is uniform over a 35 year period (that is, if there was $35 \mathrm{Ci}$ total, then assume that $1 \mathrm{Ci}$ was sold each year over the past 35 years). The total activity of each isotope can be seen in Table B-5 for the base case. Adjusting these values for decay under the uniform assumption results in nearly a one third decrease in the total activity, with most of that decrease associated with cesium-137. The results are shown in Table B-9. 
Table B-8. Half-lifes, in years, of the radionuclides that can be GTCC LLW.

\begin{tabular}{cc}
\hline Isotope & Half-life \\
\cline { 2 - 3 } & \\
Am-241 & 433 \\
C-14 & 5,730 \\
Cm-244 & 18.11 \\
Cs-137 & 30.17 \\
Ni-63 & 100 \\
Np-237 & $2.14 \times 10^{6}$ \\
Pu-238 & 87.74 \\
Pu-239 & $2.41 \times 10^{4}$ \\
Pu-241 & 14.4 \\
Sr-90 & 28.8 \\
Tc-99 & $2.14 \times 10^{5}$ \\
U-238 & $4.47 \times 10^{9}$ \\
\hline
\end{tabular}

Table B-9. Summary example of the effect of decay on the activity estimates. The analysis assumes that the total activity for each isotope is distributed over a 35-year period.

\begin{tabular}{lrrr}
\hline & & & \\
Isotope & Initial activity (Ci) & Decayed activity (Ci) & $\begin{array}{c}\text { \% oftivity remaining } \\
\text { after decay }\end{array}$ \\
\hline Am-241 & 39,189 & 38,081 & 97 \\
C-14 & 1 & 1 & 100 \\
Cm-244 & 30 & 16 & 54 \\
Cs-137 & $2,200,987$ & $1,495,016$ & 68 \\
Ni-63 & 62 & 55 & 88 \\
Np-237 & 1 & 1 & 100 \\
Pu-238 & 11,136 & 9,691 & 87 \\
Pu-239 & 8,968 & 8,963 & 400 \\
Pu-241 & 162 & 76 & 67 \\
Sr-90 & 823 & 550 & 100 \\
Tc-99 & 1,156 & 1,156 & 100 \\
U-238 & 11 & 11 & 69 \\
& & & \\
Total & $2,262,526$ & $1,553,617$ & \\
\hline
\end{tabular}


Thus, the use of the activity estimates given in this report should take into consideration that the estimates are not adjusted for decay. In order to adjust for decay, assumptions similar to that given in the example above must be made. A further complicating factor is that some of the activities given by the survey respondents were adjusted for decay and others were not.

Based on knowledge of the data and cautious judgment, it would be reasonable to reduce the total activity and cesium activity estimates by $20 \%$ to get a more accurate, but conservative, estimate of the activities after adjusting for decay. Adjusting the other isotopes for decay is relatively inconsequential unless the user is interested in a particular isotope.

\section{B-3. SUMMARY}

There are some important uncertainties in the results reported in this document. While the quantitative uncertainties in the estimated number of PGTCC sources are reasonable, the uncertainties in the estimated total activities are fairly large. In addition, the activity estimates have not been adjusted for decay - which may reduce the overall activity estimate by up to $30 \%$ and reduce activity estimates of particular isotopes even more. Hence, caution should be taken in using the total activity results from this report without appropriate consideration of the uncertainties in the estimates.

The qualitative assessment of the uncertainty indicates that the largest source of error in the results is due to concentration averaging over the source volume. This was intended to allow flexibility in the application of these results in the projection model. In addition, a positive bias due to non-response may also be of concern.

\section{B-4. REFERENCES}

Cochran, William G. (1977), Sampling Techniques, Third Edition, John Wiley \& Sons, N.Y. 


\section{Appendix C}

\section{Sealed Source Activity Distributions}


C-2 


\section{Appendix C \\ Sealed Source Activity Distributions}

The cumulative distributions of the undecayed activities of PGTCC sources reported in the 1992 survey are shown in the following tables and figures. The figures show the empirical cumulative distribution functions. Note that the "Activity" axis of the plot is on a log scale to account for the magnitude of activities observed in the results. Note also that a value of " $10^{\wedge} n$ " given on the activity axis means " $1 \times 10^{n}$." The table following each figure shows the activity at every fifth percentile. For example, $40 \%$ of the americium-241 sources have activities less than or equal to $30 \mathrm{mCi}$.

Activities are included only if they are PGTCC material. If an activity exceeded the maximum activity reported in the NRC's Sealed Source and Device Registry for the particular combination of principal use and isotope, then that activity is not included in the calculations. The cumulative distribution function is calculated only if there are at least 10 observations with different activities.

In the plots, one will notice vertical lines. These lines are an indication that there are multiple sources at that activity level - the longer the vertical line, the more sources observed at that level. This generally indicates that activity level is common for the isotope and principal use. For example, nickel sources are most frequently $15 \mathrm{mCi}$ as this is the activity commonly used in electron capture detectors. Sometimes, however, it may indicate a survey response with many of the same model sources. For example, the strontium-90 calibration sources have over $50 \%$ at $190 \mathrm{mCi}$; this is due to only one licensee who had 383 of these sources, out of 558 total strontium- 90 calibration sources used in the calculations.

As well as providing more characterization of the sources currently in use, these distributions are given to provide the reader some flexibility in assessing the quantities of GTCC sealed sources. For example, if one assumes that only cesium sources greater than $30 \mathrm{Ci}$ will be GTCC LLW, the tables provide information on the percentage of sources that are greater than this value; multiplying this percentage by the results in Section 4 of the main body of this report for projected number of sources will give an estimate of the cesium GTCC sources.

There are limitations and uncertainties in these data. It is recommended that the reader scan Appendix B before using the results presented in this Appendix. 


\section{Am-241 Calibration Sources}

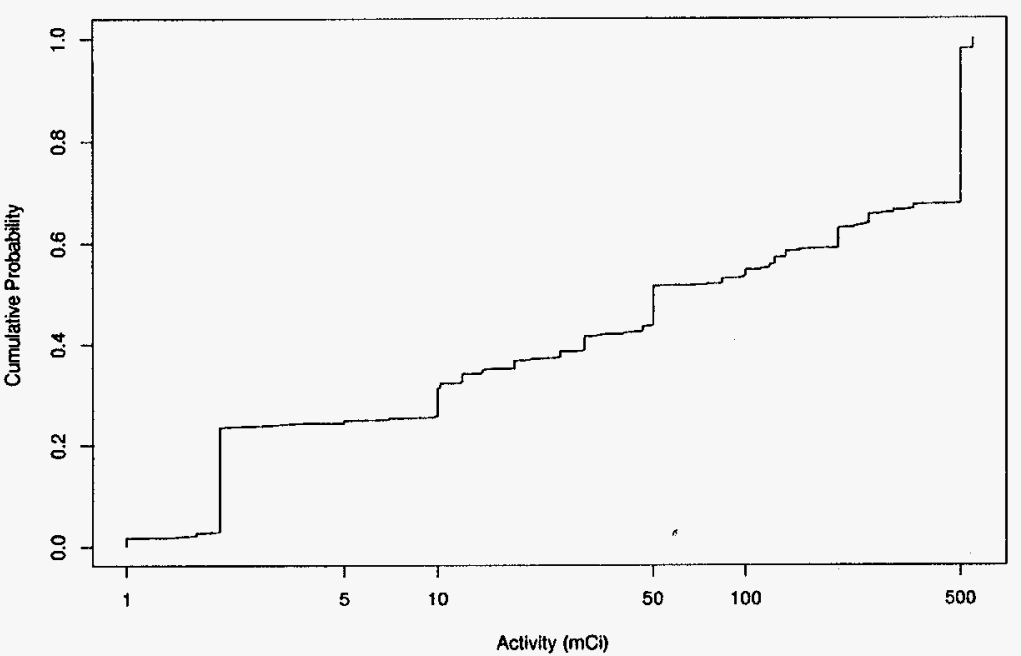

\begin{tabular}{cccc}
$\begin{array}{c}\text { Cumulative } \\
\text { probability }\end{array}$ & $\begin{array}{c}\text { Activity } \\
(\mathrm{mCi})\end{array}$ & $\begin{array}{c}\text { Cumulative } \\
\text { probability }\end{array}$ & $\begin{array}{c}\text { Activity } \\
(\mathrm{mCi})\end{array}$ \\
\hline $5 \%$ & 2 & $55 \%$ & 117 \\
$10 \%$ & 2 & $60 \%$ & 200 \\
$15 \%$ & 2 & $65 \%$ & 250 \\
$20 \%$ & 2 & $70 \%$ & 500 \\
$25 \%$ & 7 & $75 \%$ & 500 \\
$30 \%$ & 10 & $80 \%$ & 500 \\
$35 \%$ & 15 & $85 \%$ & 500 \\
$40 \%$ & 30 & $90 \%$ & 500 \\
$45 \%$ & 50 & $95 \%$ & 500 \\
$50 \%$ & 50 & $100 \%$ & 550 \\
\hline
\end{tabular}

\section{Cs-137 Calibration Sources}

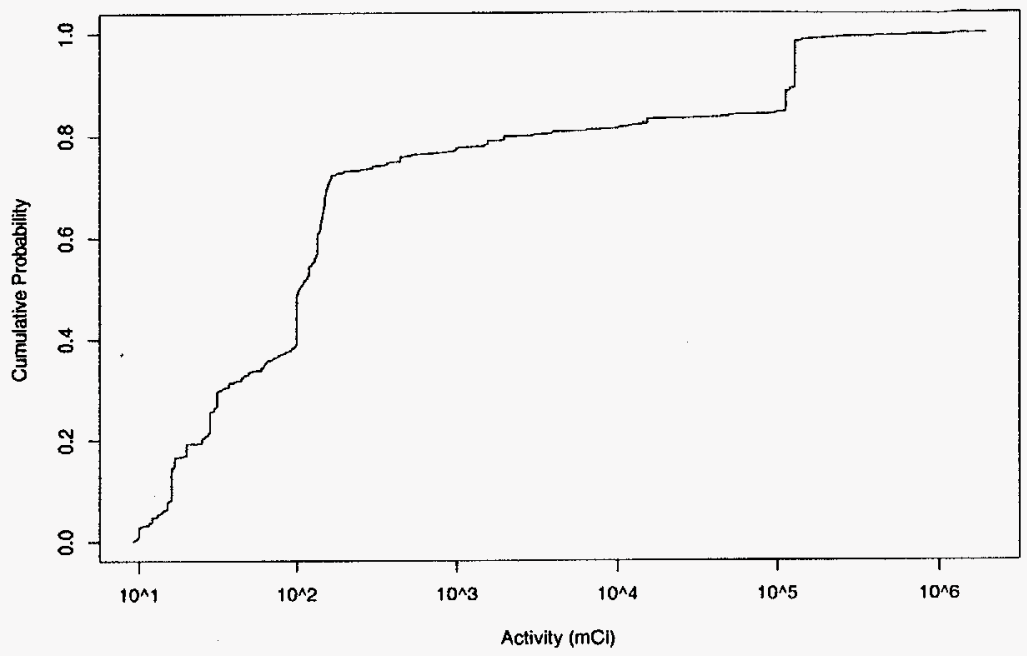

\begin{tabular}{cccc}
$\begin{array}{c}\text { Cumulative } \\
\text { probability }\end{array}$ & $\begin{array}{c}\text { Activity } \\
(\mathrm{mCi})\end{array}$ & $\begin{array}{c}\text { Cumulative } \\
\text { probability }\end{array}$ & $\begin{array}{c}\text { Activity } \\
(\mathrm{mCi})\end{array}$ \\
\hline & & & \\
$5 \%$ & 13 & $55 \%$ & 125 \\
$10 \%$ & 16 & $60 \%$ & 135 \\
$15 \%$ & 17 & $65 \%$ & 146 \\
$20 \%$ & 25 & $70 \%$ & 156 \\
$25 \%$ & 28 & $75 \%$ & 446 \\
$30 \%$ & 33 & $80 \%$ & 3,000 \\
$35 \%$ & 63 & $85 \%$ & 113,720 \\
$40 \%$ & 100 & $90 \%$ & 130,000 \\
$45 \%$ & 100 & $95 \%$ & 130,000 \\
$50 \%$ & 104 & $100 \%$ & $1,947,000$ \\
\hline
\end{tabular}


Ni-63 Calibration Sources

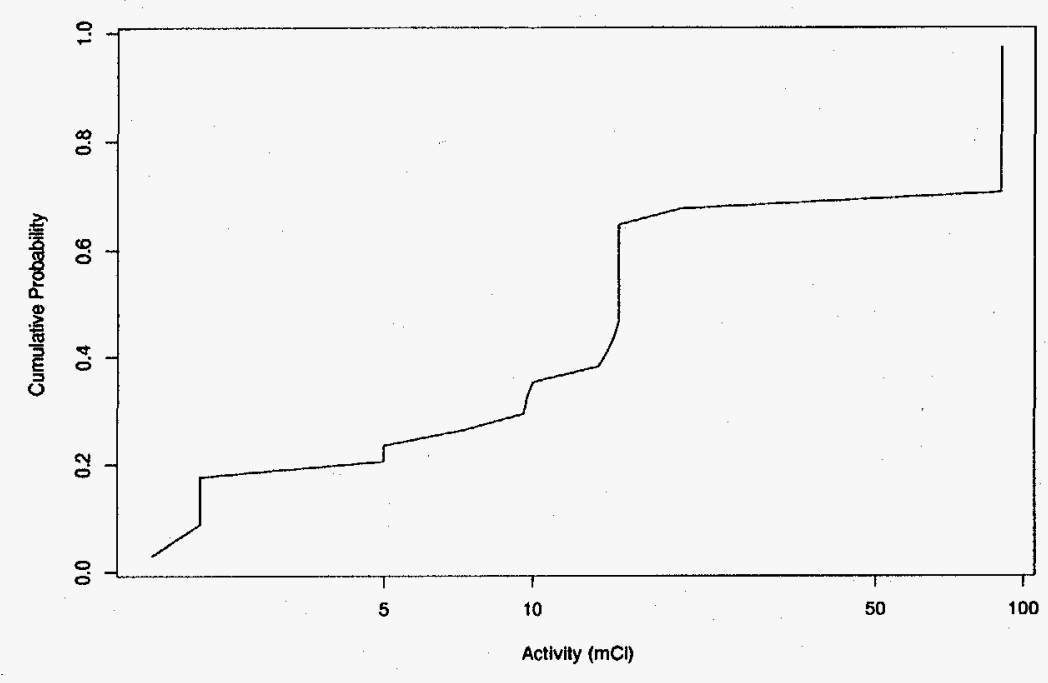

\begin{tabular}{cccc}
$\begin{array}{c}\text { Cumulative } \\
\text { probability }\end{array}$ & $\begin{array}{c}\text { Activity } \\
(\mathrm{mCi})\end{array}$ & $\begin{array}{c}\text { Cumulative } \\
\text { probability }\end{array}$ & $\begin{array}{c}\text { Activity } \\
(\mathrm{mCi})\end{array}$ \\
\hline $5 \%$ & 2 & $55 \%$ & 15 \\
$10 \%$ & 2 & $60 \%$ & 15 \\
$15 \%$ & 2 & $65 \%$ & 15 \\
$20 \%$ & 5 & $70 \%$ & 20 \\
$25 \%$ & 5 & $75 \%$ & 90 \\
$30 \%$ & 10 & $80 \%$ & 90 \\
$35 \%$ & 10 & $85 \%$ & 90 \\
$40 \%$ & 14 & $90 \%$ & 90 \\
$45 \%$ & 15 & $95 \%$ & 90 \\
$50 \%$ & 15 & $100 \%$ & 90 \\
\hline
\end{tabular}

Pu-239 Calibration Sources

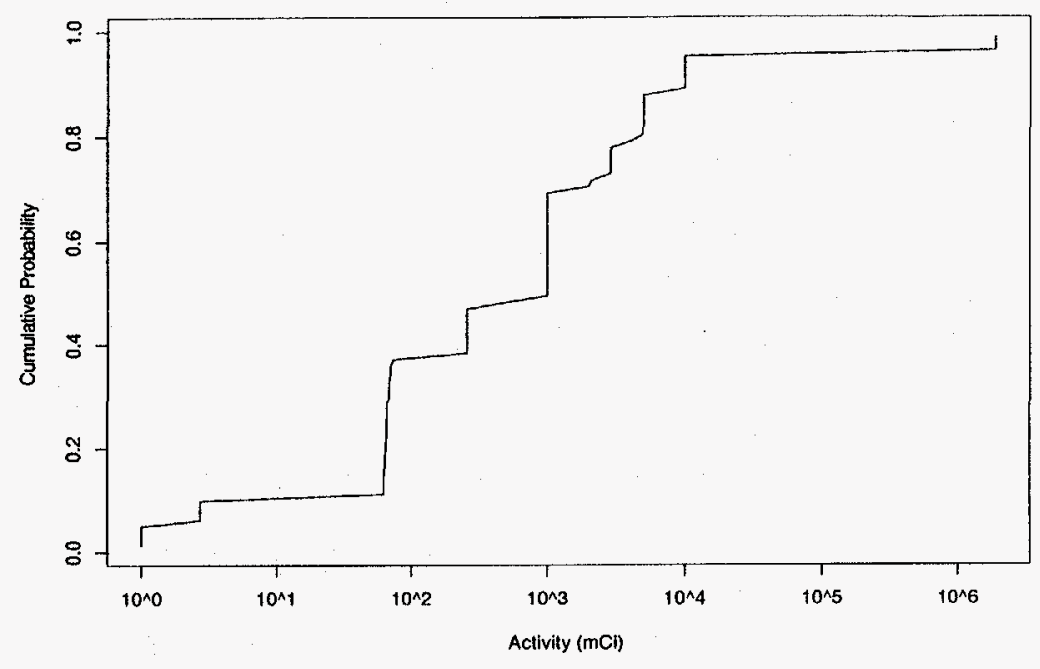

\begin{tabular}{cccc}
$\begin{array}{c}\text { Cumulative } \\
\text { probability }\end{array}$ & $\begin{array}{c}\text { Activity } \\
(\mathrm{mCi})\end{array}$ & $\begin{array}{c}\text { Cumulative } \\
\text { probability }\end{array}$ & $\begin{array}{c}\text { Activity } \\
(\mathrm{mCi})\end{array}$ \\
\hline & 1 & $55 \%$ & 999 \\
$5 \%$ & 3 & $60 \%$ & 1,000 \\
$10 \%$ & 62 & $65 \%$ & 1,000 \\
$15 \%$ & 65 & $70 \%$ & 1,000 \\
$20 \%$ & 65 & $75 \%$ & 2,921 \\
$25 \%$ & 67 & $80 \%$ & 4,050 \\
$30 \%$ & 70 & $85 \%$ & 5,000 \\
$35 \%$ & 256 & $90 \%$ & 9,945 \\
$40 \%$ & 256 & $95 \%$ & 10,000 \\
$45 \%$ & 992 & $100 \%$ & $1,877,000$ \\
$50 \%$ & & &
\end{tabular}




\section{Sr-90 Calibration Sources}

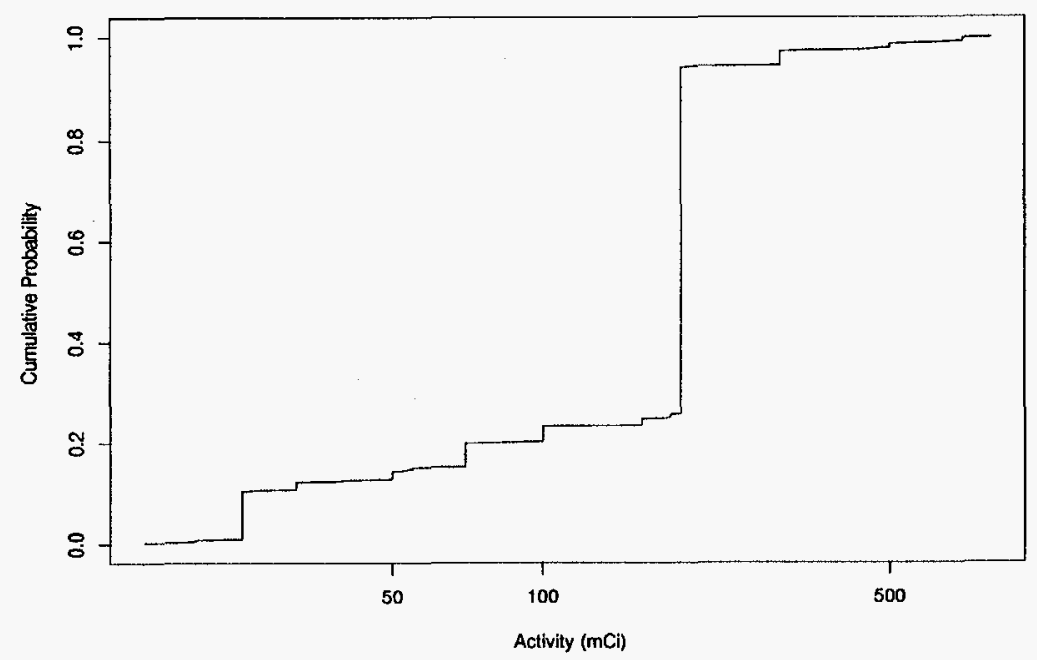

\begin{tabular}{cccc}
$\begin{array}{c}\text { Cumulative } \\
\text { probability }\end{array}$ & $\begin{array}{c}\text { Activity } \\
(\mathrm{mCi})\end{array}$ & $\begin{array}{c}\text { Cumulative } \\
\text { probability }\end{array}$ & $\begin{array}{c}\text { Activity } \\
(\mathrm{mCi})\end{array}$ \\
\hline $5 \%$ & 25 & $55 \%$ & 190 \\
$10 \%$ & 25 & $60 \%$ & 190 \\
$15 \%$ & 55 & $65 \%$ & 190 \\
$20 \%$ & 90 & $70 \%$ & 190 \\
$25 \%$ & 180 & $75 \%$ & 190 \\
$30 \%$ & 190 & $80 \%$ & 190 \\
$35 \%$ & 190 & $85 \%$ & 190 \\
$40 \%$ & 190 & $90 \%$ & 190 \\
$45 \%$ & 190 & $95 \%$ & 300 \\
$50 \%$ & 190 & $100 \%$ & 800 \\
\hline
\end{tabular}

Am-241 Medical Sources

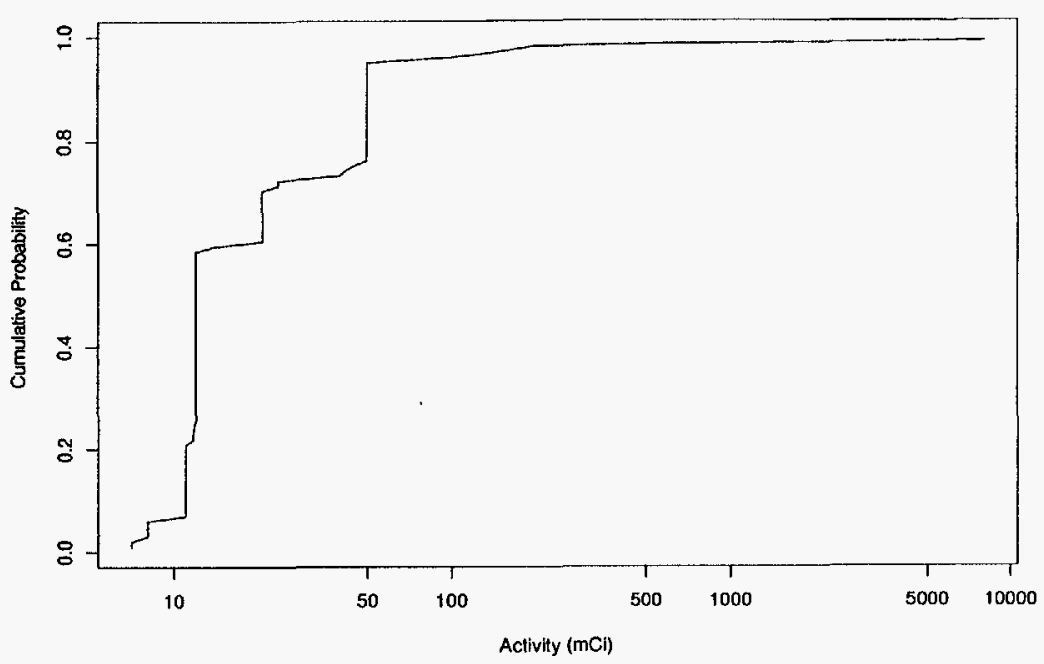

\begin{tabular}{cccc}
$\begin{array}{c}\text { Cumulative } \\
\text { probability }\end{array}$ & $\begin{array}{c}\text { Activity } \\
(\mathrm{mCi})\end{array}$ & $\begin{array}{c}\text { Cumulative } \\
\text { probability }\end{array}$ & $\begin{array}{c}\text { Activity } \\
(\mathrm{mCi})\end{array}$ \\
\hline $5 \%$ & 8 & $55 \%$ & 12 \\
$10 \%$ & 11 & $60 \%$ & 14 \\
$15 \%$ & 11 & $65 \%$ & 21 \\
$20 \%$ & 11 & $70 \%$ & 21 \\
$25 \%$ & 12 & $75 \%$ & 42 \\
$30 \%$ & 12 & $80 \%$ & 50 \\
$35 \%$ & 12 & $85 \%$ & 50 \\
$40 \%$ & 12 & $90 \%$ & 50 \\
$45 \%$ & 12 & $95 \%$ & 50 \\
$50 \%$ & 12 & $100 \%$ & 8,000 \\
\hline
\end{tabular}




\section{Cs-137 Medical Sources}

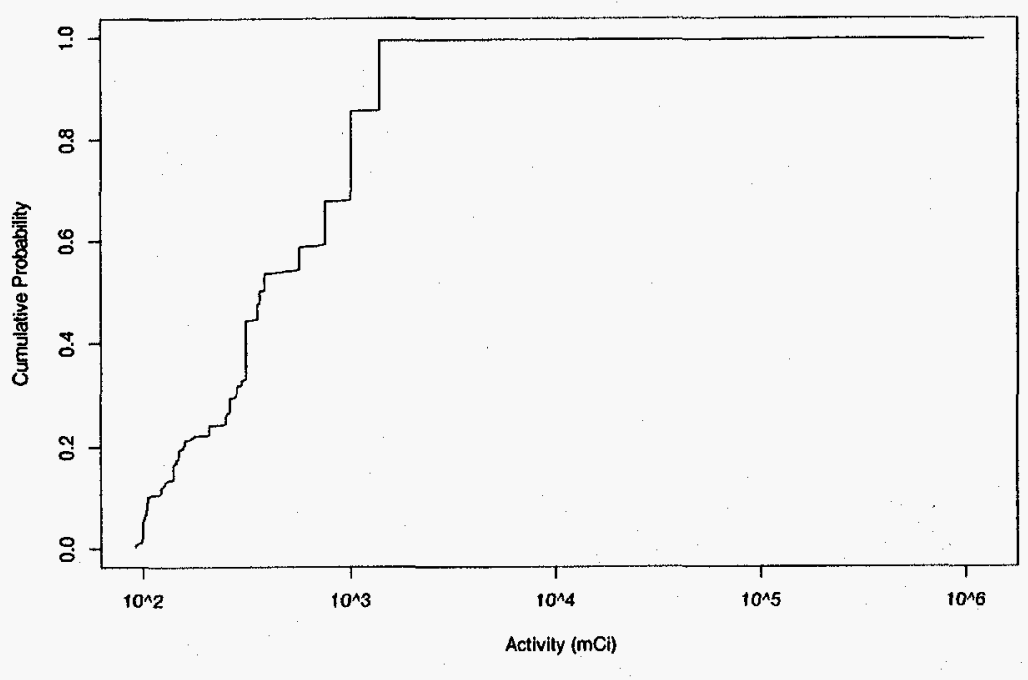

\begin{tabular}{cccc}
$\begin{array}{c}\text { Cumulative } \\
\text { probability }\end{array}$ & $\begin{array}{c}\text { Activity } \\
(\mathrm{mCi})\end{array}$ & $\begin{array}{c}\text { Cumulative } \\
\text { probability }\end{array}$ & $\begin{array}{c}\text { Activity } \\
(\mathrm{mCi})\end{array}$ \\
\hline $5 \%$ & 100 & $55 \%$ & 572 \\
$10 \%$ & 106 & $60 \%$ & 759 \\
$15 \%$ & 141 & $65 \%$ & 759 \\
$20 \%$ & 158 & $70 \%$ & 1,002 \\
$25 \%$ & 252 & $75 \%$ & 1,002 \\
$30 \%$ & 285 & $80 \%$ & 1,002 \\
$35 \%$ & 314 & $85 \%$ & 1,002 \\
$40 \%$ & 314 & $90 \%$ & 1,386 \\
$45 \%$ & 357 & $95 \%$ & 1,386 \\
$50 \%$ & 367 & $100 \%$ & $1,230,000$ \\
\hline
\end{tabular}

Am-241 Well Logging Sources

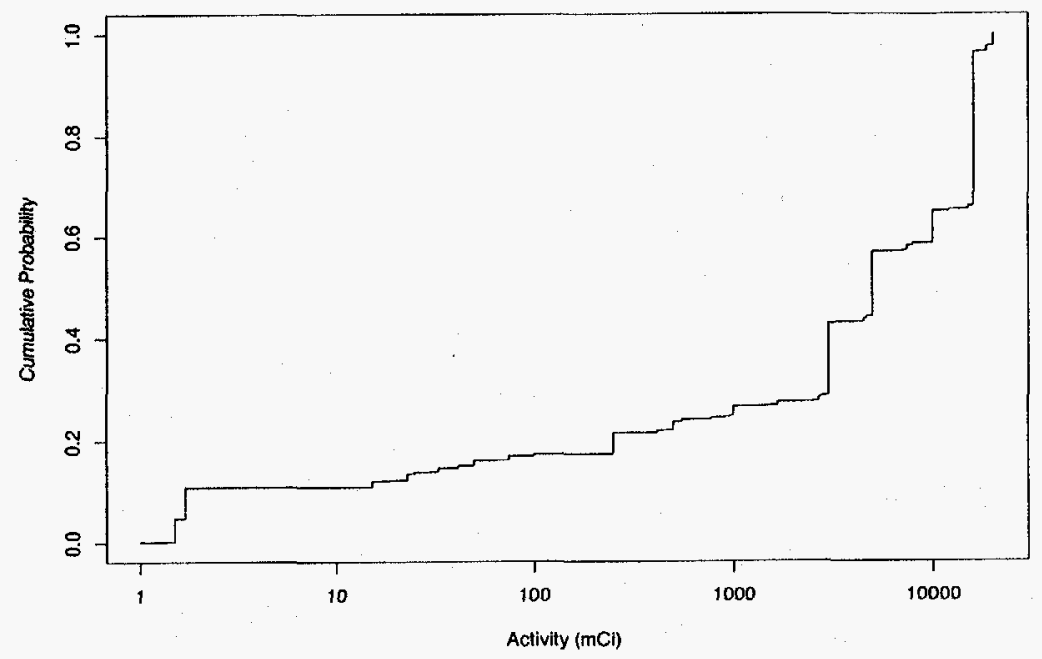

\begin{tabular}{cccc}
$\begin{array}{c}\text { Cumulative } \\
\text { probability }\end{array}$ & $\begin{array}{c}\text { Activity } \\
(\mathrm{mCi})\end{array}$ & $\begin{array}{c}\text { Cumulative } \\
\text { probability }\end{array}$ & $\begin{array}{c}\text { Activity } \\
(\mathrm{mCi})\end{array}$ \\
\hline $5 \%$ & 2 & $55 \%$ & 5,000 \\
$10 \%$ & 2 & $60 \%$ & 10,000 \\
$15 \%$ & 42 & $65 \%$ & 10,000 \\
$20 \%$ & 250 & $70 \%$ & 16,000 \\
$25 \%$ & 1,000 & $75 \%$ & 16,000 \\
$30 \%$ & 3,000 & $80 \%$ & 16,000 \\
$35 \%$ & 3,000 & $85 \%$ & 16,000 \\
$40 \%$ & 3,000 & $90 \%$ & 16,000 \\
$45 \%$ & 5,000 & $95 \%$ & 16,000 \\
$50 \%$ & 5,000 & $100 \%$ & 20,000 \\
\hline
\end{tabular}


Cs-137 Well Logging Sources

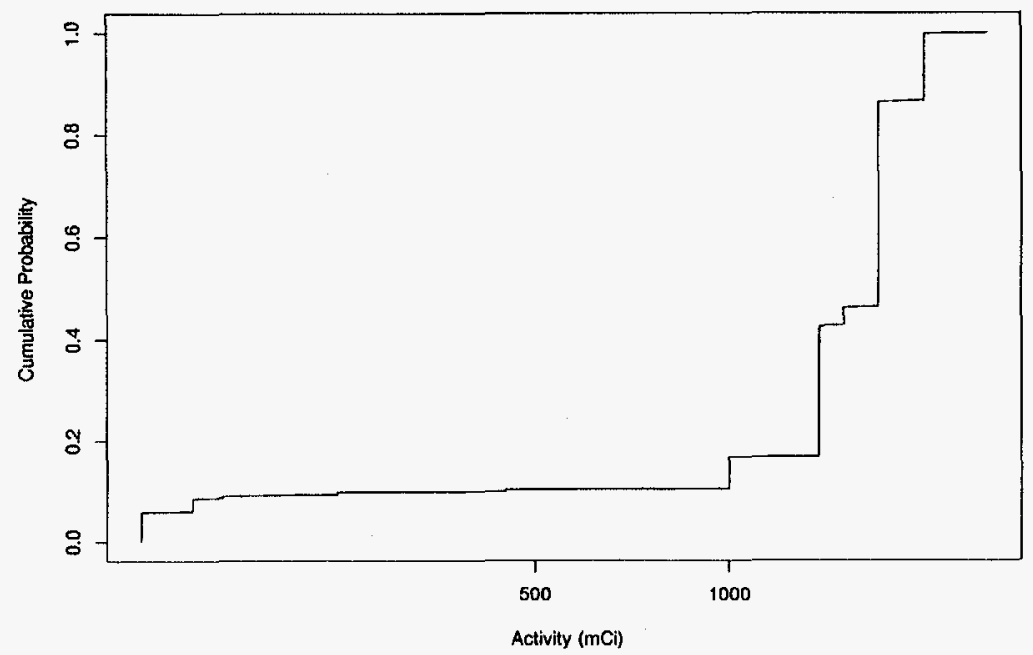

\&

\begin{tabular}{cccc}
$\begin{array}{c}\text { Cumulative } \\
\text { probability }\end{array}$ & $\begin{array}{c}\text { Activity } \\
(\mathrm{mCi})\end{array}$ & $\begin{array}{c}\text { Cumulative } \\
\text { probability }\end{array}$ & $\begin{array}{c}\text { Activity } \\
\text { (mCi) }\end{array}$ \\
\hline & & & \\
$5 \%$ & 125 & $55 \%$ & 1,700 \\
$10 \%$ & 450 & $60 \%$ & 1,700 \\
$15 \%$ & 1,000 & $65 \%$ & 1,700 \\
$20 \%$ & 1,376 & $70 \%$ & 1,700 \\
$25 \%$ & 1,376 & $75 \%$ & 1,700 \\
$30 \%$ & 1,376 & $80 \%$ & 1,700 \\
$35 \%$ & 1,376 & $85 \%$ & 1,700 \\
$40 \%$ & 1,376 & $90 \%$ & 2,000 \\
$45 \%$ & 1,500 & $95 \%$ & 2,000 \\
$50 \%$ & 1,700 & $100 \%$ & 2,500 \\
\hline
\end{tabular}

Pu-238 Well Logging Sources

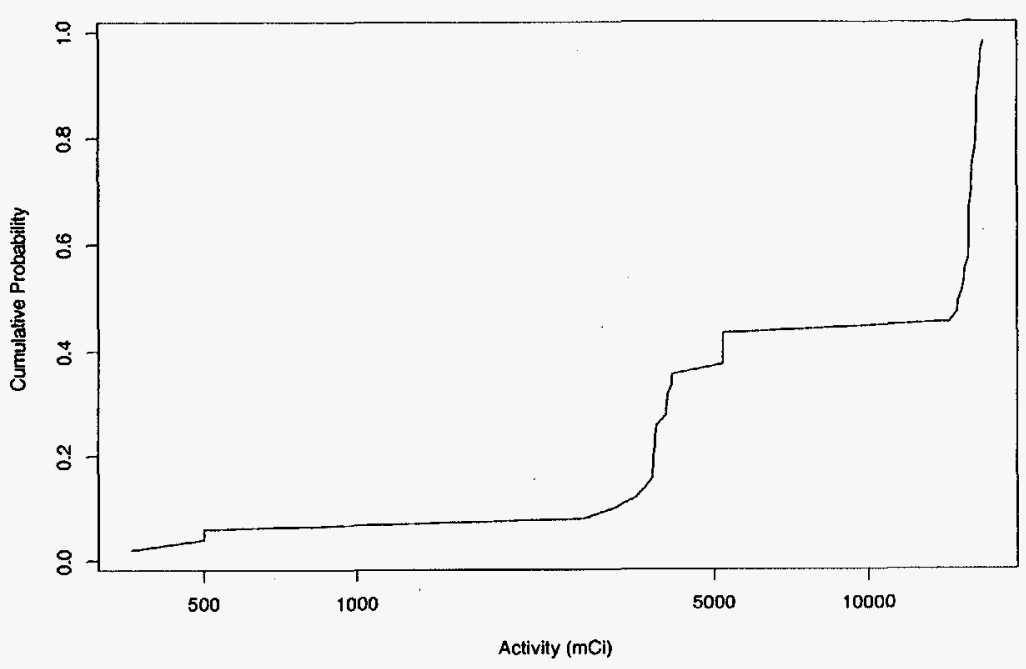

\begin{tabular}{cccc}
$\begin{array}{c}\text { Cumulative } \\
\text { probability }\end{array}$ & $\begin{array}{c}\text { Activity } \\
(\mathrm{mCi})\end{array}$ & $\begin{array}{c}\text { Cumulative } \\
\text { probability }\end{array}$ & $\begin{array}{c}\text { Activity } \\
(\mathrm{mCi})\end{array}$ \\
\hline & & & \\
$5 \%$ & 500 & $55 \%$ & 15,400 \\
$10 \%$ & 3,200 & $60 \%$ & 15,670 \\
$15 \%$ & 3,800 & $65 \%$ & 15,690 \\
$20 \%$ & 3,820 & $70 \%$ & 15,810 \\
$25 \%$ & 3,850 & $75 \%$ & 15,970 \\
$30 \%$ & 4,050 & $80 \%$ & 16,200 \\
$35 \%$ & 4,150 & $85 \%$ & 16,240 \\
$40 \%$ & 5,200 & $90 \%$ & 16,280 \\
$45 \%$ & 5,200 & $95 \%$ & 16,500 \\
$50 \%$ & 14,940 & $100 \%$ & 16,700 \\
\hline
\end{tabular}


Am-241 Portable Gauge Sources

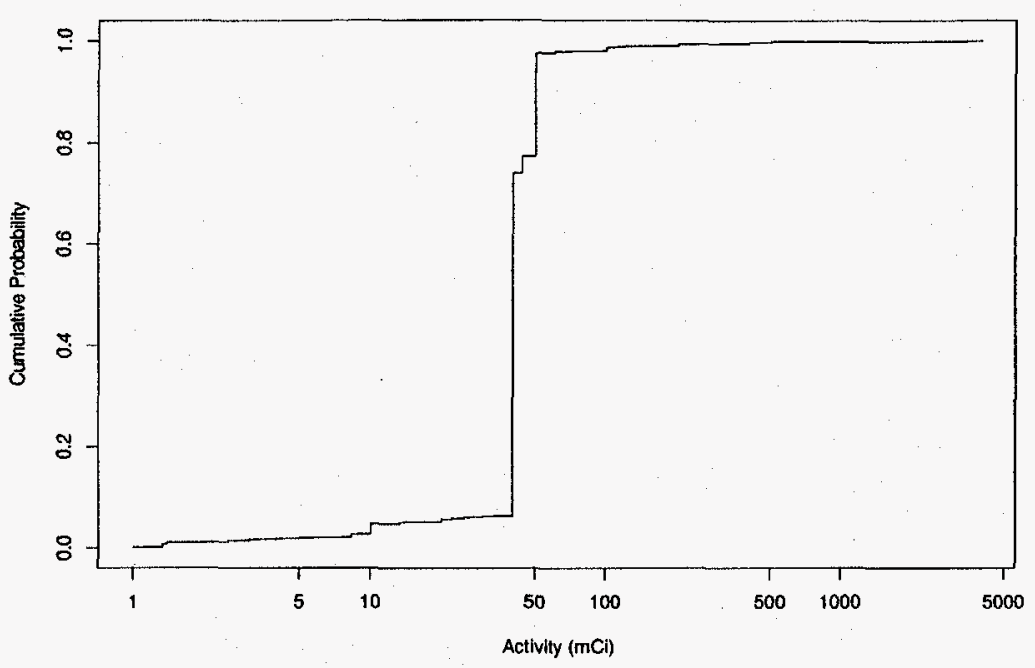

?

\begin{tabular}{cccc}
$\begin{array}{c}\text { Cumulative } \\
\text { probability }\end{array}$ & $\begin{array}{c}\text { Activity } \\
(\mathrm{mCi})\end{array}$ & $\begin{array}{c}\text { Cumulative } \\
\text { probability }\end{array}$ & $\begin{array}{c}\text { Activity } \\
(\mathrm{mCi})\end{array}$ \\
\hline $5 \%$ & 14 & $55 \%$ & 40 \\
$10 \%$ & 40 & $60 \%$ & 40 \\
$15 \%$ & 40 & $65 \%$ & 40 \\
$20 \%$ & 40 & $70 \%$ & 40 \\
$25 \%$ & 40 & $75 \%$ & 44 \\
$30 \%$ & 40 & $80 \%$ & 50 \\
$35 \%$ & 40 & $85 \%$ & 50 \\
$40 \%$ & 40 & $90 \%$ & 50 \\
$45 \%$ & 40 & $95 \%$ & 50 \\
$50 \%$ & 40 & $100 \%$ & 4,000 \\
\hline
\end{tabular}

Cs-137 Portable Gauge Sources

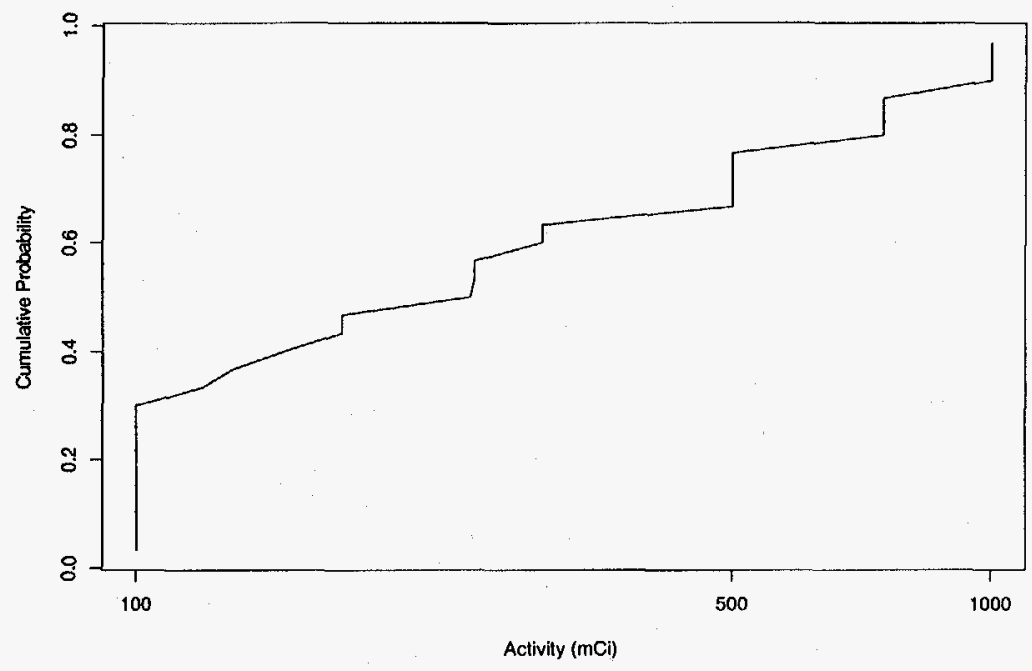

\begin{tabular}{cccc}
$\begin{array}{c}\text { Cumulative } \\
\text { probability }\end{array}$ & $\begin{array}{c}\text { Activity } \\
(\mathrm{mCi})\end{array}$ & $\begin{array}{c}\text { Cumulative } \\
\text { probability }\end{array}$ & $\begin{array}{c}\text { Activity } \\
(\mathrm{mCi})\end{array}$ \\
\hline & & & \\
$5 \%$ & 100 & $55 \%$ & 250 \\
$10 \%$ & 100 & $60 \%$ & 250 \\
$15 \%$ & 100 & $65 \%$ & 300 \\
$20 \%$ & 100 & $70 \%$ & 500 \\
$25 \%$ & 100 & $75 \%$ & 500 \\
$30 \%$ & 100 & $80 \%$ & 500 \\
$35 \%$ & 120 & $85 \%$ & 750 \\
$40 \%$ & 150 & $90 \%$ & 750 \\
$45 \%$ & 175 & $95 \%$ & 1,000 \\
$50 \%$ & 175 & $100 \%$ & 1,000 \\
\hline
\end{tabular}


Am-241 Irradiation Sources

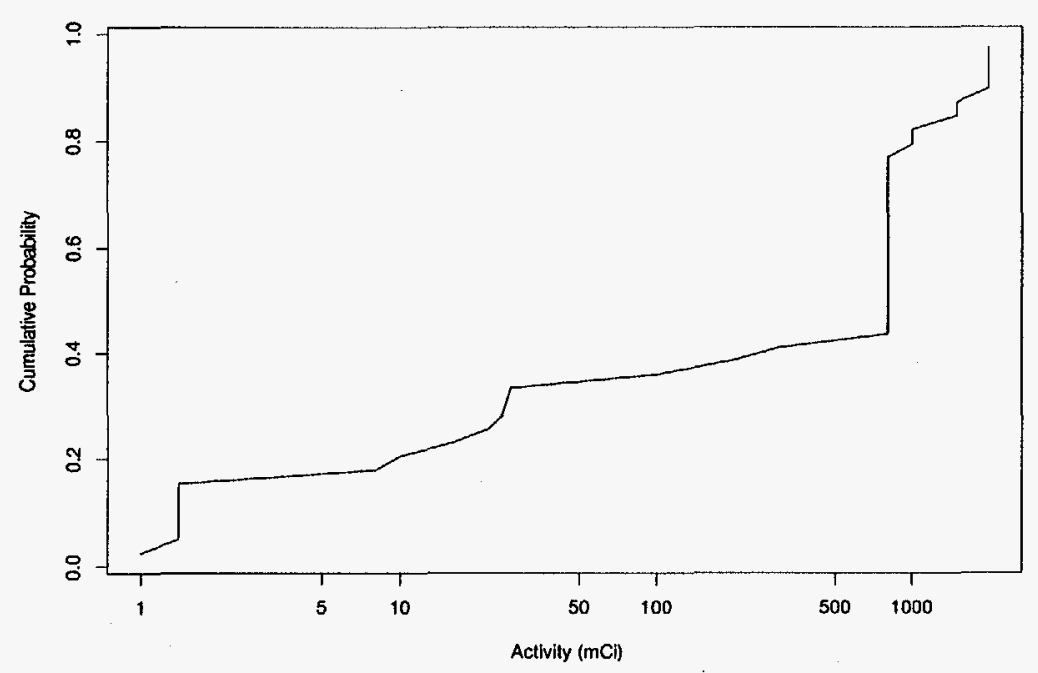

$\frac{P}{0}$

\begin{tabular}{cccc}
$\begin{array}{c}\text { Cumulative } \\
\text { probability }\end{array}$ & $\begin{array}{c}\text { Activity } \\
(\mathrm{mCi})\end{array}$ & $\begin{array}{c}\text { Cumulative } \\
\text { probability }\end{array}$ & $\begin{array}{c}\text { Activity } \\
(\mathrm{mCi})\end{array}$ \\
\hline & & & \\
$5 \%$ & 1 & $55 \%$ & 800 \\
$10 \%$ & 1 & $60 \%$ & 800 \\
$15 \%$ & 1 & $65 \%$ & 800 \\
$20 \%$ & 10 & $70 \%$ & 800 \\
$25 \%$ & 22 & $75 \%$ & 800 \\
$30 \%$ & 25 & $80 \%$ & 800 \\
$35 \%$ & 27 & $85 \%$ & 1,000 \\
$40 \%$ & 200 & $90 \%$ & 1,500 \\
$45 \%$ & 800 & $95 \%$ & 2,000 \\
$50 \%$ & 800 & $100 \%$ & 2,000 \\
\hline
\end{tabular}

Cs-137 Irradiation Sources

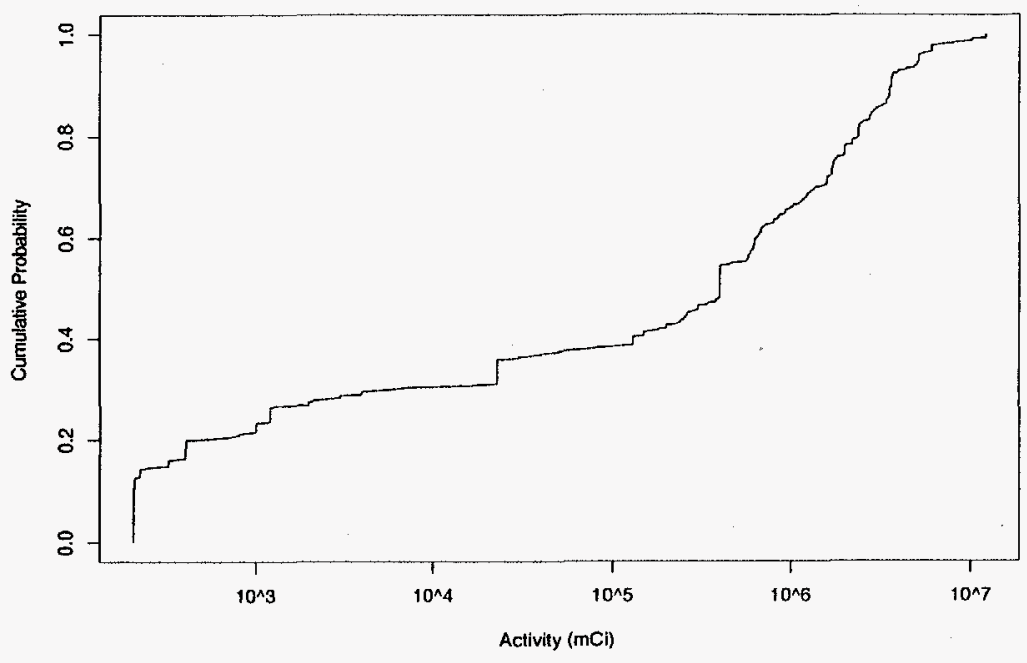

\begin{tabular}{cccc}
$\begin{array}{c}\text { Cumulative } \\
\text { probability }\end{array}$ & $\begin{array}{c}\text { Activity } \\
(\mathrm{mCi})\end{array}$ & $\begin{array}{c}\text { Cumulative } \\
\text { probability }\end{array}$ & $\begin{array}{c}\text { Activity } \\
(\mathrm{mCi})\end{array}$ \\
\hline & & & \\
$5 \%$ & 200 & $55 \%$ & 491,162 \\
$10 \%$ & 200 & $60 \%$ & 651,000 \\
$15 \%$ & 315 & $65 \%$ & 920,500 \\
$20 \%$ & 400 & $70 \%$ & $1,408,000$ \\
$25 \%$ & 1,200 & $75 \%$ & $1,752,000$ \\
$30 \%$ & 6,000 & $80 \%$ & $2,366,000$ \\
$35 \%$ & 23,007 & $85 \%$ & $2,956,000$ \\
$40 \%$ & 130,000 & $90 \%$ & $3,600,000$ \\
$45 \%$ & 260,000 & $95 \%$ & $5,100,000$ \\
$50 \%$ & 400,000 & $100 \%$ & $12,000,000$ \\
\hline
\end{tabular}


Am-241 Fixed Gauge Sources

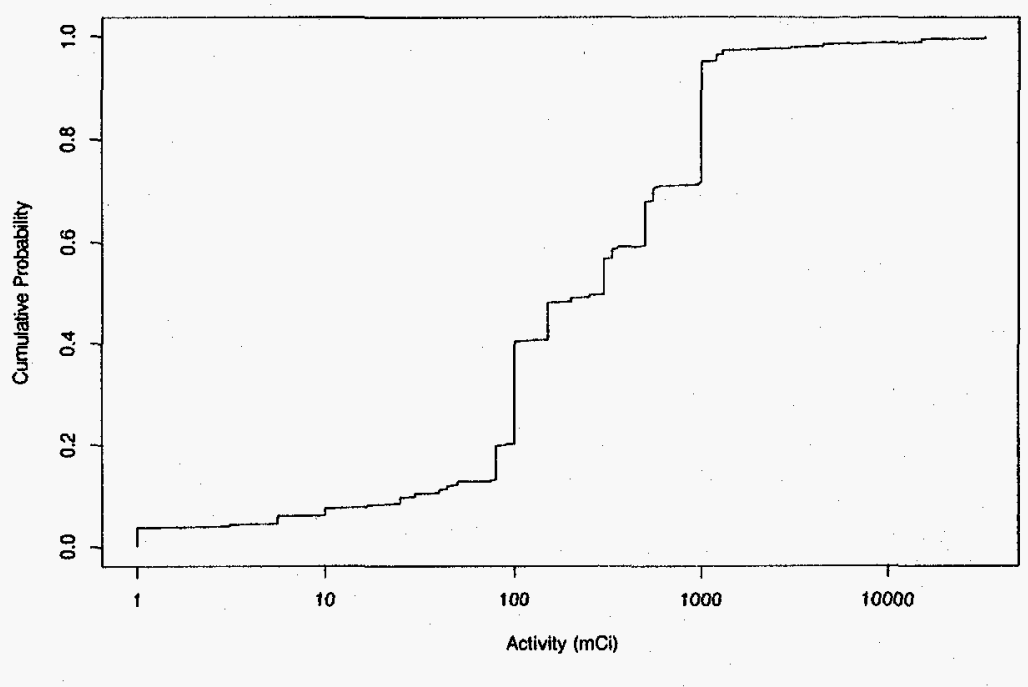

\begin{tabular}{cccc}
$\begin{array}{c}\text { Cumulative } \\
\text { probability }\end{array}$ & $\begin{array}{c}\text { Activity } \\
(\mathrm{mCi})\end{array}$ & $\begin{array}{c}\text { Cumulative } \\
\text { probability }\end{array}$ & $\begin{array}{c}\text { Activity } \\
(\mathrm{mCi})\end{array}$ \\
\hline $5 \%$ & 6 & & \\
$10 \%$ & 30 & $55 \%$ & 300 \\
$15 \%$ & 80 & $60 \%$ & 500 \\
$20 \%$ & 90 & $75 \%$ & 500 \\
$25 \%$ & 100 & $75 \%$ & 550 \\
$30 \%$ & 100 & $80 \%$ & 1,000 \\
$35 \%$ & 100 & $85 \%$ & 1,000 \\
$40 \%$ & 100 & $90 \%$ & 1,000 \\
$45 \%$ & 150 & $95 \%$ & 1,000 \\
$50 \%$ & 300 & $100 \%$ & 33,000 \\
\hline
\end{tabular}

Cs-137 Fixed Gauge Sources

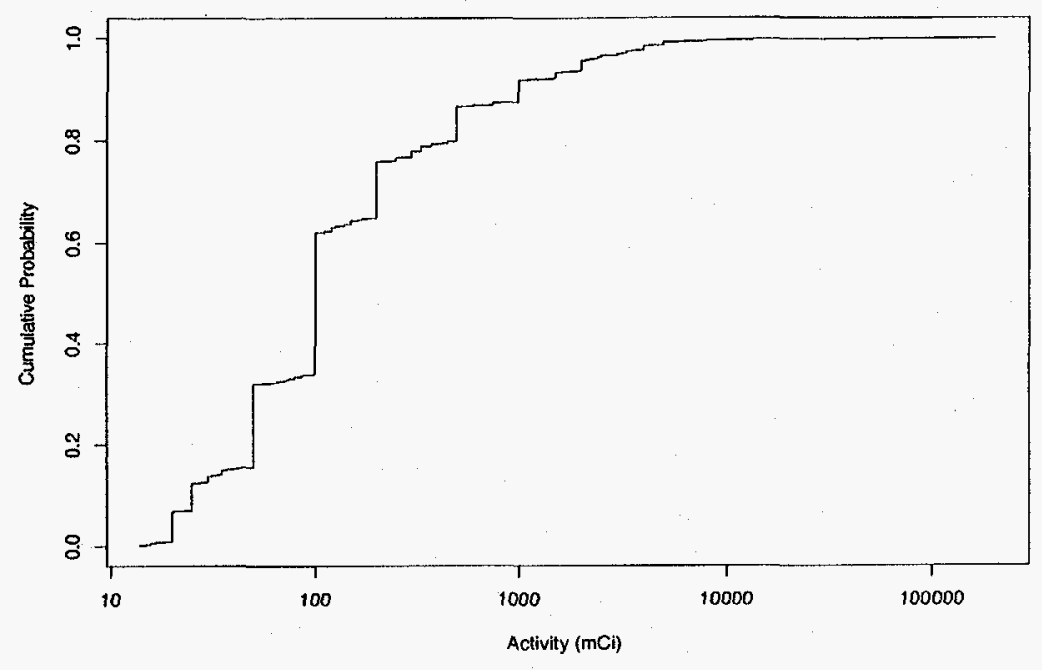

\begin{tabular}{cccc}
$\begin{array}{c}\text { Cumulative } \\
\text { probability }\end{array}$ & $\begin{array}{c}\text { Activity } \\
(\mathrm{mCi})\end{array}$ & $\begin{array}{c}\text { Cumulative } \\
\text { probability }\end{array}$ & $\begin{array}{c}\text { Activity } \\
\text { (mCi) }\end{array}$ \\
\hline & & & \\
$5 \%$ & 20 & $55 \%$ & 100 \\
$10 \%$ & 25 & $60 \%$ & 100 \\
$15 \%$ & 37 & $65 \%$ & 200 \\
$20 \%$ & 50 & $70 \%$ & 200 \\
$25 \%$ & 50 & $75 \%$ & 200 \\
$30 \%$ & 50 & $80 \%$ & 500 \\
$35 \%$ & 100 & $85 \%$ & 500 \\
$40 \%$ & 100 & $90 \%$ & 1,000 \\
$45 \%$ & 100 & $95 \%$ & 2,000 \\
$50 \%$ & 100 & $100 \%$ & 200,000 \\
\hline
\end{tabular}


Sr-90 Fixed Gauge Sources

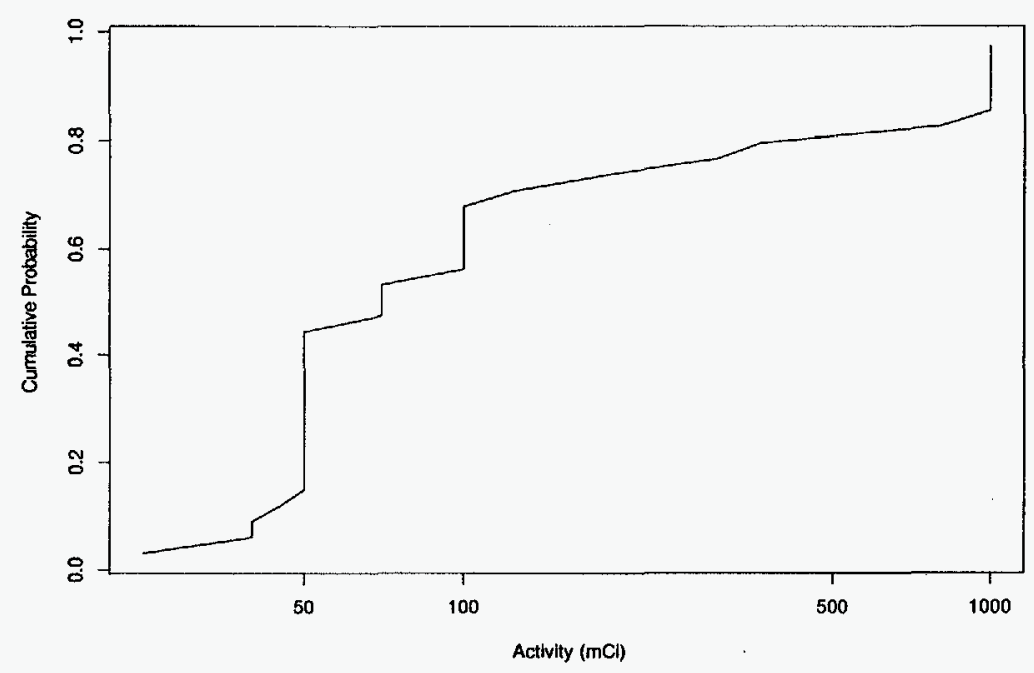

$\frac{P}{N}$

\begin{tabular}{cccc}
$\begin{array}{c}\text { Cumulative } \\
\text { probability }\end{array}$ & $\begin{array}{c}\text { Activity } \\
\text { (mCi) }\end{array}$ & $\begin{array}{c}\text { Cumulative } \\
\text { probability }\end{array}$ & $\begin{array}{c}\text { Activity } \\
\text { (mCi) }\end{array}$ \\
\hline $5 \%$ & & & 70 \\
$10 \%$ & 40 & $55 \%$ & 100 \\
$15 \%$ & 40 & $60 \%$ & 100 \\
$20 \%$ & 50 & $65 \%$ & 100 \\
$25 \%$ & 50 & $70 \%$ & 185 \\
$30 \%$ & 50 & $75 \%$ & 300 \\
$35 \%$ & 50 & $80 \%$ & 800 \\
$40 \%$ & 50 & $85 \%$ & 1,000 \\
$45 \%$ & 50 & $90 \%$ & 1,000 \\
$50 \%$ & 50 & $95 \%$ & 1,000 \\
\hline
\end{tabular}

Am-241 General Neutron Applications Sources

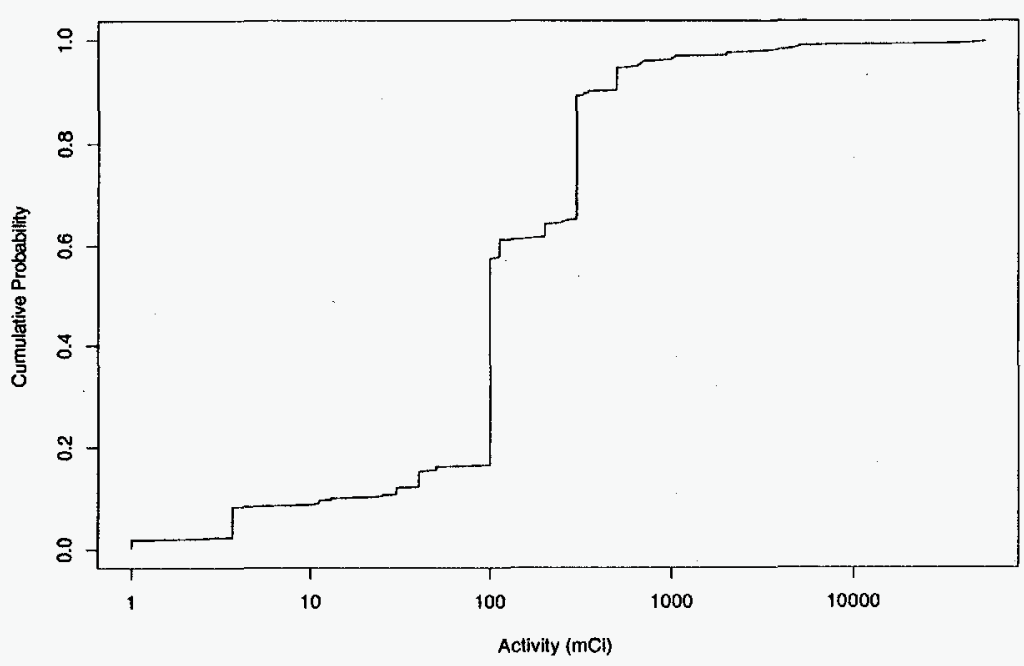

\begin{tabular}{cccc}
$\begin{array}{c}\text { Cumulative } \\
\text { probability }\end{array}$ & $\begin{array}{c}\text { Activity } \\
(\mathrm{mCi})\end{array}$ & $\begin{array}{c}\text { Cumulative } \\
\text { probability }\end{array}$ & $\begin{array}{c}\text { Activity } \\
(\mathrm{mCi})\end{array}$ \\
\hline & & & \\
$5 \%$ & 4 & $55 \%$ & 100 \\
$10 \%$ & 13 & $60 \%$ & 113 \\
$15 \%$ & 40 & $65 \%$ & 298 \\
$20 \%$ & 100 & $70 \%$ & 300 \\
$25 \%$ & 100 & $75 \%$ & 300 \\
$30 \%$ & 100 & $80 \%$ & 300 \\
$35 \%$ & 100 & $85 \%$ & 300 \\
$40 \%$ & 100 & $90 \%$ & 350 \\
$45 \%$ & 100 & $95 \%$ & 650 \\
$50 \%$ & 100 & $100 \%$ & 52,000 \\
\hline
\end{tabular}




\section{Pu-238 General Neutron Applications Sources}

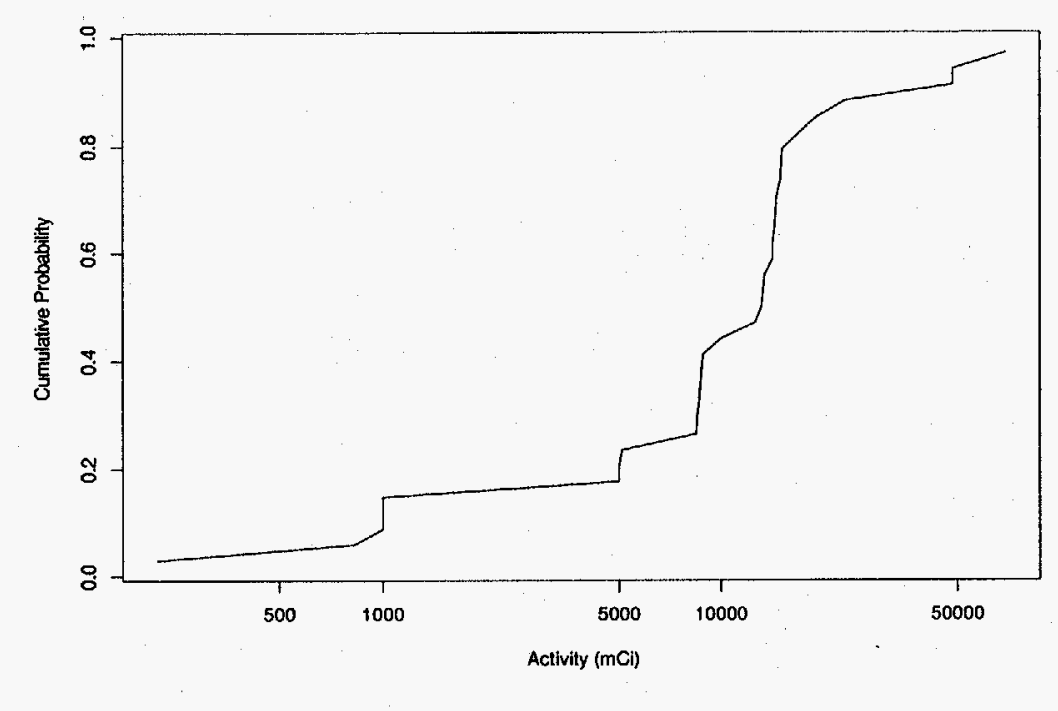

\begin{tabular}{cccc}
$\begin{array}{c}\text { Cumulative } \\
\text { probability }\end{array}$ & $\begin{array}{c}\text { Activity } \\
(\mathrm{mCi})\end{array}$ & $\begin{array}{c}\text { Cumulative } \\
\text { probability }\end{array}$ & $\begin{array}{c}\text { Activity } \\
(\mathrm{mCi})\end{array}$ \\
\hline $5 \%$ & 830 & $55 \%$ & 13,300 \\
$10 \%$ & 1,000 & $60 \%$ & 14,200 \\
$15 \%$ & 1,000 & $65 \%$ & 14,200 \\
$20 \%$ & 5,000 & $70 \%$ & 14,500 \\
$25 \%$ & 5,110 & $75 \%$ & 15,000 \\
$30 \%$ & 8,490 & $80 \%$ & 15,100 \\
$35 \%$ & 8,680 & $85 \%$ & 17,000 \\
$40 \%$ & 8,756 & $90 \%$ & 23,300 \\
$45 \%$ & 10,000 & $95 \%$ & 48,500 \\
$50 \%$ & 12,640 & $100 \%$ & 70,000 \\
\hline
\end{tabular}

\section{Pu-239 General Neutron Applications Sources}

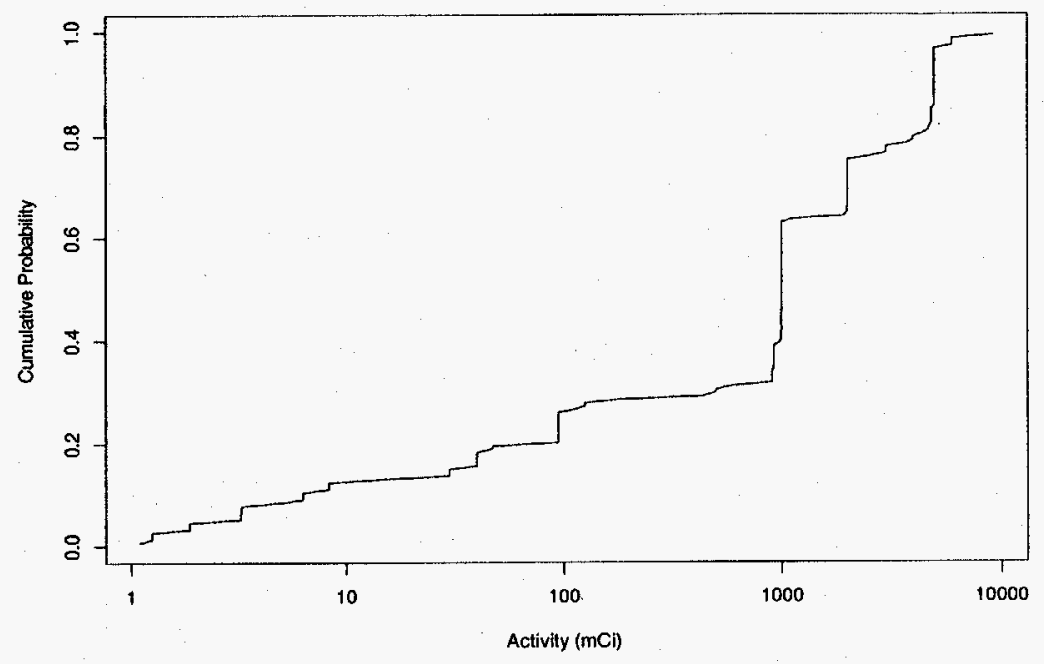

\begin{tabular}{cccc}
$\begin{array}{c}\text { Cumulative } \\
\text { probability }\end{array}$ & $\begin{array}{c}\text { Activity } \\
(\mathrm{mCi})\end{array}$ & $\begin{array}{c}\text { Cumulative } \\
\text { probability }\end{array}$ & $\begin{array}{c}\text { Activity } \\
(\mathrm{mCi})\end{array}$ \\
\hline $5 \%$ & 3 & $55 \%$ & 1,000 \\
$10 \%$ & 6 & $60 \%$ & 1,000 \\
$15 \%$ & 30 & $65 \%$ & 1,932 \\
$20 \%$ & 94 & $70 \%$ & 2,000 \\
$25 \%$ & 94 & $75 \%$ & 2,000 \\
$30 \%$ & 491 & $80 \%$ & 4,000 \\
$35 \%$ & 920 & $85 \%$ & 4,844 \\
$40 \%$ & 983 & $90 \%$ & 5,000 \\
$45 \%$ & 995 & $95 \%$ & 5,000 \\
$50 \%$ & 999 & $100 \%$ & 9,198 \\
\hline
\end{tabular}


Am-241 X-Ray Fluorescence Sources

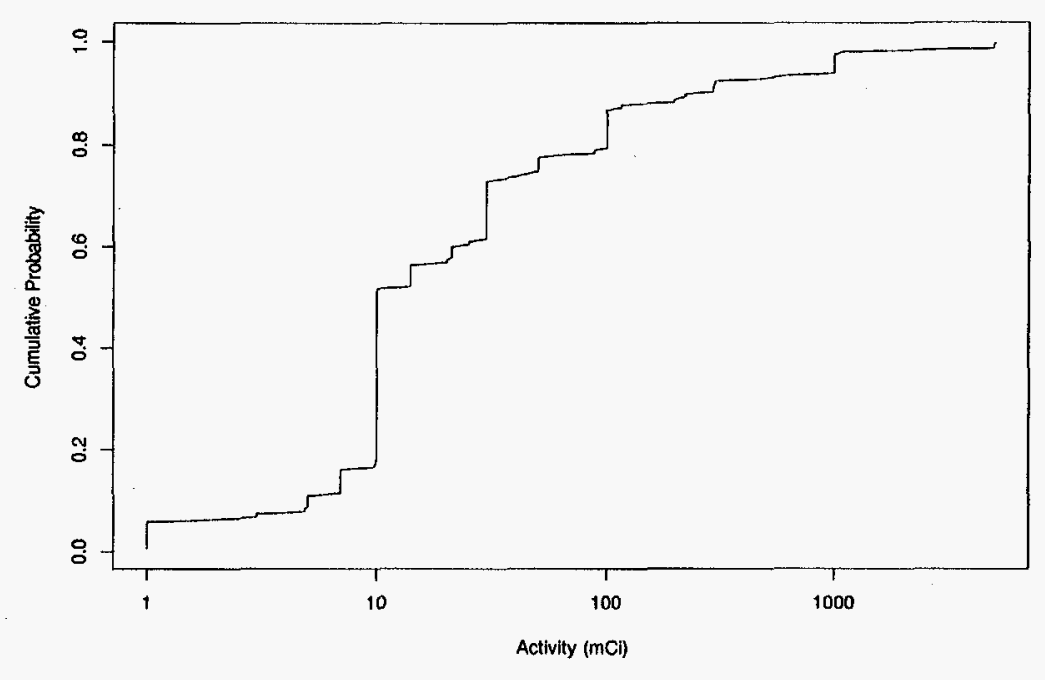

$\frac{P}{P}$

\begin{tabular}{cccc}
$\begin{array}{c}\text { Cumulative } \\
\text { probability }\end{array}$ & $\begin{array}{c}\text { Activity } \\
\text { (mCi) }\end{array}$ & $\begin{array}{c}\text { Cumulative } \\
\text { probability }\end{array}$ & $\begin{array}{c}\text { Activity } \\
\text { (mCi) }\end{array}$ \\
\hline $5 \%$ & 1 & $55 \%$ & 14 \\
$10 \%$ & 5 & $60 \%$ & 21 \\
$15 \%$ & 7 & $65 \%$ & 30 \\
$20 \%$ & 10 & $70 \%$ & 30 \\
$25 \%$ & 10 & $75 \%$ & 50 \\
$30 \%$ & 10 & $80 \%$ & 100 \\
$35 \%$ & 10 & $85 \%$ & 100 \\
$40 \%$ & 10 & $90 \%$ & 222 \\
$45 \%$ & 10 & $95 \%$ & 1,000 \\
$50 \%$ & 10 & $100 \%$ & 5,070 \\
\hline
\end{tabular}

Cm-244 X-Ray Fluorescence Sources

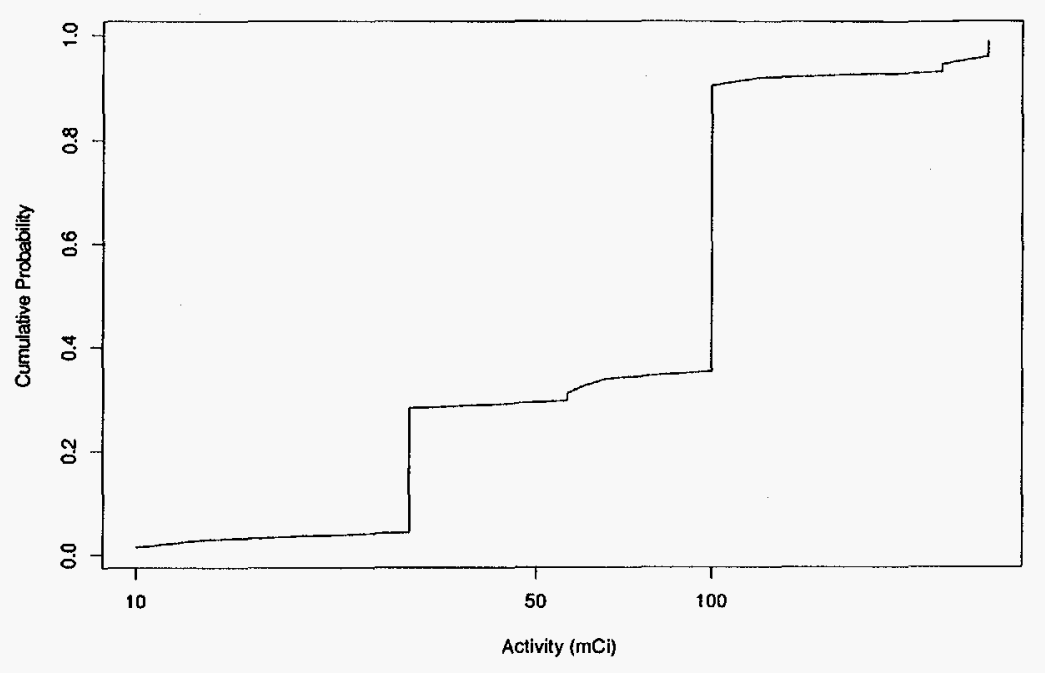

\begin{tabular}{cccc}
$\begin{array}{c}\text { Cumulative } \\
\text { probability }\end{array}$ & $\begin{array}{c}\text { Activity } \\
(\mathrm{mCi})\end{array}$ & $\begin{array}{c}\text { Cumulative } \\
\text { probability }\end{array}$ & $\begin{array}{c}\text { Activity } \\
(\mathrm{mCi})\end{array}$ \\
\hline & & & \\
$5 \%$ & 30 & $55 \%$ & 100 \\
$10 \%$ & 30 & $60 \%$ & 100 \\
$15 \%$ & 30 & $65 \%$ & 100 \\
$20 \%$ & 30 & $70 \%$ & 100 \\
$25 \%$ & 30 & $75 \%$ & 100 \\
$30 \%$ & 57 & $80 \%$ & 100 \\
$35 \%$ & 100 & $85 \%$ & 100 \\
$40 \%$ & 100 & $90 \%$ & 100 \\
$45 \%$ & 100 & $95 \%$ & 250 \\
$50 \%$ & 100 & $100 \%$ & 300 \\
\hline
\end{tabular}




\section{Am-241 Other-Use Sources}

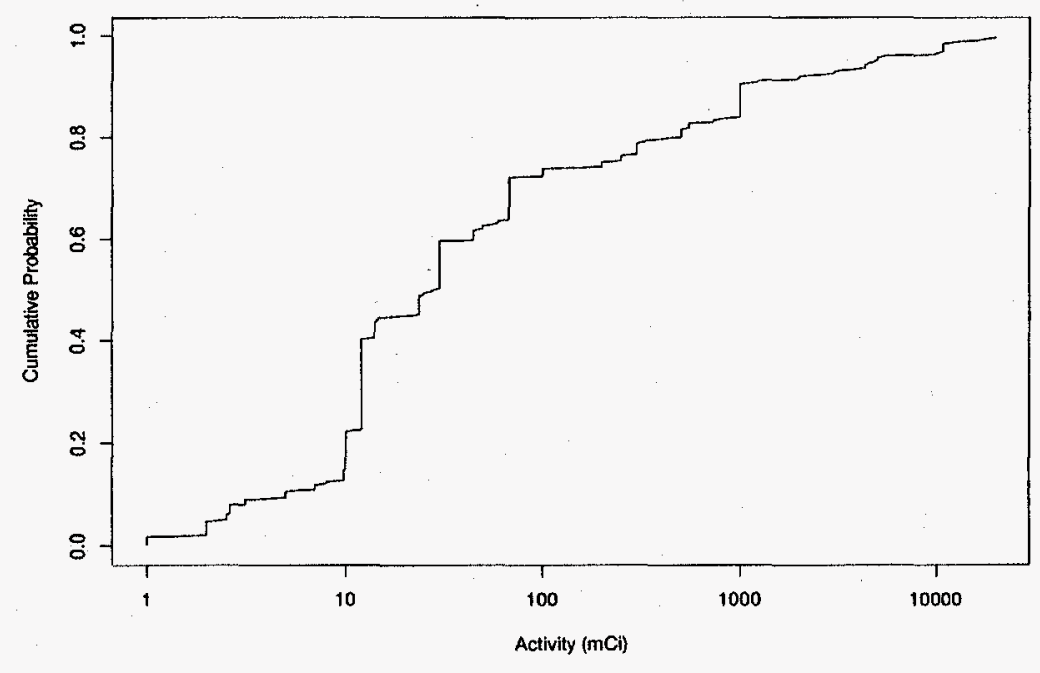

$\frac{P}{4}$

\begin{tabular}{cccc}
$\begin{array}{c}\text { Cumulative } \\
\text { probability }\end{array}$ & $\begin{array}{c}\text { Activity } \\
(\mathrm{mCi})\end{array}$ & $\begin{array}{c}\text { Cumulative } \\
\text { probability }\end{array}$ & $\begin{array}{c}\text { Activity } \\
(\mathrm{mCi})\end{array}$ \\
\hline $5 \%$ & 2 & $55 \%$ & 30 \\
$10 \%$ & 5 & $60 \%$ & 45 \\
$15 \%$ & 10 & $65 \%$ & 68 \\
$20 \%$ & 10 & $70 \%$ & 68 \\
$25 \%$ & 12 & $75 \%$ & 200 \\
$30 \%$ & 12 & $80 \%$ & 400 \\
$35 \%$ & 12 & $85 \%$ & 1,000 \\
$40 \%$ & 12 & $90 \%$ & 1,000 \\
$45 \%$ & 20 & $95 \%$ & 4,700 \\
$50 \%$ & 28 & $100 \%$ & 20,000 \\
\hline
\end{tabular}

\section{C-14 Other-Use Sources}

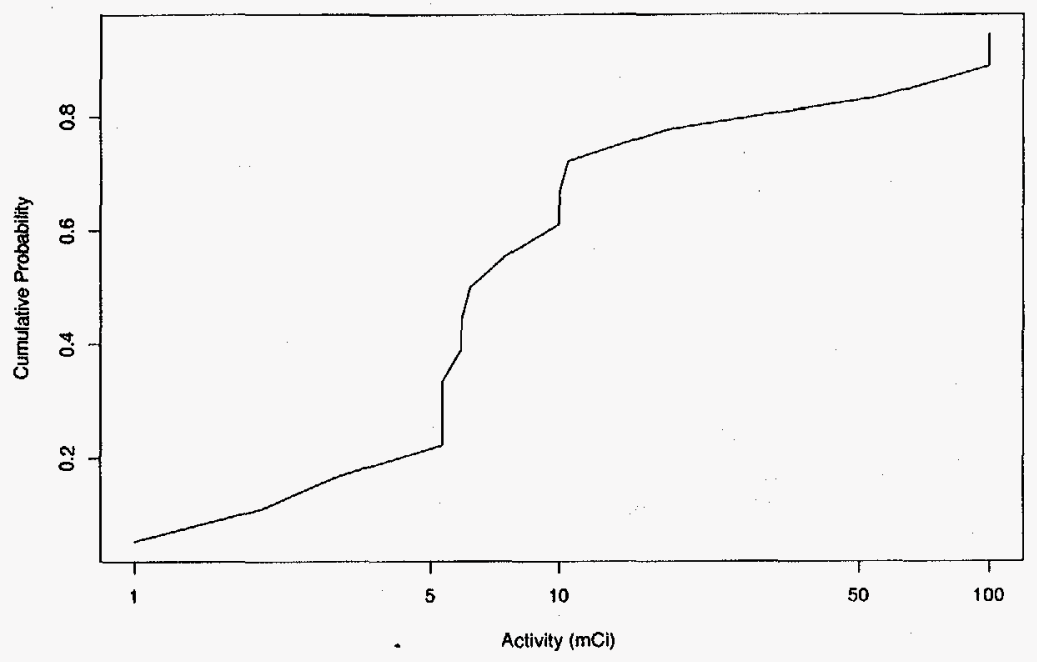

\begin{tabular}{cccc}
$\begin{array}{c}\text { Cumulative } \\
\text { probability }\end{array}$ & $\begin{array}{c}\text { Activity } \\
(\mathrm{mCi})\end{array}$ & $\begin{array}{c}\text { Cumulative } \\
\text { probability }\end{array}$ & $\begin{array}{c}\text { Activity } \\
(\mathrm{mCi})\end{array}$ \\
\hline & & & \\
$5 \%$ & 1 & $55 \%$ & 6 \\
$10 \%$ & 2 & $60 \%$ & 8 \\
$15 \%$ & 3 & $65 \%$ & 10 \\
$20 \%$ & 3 & $70 \%$ & 10 \\
$25 \%$ & 5 & $75 \%$ & 11 \\
$30 \%$ & 5 & $80 \%$ & 18 \\
$35 \%$ & 5 & $85 \%$ & 18 \\
$40 \%$ & 6 & $90 \%$ & 55 \\
$45 \%$ & 6 & $95 \%$ & 100 \\
$50 \%$ & 6 & $100 \%$ & 100 \\
\hline
\end{tabular}


Cs-137 Other-Use Sources

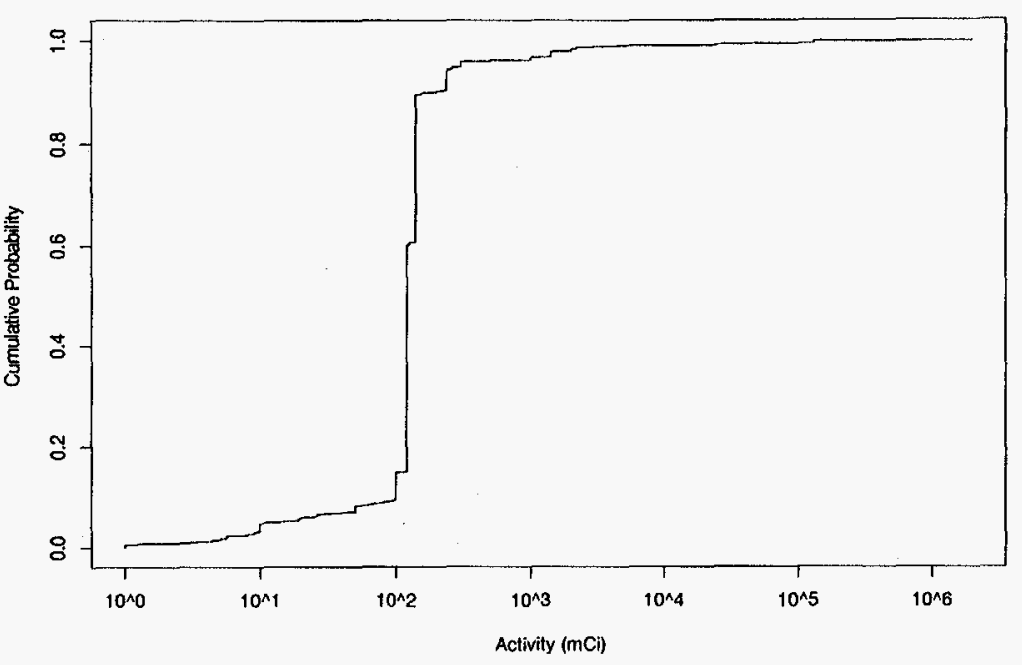

$\frac{1}{a}$

\begin{tabular}{cccc}
$\begin{array}{c}\text { Cumulative } \\
\text { probability }\end{array}$ & $\begin{array}{c}\text { Activity } \\
(\mathrm{mCi})\end{array}$ & $\begin{array}{c}\text { Cumulative } \\
\text { probability }\end{array}$ & $\begin{array}{c}\text { Activity } \\
(\mathrm{mCi})\end{array}$ \\
\hline & & & \\
$5 \%$ & 13 & $55 \%$ & 120 \\
$10 \%$ & 100 & $60 \%$ & 120 \\
$15 \%$ & 116 & $65 \%$ & 138 \\
$20 \%$ & 120 & $70 \%$ & 138 \\
$25 \%$ & 120 & $75 \%$ & 138 \\
$30 \%$ & 120 & $80 \%$ & 138 \\
$35 \%$ & 120 & $85 \%$ & 138 \\
$40 \%$ & 120 & $90 \%$ & 200 \\
$45 \%$ & 120 & $95 \%$ & 300 \\
$50 \%$ & 120 & $100 \%$ & $2,000,000$ \\
\hline
\end{tabular}

Ni-63 Other-Use Sources

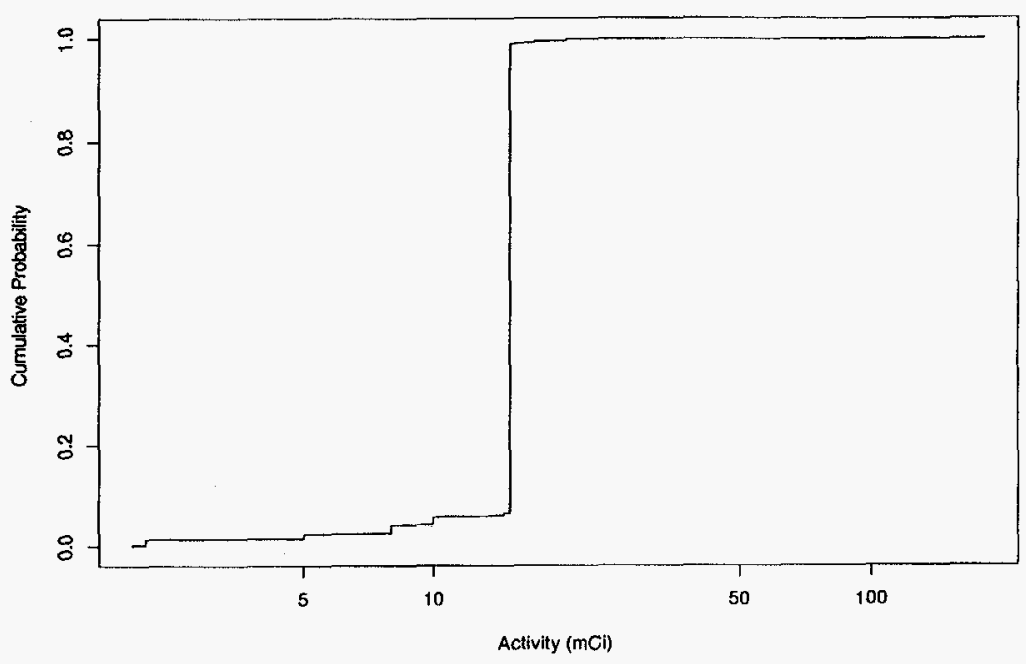

\begin{tabular}{cccc}
$\begin{array}{c}\text { Cumulative } \\
\text { probability }\end{array}$ & $\begin{array}{c}\text { Activity } \\
(\mathrm{mCi})\end{array}$ & $\begin{array}{c}\text { Cumulative } \\
\text { probability }\end{array}$ & $\begin{array}{c}\text { Activity } \\
(\mathrm{mCi})\end{array}$ \\
\hline & & & \\
$5 \%$ & 10 & $55 \%$ & 15 \\
$10 \%$ & 15 & $60 \%$ & 15 \\
$15 \%$ & 15 & $65 \%$ & 15 \\
$20 \%$ & 15 & $70 \%$ & 15 \\
$25 \%$ & 15 & $75 \%$ & 15 \\
$30 \%$ & 15 & $80 \%$ & 15 \\
$35 \%$ & 15 & $85 \%$ & 15 \\
$40 \%$ & 15 & $90 \%$ & 15 \\
$45 \%$ & 15 & $95 \%$ & 15 \\
$50 \%$ & 15 & $100 \%$ & 180 \\
\hline
\end{tabular}


Pu-238 Other-Use Sources

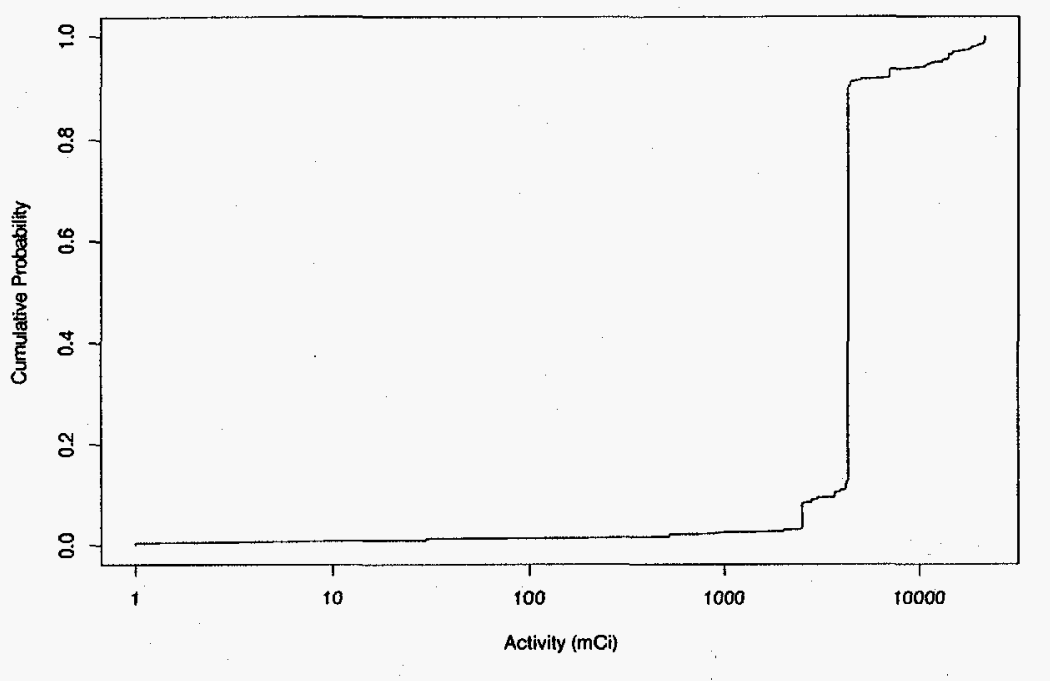

\begin{tabular}{cccc}
$\begin{array}{c}\text { Cumulative } \\
\text { probability }\end{array}$ & $\begin{array}{c}\text { Activity } \\
(\mathrm{mCi})\end{array}$ & $\begin{array}{c}\text { Cumulative } \\
\text { probability }\end{array}$ & $\begin{array}{c}\text { Activity } \\
(\mathrm{mCi})\end{array}$ \\
\hline $5 \%$ & 2,500 & $55 \%$ & 4,300 \\
$10 \%$ & 3,678 & $60 \%$ & 4,300 \\
$15 \%$ & 4,300 & $65 \%$ & 4,300 \\
$20 \%$ & 4,300 & $70 \%$ & 4,300 \\
$25 \%$ & 4,300 & $75 \%$ & 4,300 \\
$30 \%$ & 4,300 & $80 \%$ & 4,300 \\
$35 \%$ & 4,300 & $85 \%$ & 4,300 \\
$40 \%$ & 4,300 & $90 \%$ & 4,300 \\
$45 \%$ & 4,300 & $95 \%$ & 11,500 \\
$50 \%$ & 4,300 & $100 \%$ & 21,452 \\
\hline
\end{tabular}

Pu-239 Other-Use Sources

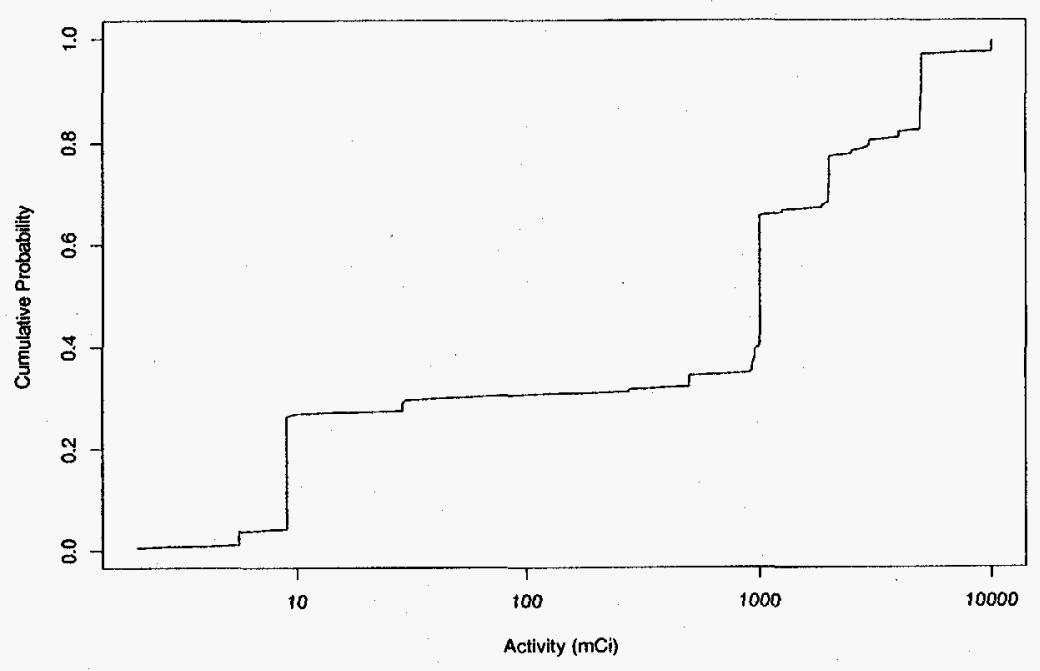

\begin{tabular}{cccc}
$\begin{array}{c}\text { Cumulative } \\
\text { probability }\end{array}$ & $\begin{array}{c}\text { Activity } \\
(\mathrm{mCi})\end{array}$ & $\begin{array}{c}\text { Cumulative } \\
\text { probability }\end{array}$ & $\begin{array}{c}\text { Activity } \\
(\mathrm{mCi})\end{array}$ \\
\hline $5 \%$ & 9 & $55 \%$ & 1,000 \\
$10 \%$ & 9 & $60 \%$ & 1,000 \\
$15 \%$ & 9 & $65 \%$ & 1,000 \\
$20 \%$ & 9 & $70 \%$ & 1,989 \\
$25 \%$ & 9 & $75 \%$ & 2,000 \\
$30 \%$ & 30 & $80 \%$ & 2,983 \\
$35 \%$ & 904 & $85 \%$ & 4,972 \\
$40 \%$ & 957 & $90 \%$ & 5,000 \\
$45 \%$ & 1,000 & $95 \%$ & 5,000 \\
$50 \%$ & 1,000 & $100 \%$ & 10,000 \\
\hline
\end{tabular}




\section{Sr-90 Other-Use Sources}

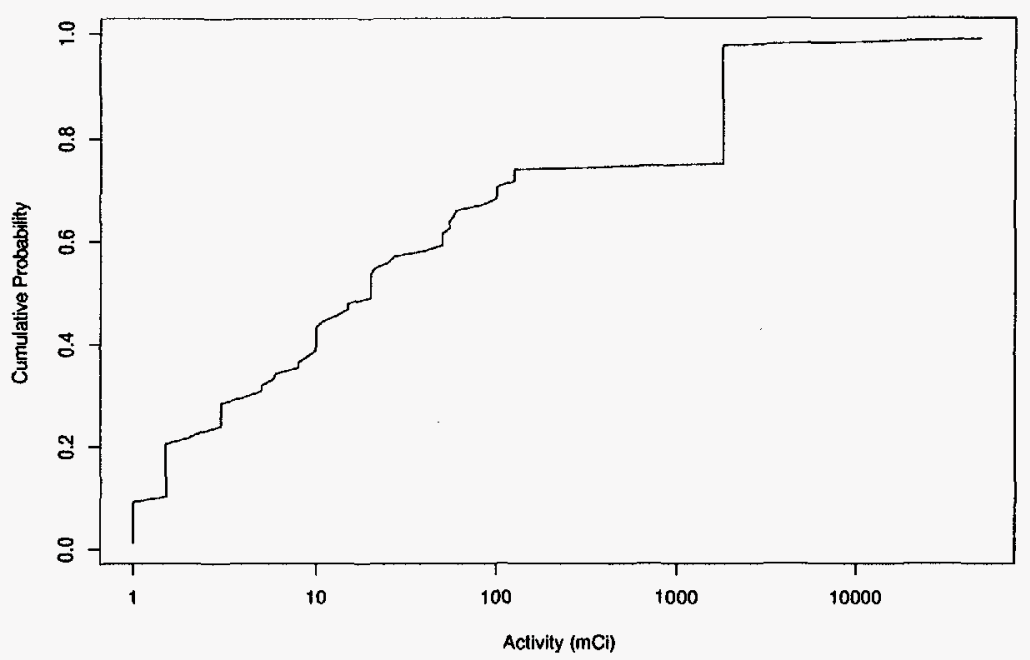

$\frac{?}{\infty}$

\begin{tabular}{cccc}
$\begin{array}{c}\text { Cumulative } \\
\text { probability }\end{array}$ & $\begin{array}{c}\text { Activity } \\
(\mathrm{mCi})\end{array}$ & $\begin{array}{c}\text { Cumulative } \\
\text { probability }\end{array}$ & $\begin{array}{c}\text { Activity } \\
(\mathrm{mCi})\end{array}$ \\
\hline & & & \\
$5 \%$ & 1 & $55 \%$ & 21 \\
$10 \%$ & 2 & $60 \%$ & 50 \\
$15 \%$ & 2 & $65 \%$ & 58 \\
$20 \%$ & 2 & $70 \%$ & 100 \\
$25 \%$ & 3 & $75 \%$ & 125 \\
$30 \%$ & 4 & $80 \%$ & 1,800 \\
$35 \%$ & 6 & $85 \%$ & 1,800 \\
$40 \%$ & 10 & $90 \%$ & 1,800 \\
$45 \%$ & 11 & $95 \%$ & 1,800 \\
$50 \%$ & 20 & $100 \%$ & 50,000 \\
\hline
\end{tabular}

U-238 Other-Use Sources

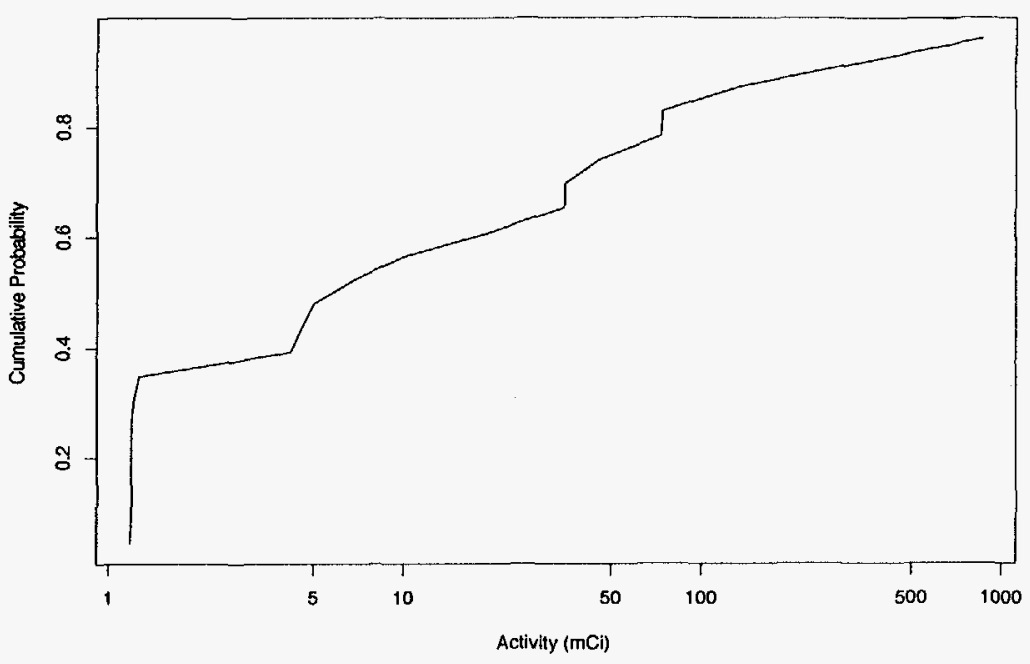

\begin{tabular}{cccc}
$\begin{array}{c}\text { Cumulative } \\
\text { probability }\end{array}$ & $\begin{array}{c}\text { Activity } \\
(\mathrm{mCi})\end{array}$ & $\begin{array}{c}\text { Cumulative } \\
\text { probability }\end{array}$ & $\begin{array}{c}\text { Activity } \\
(\mathrm{mCi})\end{array}$ \\
\hline & & & \\
$5 \%$ & 1 & $55 \%$ & 7 \\
$10 \%$ & 1 & $60 \%$ & 10 \\
$15 \%$ & 1 & $65 \%$ & 20 \\
$20 \%$ & 1 & $70 \%$ & 35 \\
$25 \%$ & 1 & $75 \%$ & 45 \\
$30 \%$ & 1 & $80 \%$ & 73 \\
$35 \%$ & 1 & $85 \%$ & 74 \\
$40 \%$ & 4 & $90 \%$ & 134 \\
$45 \%$ & 5 & $95 \%$ & 344 \\
$50 \%$ & 5 & $100 \%$ & 859 \\
\hline
\end{tabular}




\section{Appendix D}

Comparison to 1989 NRC Report Results

D-1 
D-2 


\section{Appendix D}

\section{Comparison to 1989 NRC Report Results}

In 1989, the NRC performed a survey of specific licensees to define the scope of the problem of excess sources. The survey was given to a sample of 2,202 NRC specific licensees and Agreement State licensees. The survey was similar to the survey sent in 1992. A copy of it is included in the first attachment to Appen$\operatorname{dix} A$ of this report. The results are documented in the report Above Class C Source/Device Inventory Survey (Reference 2). The report on the 1989 survey is included as Appendix D of the 1991 DOE/LLW-114 report (Reference 1).

The results from that report differ from those given in this report because they assumed that the sources were contained in concrete within a 55-gal drum for disposal purposes, and that activities were averaged over the volume of the entire drum. Based on this assumption, the cutoff activities for PGTCC isotopes are much higher than those discussed in Section 3.1 of this report. Specifically, the cutoffs were $27 \mathrm{mCi}$ for TRU isotopes and $910 \mathrm{Ci}$ for $\mathrm{Cs}-137$. Under the NRC assumptions, radionuclides such as Ni-63 and Sr-90 could not be GTCC LLW.

The placement of the source in a drum for disposal is a simple method for disposing of a sealed source. By concentration averaging over the total volume of the drum (rather than the volume of the source capsule as was done in Section 4 of this report), many sources would no longer be GTCC LLW. Since sealed source activities are commonly less than $100 \mathrm{mCi}$, many sources would be well below the GTCC limit when averaged over the volume of the drum.

In the following sections, the current data are analyzed using the same assumptions as those used in the 1989 NRC report, and the results are compared. The current results still produced slightly larger estimates of the number of licensees with GTCC sources. While the number of GTCC sources is also somewhat larger, this is solely because of the larger estimate in the number of licensees with GTCC sources. Also, the current estimate of the volume of sealed sources being stored for future use is somewhat larger than those given in the 1989 report, while the estimated activity of stored sources is slightly smaller. The estimated volume and activity of sources requiring disposal or transfer is considerably smaller than the 1989 estimates.

The next two sections are structured to closely follow the presentation of results in the 1989 NRC report, particularly Section 5, "Findings," and Section 6, "Data Analysis." The 1989 NRC report does include information on GTCC sources held by general licensees. Because the current survey did not include general licensees, no comparison is made to the 1989 report with regard to these licensees. Only the specific licensee results are considered.

\section{D-1 Findings}

The findings are summarized in Tables D-1 through D-7. The number of specific licensees responding to the combined 1992 surveys was 6,316. Using the 1989 NRC evaluation assumptions described above, 1,547 licensees of the 6,316 had 8,255 GTCC sealed sources.

Of the 1,547 specific licensees with GTCC sources or devices, 27 (1.75\%) are experiencing problems in disposing of their sources or devices. Of the 8,255 GTCC sources, about 1,644 (19.9\%) are not actively used. Of these, 1,435 are not needed, 15 are damaged, and 205 are inactive for other reasons. The plans for the inactive GTCC sources breaks down as follows. The licensees have 874 sources in storage (10.6\%). The licensees plan to transfer 51 sources to other licensees, send 171 sources for disposal, and transfer 49 sources to the manufacturer. There are 525 GTCC sources that the licensees are having difficulty disposing of. Fiftyfive inactive GTCC sources are expected to be handled by other methods. 
Table D-1. Number of GTCC sealed sources, by isotope, using the 1989 NRC assumptions.

\begin{tabular}{lrrr}
\hline Isotope & $\begin{array}{c}\text { Number } \\
\text { GTCC }\end{array}$ & \% GTCC & $\begin{array}{c}\text { Number } \\
\text { not GTCC }\end{array}$ \\
\hline & & & \\
Am-241 & 7,075 & 85.28 & 1,221 \\
Cm-244 & 79 & 83.16 & 16 \\
Cs-137 & 180 & 0.64 & 27,931 \\
Np-237 & 0 & 0.00 & 4 \\
Pu-238 & 552 & 87.90 & 76 \\
Pu-239 & 344 & 81.32 & 79 \\
Pu-241 & 10 & 90.91 & 1 \\
U-238 & 15 & 36.59 & 26 \\
\hline & & & \\
Total & 8,255 & 18.60 & 36,136 \\
\hline
\end{tabular}

Table D-2. Number of GTCC sealed sources, by principal use, using the 1989 NRC assumptions.

\begin{tabular}{lrrr}
\multicolumn{1}{c}{ Device type } & $\begin{array}{c}\text { Number } \\
\text { GTCC }\end{array}$ & \% GTCC & $\begin{array}{c}\text { Number } \\
\text { not GTCC }\end{array}$ \\
\hline Calibration & 657 & 22.87 & 2,216 \\
Medical & 37 & 0.52 & 7,037 \\
Well logging & 1,061 & 47.86 & 1,156 \\
Gas chromatography & 0 & 0.00 & 3,902 \\
Portable gauge & 4,170 & 46.71 & 4,758 \\
& & & \\
Irradiation & 204 & 10.39 & 1,759 \\
Fixed gauge & 612 & 5.81 & 9,914 \\
General neutron applications & 549 & 89.27 & 66 \\
X-ray fluorescence & 201 & 61.85 & 124 \\
Other & 764 & 13.71 & 4,810 \\
\hline & & & \\
Total & 8,255 & 18.60 & 36,136 \\
\hline
\end{tabular}


Table D-3. Number of licensees with GTCC sources, by principal use, using the 1989 NRC assumptions.

\begin{tabular}{lcccc}
\hline \multicolumn{1}{c}{ Device type } & $\begin{array}{c}\text { Number of } \\
\text { licensees }\end{array}$ & $\begin{array}{c}\text { Number of } \\
\text { GTCC } \\
\text { licensees }\end{array}$ & \% GTCC & $\begin{array}{c}\text { 1989 NRC } \\
\text { \% GTCC }\end{array}$ \\
\hline Calibration & 507 & 95 & 18.74 & - \\
Medical & 352 & 17 & 4.83 & 1.26 \\
Well logging & 88 & 75 & 85.23 & 85.00 \\
Gas chromatography & 643 & 0 & 0.00 & - \\
Portable gauge & 1,009 & 900 & 89.20 & 89.00 \\
Irradiation & & & & \\
Fixed gauge & 357 & 108 & 30.25 & 43.20 \\
General neutron applications & 795 & 143 & 17.99 & 19.87 \\
X-ray fluorescence & 236 & 228 & 96.61 & - \\
Other & 114 & 83 & 72.81 & 35.85 \\
Total & 514 & 143 & 27.82 & - \\
\hline
\end{tabular}

a. A licensee may be counted more than once in the total because of the licensee having sources under different device types. 
Table D-4. Observed total number of GTCC sources by isotope and principal use, using the 1989 NRC assumptions.

\begin{tabular}{|c|c|c|c|c|c|c|c|c|}
\hline Device type & Am-241 & $\mathrm{Cm}-244$ & Cs-137 & Pu-238 & $\mathrm{Pu}-239$ & $\mathrm{Pu}-241$ & $\mathrm{U}-238$ & Subtotal \\
\hline Calibration & 561 & 4 & 3 & 13 & 72 & 4 & - & 657 \\
\hline Medical & 27 & - & 3 & - & - & - & 7 & 37 \\
\hline Well logging & 1,061 & - & - & - & - & - & - & 1,061 \\
\hline Gas chromatography & - & - & - & - & - & - & - & 0 \\
\hline Portable gauge & 4,170 & - & - & - & - & - & - & 4,170 \\
\hline Irradiation & 33 & - & 171 & - & - & - & - & 204 \\
\hline Fixed gauge & 598 & 1 & - & 13 & - & - & - & 612 \\
\hline General neutron applications & 384 & - & - & 32 & 133 & - & - & 549 \\
\hline$X$-ray fluorescence & 81 & 68 & - & 52 & - & - & - & 201 \\
\hline Other & 160 & 6 & 3 & 442 & 139 & 6 & 8 & 764 \\
\hline Subtotal & 7,075 & 79 & 180 & 552 & 344 & 10 & 15 & 8,255 \\
\hline
\end{tabular}


Table D-5. Observed total activity, in curies, of GTCC sources by isotope and principal use, using the 1989 NRC assumptions (not adjusted for decay).

\begin{tabular}{|c|c|c|c|c|c|c|c|c|}
\hline Device type & Am-241 & $\mathrm{Cm}-244$ & Cs-137 & $\mathrm{Pu}-238$ & $\mathrm{Pu}-239$ & $\mathrm{Pu}-241$ & $\mathrm{U}-238$ & Subtotal \\
\hline Calibration & 843.30 & 0.92 & $4,557.00$ & $16,682.74$ & $5,769.63$ & 494.88 & - & 28,348 \\
\hline Medical & 9.57 & - & $12,960.00$ & - & - & - & 1.68 & 12,971 \\
\hline Well logging & $9,390.16$ & - & - & - & - & - & 一 & 9,390 \\
\hline Gas chromatography & - & - & - & - & - & - & - & 0 \\
\hline Portable gauge & 349.06 & 一 & - & - & - & - & - & 349 \\
\hline Irradiation & 60.80 & - & $861,462.95$ & - & - & - & - & 861,524 \\
\hline Fixed gauge & 453.28 & 0.04 & - & 292.45 & - & - & - & 746 \\
\hline General neutron applications & 239.36 & - & - & 950.73 & 267.18 & - & - & 1,457 \\
\hline $\mathrm{X}$-ray fluorescence & 105.58 & 36.27 & - & 2.31 & - & - & - & 144 \\
\hline Other & 231.98 & 1.57 & $5,932.00$ & $6,919.48$ & $40,107.09$ & 337.92 & 1.60 & 53,532 \\
\hline Subtotal & $11,683.08$ & 38.80 & $884,911.95$ & $24,847.71$ & $46,143.90$ & 832.81 & 3.28 & 968,462 \\
\hline
\end{tabular}


Table D-6. Observed total activity, in curies, of inactive GTCC sources by reason of inactivity, using the 1989 NRC assumptions (not adjusted for decay).

\begin{tabular}{lrrrrrrrrr}
\hline \multicolumn{1}{c}{ Reason for inactivity } & Am-241 & Cm-244 & Cs-137 & Pu-238 & Pu-239 & Pu-241 & U-238 & Subtotal \\
\hline \multirow{2}{*}{$\begin{array}{l}\text { Not needed } \\
\text { Damaged }\end{array}$} & $5,269.28$ & 0.82 & $30,038.0$ & $2,255.20$ & $24,790.93$ & 825.81 & 0.07 & $63,180.11$ \\
Other & 14.05 & - & $2,000.0$ & - & - & - & - & $2,014.05$ \\
& 179.07 & - & $9,600.0$ & 107.79 & 39.08 & - & - & $9,925.94$ \\
\cline { 2 - 6 } Subtotal & $5,462.41$ & 0.82 & $41,638.0$ & $2,362.99$ & $24,830.01$ & 825.81 & 0.07 & $75,120.11$ \\
\hline
\end{tabular}

Table D-7. Observed total activity, in curies, of inactive GTCC sources by plans for disposal method, using the 1989 NRC assumptions (not adjusted for decay).

\begin{tabular}{|c|c|c|c|c|c|c|c|c|}
\hline Plan for inactive source & Am-241 & $\mathrm{Cm}-244$ & Cs-137 & $\mathrm{Pu}-238$ & Pu-239 & $\mathrm{Pu}-241$ & U-238 & Subtotal \\
\hline Storage for future use & 415.16 & 0.60 & $11,888.0$ & $1,525.26$ & $24,741.83^{a}$ & 1.00 & 一 & $38,571.85$ \\
\hline Transfer to a licensee & 56.04 & - & - & 40.73 & 17.96 & 一 & 一 & 114.73 \\
\hline Send for disposal & 30.55 & 1.89 & - & 657.01 & 20.46 & - & 0.07 & 709.99 \\
\hline Transfer to manufacturer & 48.42 & - & - & 29.81 & 2.50 & - & - & 80.72 \\
\hline Problems with disposal & $4,833.20$ & - & $23,750.0$ & 140.45 & 34.27 & 824.81 & - & $29,582.73$ \\
\hline Other & 126.68 & - & $6,000.0$ & - & 11.99 & - & - & $6,148.67$ \\
\hline Subtotal & $5,510.05$ & 2.49 & $41,638.0$ & $2,403.26$ & $24,829.01$ & 825.81 & 0.07 & $75,208.70$ \\
\hline
\end{tabular}

a. This value includes $24,631 \mathrm{Ci}$ of $\mathrm{Pu}-239$ contained in five sources. 
The bulk of the sources was Am-241 (7,075 or 85\%). These Am-241 sources account for an approximate total activity of $11,683 \mathrm{Ci}, 5,500(47 \%)$ of which are from inactive sources. The licensees are having notable difficulty in disposing of the Am-241 sources, accounting for 4,800 of $5,500 \mathrm{Ci}, 88 \%$, of the total inactive activity.

There are $180 \mathrm{Cs}-137$ sources with a total activity of $884,912 \mathrm{Ci}, 41,638 \mathrm{Ci}$ of which are from inactive sources. The majority of these sources are being held in storage. About $55 \%(23,750 \mathrm{Ci})$ of the total activity of inactive Cs-137 sources are proving difficult to dispose of. Unlike the 1989 NRC results, current analysis shows a much more significant total activity of Pu-238 (2,400 Ci) and Pu-239 (24,830 Ci) from inactive sources. The Pu-239 total activity from inactive sources is extremely large and is mostly due to two licensees holding five sources, which account for $24,631 \mathrm{Ci}$. Pu-241 GTCC sources accounted for $833 \mathrm{Ci}, 826$ $(99 \%)$ of which are inactive. The remaining isotopes, $\mathrm{Cm}-244$ and U-238, account for under $43 \mathrm{Ci}$, less than $3 \mathrm{Ci}$ of which is inactive.

Similar to what was found in the NRC 1989 report, about 50\% of the GTCC sources are in portable gauges, although the total activity tied up in these devices is relatively small at $349 \mathrm{Ci}$ of $\mathrm{Am}-241$. Well logging accounted for $13 \%$ of the total number of GTCC sources, about half what the 1989 NRC report found. Yet these devices accounted for $80 \%$ of the total Am-241 activity, which agrees with what the NRC found. Also, while the NRC report found that well logging devices accounted for $30 \%$ of the total Pu-238 activity, our results showed no GTCC Pu- 238 sources in well logging devices.

\section{D-2. Data Analysis}

Based on the findings from Tables D-1 through D-7, it is estimated that $24 \%(=1,547 / 6,316)$ of the licensees have GTCC sources, using the NRC's definition of GTCC sources from their 1989 report. Since there are approximately 21,732 licensees, it is estimated that 5,323 licensees have GTCC sources.

Each licensee that possesses GTCC sources has approximately $5.3(8,255 / 1,547)$ GTCC sources, totalling 28,404 GTCC sources. We estimate that 93 licensees $[=5,323(27 / 1,547)]$ are experiencing trouble disposing of their GTCC sources and that 932 inactive GTCC sources $[=28,404(271 / 8,255)]$ are planned for disposal or transfer; 3,007 inactive GTCC sources $[=28,404(874 / 8,255)]$ are in storage.

Given the approximate volume, assuming that all the sources are well logging sources (typical volume $\left.=0.603 \mathrm{~cm}^{3}\right)$, the minimum amount of space for GTCC sources requiring disposal is $562 \mathrm{~cm}^{3}(=0.603 \times$ 932). If all 3,007 stored sources were to be disposed of, then those sources would account for an approximate volume of $1,813 \mathrm{~cm}^{3}$.

The 3,007 GTCC sources in storage that will possibly require disposal accounts for the following estimated activities (Table 5-7 results $\times 28,404 / 8,255$ ):

- $\quad 1,428 \mathrm{Ci}$ of Am-241

- $\quad 40,905 \mathrm{Ci}$ of Cs-137

- $\quad 5,248 \mathrm{Ci}$ of $\mathrm{Pu}-238$

- $\quad 85,132 \mathrm{Ci}$ of Pu-239.

The 932 GTCC sources that the licensees would like to dispose of or transfer account for the following estimated activities: 
- $\quad 465 \mathrm{Ci}$ of Am-241

- 6.5 Ci of $\mathrm{Cm}-244$

- $\quad$ 2,503 Ci of Pu-238

- $\quad 141 \mathrm{Ci}$ of $\mathrm{Pu}-239$.

\section{D-3. Comparison with 1989 Results}

Table D-8 compares the 1989 NRC report results to the results of this Appendix D. Overall, there does appear to be a great deal of agreement between the results. However, there are some discrepancies.

The current estimate of the number of licensees $(5,323)$ with GTCC sources is roughly in agreement the 1989 NRC estimate $(4,928)$. The estimated number of GTCC sources per licensee with GTCC sources is also very much in agreement as is the estimate of the total number of GTCC sources.

Another notable difference is the NRC assumption that $36 \%$ of the $\mathrm{x}$-ray fluorescence sources will be GTCC; this report found the value to be closer to $73 \%$. A smaller discrepancy is seen in the irradiation sources, where the NRC assumed $43 \%$ are GTCC, while the current results show only $30 \%$. These results can be seen in Table D-3.

As for discrepancies in isotope estimates between the two sets of results, Cs-137 is the most striking. The 1989 NRC report estimates nearly $250,000 \mathrm{Ci}$ of Cs-137 presently needing to be disposed of or transferred. The current survey results did not find that any Cs-137 presently needed disposal or transferal. Also, the current survey finds much lower activities in the Am-241 sources.

The apparent discrepancy between the number of licensees having problems with disposal may be because of differences in the survey. In the 1989 survey, the licensee is explicitly asked if they have had problems in disposing of sources. In the current survey, the licensee would only mention if they are having problems disposing of an inactive source; that is, in the current survey, the licensee only considers the question of having a problem with disposal if they have an inactive source.

This report concludes that a smaller number of sources will require imminent disposal or transfer, but that a larger number of sources is being stored for future use; the conclusions are similar for volume and activity. Again, the reasons for the discrepancies are not clear; the surveys are similar enough with respect to these questions that one would not expect to see such differences. 
Table D-8. Comparison of 1992 results (Appendix D) with 1989 NRC estimates, both using the 1989 NRC assumptions.

\begin{tabular}{|c|c|c|}
\hline Result & 1989 & 1992 \\
\hline Percent of specific licensees with GTCC sources & $21 \%$ & $24 \%$ \\
\hline Total number of licensees with GTCC sources & 4,928 & 5,323 \\
\hline Average number of GTCC sources per licensee with GTCC sources & 5.51 & 5.34 \\
\hline Total number of GTCC sources & 27,156 & 28,404 \\
\hline Number of licensees having problems with disposal ${ }^{a}$ & $200+$ & 93 \\
\hline $\begin{array}{l}\text { Number of GTCC sources needing to be disposed of or } \\
\text { transferred }\end{array}$ & 1,784 & 932 \\
\hline Number of GTCC sources in storage & 2,645 & 3,007 \\
\hline $\begin{array}{l}\text { Volume of GTCC sources needing to be disposed of or } \\
\text { transferred }\left(\mathrm{cm}^{3}\right)\end{array}$ & 1,076 & 562 \\
\hline Volume of stored GTCC sources $\left(\mathrm{cm}^{3}\right)$ & 1,595 & 1,813 \\
\hline \multicolumn{3}{|l|}{ Activity of stored GTCC sources (Ci): } \\
\hline Americium-241 & 19,643 & 1,428 \\
\hline Cesium-137 & 80,184 & 40,904 \\
\hline Plutonium-238 & 1,555 & 5,248 \\
\hline Plutonium-239 & 137 & $85,131^{b}$ \\
\hline Total & 101,519 & $132,717^{c}$ \\
\hline
\end{tabular}

Activity of GTCC sources currently needing to be disposed of or transferred (Ci):

Americium-241

\begin{tabular}{rr}
2,975 & 465 \\
249,717 & 0 \\
0.1 & 6.5 \\
2,672 & 2,503 \\
313 & 141 \\
\hline 255,677 & $3,115^{d}$
\end{tabular}

Cesium-137

Curium-244

Plutonium-238

Plutonium-239

Total

a. The 1992 result is not necessarily comparable to the 1989 results because of differences between the surveys in the assessment of whether a problem with disposal occurs (discussed further in text).

b. Value includes two licensees reporting $24,600 \mathrm{Ci}$ in five stored $\mathrm{Pu}-239$ sources.

c. Total estimate also includes $\mathrm{Cm}-244$ with $2 \mathrm{Ci}$, and $\mathrm{Pu}-241$ with $3 \mathrm{Ci}$.

d. Total estimate also includes U-238 with $0.2 \mathrm{Ci}$. 